\title{
EFFECTS OF ABS CONTROLLER PARAMETERS ON HEAVY TRUCK MODEL BRAKING PERFORMANCE
}

\author{
A Thesis \\ Presented in Partial Fulfillment of the Requirements for \\ the Degree Master of Science in the \\ Graduate School of The Ohio State University
}

By

Matthew Leonard Shurtz, B.S.M.E.

$* * * * *$

The Ohio State University

2006

Master's Examination Committee:

Dr. Dennis Guenther, Adviser

Approved by

Dr. Gary J. Heydinger

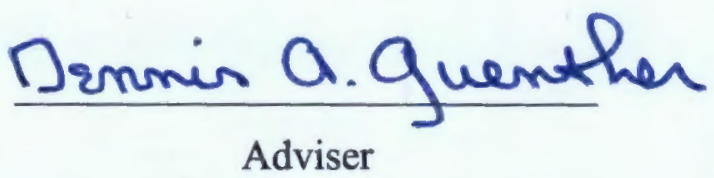

Graduate Program in Mechanical Engineering 


\section{ABSTRACT}

The National Highway Traffic Safety Administration (NHTSA) aims to keep America's roadways safe for vehicle operators, passengers, and pedestrians; a key component to this mission is the element of crash avoidance. Because so many injury related accidents involve heavy trucks, that sector is of significant concern. Most heavy truck braking accidents result from a failure to control under extreme braking maneuvers. One component which has aided this problem is the implementation of anti-lock braking systems (ABS) into these vehicles.

In order to study the ABS braking behavior of these vehicles, models were created to accurately simulate their braking behaviors, by using the vehicle dynamics software package TruckSim along with Simulink, which was used to create brake and ABS controller models. These models were run in parallel to create a full vehicle simulation.

A model of a $6 \times 4$ Peterbilt straight truck was completed in 2004, which used this same modeling scheme. An ABS controller model was developed that accurately mimicked the behavior of the Peterbilt's ABS system, verified through experimental data. This model was upgraded in this study to include better modeling of brake treadle and chamber pressures and also to include the capability of modeling other ABS configurations. The previous ABS model simulated a 6s6m system, in which the wheel 
speeds of all six wheels were monitored and the brakes of each wheel could be modulated independently. Through modifications to the model in this study, $4 \mathrm{~s} 4 \mathrm{~m}$ and $4 \mathrm{~s} 3 \mathrm{~m}$ ABS configurations can now be studied. The new Peterbilt model was then verified by comparison to experimental data, and was found to accurately model the response of the Peterbilt for each ABS configuration.

The ABS controller model was then manipulated to be used for the simulation of a tractor-trailer combination vehicle. Again, TruckSim models were created for a $4 \times 2$ Sterling tractor and a $48 \mathrm{ft}$, 2-axle van trailer. Also, an individual ABS controller model was created for each by matching the simulated response of the vehicle to experimentally determined results. In addition, the ABS controller model of the trailer included the capability of simulating $4 \mathrm{~s} 4 \mathrm{~m}, 4 \mathrm{~s} 2 \mathrm{~m}$, and $2 \mathrm{~s} 1 \mathrm{~m}$ ABS systems. Through this process, a tractor-trailer model was completed so that the effects of various ABS controller parameters and ABS configurations could be studied for the vehicle.

A total of five different ABS systems were created for the trailer model. The first of those was a $2 \mathrm{~s} 1 \mathrm{~m}$ system, which was created to simulate an experimentally studied trailer ABS system. This $2 \mathrm{~s} 1 \mathrm{~m}$ system was then used to create a $4 \mathrm{~s} 2 \mathrm{~m}$ and a $4 \mathrm{~s} 4 \mathrm{~m}$ system that had the exact same controller parameters. Two additional $2 \mathrm{~s} 1 \mathrm{~m}$ systems were created, one of which was designed to perform poorly in straight-ahead braking situations and the other was designed to perform poorly in brake-in-curve situations. More details of these models will be given later in this report.

Straight-ahead braking and brake-in-curve simulations were conducted to study the longitudinal and lateral effectiveness of the tractor-trailer equipped with these five 
different ABS systems. It was found that upgrading to a $4 \mathrm{~s} 2 \mathrm{~m}$ or $4 \mathrm{~s} 4 \mathrm{~m}$ ABS system resulted in no discernable difference in longitudinal braking performance. Also, it was shown that a very aggressive trailer ABS system (allows a very low amount of slip to develop in the tires) will perform poorly in longitudinal braking situations but will perform very well in lateral tests. The opposite is true for an ABS system that is very lax, in that the controller allows a great deal of wheel slip (approaching lock-up). Finally, it was discovered that the optimum ABS controller system for lateral braking performance will include select-low logic. 


\section{DEDICATION}

To my family and their constant encouragement

To my wife and her loving support

To God and His guiding hand 


\section{ACKNOWLEDGMENTS}

I would like to express my gratitude to a number of people, without whom my work would not have been possible. First, I would like to thank my advisor, Dennis Guenther, who offered encouragement, motivation, and valuable career advice. Also, I would like to thank Paul Grygier and Riley Garrott for allowing me to conduct my research at NHTSA's Vehicle Research and Test Center and for the financial support received by me through the duration of my project.

Gratitude should also be expressed to those who aided my research through their technical insight, especially Al Dunn and Scott Zagorski. I would like to thank them both for their help with truck mechanics, simulation suggestions, and general guidance about life and work. It was a pleasure working them both. Also, I would be remiss in not thanking Gary Heydinger and Kamel Salaani for helping me navigate the complex realm of brake and tire mechanics. Their contributions are greatly appreciated.

Lastly, I would like to thank my family for their constant support and encouragement. I will never be able to thank you all enough for instilling in me the confidence, desire, and toughness needed to reach my goals in life. In addition, I would like to thank my wife, Emily, for her loving support and putting up with my absence and bad attitude after long, exhausting, frustrating days of research. 


\section{VITA}

October $1,1982 \ldots \ldots \ldots \ldots \ldots \ldots$........... Coshocton, Ohio

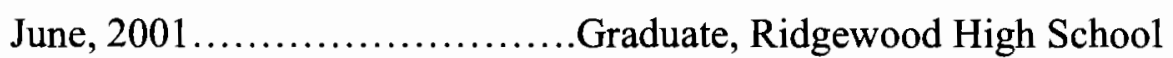

June, $2005 \ldots \ldots \ldots \ldots \ldots \ldots \ldots . . . . . . . .$. B......, The Ohio State University

2005 to present................Graduate Research Assistant, The Ohio State University

\section{FIELDS OF STUDY}

Major Field: Mechanical Engineering

Vehicle Dynamics

Vehicle Modeling 


\section{TABLE OF CONTENTS}

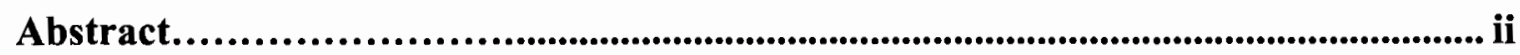

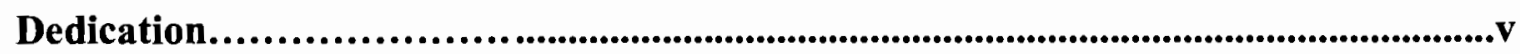

Acknowledgments.......................................................................................................... vi

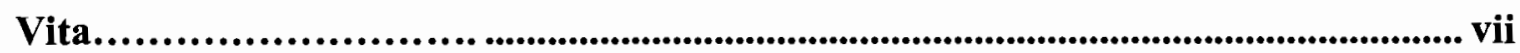

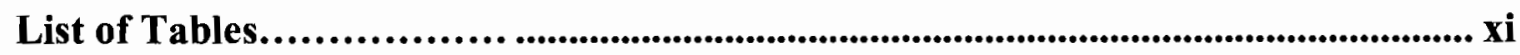

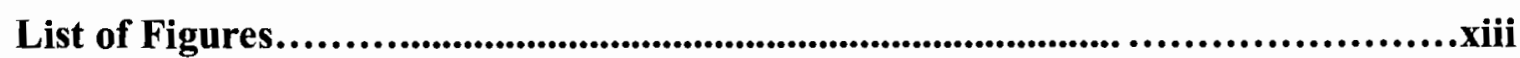

Chapter 1 - Introduction ..........................................................................................................1

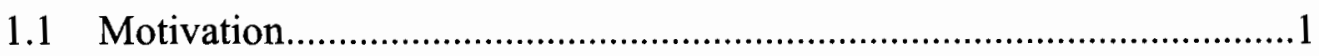

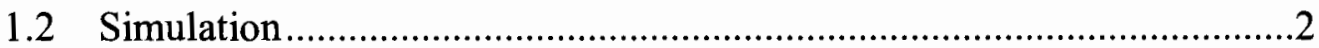

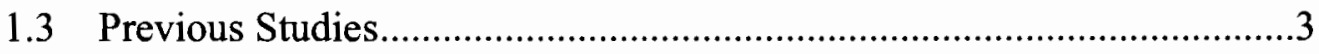

1.4 Objective

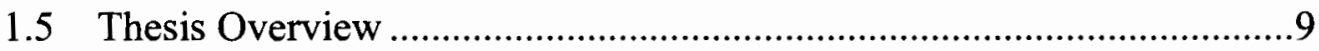

Chapter 2 - 6X4 Truck ABS Model Improvements and Applications...........................11

2.1 Overview of Existing 6x4 Model..........................................................11

2.1.1 TruckSim Model ...................................................................12

2.1.2 Brake Torque and Pneumatics Models ....................................13

2.1.3 Simulink ABS Controller.......................................................16

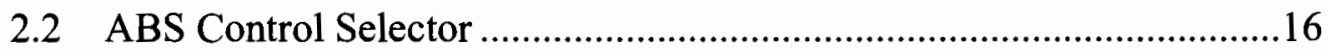

2.3 Modeling of Brake Chamber and Treadle Pressures ..............................35

2.3.1 Inclusion of Primary and Secondary Treadles ............................36

2.3.2 Brake Chamber Time Constants ................................................38

2.3.3 Modeling of Treadle Dynamics ..................................................43

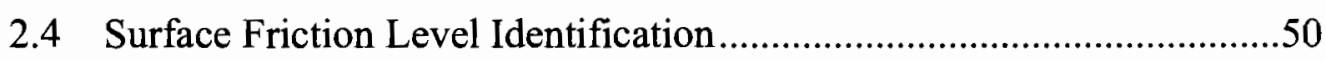

2.4.1 Controller Friction Level Estimation .......................................50

2.4.2 Initial Braking Acceleration Characteristics..............................51

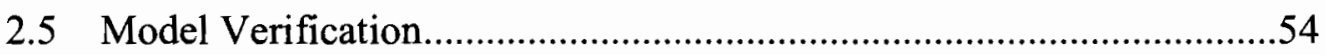




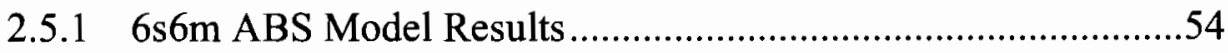

2.5.2 4s4m Lead Control ABS Model Results....................................73

2.5.3 4s $4 \mathrm{~m}$ Trail Control ABS Model Results....................................89

Chapter 3 - Tractor-Trailer Model ..........................................................................................92

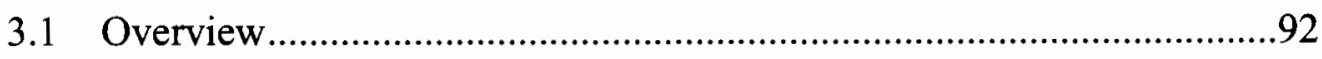

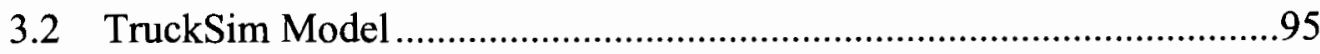

3.2.1 Sterling Tractor Model..............................................................95

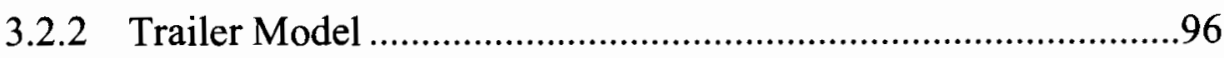

3.2.3 Total Vehicle Model ............................................................97

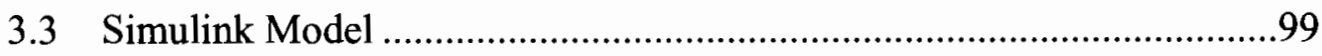

3.3.1 Model Environment ...............................................................99

3.3.2 Tractor ABS Controller Model .................................................103

3.3.3 Trailer ABS Controller Model .................................................104

3.3.4 Trailer ABS Control Selector....................................................109

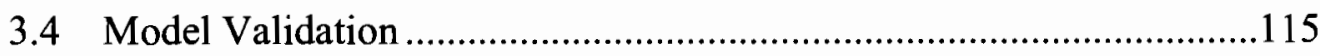

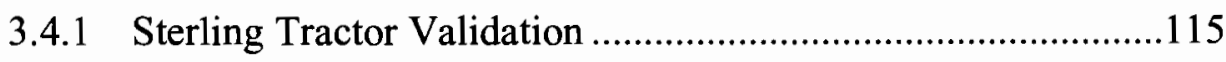

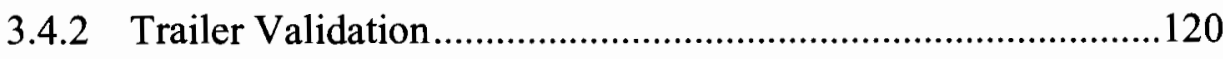

3.5 Semi-Trailer Model Test Plan...........................................................131

3.5.1 ABS Configurations............................................................131

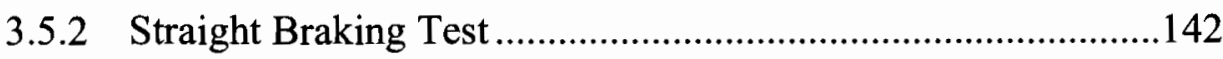

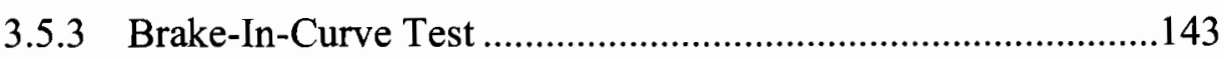

Chapter 4 - Tractor-Trailer Model Simulation Results ...................................................144

4.1 Straight-Ahead Stops - Full Vehicle Braking .......................................144

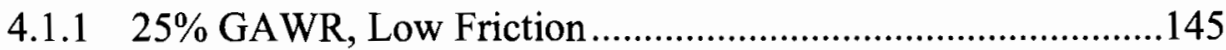

4.1.2 25\% GAWR, High Friction ....................................................150

4.1.3 75\% GAWR, Low Friction..................................................154

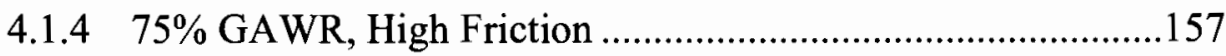

4.2 Straight-Ahead Snubs - Trailer-Only Braking .....................................158

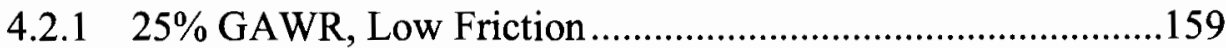

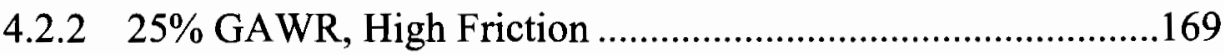

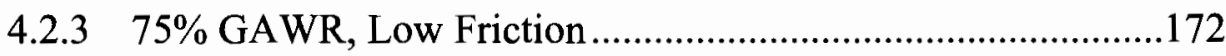




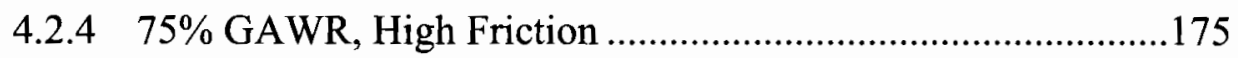

4.3 Brake-In-Curve Tests.........................................................................177

4.3.1 25\% GAWR, BIC Results....................................................177

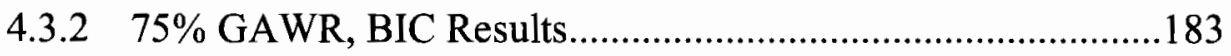

Chapter 5 - Conclusions and Recommendations ............................................................189

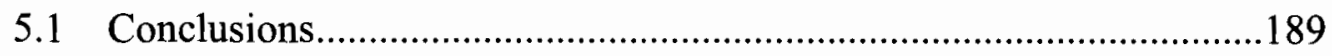

5.1.1 Peterbilt Straight Truck Model .............................................189

5.1.2 Semi-Trailer Model..........................................................190

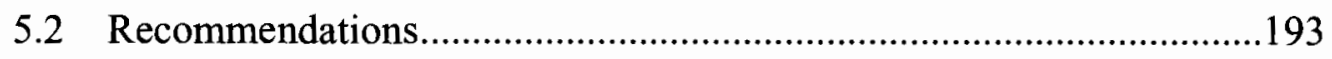

References...................................................................................................................196 


\section{LIST OF TABLES}

Table 2.1 - Development for Select-High Logic Command [6] .....................27

Table 2.2 - Logic Statements for Select-High ABS Modulation [6] ...................27

Table 2.3 - Select-High Logic Truth Table, Employed in Figure 2.8 [6]................28

Table 2.4 - Development for Select-Low Logic Command [6] ........................31

Table 2.5 - Logic Statements for Select-Low ABS Modulation [6]....................31

Table 2.6 - Select-Low Logic Truth Table, Employed in Figure $2.10[6] \ldots \ldots \ldots \ldots \ldots \ldots . . .32$

Table 2.7 - Treadle Time Constants................................................ 38

Table 2.8 - Chamber Time Constants for Each Axle................................43

Table 2.9 - Friction Estimation Thresholds.....................................5

Table 2.10 - Stopping Distances for 6s6m High Friction Stops at GVWR..............61

Table 2.11 - Stopping Distances for 6s6m High Friction Stops at LLVW..............65

Table 2.12 - Stopping Distances for 6s6m Low Friction Stops at GVWR..............69

Table 2.13 - Stopping Distances for 6s6m Low Friction Stops at LLVW...............73

Table 2.14 - Stopping Distances for Lead Control High Friction Stops at GVWR.......77

Table 2.15 - Stopping Distances for Lead Control High Friction Stops at LLVW........81

Table 2.16 - Stopping Distances for Lead Control Low Friction Stops at GVWR.........85

Table 2.17 - Stopping Distances for Lead Control Low Friction Stops at LLVW........89

Table 2.18 - Stopping Distances for Trailing Axle Control High Friction Stops at

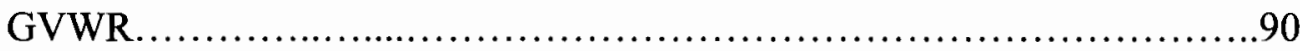

Table 2.19 - Stopping Distances for Trailing Axle Control High Friction Stops at

LLVW........................................................... 90

Table 2.20 - Stopping Distances for Trailing Axle Control Low Friction Stops at GVWR............................................................ 90

Table 2.21 - Stopping Distances for Trailing Control Low Friction Stops at LLVW......91 
Table 3.1 - Trailer Payload Masses and Distances from Kingpin......................99

Table 3.2 - Straight-Ahead Braking Test Plan..................................142

Table 4.1 - Longitudinal Performance of Full Vehicle Braking, 25\% GAWR, Low Friction...........................................................

Table 4.2 - Longitudinal Performance of Full Vehicle Braking, 25\% GAWR, High Friction.

Table 4.3 - Longitudinal Performance of Full Vehicle Braking, 75\% GAWR, Low Friction.

Table 4.4 - Longitudinal Performance of Full Vehicle Braking, 75\% GAWR, High Friction.

Table 4.5 - Longitudinal Performance of Trailer-Only Braking, 25\% GAWR, Low Friction. 160

Table 4.6 - Longitudinal Performance of Trailer-Only Braking, 25\% GAWR, High Friction. 170

Table 4.7 - Longitudinal Performance of Trailer-Only Braking, 75\% GAWR, Low Friction. 173

Table 4.8 - Longitudinal Performance of Trailer-Only Braking, 75\% GAWR, High Friction. 176

Table 4.9 - Brake-In-Curve Results, 25\% GAWR 178

Table 4.10 - Brake-In-Curve Results, 75\% GAWR 184

Table 5.1 - Average Surface Utilization Factors for Longitudinal Tests. 191 


\section{LIST OF FIGURES}

Figure 1.1 - Base Layer of Dunn's ABS Model.......................................4

Figure 1.2 - Top Half of Model Base Layer, Friction and Vehicle Dynamics Subsystem.7

Figure 1.3 - Bottom Half of Model Base Layer, ABS and Brake Systems...............8

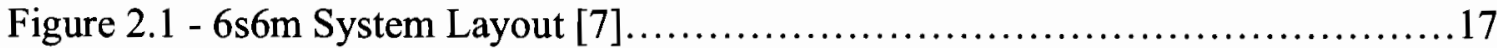

Figure 2.2 - 4s4m System Layout - Trailing Drive Axle Control [10]..................19

Figure 2.3 - ABS Control Selector Integration...................................21

Figure 2.4 - ABS Control Selector Base Layer..................................22

Figure 2.5 - Control Axle Selector............................................23

Figure 2.6 - Trail Axle Control..................................................23

Figure 2.7 - Select High Modulation..........................................25

Figure 2.8 - Select High Logic....................................................

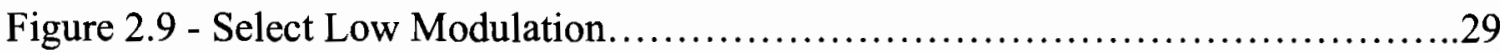

Figure 2.10 - Select Low Logic ................................................ 30

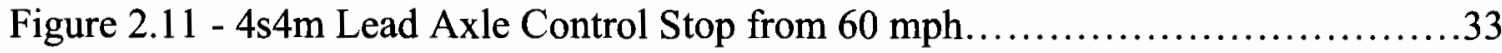

Figure 2.12 - 4s3m Lead Axle Control with Select High Logic.........................34

Figure 2.13 - 4s3m Lead Axle Control with Select Low Logic........................34

Figure 2.14 - Inclusion of Both Treadles..........................................

Figure 2.15 - Primary and Secondary Treadles....................................37

Figure 2.16 - Experimentally Measured Brake Chamber Pressures [7] ...............40

Figure 2.17 - Chamber 1 Pressure Dynamics....................................4 41

Figure 2.18 - Chamber 1 Initial Build........................................42

Figure 2.19 - Brake Position 1 with Original Treadle Reference.......................44

Figure 2.20 - Brake Position 4 with Original Treadle Reference.......................44

Figure 2.21 - Original Modeling of the Primary Treadle.............................45 


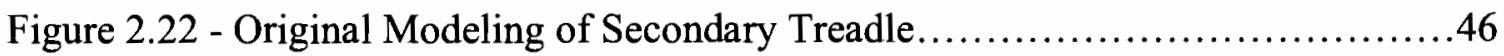

Figure 2.23 - New Modeling of Primary Treadle ..................................48

Figure 2.24 - New Modeling of Secondary Treadle.................................48

Figure 2.25 - Chamber 1 with New Treadle Reference...............................49

Figure 2.26 - Chamber 4 with New Treadle Reference.................................49

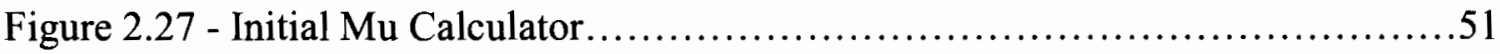

Figure 2.28 - Initial Braking Deceleration of 4s $4 \mathrm{~m}$ System........................55

Figure 2.29 - Initial Braking Deceleration of $6 \mathrm{~s} 6 \mathrm{~m}$ System..........................53

Figure 2.30 - 6s6m High Friction Stops at GVWR - Chamber 1 Dynamics..............56

Figure 2.31 - 6s6m High Friction Stops at GVWR - Chamber 4 Dynamics..............57

Figure 2.32 - Simulated Brake Torques for $6 \mathrm{~s} 6 \mathrm{~m}$ High Friction Stop....................59

Figure 2.33 - Mean Torque vs. Chamber Pressure for Drive Axle Brakes...............60

Figure 2.34 - 6s6m High Friction Stops at GVWR - Speed Profiles....................61

Figure 2.35 - 6s6m High Friction Stops at LLVW - Chamber 1 Dynamics.............63

Figure 2.36 - 6s6m High Friction Stops at LLVW - Chamber 4 Dynamics...............64

Figure 2.37 - 6s6m High Friction Stops at LLVW - Speed Profiles.....................65

Figure 2.38 - 6s6m Low Friction Stops at GVWR - Chamber 1 Dynamics...............67

Figure 2.39 - 6s6m Low Friction Stops at GVWR - Chamber 4 Dynamics...............68

Figure 2.40 - 6s6m Low Friction Stops at GVWR - Speed Profiles.....................69

Figure 2.41 - 6s6m Low Friction Stops at LLVW - Chamber 1 Dynamics................71

Figure 2.42 - 6s6m Low Friction Stops at LLVW - Chamber 4 Dynamics................72

Figure 2.43 - 6s6m Low Friction Stops at LLVW - Speed Profiles....................73

Figure 2.44 - Lead Control High Friction Stops at GVWR - Chamber 1 Dynamics....... 75

Figure 2.45 - Lead Control High Friction Stops at GVWR - Chamber 4 Dynamics.......76

Figure 2.46 - Lead Control High Friction Stops at GVWR - Speed Profiles.............77

Figure 2.47 - Lead Control High Friction Stops at LLVW - Chamber 1 Dynamics.......79

Figure 2.48 - Lead Control High Friction Stops at LLVW - Chamber 4 Dynamics.......80

Figure 2.49 - Lead Control High Friction Stops at LLVW - Speed Profiles...............81

Figure 2.50 - Lead Control Low Friction Stops at GVWR - Chamber 1 Dynamics.......83

Figure 2.51 - Lead Control Low Friction Stops at GVWR - Chamber 4 Dynamics.......84 
Figure 2.52 - Lead Control Low Friction Stops at GVWR - Speed Profiles..............85

Figure 2.53 - Lead Control Low Friction Stops at LLVW - Chamber 1 Dynamics........87

Figure 2.54 - Lead Control Low Friction Stops at LLVW - Chamber 4 Dynamics........88

Figure 2.55 - Lead Control Low Friction Stops at LLVW - Speed Profiles...............89

Figure 3.1 - Example Response of Trailer ABS...................................94

Figure 3.2 - Total Vehicle View.............................................. 98

Figure 3.3 - Top Layer of Tractor-Trailer Simulink Model..........................101

Figure 3.4 - Bottom Layer of Tractor-Trailer Simulink Model........................102

Figure 3.5 - Low and High Friction Stops for Experimental Trailer....................105

Figure 3.6 - Experimental Slip Ratios for High and Low Friction Stops...............106

Figure 3.7 - Slip Ratio Dump System of Trailer ABS Model........................107

Figure 3.8 - Hold Timing Section of Lead Axle Stair-Step Build System................108

Figure 3.9 - Lead Axle Hold Duration Selector.....................................109

Figure 3.10 - Base Layer of Trailer ABS Control Selector...........................110

Figure 3.11 - 4s2m Select-High Module....................................112

Figure 3.12 - 4s2m Select-Low Module.......................................112

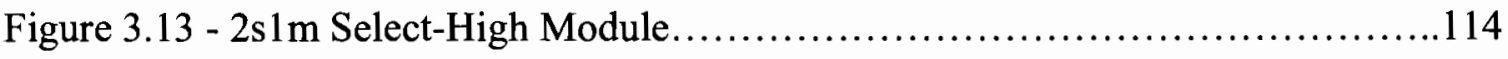

Figure 3.14 - 2s1m Select-Low Module......................................114

Figure 3.15 - Steer Axle Brake Chamber Pressures, Tractor at GVWR, BIC on Low

Friction Surface..................................................117

Figure 3.16 - Drive Axle Brake Chamber Pressures, Tractor at GVWR, BIC on Low

Friction Surface..................................................118

Figure 3.17 - Steer Axle Brake Chamber Pressures, Tractor at LLVW, Straight-ahead

Stop from $60 \mathrm{mph}$ on High Friction Surface...........................119

Figure 3.18 - Drive Axle Brake Chamber Pressures, Tractor at LLVW, Straight-ahead

Stop from $60 \mathrm{mph}$ on High Friction Surface........................... 120

Figure 3.19 - Chamber 1 Brake Pressures for Trailer, High Friction Stop from $60 \mathrm{mph}$ at

LLVW.

Figure 3.20 - Chamber 1 Slip Ratio for Trailer, High Friction Stop from $60 \mathrm{mph}$ at

LLVW. 
Figure 3.21 - Experimental Slip Ratio Histograms for High Friction Stop.............124

Figure 3.22 - Simulated Slip Ratio Histograms for High Friction Stop.................125

Figure 3.23 - Chamber 1 Brake Pressures for Trailer, Low Friction BIC at LLVW.....127

Figure 3.24 - Chamber 1 Slip Ratios for Trailer, Low Friction BIC at LLVW...........128

Figure 3.25 - Experimental Slip Ratio Histograms for Low Friction Stop...............129

Figure 3.26 - Simulated Slip Ratio Histograms for Low Friction Stop.................130

Figure 3.27 - Normalized Tire Longitudinal and Lateral Force vs. Slip Ratio at Different Slip Angles [1] for Steer Axle Heavy Truck Tire.......................133

Figure 3.28 - Histogram of Optimally Tuned 2s $1 \mathrm{~m}$, Low Friction Stop................136

Figure 3.29 - Poor Longitudinal 2s 1m, Low Friction Stop............................137

Figure 3.30 - Poor Lateral 2s 1 m, Low Friction Stop.............................138

Figure 3.31 - Histogram of Optimally Tuned 2s1m, High Friction Stop...............139

Figure 3.32 - Poor Longitudinal 2s1m, High Friction Stop .......................140

Figure 3.33 - Poor Lateral 2s1m, High Friction Stop...............................141

Figure 4.1- Surface Utilization of Full Vehicle Braking, 25\% GAWR, Low Friction... 146

Figure 4.2 - Response of 2s1mA system, 25\% GAWR, Low Friction.................148

Figure 4.3 - Response of $2 \mathrm{~s} 1 \mathrm{mC}$ system, 25\% GAWR, Low Friction...................149

Figure 4.4 - Response of $2 \mathrm{~s} 1 \mathrm{mB}$ system, 25\% GAWR, Low Friction.................150

Figure 4.5 - Surface Utilization of Full Vehicle Braking, 25\% GAWR, High Friction..152

Figure 4.6 - Response of $2 \mathrm{~s} 1 \mathrm{mB}$ system, 25\% GAWR, High Friction.................153

Figure 4.7 - Response of 2s1mA System, 25\% GAWR, High Friction................. 154

Figure 4.8 - Surface Utilization of Full Vehicle Braking, 75\% GAWR, Low Friction...156 Figure 4.9 - Response of $2 \mathrm{~s} 1 \mathrm{mB}$ system, 75\% GAWR, Low Friction.................156 Figure 4.10 - Surface Utilization of Full Vehicle Braking,75\% GAWR, High Friction 158 Figure 4.11 - Surface Utilization of Trailer-Only Braking, 25\% GAWR, Low Friction 160 Figure 4.12 - Trailer-Only Braking Response of 2s1 mA system, 25\% GAWR, Low

Friction.......................................................... 161

Figure 4.13 - Trailer-Only Braking Response of 2s1mC system, 25\% GAWR, Low

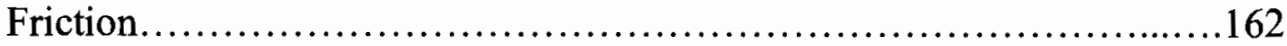


Figure 4.14 - Trailer-Only Braking Response of 2s1 mB system, 25\% GAWR, Low

Friction, from $60 \mathrm{mph}-40 \mathrm{mph}$.

Figure 4.15 - Trailer-Only Braking Response of 2s $1 \mathrm{mB}$ system, 25\% GAWR, Low

Friction, from $30 \mathrm{mph}-15 \mathrm{mph}$.

Figure 4.16 - Actual and Controller Estimated Trailer Speeds for $2 \mathrm{~s} 1 \mathrm{mB}$ system from 30

mph.

Figure 4.17 - Actual and Controller Estimated Trailer Speeds for $2 \mathrm{~s} 1 \mathrm{mB}$ system from 60

mph.

Figure 4.18 - Actual and Controller Calculated Slip Ratios for $2 \mathrm{~s} 1 \mathrm{mB}$ system from 60

$\mathrm{mph}$ 168

Figure 4.19 - Surface Utilization of Trailer-Only Braking,25\% GAWR, Low Friction 170 Figure 4.20 - Trailer-Only Braking Response of $2 \mathrm{~s} 1 \mathrm{mB}$ system, 25\% GAWR, High

Friction, from $60 \mathrm{mph}$

Figure 4.21 - Actual and Controller Estimated Trailer Speeds for $2 \mathrm{~s} 1 \mathrm{mB}$ system from 60 mph, 25\% GAWR, High Friction

Figure 4.22 - Surface Utilization of Trailer-Only Braking,75\% GAWR, Low Friction 174

Figure 4.23 - Actual and Controller Estimated Trailer Speeds for $2 \mathrm{~s} 1 \mathrm{~mA}$ system from 60 mph,75\% GAWR, Low Friction.

Figure 4.24 - Surface Utilization of Trailer-Only Braking,75\% GAWR, High Friction 176

Figure 4.25 - Response to BIC Maneuver, 2s1mB System at 25\% GAWR.............179

Figure 4.26 - Response to BIC Maneuver, 2s1mC System at 25\% GAWR.............180

Figure 4.27 - Response to BIC Maneuver, 2s $1 \mathrm{~mA}$ System at 25\% GAWR.............181

Figure 4.28 - Response to BIC Maneuver, 4s2m System at 25\% GAWR...............182

Figure 4.29 - Response to BIC Maneuver, 4s4m System at 25\% GAWR...............183

Figure 4.30 - Response to BIC Maneuver, 2s1mB System at 75\% GAWR ............185

Figure 4.31 - Response to BIC Maneuver, 2s1mA System at 75\% GAWR.............186

Figure 4.32 - Response to BIC Maneuver, 4s2m System at 75\% GAWR................187

Figure 4.33 - Response to BIC Maneuver, 4s4m System at 75\% GAWR...............188 


\section{CHAPTER 1}

\section{INTRODUCTION}

\subsection{Motivation}

Over 75 million heavy trucks travel over 200 billion miles annually on U.S. roads. Because of the volume of accumulated miles by heavy trucks and due to their size and weight, many fatal accidents on America's roads involve heavy trucks. In 2002 alone, there were 4,897 deaths resulting from 4,183 fatal accidents involving heavy trucks [1].

Commercial trucks have become safer over the past 20 years due to increased training and technology, resulting largely from the creation of a Federal Motor Vehicle Safety Standard pertaining to these large vehicles (FMVSS 121) [2]. FMVSS 121 was updated in 1997 to require that anti-lock braking systems (ABS) be installed in all heavy trucks. Although the implementation of ABS systems into heavy trucks has led to safer operation, many operational parameters remain unclear to the vehicle modeling community due to the proprietary nature of these systems. Research into these braking 
systems is essential to achieving the desired safety of these vehicles, which are so vital to the American infrastructure. An extensive catalog of research in crash avoidance of heavy trucks is being conducted by the National Highway Traffic Safety Administration (NHTSA) at its Vehicle Research and Test Center (VRTC) in East Liberty, Ohio. This study will assist VRTC engineers in understanding the ABS braking performance of heavy trucks through simulation, as experimentally validated models will be used to study the effects that changing ABS system parameters and configurations have on vehicle performance.

\subsection{Simulation}

Two software programs were used to create truck braking models in this study as well as others conducted previously. Simulink, a system modeling tool, was used to create the simulation environment, in which the models of the brake systems, ABS controller, and a friction generation system were created. TruckSim was used to create a full vehicle multi-body dynamics model, which was run in parallel with the brake system, ABS, and friction generation models in the Simulink environment. The two programs ran simultaneously to create a total truck model, as brake torques and surface friction levels from Simulink were sent to TruckSim, which returned individual wheel and full body dynamics parameters to be considered in the next time iteration. 


\subsection{Previous Studies}

Over the last five years a great deal of work has been devoted to creating an accurate braking model, to be used by NHTSA engineers for the study of heavy truck braking performance. An in-depth study of brake dynamics and the creation of an initial anti-lock braking system (ABS) model were completed by Dunn [3, 4] in 2003 . These brake and ABS models were then used to study jackknife stability in Class VIII vehicles with trailers by Zagorski $[5,6]$. The ABS model of Dunn and Zagorski was then improved by Zaugg $[7,8]$ and was used to create an accurate braking model for a $6 \times 4$ Peterbilt straight truck.

The original ABS braking model of Dunn was created in Simulink, and in the manner described in Section 1.2, it consisted of several subsystems which corresponded to physical systems of the truck. The Simulink environment, shown in Figure 1.1, consisted of a TruckSim model, a random friction generator system, an ABS controller model, and pneumatic brake systems. 

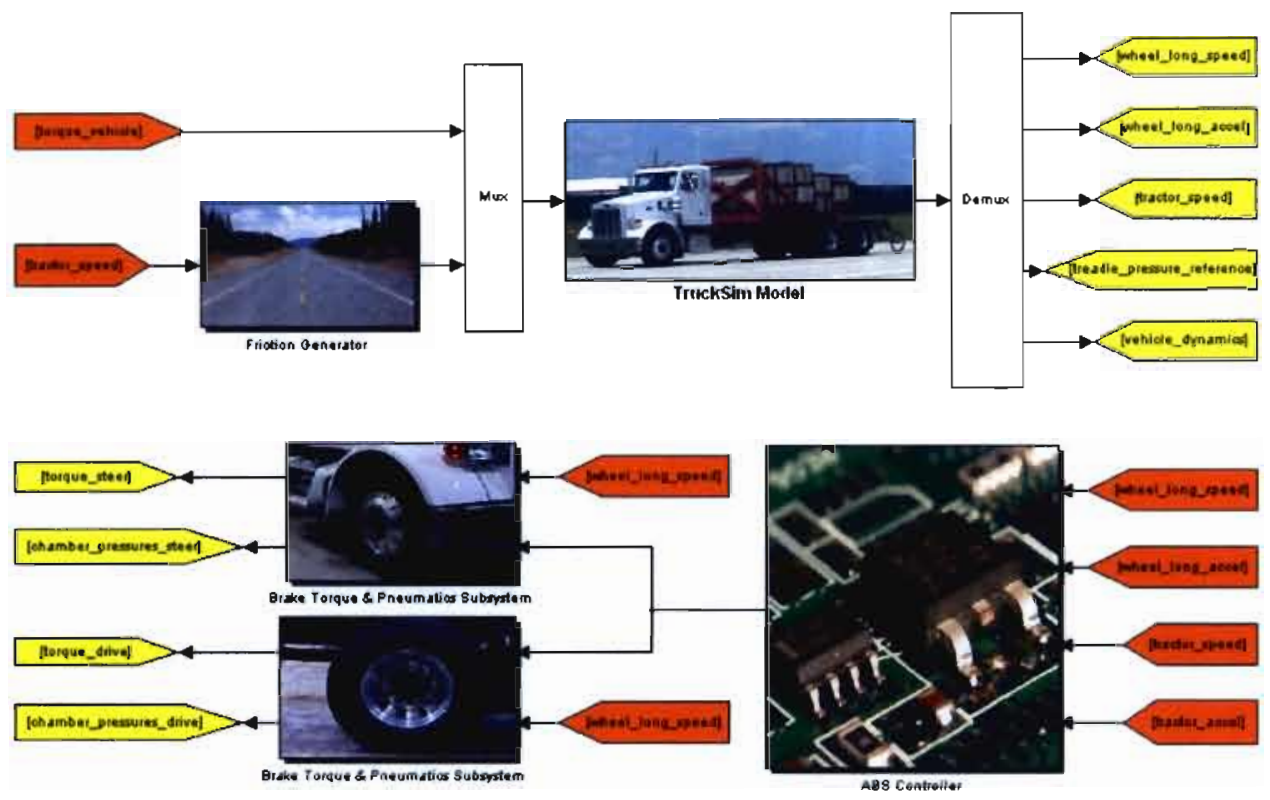

Figure 1.1 - Base Layer of Dunn's ABS Model

This environment was created in such a way that the created Simulink systems and the TruckSim model run in parallel. The user input a nominal coefficient of friction, and as a function of wheel position, randomly varied coefficients (about the nominal value) were sent to the TruckSim model block. This block contains the S-Function, and was the link between the Simulink environment and the TruckSim model, as it used the friction level and brake torques to calculate vehicle dynamics characteristics. The TruckSim model also provided the brake pressure reference signal, which was the input for the brake torque and pneumatic systems along with the commands from the ABS controller. The longitudinal wheel speed and acceleration for each wheel and the total vehicle speed and acceleration were calculated in TruckSim and were the inputs to the ABS controller model. Based on these inputs, the ABS controller returned a hold, dump, 
or build command to each of the brake chambers. More information on the Friction Generation system and the brake torque and pneumatics subsystems can be found in $[3,4$, $5,7]$. One can see from this description of the original ABS model of Dunn [3] how the combination of Simulink and TruckSim are a powerful tool for vehicle simulation.

Dunn's was used as a starting point for the work of Zaugg [7, 8], as a new ABS controller model was created to go along with the other subsystems. The previously described ABS model accepted longitudinal wheel speeds and accelerations as inputs along with total speed and acceleration for the vehicle. These numbers, from the TruckSim calculations, were then compared to various slip ratio and acceleration thresholds. Then, ABS modulation decisions were made accordingly. This is not how real ABS system work, however, as they must estimate these parameters. Zaugg updated the ABS model of Dunn so that it would function in a manner characteristic of an actual ABS controller, as a longitudinal wheel speed for each wheel and a brake on/off signal are its only inputs. From the wheel speed inputs at each instance of time, Zaugg's controller was able to estimate the slip ratio and acceleration at each wheel, the total vehicle speed, and the surface coefficient of friction (these parameters were fed into Dunn's model). The controller then had a set of thresholds which are valid for combinations of these parameters. The ABS controller could then instruct each brake chamber to dump, hold, or build pressure based on the current slip ratio and acceleration at each wheel in relation to these thresholds. The base layer for Zaugg's simulation environment can be seen in Figure 1.2 and Figure 1.3, which show the top half 
subsystems (Friction Generation, TruckSim model, and vehicle dynamics) and the bottom half subsystems (ABS controller and brakes), respectively.

One can see that this model works in the same fashion as the original model of Dunn, with the difference being the ABS controller inputs. A complete description of Zaugg's ABS controller can be found in Chapter 4 of [7], including a detailed outline of each subsystem contained within the ABS controller model. 


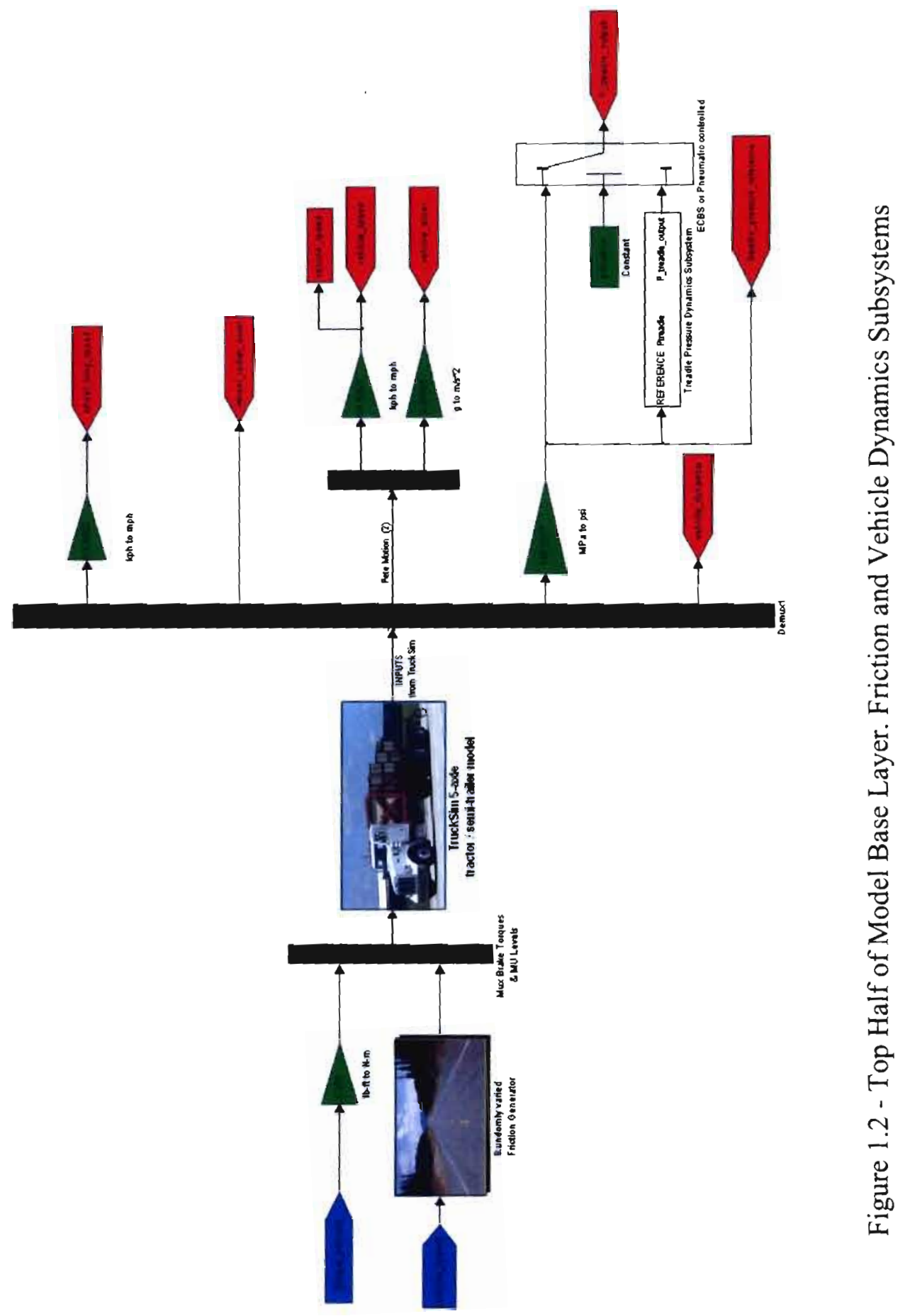




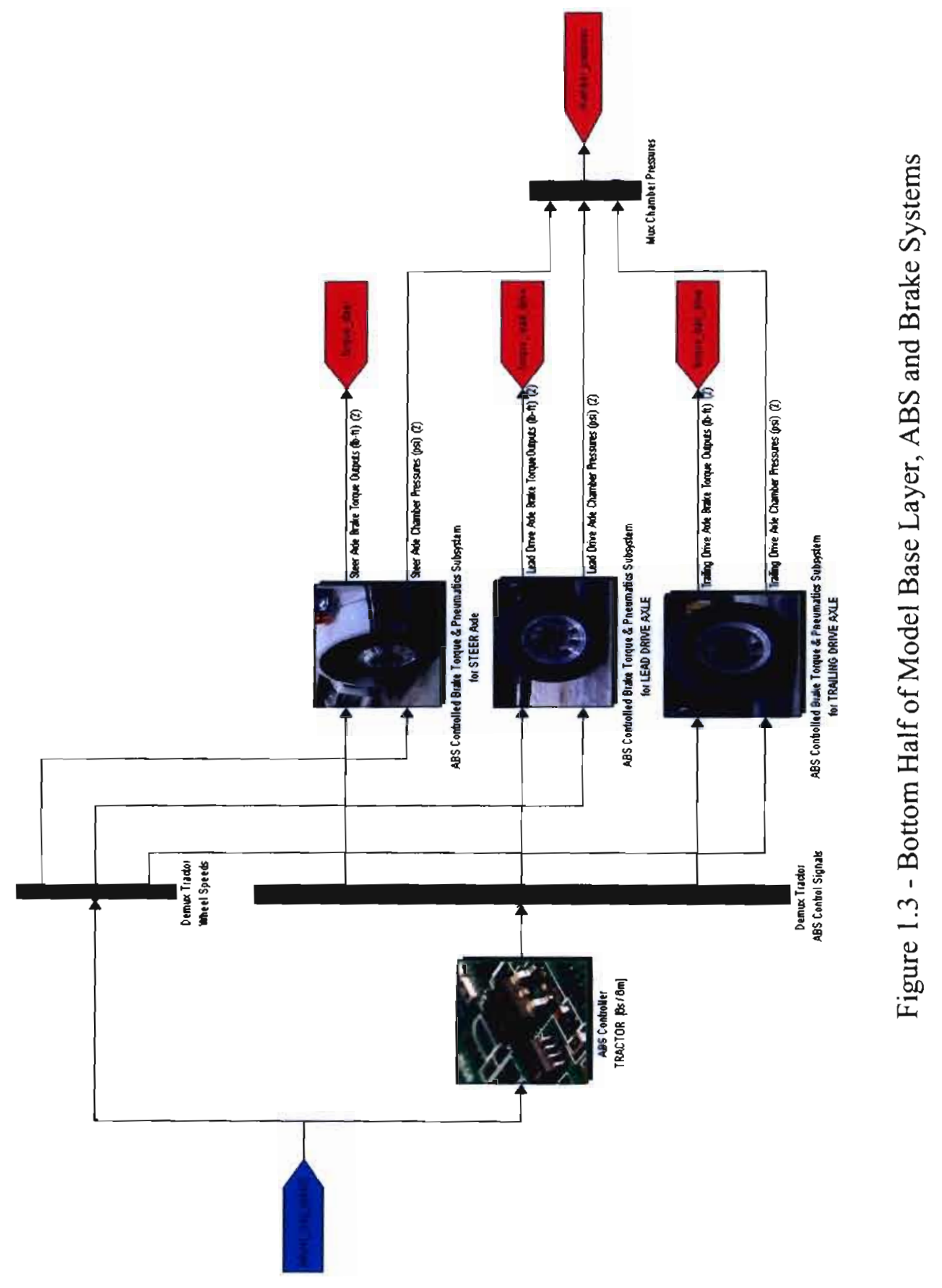




\subsection{Objective}

To further the understanding of heavy truck braking performance, two different modeling projects were completed for this study. First, the 6s6s ABS controller model of Zaugg [7] was modified to include the capability of simulating a variety of different ABS control configurations, including $4 \mathrm{~s} 4 \mathrm{~m}$ and $4 \mathrm{~s} 3 \mathrm{~m}$ systems. Also, the vehicle model was modified to create a simulation that is more representative of the Peterbilt truck. Second, a tractor-trailer vehicle model was created, so that the performance of trailer ABS systems could be studied. Trade-offs between longitudinal and lateral effectiveness were examined by studying the simulated results of a variety of trailer ABS controller systems.

\subsection{Thesis Overview}

Chapter 2 outlines the measures taken to improve the existing model of the $6 \times 4$ Peterbilt truck. Details of how the model switched between ABS configurations and the measures taken to improve the accuracy of the model are explained. Also, the model is validated through comparison to experimental data taken from the Peterbilt truck as it was equipped with various $\mathrm{ABS}$ configurations.

Chapter 3 explains how the model of the tractor-trailer was created. This model, consisting of a $4 \times 2$ tractor and $48 \mathrm{ft}$ trailer, was created in order to study the effects of varying semi-trailer ABS controller parameters on braking performance. This chapter goes through the details of how the ABS controller and TruckSim models were created 
for the tractor and semi-trailer. Chapter 4 displays the results of the series of simulation runs that were conducted for the tractor-trailer model.

Finally, Chapter 5 discusses the resulting Peterbilt model and the findings of the tractor-trailer braking study of Chapter 4 . Chapter 5 also suggests areas for further improvements to the models as well as recommendations for further studies. 


\section{CHAPTER 2}

\section{X4 TRUCK ABS MODEL IMPROVEMENTS AND APPLICATIONS}

\subsection{Overview of Existing 6x4 Model}

Because the braking performance of the same Peterbilt $6 \times 4$ straight truck was to be analyzed, the shell of Zaugg's ABS controller model, found in Figure 1.2 and Figure 1.3, was the starting point for this study. As described in Section 1.3, the simulation environment included a TruckSim vehicle dynamics model, a friction generation module, brake system models, and an ABS controller model; all of which ran in parallel to create a braking simulation which simulated the actual performance of the studied Peterbilt truck. Understanding the workings of these systems was crucial to any further braking performance studies of this type. 


\subsubsection{TruckSim Model}

The TruckSim model was the key element to the overall simulation because it provided the vehicle dynamics calculations (in continuous time) as well as the driver input commands. The model of the Peterbilt was created using measured or estimated parameters from the truck, such as spring stiffnesses, inertias, wheelbase, masses, and other physical dimensions, in TruckSim. A complete description of the Peterbilt TruckSim model can be found in Chapter 3 of [7]. Using the Simulink calculated brake torques and surface friction levels, TruckSim solved a set of differential equations, which provided the vehicle dynamics outputs, which must in turn be used by the ABS controller and brake models. The vehicle dynamics outputs, such as vehicle speed, wheel speeds, accelerations, and others (over 100 parameters), are finally sent to the Matlab workspace, where further analysis took place.

Zaugg created two separate TruckSim models for the Peterbilt truck, each corresponding to two different loading conditions. This allowed for easy, one-step transitions from one loading condition to the other. One model simulated the truck with no payload, in its lightly loaded vehicle weight (LLVW) state. Simulations were also conducted at the Gross Vehicle Weight Rating (GVWR) of the truck, so another model was created to account for the differences in centers of gravity, inertias, suspension deflections, etc. To accomplish GVWR on the actual vehicle, a load frame was built and concrete blocks were added to the Peterbilt. For more information on the truck setup, please see Chapter 3 of [7]. For this study, these two models were used so that the braking behavior of the truck could be studied for two extreme loading conditions. 
TruckSim also has the capability of simulating a variety of driving conditions. By creating a virtual test environment and setting the driver inputs, one can complete a total vehicle simulation of nearly any condition. The coefficient of friction for the simulation environment can be set to any desired value; however, for this study it was fed into the TruckSim model from the Friction Generator in Simulink, for each instance of time. To simulate an actual road surface, in which the coefficient of friction is not typically constant, the Friction Generator module $[1,4]$ adds band-limited white noise to a nominal coefficient of friction value. This nominal value is provided by the user as an initial input to the Simulink program. Also, the following driving maneuvers were created to be used in simulation: a high friction, straight-ahead stop from $60 \mathrm{mph}$ and a low friction, brakein-curve (BIC) maneuver (500 foot radius) from $19 \mathrm{mph}$. These simulate FMVSS test procedures used by NHTSA and will be covered in more detail in Section 2.5. The application of the brakes in this TruckSim model became the trigger for the brake and ABS models. A "brake on" signal started the monitoring of the ABS controller and the treadle pressure command was used to model the reference pressure for each brake chamber. A "brake on" signal allows intervention by the simulated ABS controller if necessary. Also, TruckSim provided a method for viewing each simulation, as it includes a useful animator tool.

\subsubsection{Brake Torque and Pneumatics Models}

The braking system of the Peterbilt truck is modeled using the Brake Torque and Pneumatics system models, originally developed by Dunn $[1,4]$. One such system model was inserted into the overall model for each of the six brakes on the Peterbilt truck (two 
each for the steer, lead drive, and trailing drive axles). Each subsystem received the appropriate treadle, wheel speeds, and ABS commands and then output the integrated pressures for each brake chamber. This architecture can be seen in Figure 1.3. Each of three subsystems (by axle) consisted of two main elements, one for accurate modeling of the brake chamber dynamics and another for precise modeling of the brake torques, which were then used in TruckSim. More information on these systems can be found in Dunn [1] and Zaugg [7].

\subsubsection{Brake Chamber Pressure Models}

In general, each individual brake chamber was modeled as a first-order response to a given input pressure. This input pressure was determined by using a simulated modulator valve, which assigned a reference based on the treadle pressure and the ABS command at each interval of time. An integrator for each brake position used this reference pressure, along with an appropriate first-order time constant, to simulate the response of each brake chamber.

At each time step, the time constant used in the chamber dynamics calculations depended on the state of the chamber pressure. The chamber pressure models used three different time constants, representing three distinct chamber pressure regions. One of the time constants governed the filling region of the brake chamber response, corresponding to pressures from 0 to approximately $7 \mathrm{psi}$. In this region, the brake chambers begin to fill with air, but the pressure is not enough to begin moving the diaphragm of the pneumatic brake chamber. The diaphragm begins to move at what is known as the push- 
out pressure, which for these models was estimated as 7 psi. For this region, rising, a different time constant is more appropriate to model its dynamics. The rising region represents all increasing pressures from $7 \mathrm{psi}$. The third region, falling, represents all decreasing pressures. These regions will be discussed further in Section 2.3.2.

The time constants used by Zaugg were gathered from classical methods, as described in [9]. Time constants were gathered for each region by using two different methods. First, a time constant for each region was estimated from simulating the response to a step input. Next, because of the finite time required for pressures to rise to or fall from their steady-state values, a time constant was estimated from assuming a terminated ramp input. Zaugg found that a situation where the filling region was modeled as a step and the rising and falling regions were modeled as a terminated ramp yielded the best results for his simulation of the Peterbilt truck (see Section 2.2.3 of [7]).

\subsubsection{Modeling of Brake Torques}

The brake chamber pressure and wheel speed were then used to create the brake torque for each wheel. The Peterbilt was equipped with traditional S-cam brakes, which represent the majority of brakes in the U.S. fleet. The behavior of these brakes was studied extensively by Dunn [3] in order to create the mechanical brake torque model used for this study. The model sent the modeled available brake torque for each brake position to the TruckSim model, based on the current chamber pressure and wheel speed. This model also included estimates of brake hysteresis that exists with any brake. 


\subsubsection{Simulink ABS Controller}

The ABS controller used for this study was initially created by Zaugg, which is described in great detail in Chapter 4 of [7]. Detailed descriptions of this controller model will not be repeated in this thesis as they were not the basis of this study. In general, the ABS controller model received only the speeds of each wheel hub and a signal indicating the application of the braking system. Based on these wheel speeds, the controller estimated acceleration and longitudinal slip ratio at each wheel hub, at each instant of time, and compared these values to thresholds inside the controller. The controller then decided to build, hold, or dump pressure at each wheel in order to avoid wheel lock-up, thus helping the driver safely bring the truck to a stop. As with actual ABS controllers, this model also used the individual wheel speeds to estimate the overall speed of the vehicle, necessary for the wheel slip calculation. The controller also attempted to determine the surface friction level based on wheel speeds, since the controller utilizes different operating parameters for different friction levels.

\subsection{ABS Control Selector}

The ABS controller model of Zaugg had the capability of sensing wheel speeds and modulating brake pressures at all six wheels of the $6 \times 4$ Peterbilt truck. Such a configuration is called a $6 \mathrm{~s} 6 \mathrm{~m}$ system, designating the use of 6 wheel sensors and 6 modulators. The layout of such a system can be seen in Figure 2.1. Note that each wheel hub has a corresponding encoder and ABS modulator valve. Although this is the most 
sophisticated ABS system layout available for a $6 \times 4$ truck, such a system is not the overwhelming choice when analyzing the U.S. fleet as a whole. Many trucks are equipped with fewer sensors and/or modulators, mainly to reduce cost. Because these systems are so common, it was necessary to make the braking model adaptable to different popular ABS configurations.

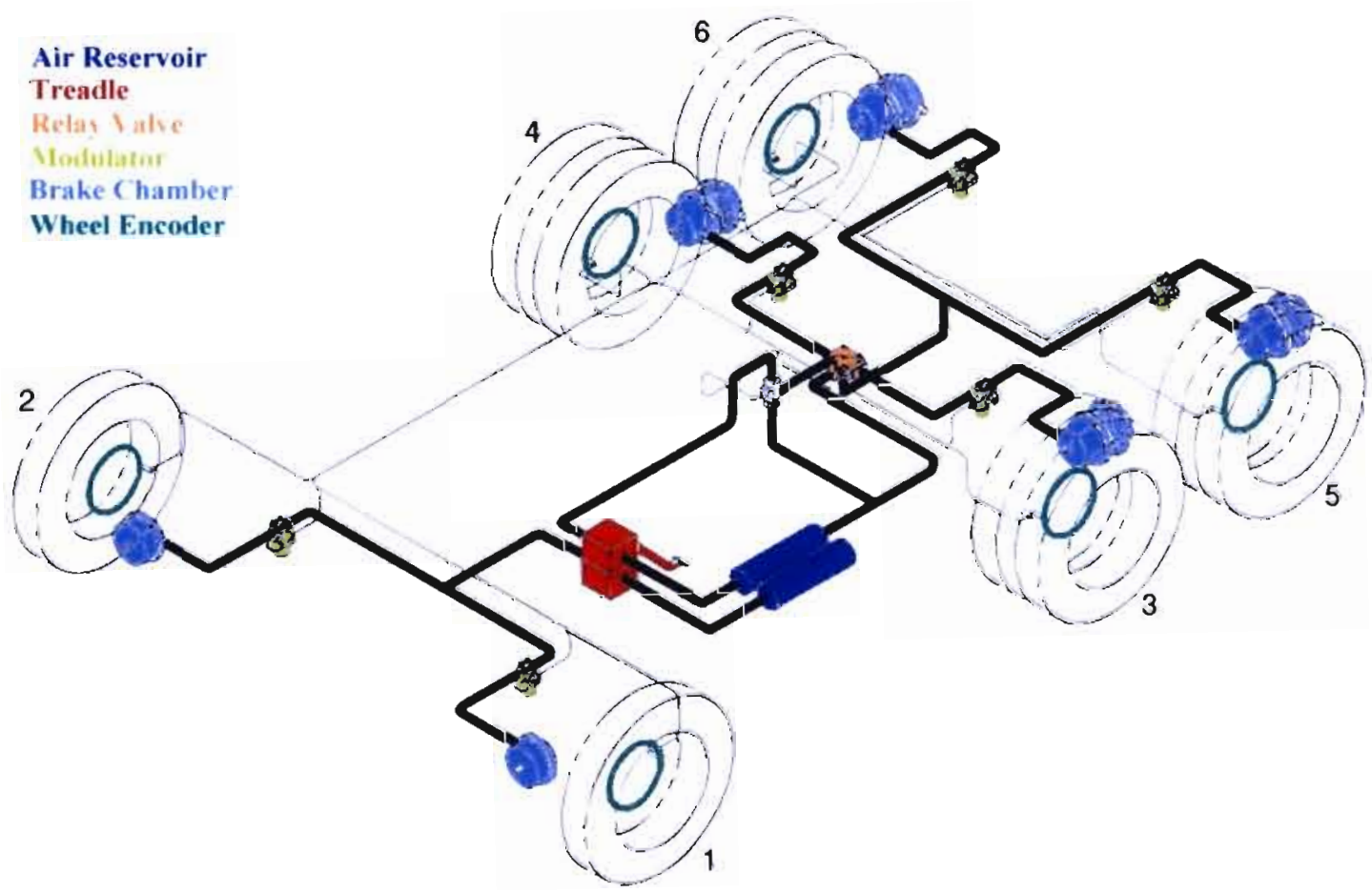

Figure $2.1-6 \mathrm{~s} 6 \mathrm{~m}$ System Layout [7]

NHTSA VRTC researchers wished to give the Peterbilt braking model the additional capability of simulating a $4 \mathrm{~s} 4 \mathrm{~m}$ ( 4 sensors, 4 modulators) or a $4 \mathrm{~s} 3 \mathrm{~m}$ ( 4 sensors, 3 modulators) system. In either a $4 \mathrm{~s} 4 \mathrm{~m}$ or a $4 \mathrm{~s} 3 \mathrm{~m}$ system, the speed of both steer axle wheels (wheels 1 and 2) is sensed and each brake chamber can be individually 
modulated, just like a $6 \mathrm{~s} 6 \mathrm{~m}$ system. The difference lies in how the drive axles are sensed and modulated; the " $4 \mathrm{~s}$ " indicates that the speeds of only two of the four drive wheels are monitored, corresponding to either the leading drive axle (wheels 3 and 4 ) or the trailing drive axle (wheels 5 and 6). Figure 2.2 shows the implementation of a $4 \mathrm{~s} 4 \mathrm{~m}$ system in which the trailing drive axle (wheels 5 and 6) is sensed for control (i.e., the axle with two sensors). One can see that the location of wheel encoders at wheels $1,2,5$, and 6 indicate that those are the four wheel speeds being monitored. One can also see from Figure 2.2 that there is one ABS modulator valve for each side of the tandem drive axles; this is the case for all $4 \mathrm{~s} 4 \mathrm{~m}$ systems. Therefore, wheel 5 is sensed in order to modulate itself as well as wheel 3 , and wheel 6 is sensed in order to modulate itself and wheel 4 . The roles of wheels 3 and 5 and 4 and 6 are reversed in a $4 \mathrm{~s} 4 \mathrm{~m}$ system with leading drive axle control. 


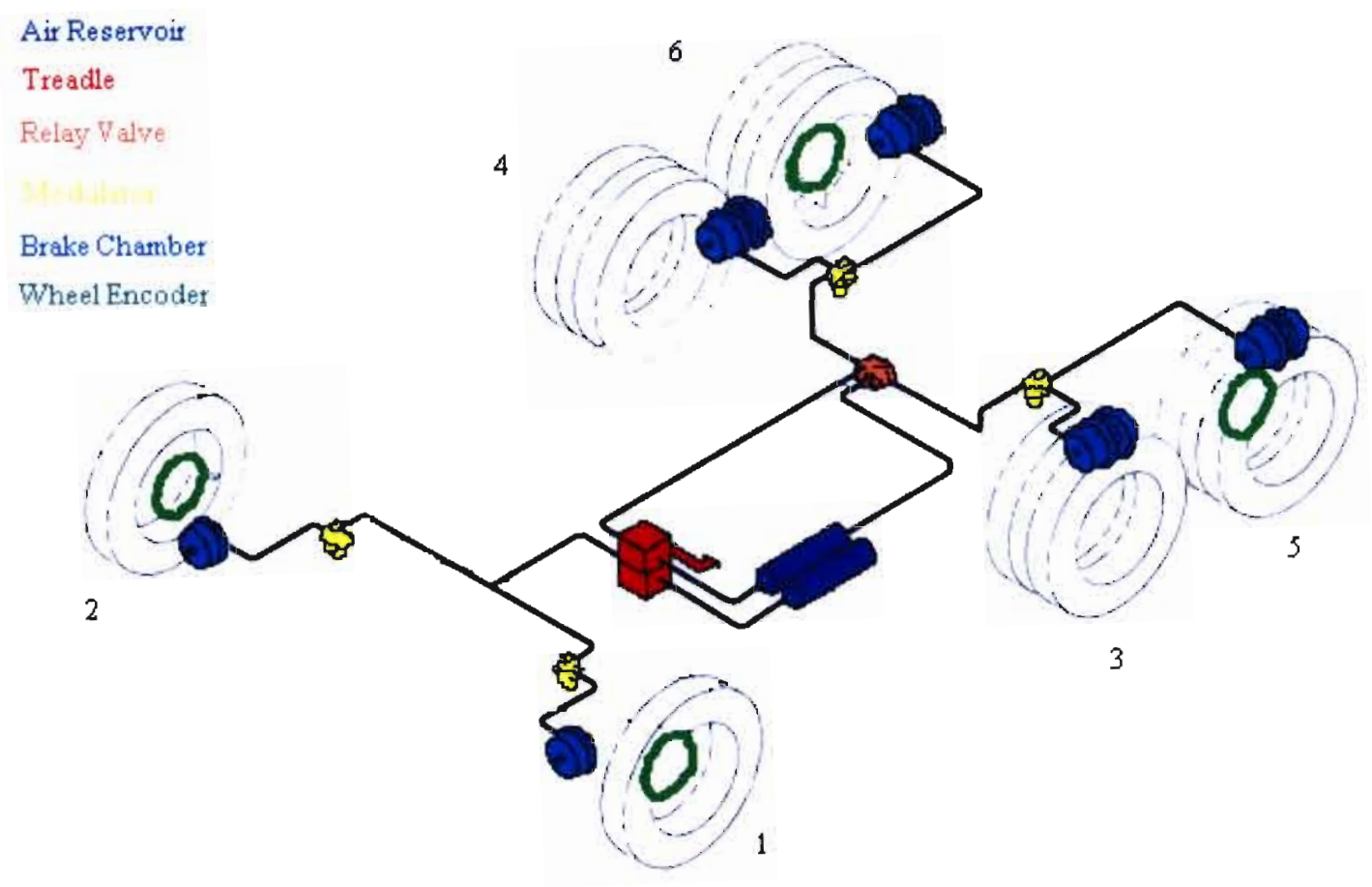

Figure 2.2 - 4s 4m System Layout - Trailing Drive Axle Control [10]

A $4 \mathrm{~s} 3 \mathrm{~m}$ system, like a $4 \mathrm{~s} 4 \mathrm{~m}$ system, senses wheel speeds of the leading or trailing drive axle. However, this system differs from a $4 \mathrm{~s} 4 \mathrm{~m}$ because it only has one modulator valve to control all of the drive axle brakes instead of one for each side. In other words, the ECU makes a decision of whether to build, hold, or dump pressure in all four drive wheels (together) based on the action of the two monitored wheels. It should be noted that although not allowed for a $6 \times 4$ truck by FMVSS No. 121 and therefore not commonly found, the behavior of such a system is of interest to NHTSA researchers. There are two basic schemes for implementing this $4 \mathrm{~s} 3 \mathrm{~m}$ strategy at the rear axles: selectlow or select-high logic. With select-low logic, pressure is dumped or held if either of the sensing wheels indicates that it is necessary to do so, for their respective wheels. In 
other words, the pressure in the drive wheels will only build if both of the control axle wheels deem it allowable. This is the more aggressive of the two schemes, since selecthigh logic requires that both of sensing wheels necessitate a dump before that command is sent to the modulator valve. These two schemes are often implemented in semi-trailer ABS systems, which utilize a similar $2 \mathrm{~s} 1 \mathrm{~m}$ system. A comprehensive study of this type was completed by Zagorski $[5,6]$ and in the second part of this research. It should also be noted that some, if not the majority, of ABS systems of this type utilize a combination of select-low and select-high control strategies.

In order to make the $6 \mathrm{~s} 6 \mathrm{~m}$ ABS controller model adaptable to the other desired configurations, the ABS Control Selector module was created. As stated earlier, the ABS controller receives all six individual wheel speeds and outputs $a+1,0$, or -1 for each brake modulator valve, corresponding to the Build, Hold, and Dump commands. To update the model, this action was retained as the configuration of the controller was decided in the ABS Control Selector. The integration of this module into the original system (Figure 1.3) can be seen in Figure 2.3. The output of the selector module remains $\mathrm{a}+1,0$, or -1 for each brake position; these are manipulated, however, to match the logic output of the desired ABS configuration. For example, the output for a $4 \mathrm{~s} 4 \mathrm{~m}$, leading drive axle control, would be such that the command of wheel 5 is set to match the command of wheel 3 at all times. The commands of wheels 6 and 4 would be governed by the same relationship. By using this basic idea, simulations of all of the desired configurations were obtained. 


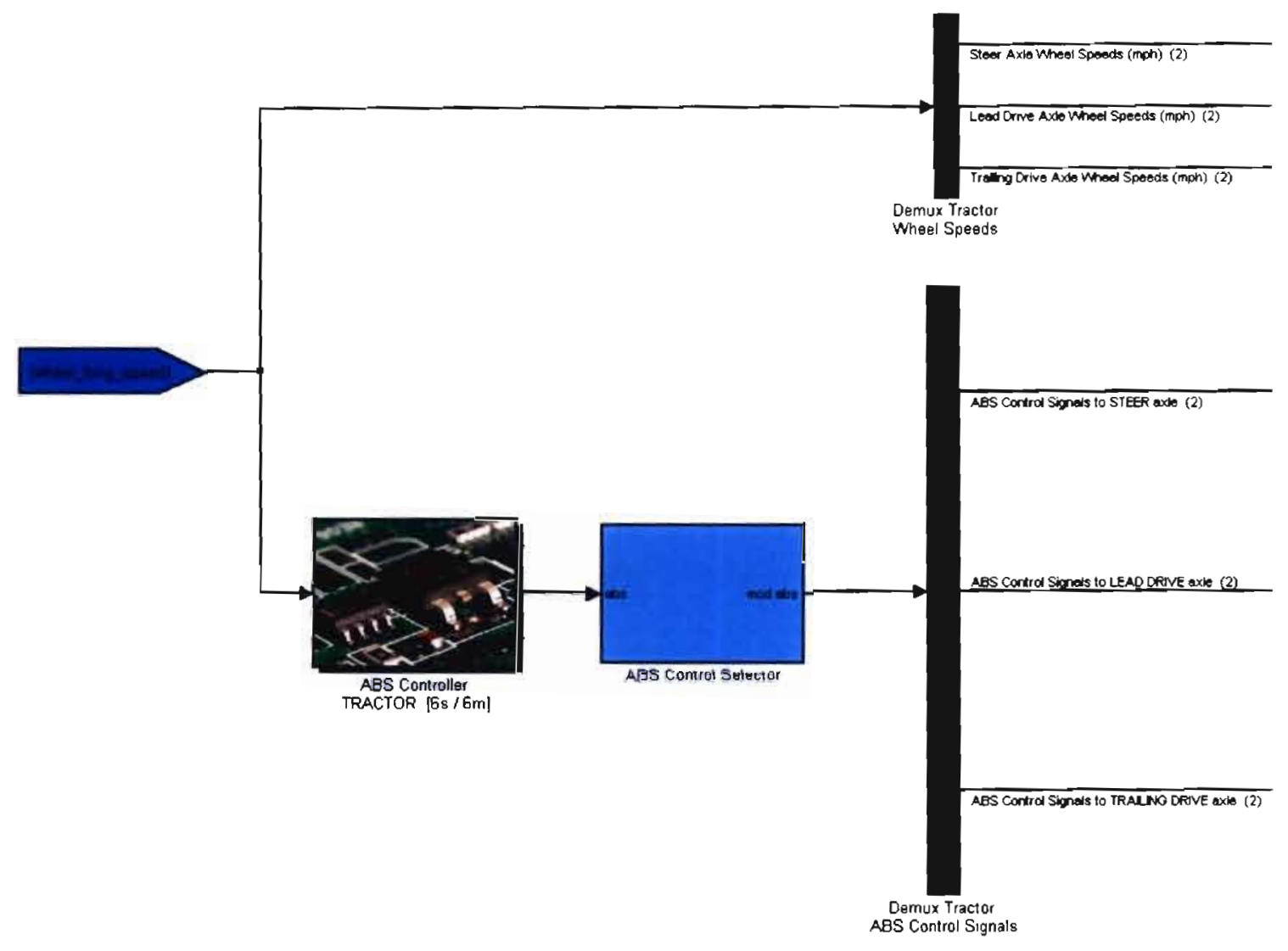

Figure 2.3 - ABS Control Selector Integration

The base layer of the ABS Control Selector can be seen in Figure 2.4. The constant abs_config is set to a value of 1,2 , or 3 , depending on a user input expressing the desired ABS configuration. The situation where abs_config equals 1 represents a desired $6 \mathrm{~s} 6 \mathrm{~m}$ system, and the original commands from the ABS Controller module are passed through the ABS Control Selector without any modification. When this constant is set to either 2 or 3 , the $4 \mathrm{~s} 4 \mathrm{~m}$ and $4 \mathrm{~s} 3 \mathrm{~m}$ configurations are employed, respectively. 


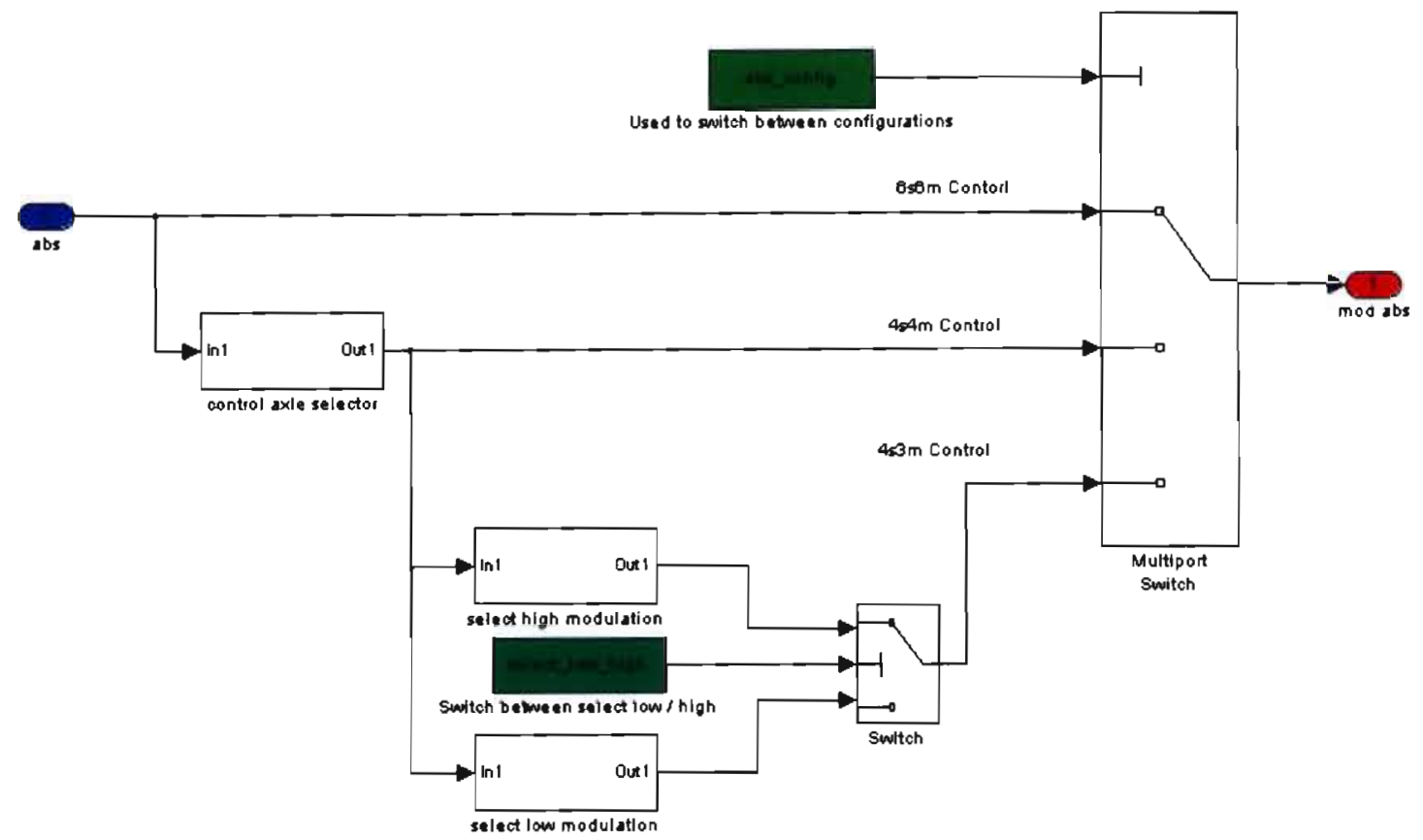

Figure 2.4 - ABS Control Selector Base Layer

If the user is desirous of simulating a $4 \mathrm{~s} 4 \mathrm{~m}$ or $4 \mathrm{~s} 3 \mathrm{~m}$ system, the drive axle to be used as the control must be set. The drive axle select for control was determined and the commands for two drive axles were subsequently modified in the control axle selector module, seen in Figure 2.5. The constant control_axle was determined from user inputs, and controlled the switch between the two possible control axle choices.

Depending on this choice, the output of either the trailing drive axle control or the leading drive axle control modulations was passed. In the axle control modules the commands of the individual wheels were extracted so that they could be manipulated according to the desired control axle input. The commands for wheels 1 and 2 were passed directly through the module and the commands for wheels 3 and 4 were set to the commands for 
wheels 5 and 6 (trailing axle control), respectively, or vice versa for leading axle control. One can see how this was accomplished for trailing axle control by viewing the trail axle control module in Figure 2.6. A similar manipulation is conducted in the lead axle control module.

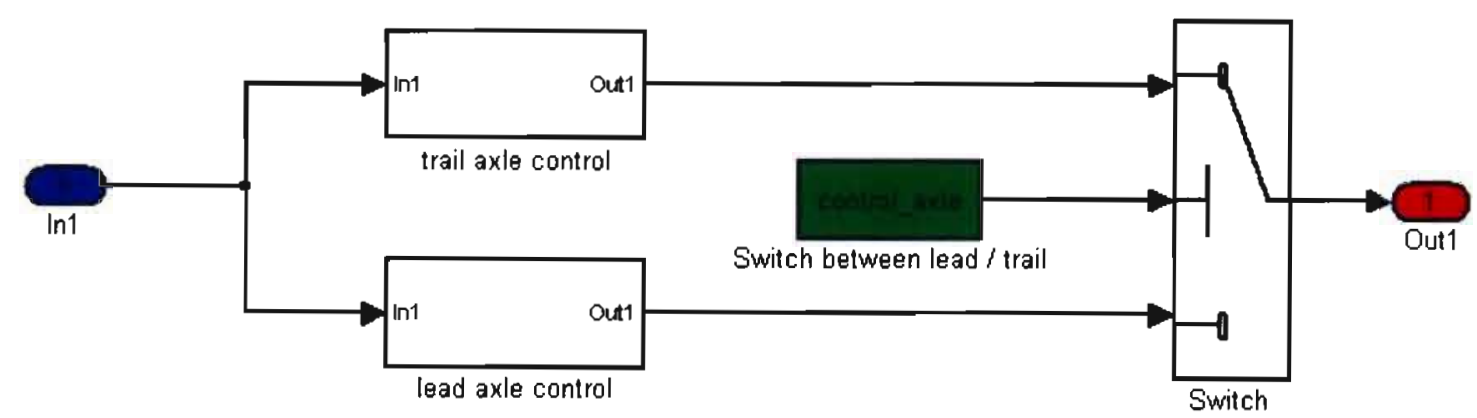

Figure 2.5 - Control Axle Selector

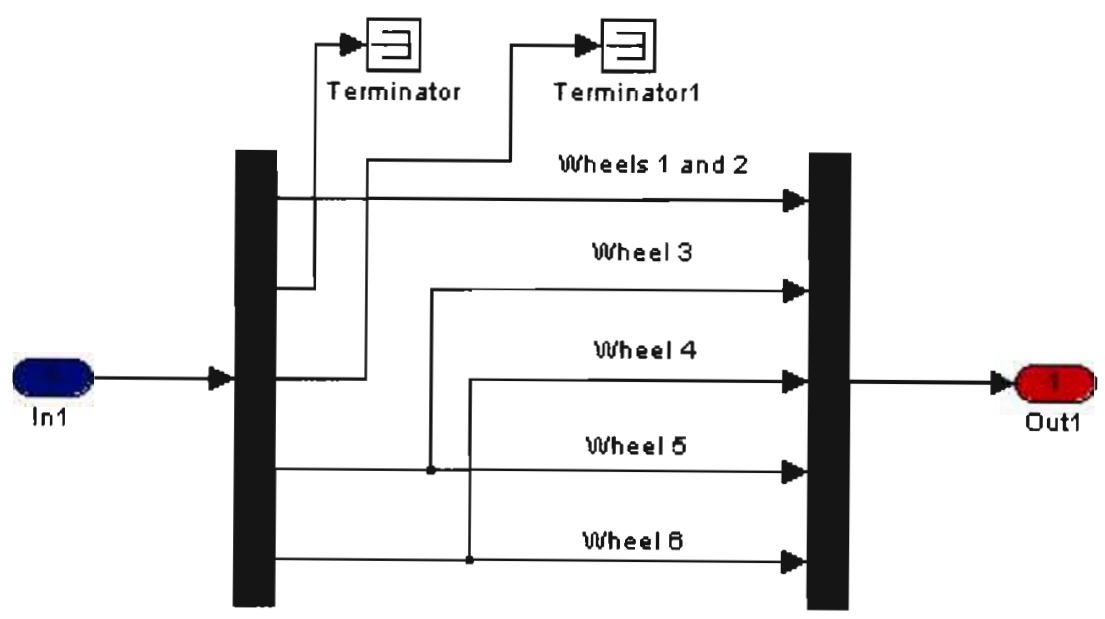

Figure 2.6 - Trail Axle Control 
If a 4s4m ABS system was to be simulated, the output of the Control Axle Selector was then passed through the ABS Control Selector and on to the brake pneumatics and torque models. For the simulation of a $4 \mathrm{~s} 3 \mathrm{~m}$ system, the output of the Control Axle Selector was passed to the Select High Modulation and the Select Low Modulation systems. The value of the constant select_low_high, set by the user, determined which of the $4 \mathrm{~s} 3 \mathrm{~m}$ modulation schemes (described earlier in this section) would be passed to the brake models. The two modulation schemes differ in how they determine when to build, hold, or dump pressure in the four drive wheels, which will be evident after the following discussion.

Figure 2.7 shows the Select High Modulation system of the ABS Control Selector. Within this module, two different scenarios were calculated, both using selecthigh logic, which correspond to the leading and trailing drive axle control cases. The constant control_axle was again used to switch between the two schemes. The two logic subsystems of Figure 2.7 are identical and they correspond to the two individual control axle cases, which can be seen from examining the inputs of the two subsystems. The output of the logic subsystems was therefore a build, hold, or dump command $(+1,0$, or -1) that was set for all four drive axle brake positions. The select-high logic utilized in these two subsystems can be seen in Figure 2.8. This logic was originally developed for the study of $2 \mathrm{~s} 1 \mathrm{~m}$ semi-trailer ABS systems by Zagorski $[5,6]$ and was adapted to control the $6 \times 4$ truck braking behavior for this study. The two inputs for the logic system are the commands for the two control wheels, and a truth table is used to output the correct command to all four drive wheels. One can see from the relational operators in 
Figure 2.8 that this system will create the output for a select-high $4 \mathrm{~s} 3 \mathrm{~m}$, which was described earlier in this section.

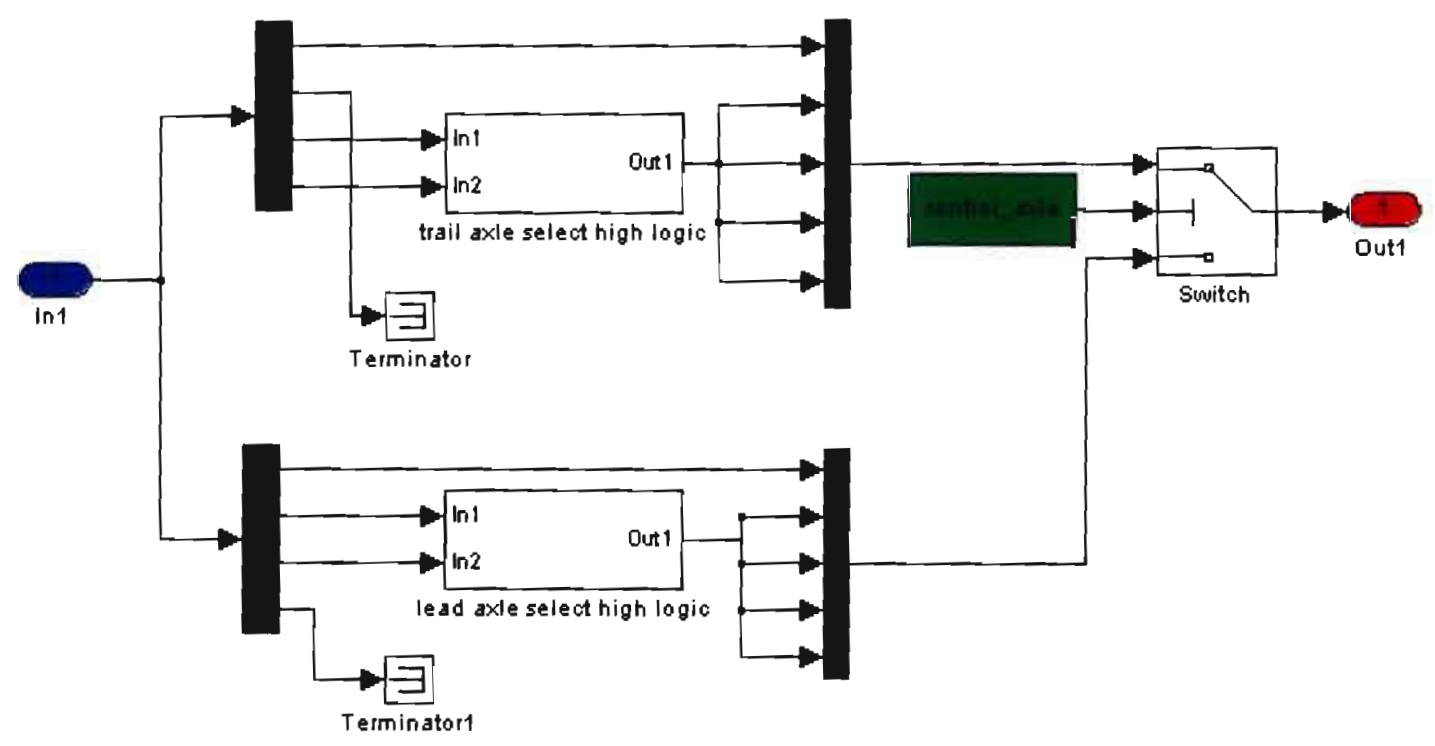

Figure 2.7 - Select High Modulation 


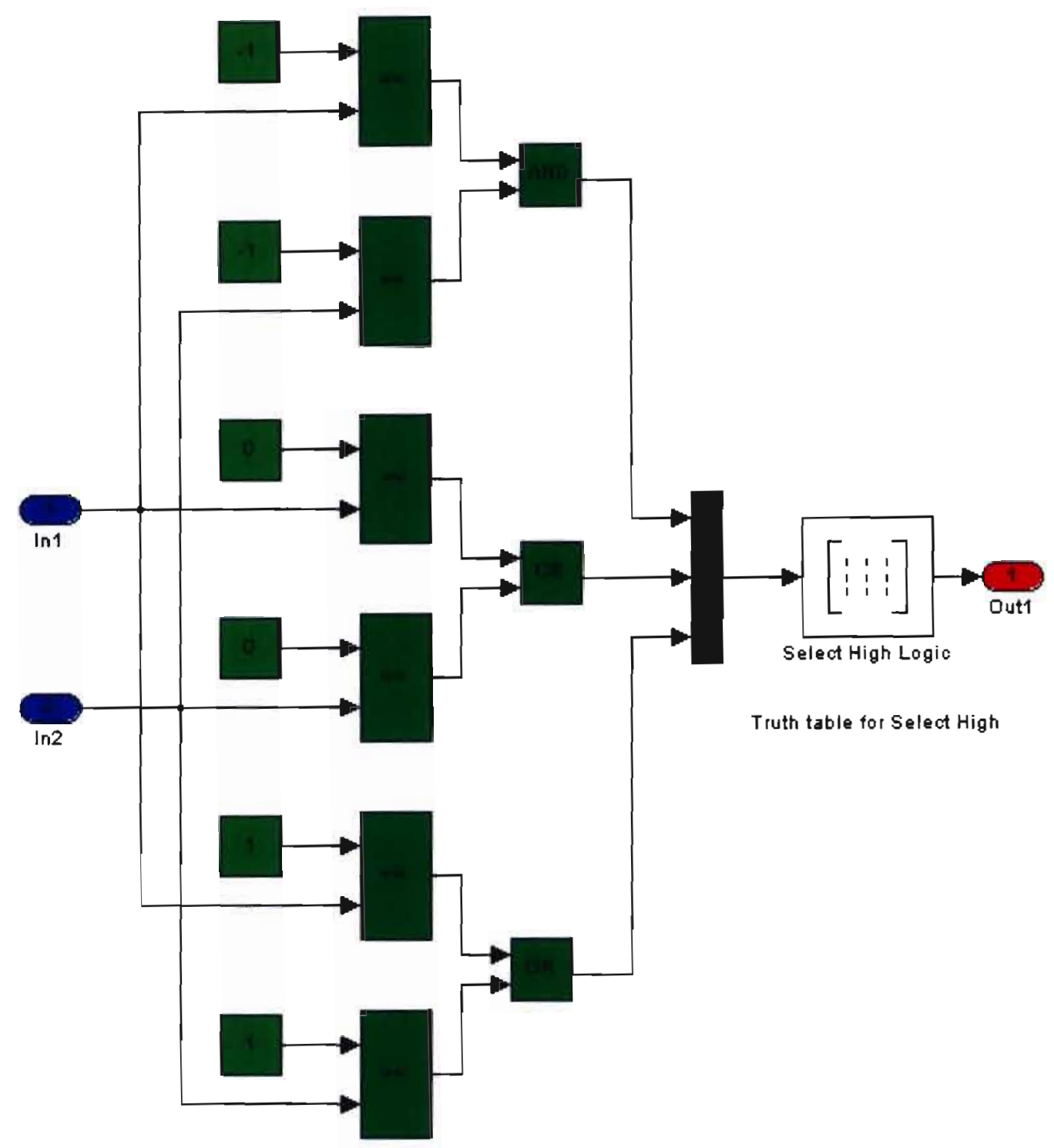

Figure 2.8 - Select High Logic

Figure 2.8 shows that a series of relational operators are used to create inputs to a truth table in order to simulate the select-high logic. This figure shows that if either of the ABS commands have a value of ' 0 ', a logic ' 1 ' will be passed to the truth table. 
Similarly, if either of the commands are to build (value of 1 ), a value of ' 1 ' is passed.

Also, this figure shows that both ABS commands must be to dump pressure (value of -1) for the same to occur. This logic is summarized in the following Table 2.1. These commands were then used to create logic statements for the truth table, seen in Table 2.2 . This truth table, employed in Figure 2.8, uses these inputs to simulate the desired selecthigh logic for the $4 \mathrm{~s} 3 \mathrm{~m}$ system, as seen in Table 2.3 .

\begin{tabular}{|c|c|c|c|}
\hline Left Wheel & Right Wheel & Command & Remarks \\
\hline-1 & -1 & -1 & Dump Pressure \\
\hline-1 & 0 & 0 & Hold Pressure \\
\hline 0 & -1 & 0 & Hold Pressure \\
\hline 0 & 0 & 0 & Hold Pressure \\
\hline 1 & 0 & 1 & Build Pressure \\
\hline 0 & 1 & 1 & Build Pressure \\
\hline 1 & 1 & 1 & Build Pressure \\
\hline 1 & -1 & 1 & Build Pressure \\
\hline-1 & 1 & 1 & Build Pressure \\
\hline
\end{tabular}

Table 2.1 - Development for Select-High Logic Command [6]

\begin{tabular}{|c|c|c|}
\cline { 2 - 3 } \multicolumn{1}{c|}{} & Logic Statement & Output \\
\hline if & right wheel and left wheel $=-1$ & 1 \\
\hline elseif & right wheel or left wheel $=0$ & 1 \\
\hline else & right wheel or left wheel $=1$ & 1 \\
\hline
\end{tabular}

Table 2.2 - Logic Statements for Select-High ABS Modulation [6] 


\begin{tabular}{|c|c|c|c|c|c|}
\cline { 2 - 6 } \multicolumn{1}{c|}{} & \multicolumn{3}{c|}{ Inputs 1-3 } & \multicolumn{1}{c|}{} \\
\hline Row & if & elseif & else & Output & Remarks \\
\hline 1 & 0 & 0 & 0 & 0 & Fault, but hold anyways \\
\hline 2 & 0 & 0 & 1 & 1 & Build Pressure \\
\hline 3 & 0 & 1 & 0 & 0 & Hold Pressure \\
\hline 4 & 0 & 1 & 1 & 1 & Build Pressure \\
\hline 5 & 1 & 0 & 0 & -1 & Dump Pressure \\
\hline 6 & 1 & 0 & 1 & 2 & Fault, but build anyways \\
\hline 7 & 1 & 1 & 0 & 0 & Fault, but hold anyways \\
\hline 8 & 1 & 1 & 1 & 0 & Fault, but hold anyways \\
\hline Note: 'FAULT" means that mutually exclusive conditions are reported \\
\hline
\end{tabular}

Table 2.3 - Select-High Logic Truth Table, Employed in Figure 2.8 [6]

The Select Low Modulation system of Figure 2.9 acts in the same manner as the previously described Select High Modulation system. The two logic subsystems for the select low case, however, utilize the logic displayed in Figure 2.10. Again, one can see from the logical operators of this system that the output will be the previously described result desired in a system utilizing select-low logic. 


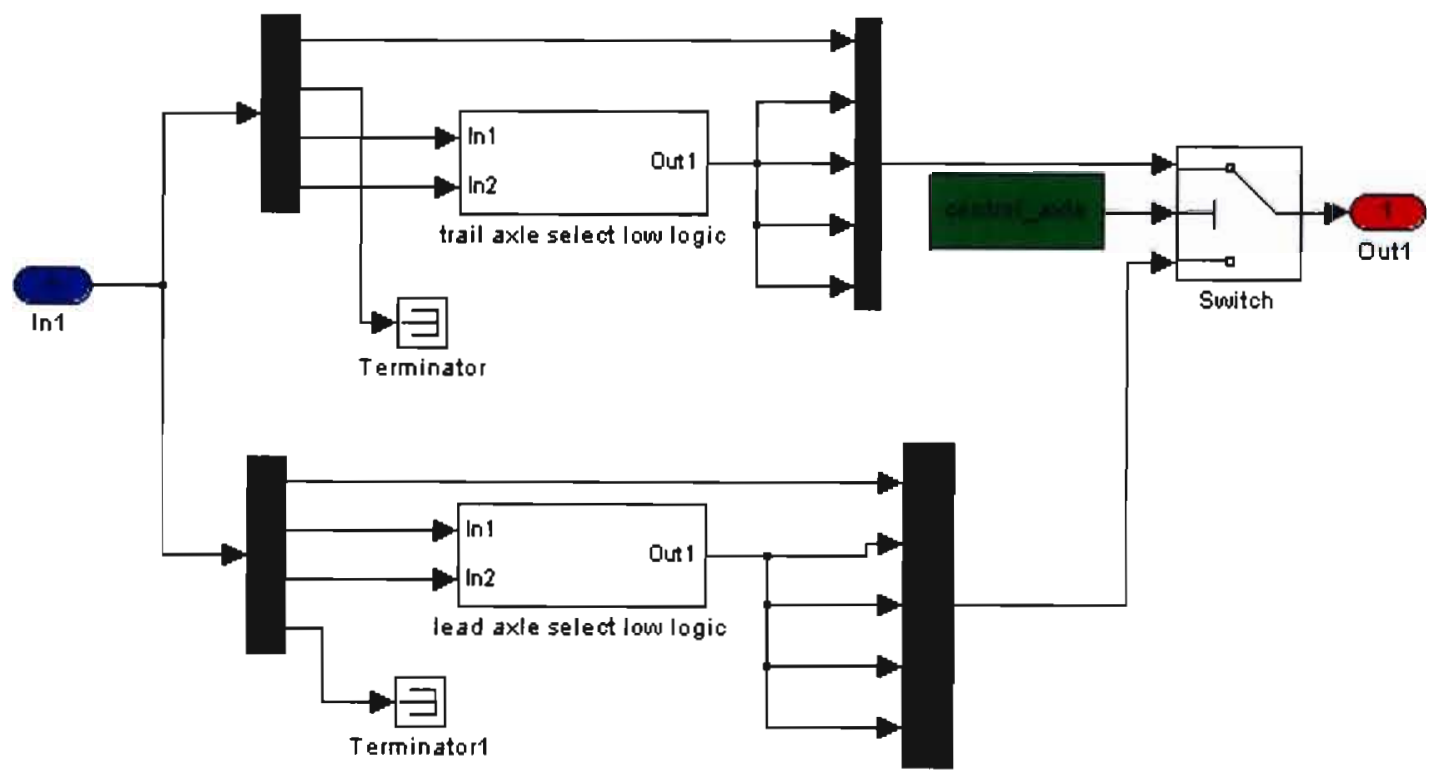

Figure 2.9 - Select Low Modulation 


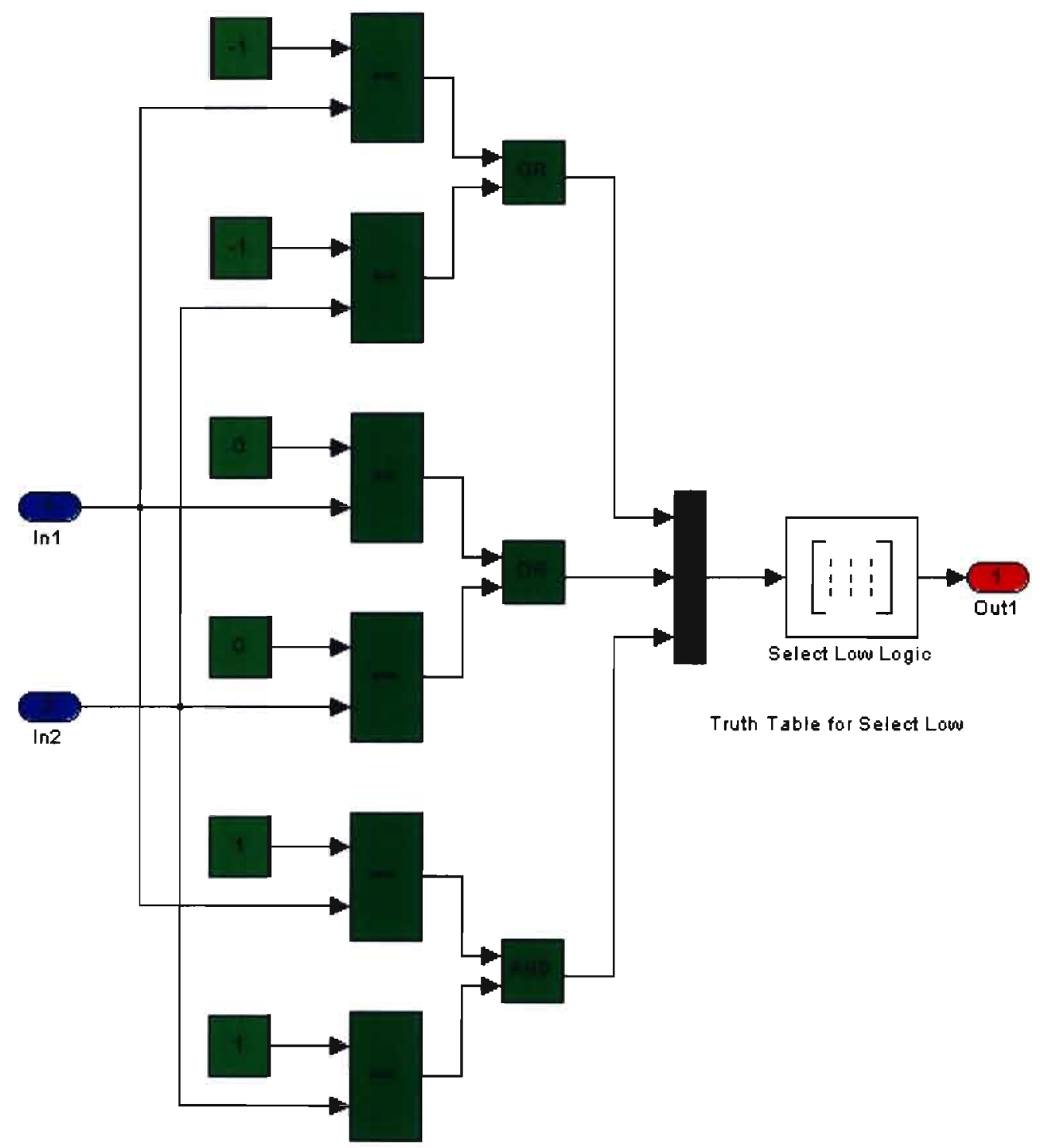

Figure 2.10 - Select Low Logic 
Table 2.4 shows that, unlike the select-high system, the ABS command for each wheel must be to build in order to increase brake pressure. This table also shows that the $4 \mathrm{~s} 3 \mathrm{~m}$ controller with select-low logic will dump pressure if either of the two commands is to do so. These commands were used to create the logic for the truth table of Table 2.5. This truth table, employed in Figure 2.10, can be seen in Table 2.6.

\begin{tabular}{|c|c|c|c|}
\hline Left Wheel & Right Wheel & Command & Remarks \\
\hline-1 & -1 & -1 & Dump Pressure \\
\hline-1 & 0 & -1 & Dump Pressure \\
\hline 0 & -1 & -1 & Dump Pressure \\
\hline 0 & 0 & 0 & Hold Pressure \\
\hline 1 & 0 & 0 & Hold Pressure \\
\hline 0 & 1 & 0 & Hold Pressure \\
\hline 1 & 1 & 1 & Build Pressure \\
\hline 1 & -1 & -1 & Dump Pressure \\
\hline-1 & 1 & -1 & Dump Pressure \\
\hline
\end{tabular}

Table 2.4 - Development for Select-Low Logic Command [6]

\begin{tabular}{|c|c|c|}
\cline { 2 - 3 } \multicolumn{1}{c|}{} & Logic Statement & Output \\
\hline if & right wheel or left wheel $=-1$ & 1 \\
\hline elseif & right wheel or left wheel $=0$ & 1 \\
\hline else & right wheel and left wheel $=1$ & 1 \\
\hline
\end{tabular}

Table 2.5 - Logic Statements for Select-Low ABS Modulation [6] 


\begin{tabular}{|c|c|c|c|c|c|}
\hline & \multicolumn{3}{|c|}{ Inputs 1-3 } & \multirow[b]{2}{*}{ Output } & \multirow[b]{2}{*}{ Remarks } \\
\hline Row & if & elseif & else & & \\
\hline 1 & 0 & 0 & 0 & -2 & Fault, but dump anyways \\
\hline 2 & 0 & 0 & 1 & 1 & Build Pressure \\
\hline 3 & 0 & 1 & 0 & 0 & Hold Pressure \\
\hline 4 & 0 & 1 & 1 & 2 & Fault, but build anyways \\
\hline 5 & 1 & 0 & 0 & -1 & Dump Pressure \\
\hline 6 & 1 & 0 & 1 & -2 & Fault, but dump anyways \\
\hline 7 & 1 & 1 & 0 & -1 & Dump Pressure \\
\hline 8 & 1 & 1 & 1 & -2 & Fault, but dump anyways \\
\hline No & & $\mathrm{me}$ & רat & ally & sive conditions are reportec \\
\hline
\end{tabular}

Table 2.6 - Select-Low Logic Truth Table, Employed in Figure 2.10 [6]

In order to test the ABS Control Selector, simulations of a high fiction (nominal peak $\mu=0.96$ ), LLVW stop from $60 \mathrm{mph}$ were conducted for the different ABS Configurations. Figure 2.11 shows drive tandem brake pressures during a simulated stop, utilizing a 4s4m controller with leading drive axle control. Note from the figure that the pressure of brake chamber 5 follows that of chamber 3. Because the same is also true for chambers 4 and 6 it can be concluded that the combination of the ABS Controller model and the ABS Control Selector works as intended. The same can be stated in regards to a 4s3m system, from examining the fact that all four drive axle chamber pressures follow the same path in Figure 2.12 and Figure 2.13. 


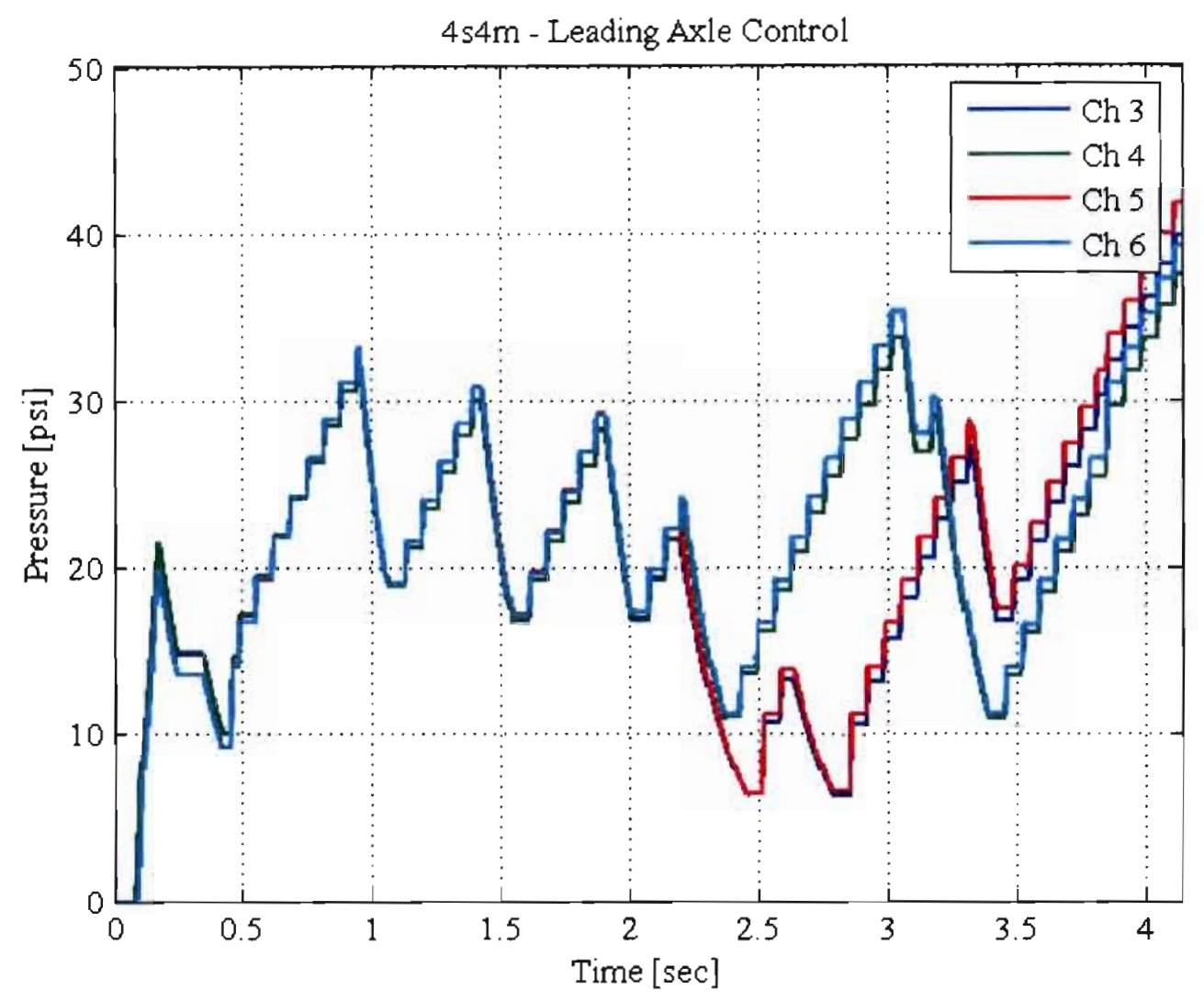

Figure $2.11-4 \mathrm{~s} 4 \mathrm{~m}$ Lead Axle Control Stop from $60 \mathrm{mph}$ 


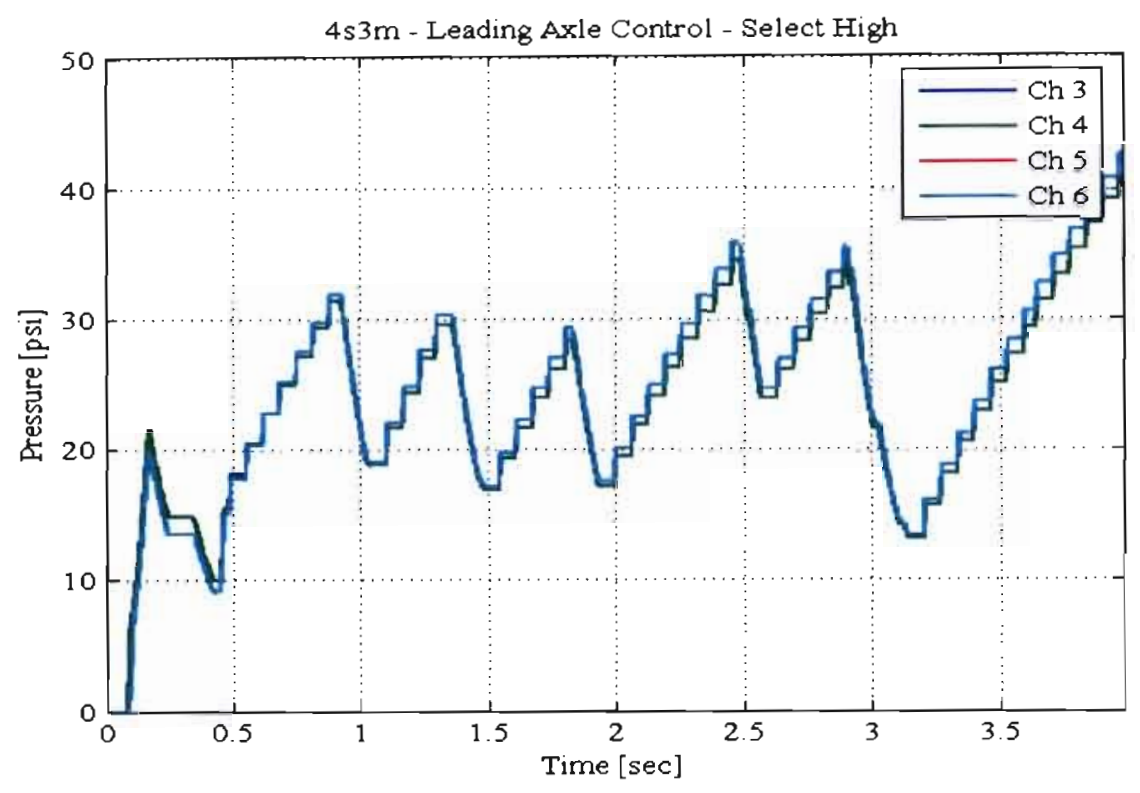

Figure 2.12 - 4s3m Lead Axle Control with Select High Logic

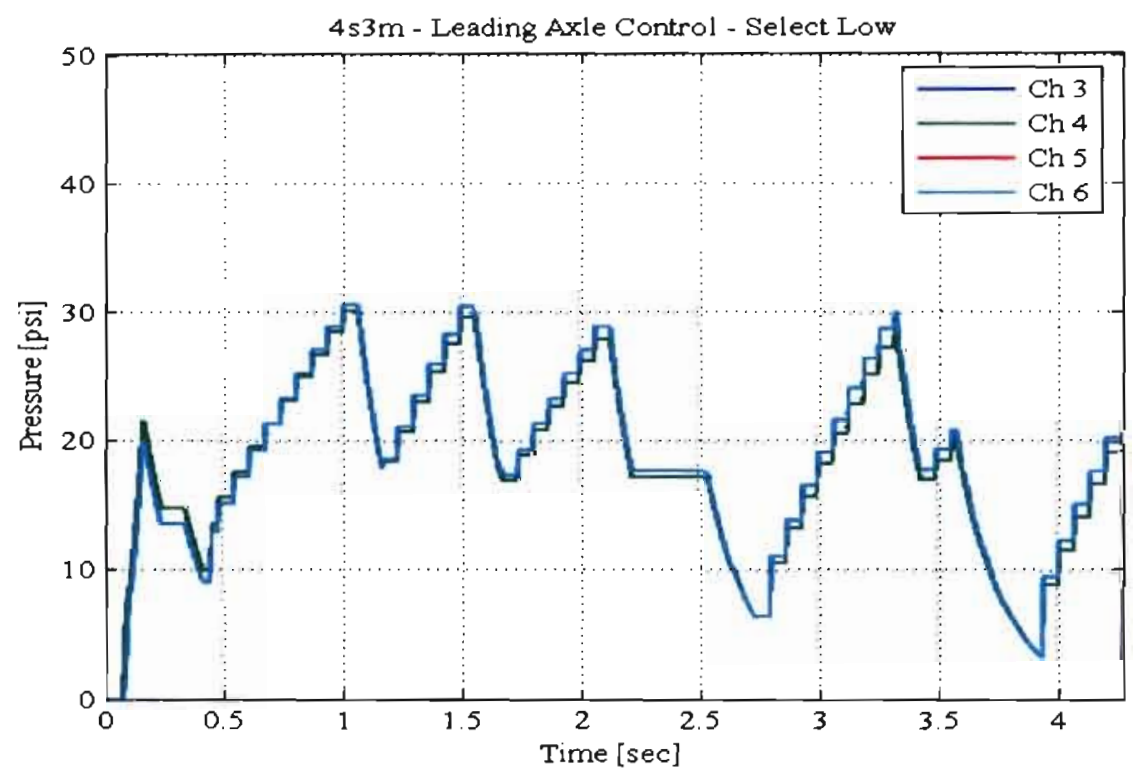

Figure 2.13 - 4s3m Lead Axle Control with Select Low Logic 
The difference in the select-high and select-low logic schemes can also be seen in the two preceding figures. When the chamber pressures after about 2.2 seconds are examined, one can see that the select-low system is more conservative in nature than the select-high system. Because a select-low system will dump if either of the control wheels indicate it to be necessary and a select-high system will continue to build (or hold) until both control wheels require a dump, it is evident that one (but not both) of wheels 3 and 4 received the dump (-1) command.

\subsection{Modeling of Brake Chamber and Treadle Pressures}

In order to create an accurate braking model for the Peterbilt truck, further investigation was conducted into how the treadle and brake chambers for the truck were modeled. To initiate braking, a reference treadle pressure was created in TruckSim. Simulink then used this reference input to create a dynamic model of the treadle pressure based on time constants estimated from experimental data. In his work, Zaugg [7] used this treadle pressure to be the reference for the brake pairs of all three axles. The Peterbilt $6 \times 4$ truck actually uses two treadles, a primary and a secondary, which control the drive and steer axles, respectively. Also, an additional set of time constants for each wheel (other than those used for $6 \mathrm{~s} 6 \mathrm{~m}$ ) was experimentally obtained, to account for the different ABS configurations. 


\subsubsection{Inclusion of Primary and Secondary Treadles}

To improve upon the previous braking model, which included only one treadle signal, the contributions of both the primary and secondary treadles were included. To accomplish this, the reference treadle signal (from TruckSim) was split and run into two different dynamic subsystems, corresponding to each treadle, illustrated in Figure 2.14. The dynamic subsystems calculate the treadle pressure from the reference signal and a first order time constant for each of the two treadles, estimated from experimental data. Switches are included to allow the modeling of an electronically controlled braking system (ECBS), in which no treadle dynamics exist; however, only pneumatic braking systems were examined in this study.

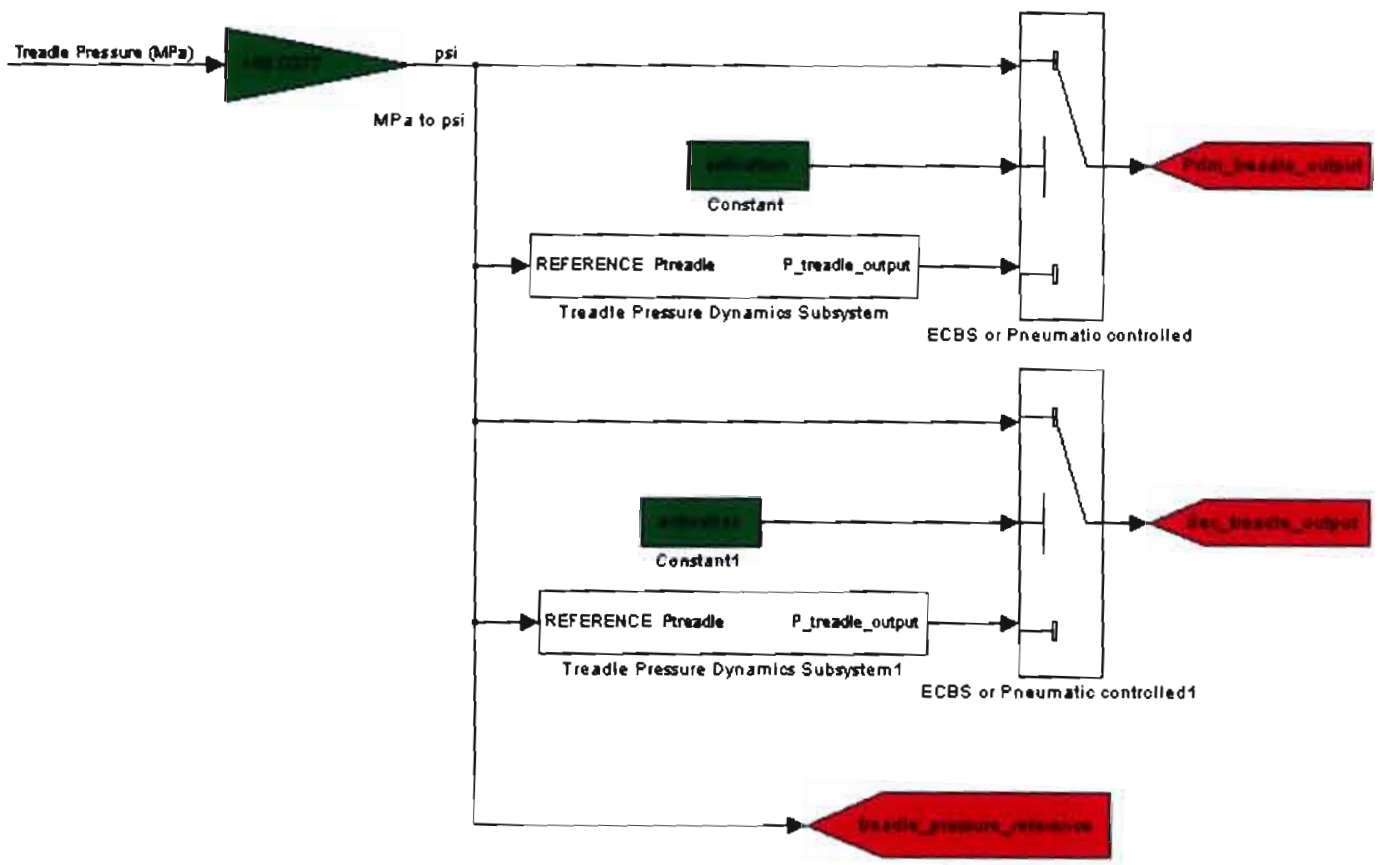

Figure 2.14 - Inclusion of Both Treadles 
It was important to include the contributions of both treadles into the model because the responses of the two vary significantly. One can see from the experimental data of Figure 2.15 that the primary treadle responds much faster than the secondary treadle in rising pressure situations. The two treadles exhibited nearly identical behavior in falling pressure situations, therefore the same time constant was used for that scenario. As described in Section 2.1.2.1, the treadle pressures are in turn used as reference inputs for the brake chamber pneumatics subsystems, which simulate the brake chamber dynamics and subsequent torques for each brake. Therefore, it was necessary to use the accurately modeled primary treadle pressure as the input for the leading drive and trailing drive axles and the secondary treadle pressure as the input for the steer axle brakes.

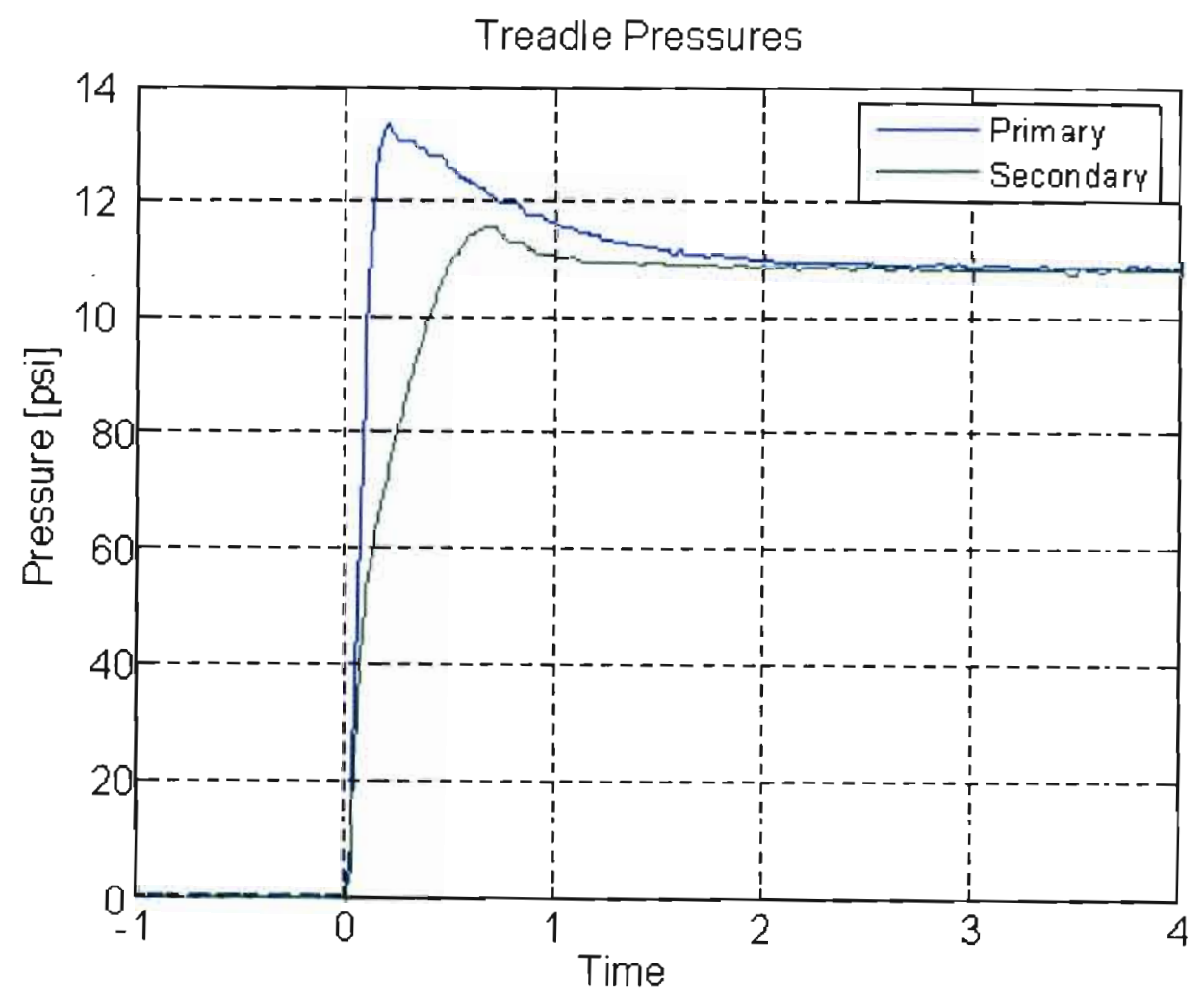

Figure 2.15 - Primary and Secondary Treadles 
Table 2.7 shows the time constants used for the rising and falling regions of the two treadles. These were calculated by assuming the response of a first order system to a step input. Figure 2.15 shows that the primary and secondary treadles did not respond as ideal first order systems, as evident by the overshoot that is exhibited. It was later found that the brake chambers showed similar dynamics, in that they did not respond as true first order systems. The treadle and brake chamber pressures were modeled as first order systems in the interest of time, as a great deal of effort would be necessary to model the complex dynamics of the pneumatic brake system. Zaugg ran into this same problem in his study, and it was proven by using Matlab's System Identification Graphical User Interface (GUI) that the dynamics were best modeled as an $8^{\text {th }}$ order system. However, it was shown in Section 2.3.2 of [7] that a first order system can mimic the experimental dynamics to a degree of over $96 \%$.

\begin{tabular}{|c|c|}
\cline { 2 - 2 } \multicolumn{1}{c|}{} & $\tau[\mathrm{sec}]$ \\
\hline Primary Rising & 0.0311 \\
\hline Secondary Rising & 0.1560 \\
\hline Falling & 0.0600 \\
\hline
\end{tabular}

Table 2.7 - Treadle Time Constants

\subsubsection{Brake Chamber Time Constants}

In this and other studies, experimental data was used to estimate time constants to model the responses of each brake chamber pressure. A set of time constants 
corresponding to each axle was obtained in [7] for the $6 \mathrm{~s} 6 \mathrm{~m}$ configuration. New drive axle time constants were needed for the Peterbilt truck in the $4 \mathrm{~s} 4 \mathrm{~m}$ configuration, because of physical differences between the two systems. In a $4 \mathrm{~s} 4 \mathrm{~m}$ system, there are only two modulator valves for the four drive axle brake chambers. Differences in time constants may therefore exist between a $4 \mathrm{~s} 4 \mathrm{~m}$ system and a $6 \mathrm{~s} 6 \mathrm{~m}$ system, which has a modulator for each drive axle brake chamber, simply due to different plumbing. One can see that this is indeed the case from examining the modulator valves and hoses of the $6 \mathrm{~s} 6 \mathrm{~m}$ system in Figure 2.1 and the $4 \mathrm{~s} 4 \mathrm{~m}$ system in Figure 2.2. Similarly, the time constants of the brake chambers in a $4 \mathrm{~s} 3 \mathrm{~m}$ system would differ from the others as well; however, time constants were not gathered for the $4 \mathrm{~s} 3 \mathrm{~m}$ system, even though the model has the ability of simulating such a system, because no experimental data existed for that configuration. For this case, time constants of the $4 \mathrm{~s} 4 \mathrm{~m}$ system were used for simulations.

In previous studies $[7,8]$ time constants were estimated from experimental data taken from the Peterbilt truck. This data was obtained by a rapid application of the brake, followed by a holding period, then a release. An example of this type of data can be seen in the following Figure 2.16. This figure also depicts the three distinct regions of each brake chamber: filling, rising, and falling. Time constants for the original $6 \mathrm{~s} 6 \mathrm{~m}$ system were calculated in the following manner: assuming a step input for the filling region and the assuming a terminated ramp input for the rising and falling regions. Refer to Section 2.3.3 of [7] for a more detailed description of that analysis. The first order time constant of a response to a ramp input is determined by the time lag between the input and the 
response [9], so it was possible to obtain such a time constant for the rising and filling regions using data similar to that displayed in Figure 2.16.

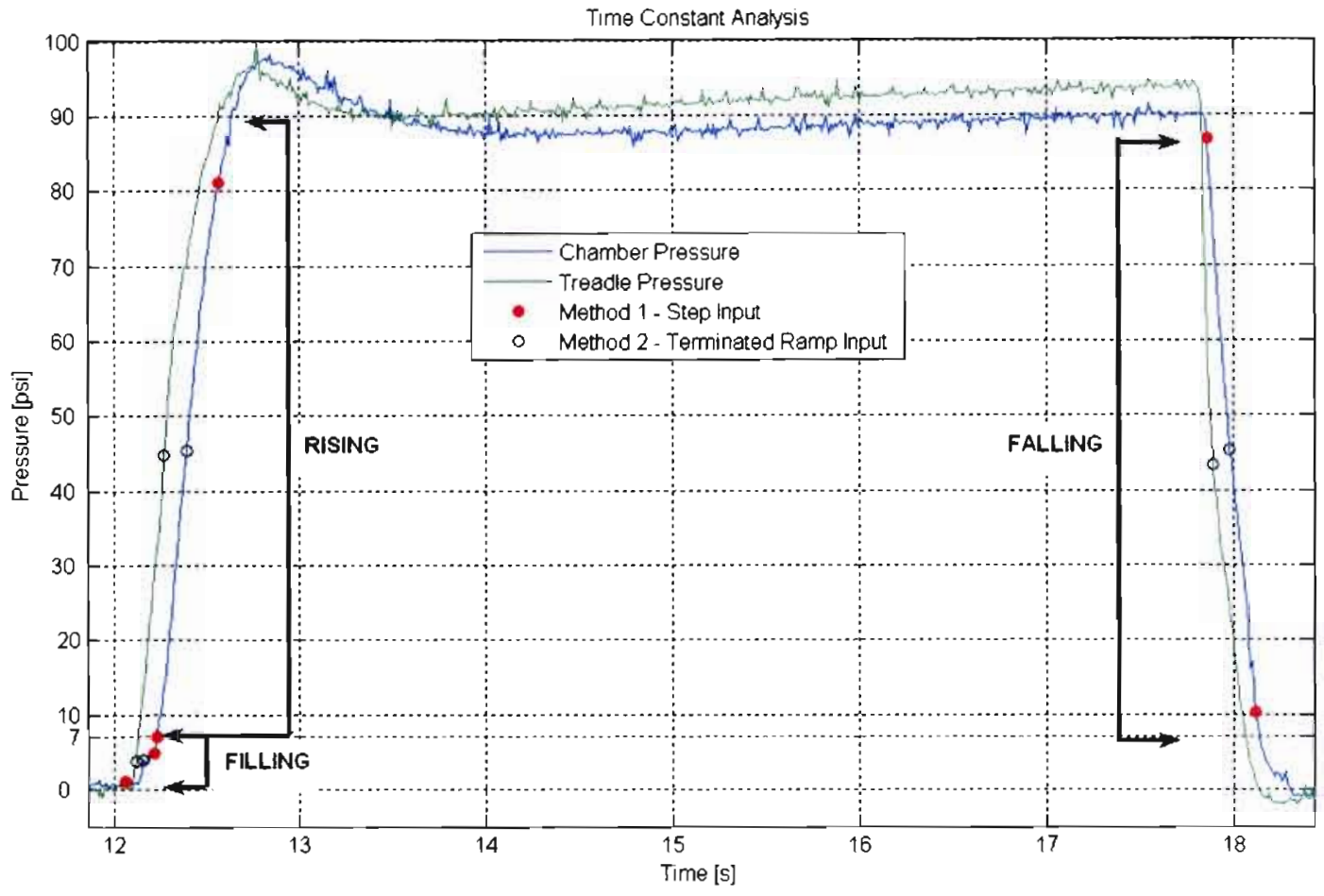

Figure 2.16 - Experimentally Measured Brake Chamber Pressures [7]

Under the initial build of a brake chamber (before any ABS modulation), the build signal is coming directly from the treadle. During ABS modulation, however, all subsequent "build" commands come from the modulator valve. It was expected that the response of a chamber to a build command directly from the treadle and one from the modulator valve would very drastically, due to physical differences in the two paths. Because the ABS valves were much closer to the individual brake chambers than the treadle controlled modulator, faster responses (smaller time constants) were expected for 
those situations. To examine this possibility, ABS modulation data similar to that seen in Figure 2.17 was collected for each chamber.

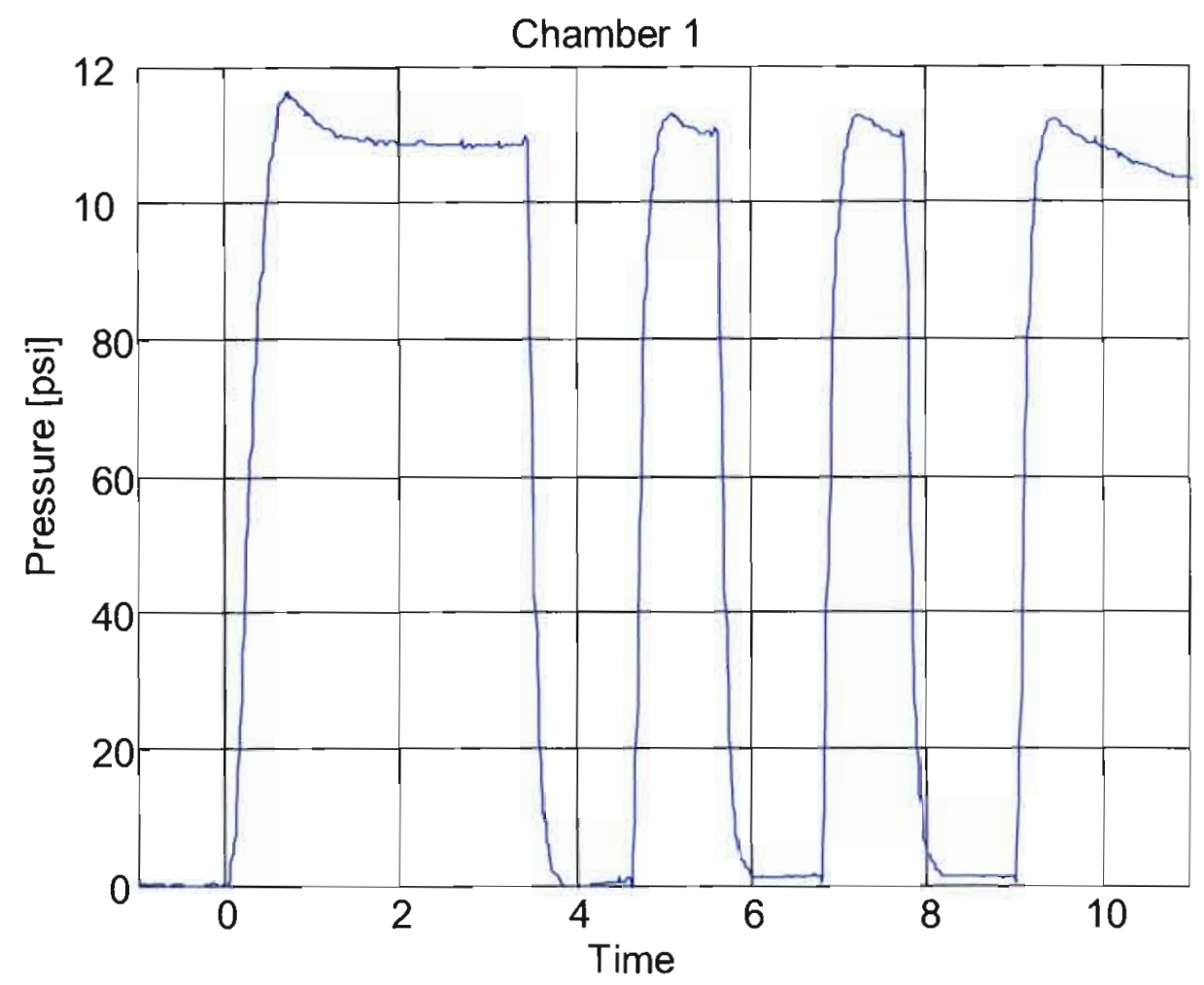

Figure 2.17 - Chamber 1 Pressure Dynamics

For this study, plots of this type were used to gather time constants for the $6 \mathrm{~s} 6 \mathrm{~m}$ and $4 \mathrm{~s} 4 \mathrm{~m}$ systems; therefore, it was possible to find a rising time constant for the initial pressure build and another corresponding to the ABS modulated builds. Throughout such a test, the treadle was held to a constant (full braking) value of around 110 psi. Because of this, it was not able to obtain a rising time constant for modulator builds by assuming it to be the response of a ramp input, like in Zaugg. Also, the initial build dynamics of each chamber resembled those displayed in Figure 2.18. The method described in [9] and 
utilized in [7] requires that a region exists in which the time delay between the reference and the response curves is somewhat steady-state. This behavior was not exhibited in the data (see Figure 2.18 ) so calculating time constants for the initial build by using the terminated ramp method was deemed unfeasible. Therefore, time constants were calculated for each chamber, for both the $6 \mathrm{~s} 6 \mathrm{~m}$ and $4 \mathrm{~s} 4 \mathrm{~m}$ configurations, by using the method of assuming the response to a step input. The time constants for each axle were created by averaging the values from each axle wheel, and can be seen in Table 2.8 .

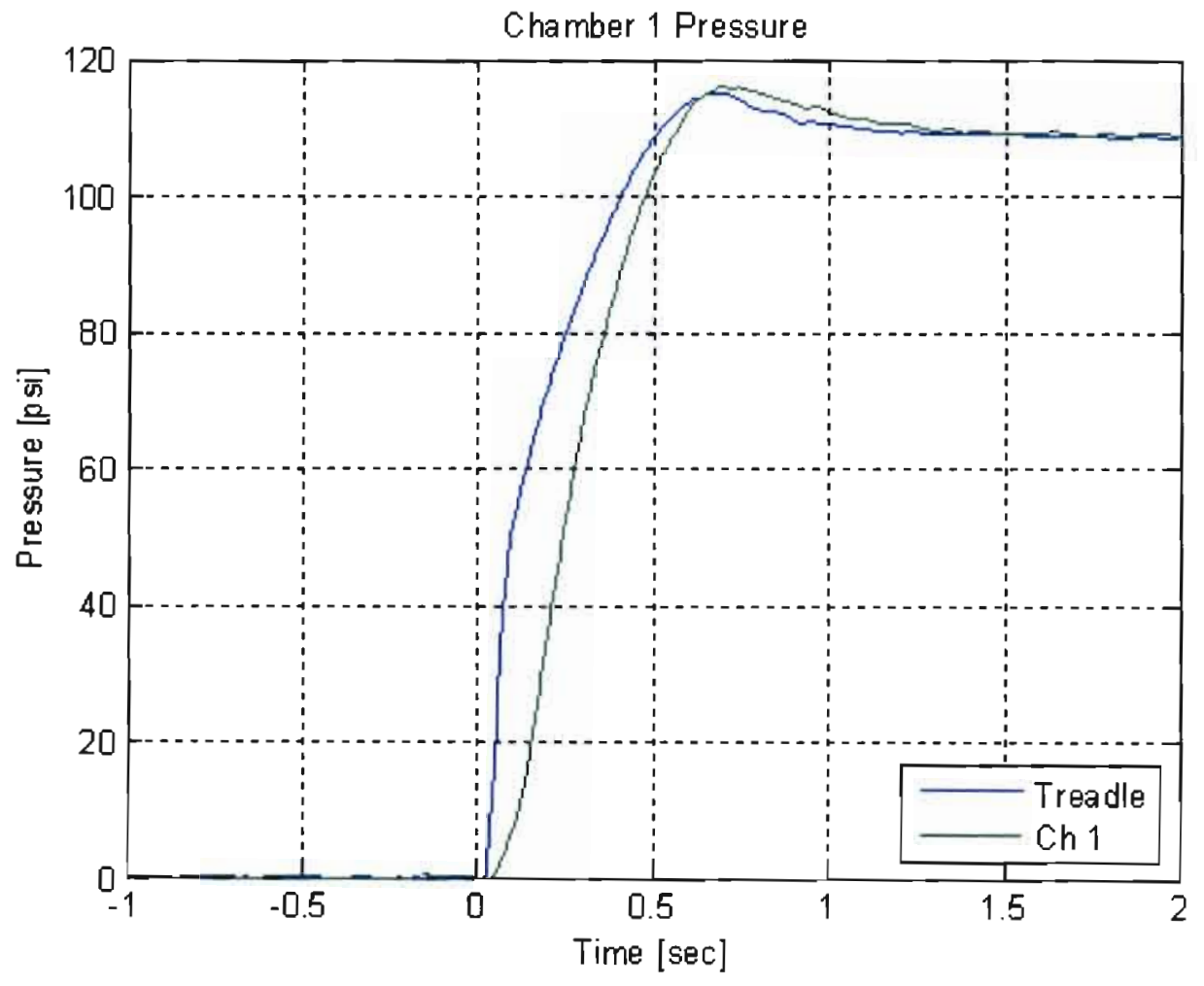

Figure 2.18 - Chamber 1 Initial Build 


\begin{tabular}{|c|c|c|}
\hline \multicolumn{2}{|c|}{$6 \mathrm{~s} 6 \mathrm{~m}$} & $4 \mathrm{~s} 4 \mathrm{~m}$ \\
\hline Steer Filling & 0.0376 & 0.0215 \\
\hline Steer Rising Initial & 0.1346 & 0.1353 \\
\hline Steer Rising from Modulators & 0.0557 & 0.0701 \\
\hline Steer Falling from Modulators & 0.0796 & 0.0737 \\
\hline \multicolumn{3}{|c|}{} \\
\hline Lead Drive Filling & 0.0187 & 0.0257 \\
\hline Lead Drive Rising Initial & 0.1398 & 0.1798 \\
\hline Lead Drive Rising from Modulators & 0.0826 & 0.1694 \\
\hline Lead Drive Falling from Modulators & 0.1053 & 0.1951 \\
\hline \multicolumn{3}{|c|}{} \\
\hline Trail Drive Filling & 0.0208 & 0.0221 \\
\hline Trail Drive Rising Initial & 0.1250 & 0.1663 \\
\hline Trail Drive Rising from Modulators & 0.0704 & 0.1588 \\
\hline Trail Drive Falling from Modulators & 0.0988 & 0.1913 \\
\hline
\end{tabular}

Table 2.8 - Chamber Time Constants for Each Axle

\subsubsection{Modeling of Treadle Dynamics}

After obtaining reasonable time constants for each configuration, comparisons between experimental data and the response of the model began. In order to verify the previously calculated time constants, simulations were run for GVWR, straight ahead stops on a high friction surface. This scenario was chosen because ABS modulation is absent under this combination of large weight and high friction coefficient. The responses for chambers 1 and 4 can be seen in Figure 2.19 and Figure 2.20, respectively. One can see from these plots that even with extensive time constant calculations, the model chamber pressures do not sufficiently match the experimental ones to a high degree. 


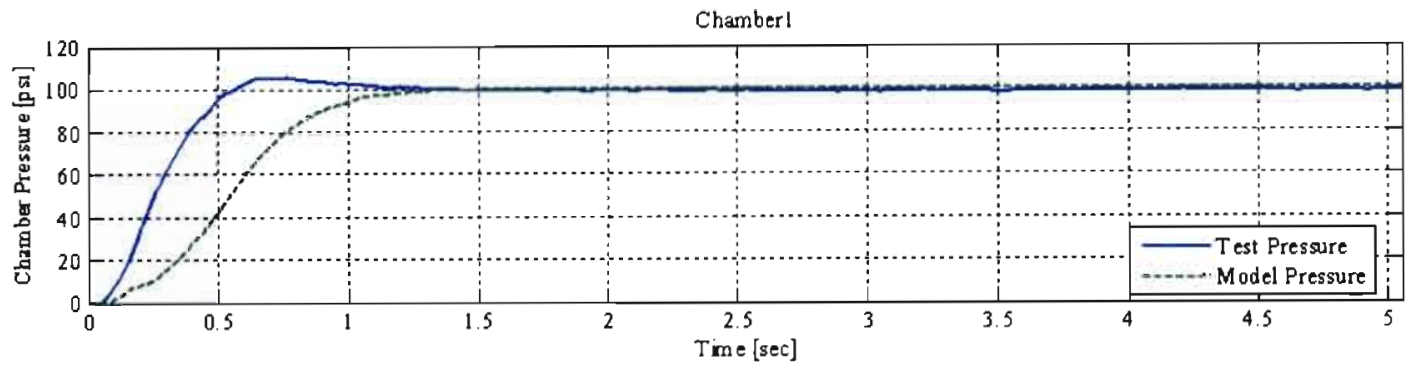

Figure 2.19 - Brake Position 1 with Original Treadle Reference

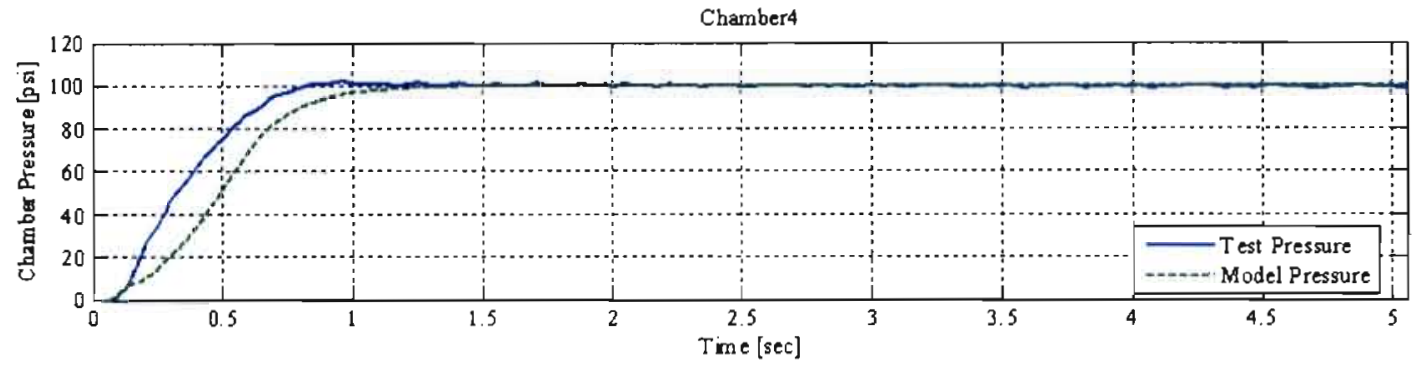

Figure 2.20 - Brake Position 4 with Original Treadle Reference

In an effort to remedy this problem, the dynamics of the primary and secondary treadles were examined. As stated in Section 2.3.1, the reference treadle, from TruckSim, was used as a reference for the treadle dynamics subsystems. So, the experimental pressure, model reference pressure (from TruckSim), and the modeled pressure for each of the primary and secondary treadles were plotted and compared. One can see from Figure 2.21 and Figure 2.22 that the actual treadles of the Peterbilt were not being adequately simulated. 


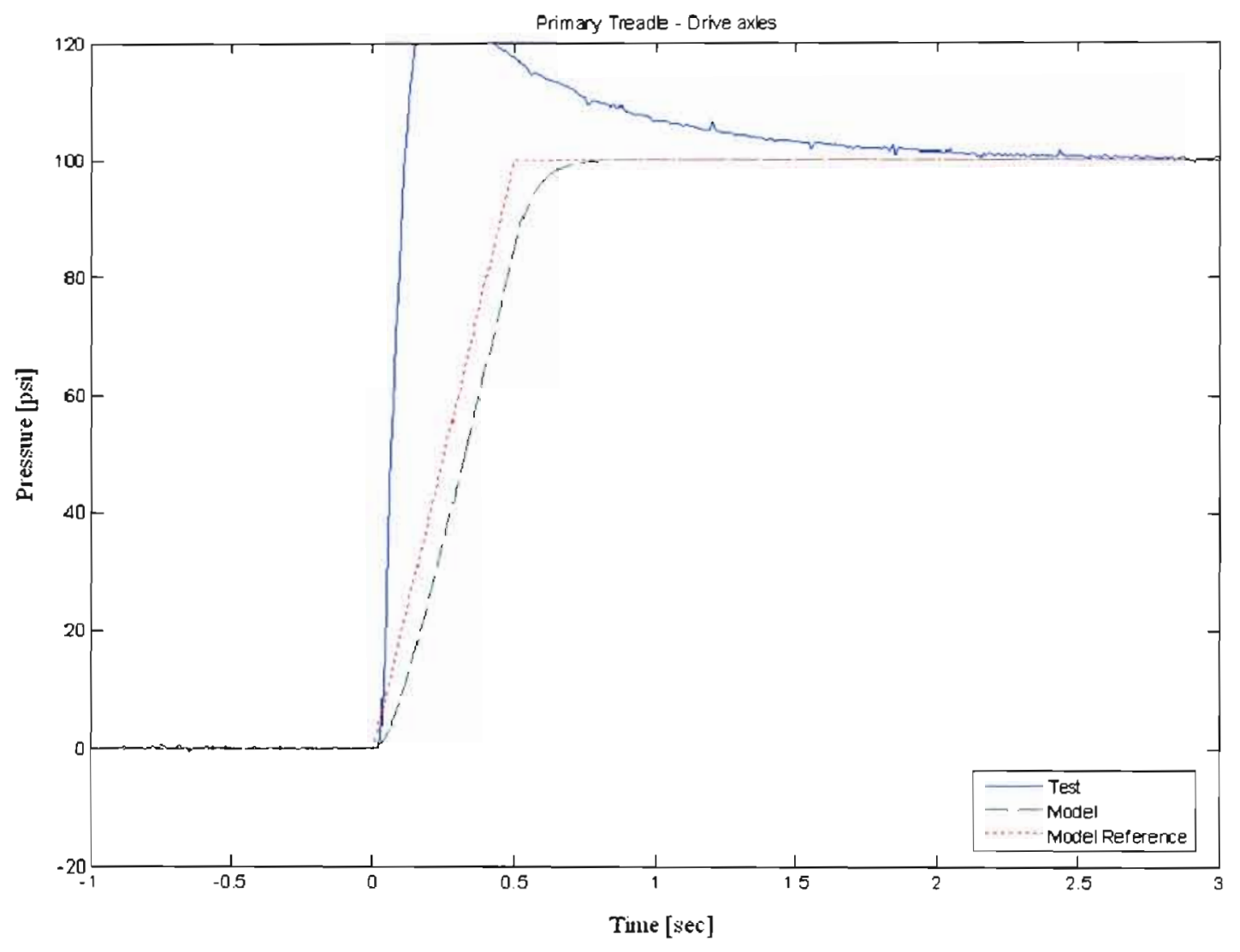

Figure 2.21 - Original Modeling of the Primary Treadle 


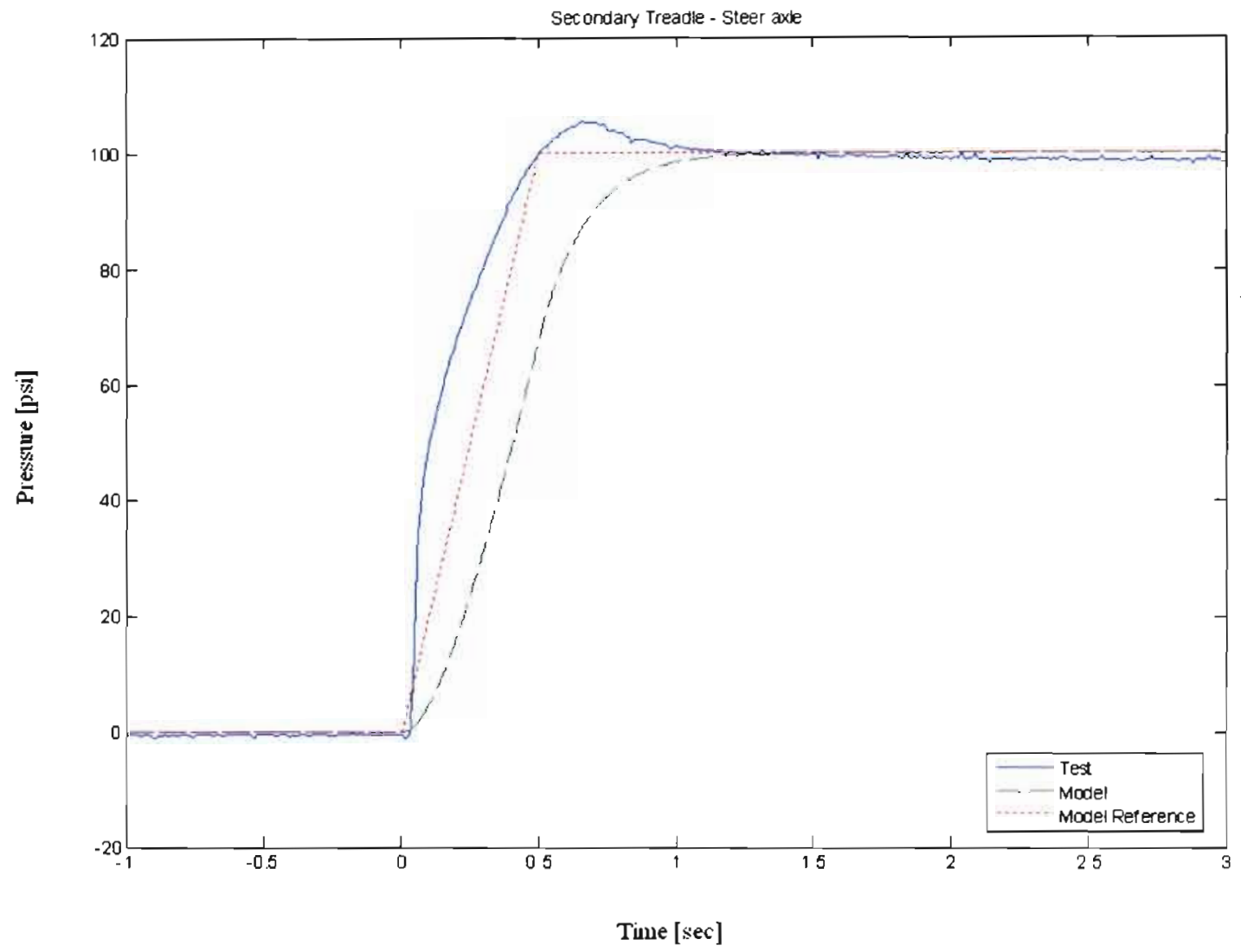

Figure 2.22 - Original Modeling of Secondary Treadle

The model reference pressure profile was set to mimic the brake pedal application of the driver in an actual experiment, outlined in NHTSA's FMVSS 121 [2] and its test procedure [11]. This test procedure states that the driver should apply the brake from 0 psi to full treadle pressure in less than 0.5 seconds. Therefore, the treadle reference pressure in TruckSim was set to go from 0 to $100 \mathrm{psi}$ in 0.5 seconds. The first order time constants, collected from analyzing the experimental treadle data, were then applied to this terminated ramp reference pressure. It can be seen from the previous two figures that 
for even an instantaneous response $(\tau=0)$, neither of the model treadle pressures would match the experimental.

Upon further examination of the treadle time constants, it was determined that they were correctly calculated. These time constants were calculated by assuming the treadle to be a first order system (see previous discussion), subjected to a step input. These first order time constants, corresponding to step inputs, were then being applied to the ramp input of 0 to $100 \mathrm{psi}$ in 0.5 seconds. In other words, time constants estimated from first order step responses were being applied to inputs which were not steps at all. Because of this, a new TruckSim reference treadle pressure command was tried, one which represented a step input. This new reference treadle pressure went from 0 to 100 psi in 0.01 seconds. This is not a "true" step input, however, because TruckSim does not have the capability of going from 0 to $100 \mathrm{psi}$ in an infinitesimal amount of time. One can see from Figure 2.23 and Figure 2.24 that using the step input in TruckSim improved the modeled treadle pressures for each treadle signal. Discrepancies between the modeled treadle pressure and the experimental do exist, however, between 0 and 1 seconds, due to overshoot displayed in the experimental treadle dynamics. A first order system model assumes the dynamic system to be massless; therefore, applying a first order model to the treadle system would assume the actuated air to be massless, as well. This of course ignores the second order behavior of the air mass inside of the treadle system that certainly exists. Also, some of this "overshoot" could be due to the dynamics of the modulator valves. 


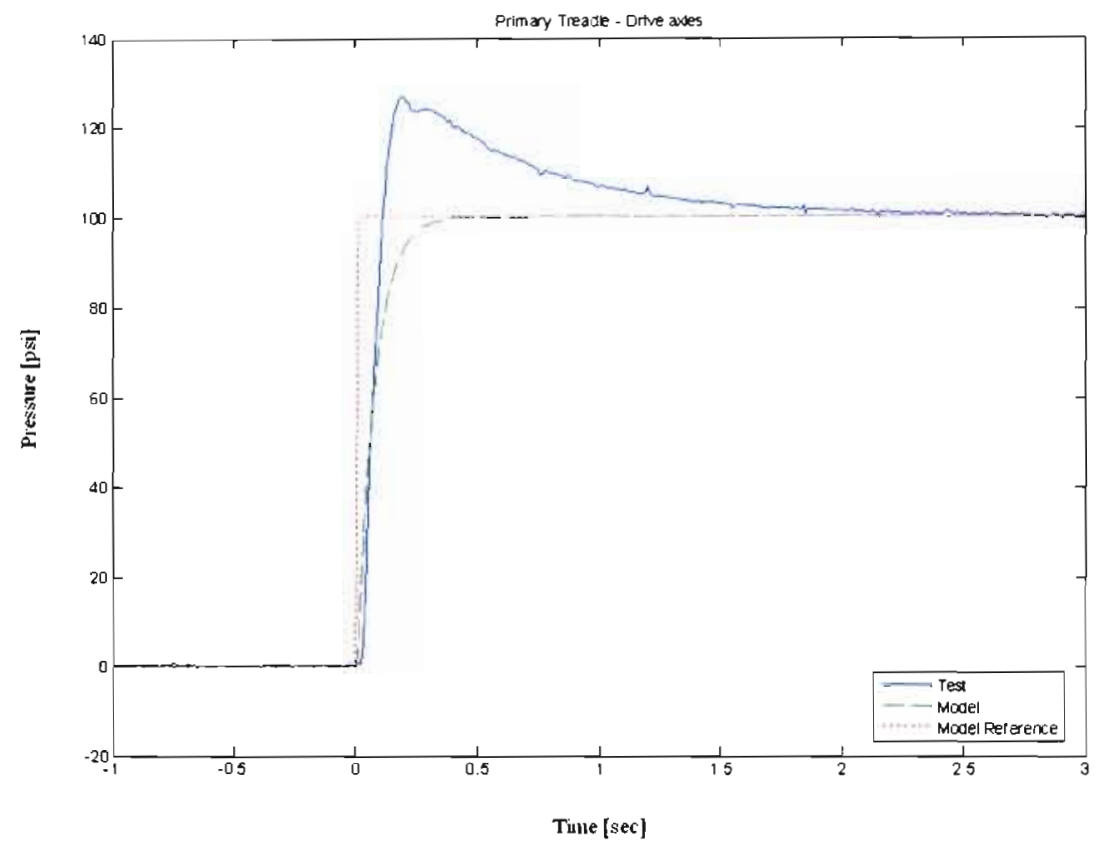

Figure 2.23 - New Modeling of Primary Treadle

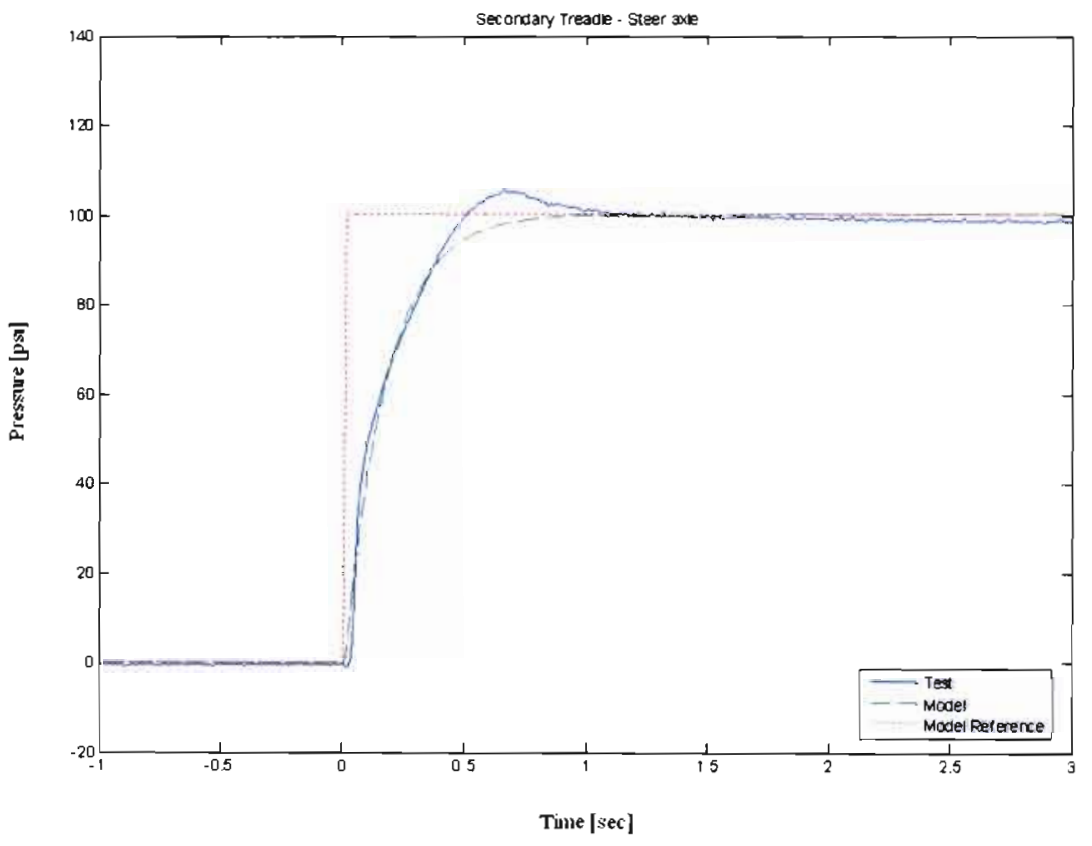

Figure 2.24 - New Modeling of Secondary Treadle 
With this scheme of modeling the primary and secondary treadles, the responses of chambers 1 and 4 were re-examined. One can see from Figure 2.25 and Figure 2.26 that the modeled chamber pressure response has been improved. Some discrepancies do still exist around the peak pressure, however, because the treadles do not represent ideal first order systems.

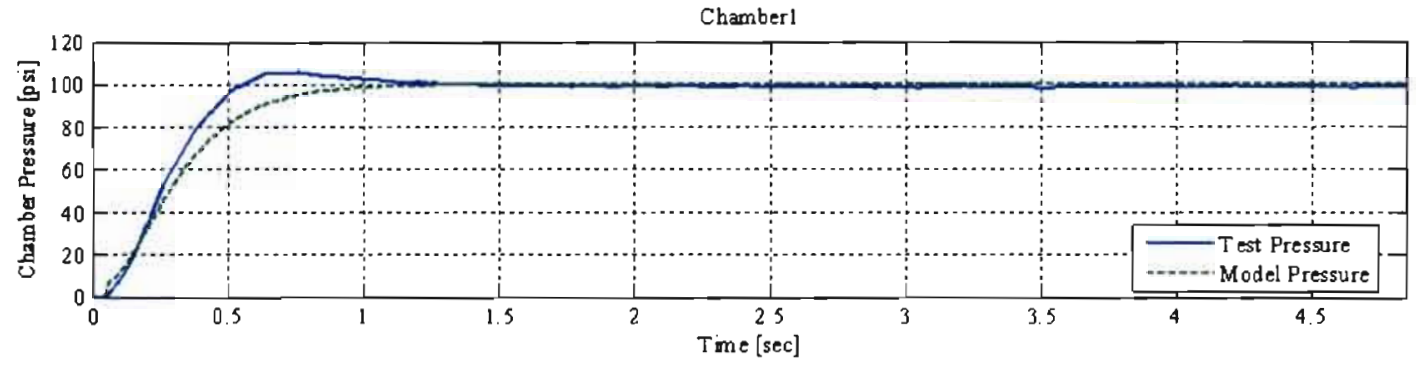

Figure 2.25 - Chamber 1 with New Treadle Reference

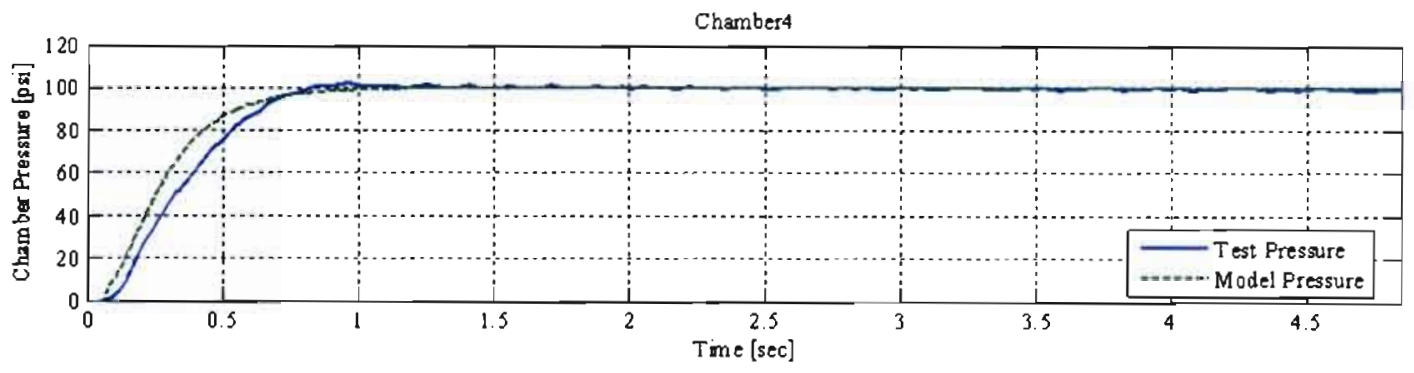

Figure 2.26 - Chamber 4 with New Treadle Reference 


\subsection{Surface Friction Level Identification}

\subsubsection{Controller Friction Level Estimation}

When trying to match model chamber pressures, slip ratios, and accelerations to experimental data, a strange scenario occurred for some simulations. These simulations corresponded to stops on a high friction surface; however, the controller appeared to be acting as if it thought it was on a low friction surface by the behavior of the chamber pressures. Because the ABS Controller model received only the six wheel speeds as inputs, it used only these to estimate the coefficient of friction at the surface. It is important for the controller to know if it is on a high or low friction surface because those situations can result in different control strategies implemented in the controller to facilitate vehicle stability. In general, the controller uses the initial deceleration of the steer axle wheels to estimate this friction level. The earlier described anomalies were in fact the result of the controller estimating that the truck was experiencing low friction braking when it was actually on a high friction surface.

The controller estimates the surface friction level in the following way. After the brakes are applied in the model, the Initial Mu Calculator module of Figure 2.27 sets the default controller estimated friction level to 'low'. Over a set time, initial_build_cutoff, the controller friction level is set to 'high' if the deceleration of either of the steer axle wheels becomes greater than a specified value, initial_build_mu_selector. The controller friction level stays at 'low' if the deceleration of neither steer axle wheel passes the set threshold. For previous studies, 
these values were empirically chosen to work with the given data set, thus the need for more robust threshold values became evident.

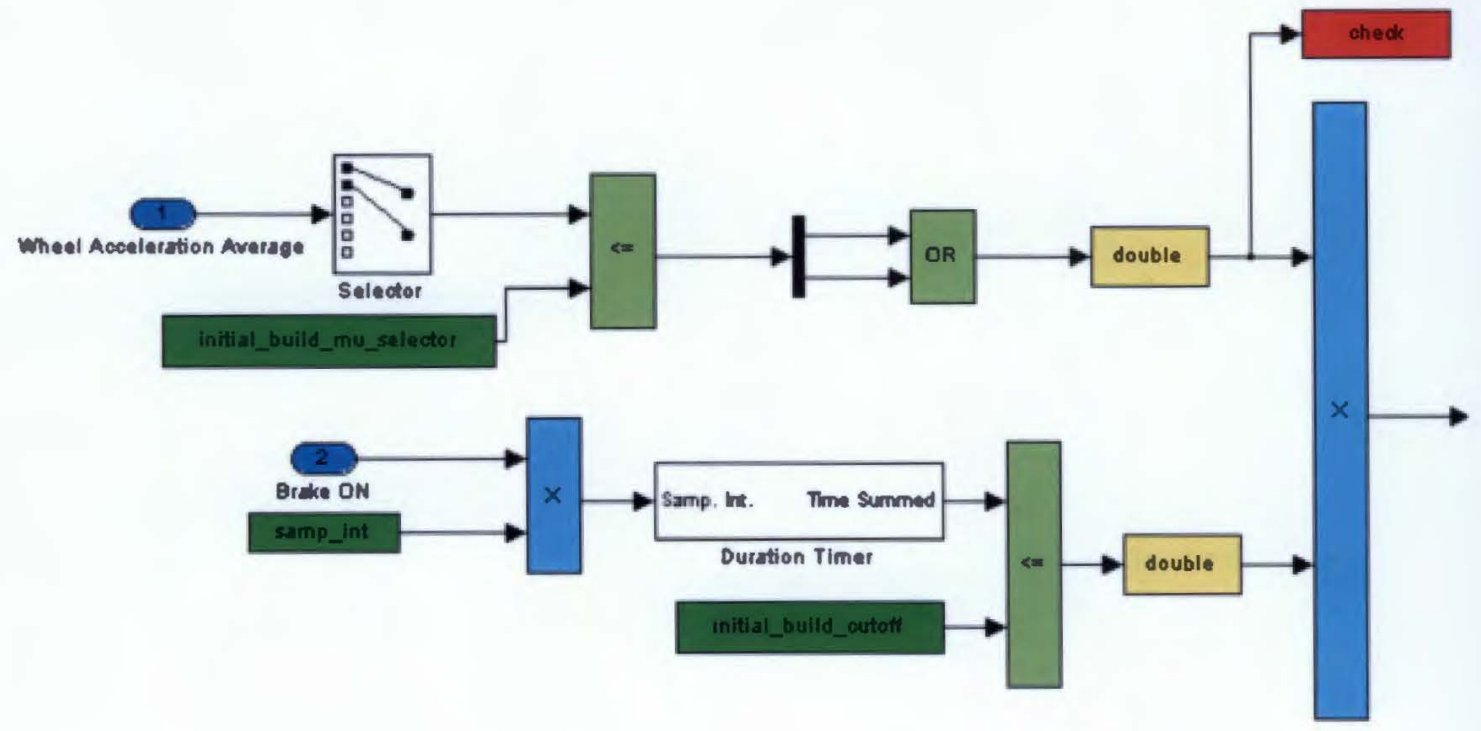

Figure 2.27 - Initial Mu Calculator

\subsubsection{Initial Braking Acceleration Characteristics}

From choosing different values for the thresholds initial_build_cutoff and initial_build_mu_selector, it was determined the best simulations were the result of situations in which the controller estimated the correct friction level during the time period very close to the brake application. An analysis was completed in which the correct friction level was "hard-wired" into the controller from the start of the simulation for each of the eight cases of interest: $6 \mathrm{~s} 6 \mathrm{~m}$ and $4 \mathrm{~s} 4 \mathrm{~m}$ high friction maneuvers at LLVW and GVWR and $6 \mathrm{~s} 6 \mathrm{~m}$ and $4 \mathrm{~s} 4 \mathrm{~m}$ brake-in-curve maneuvers (low friction) at LLVW and GVWR. The results of these tests can be seen in Figure 2.28 and Figure 
2.29 , which show the acceleration of wheel 1 over the first 0.2 seconds of braking, for the $4 \mathrm{~s} 4 \mathrm{~m}$ and $6 \mathrm{~s} 6 \mathrm{~m}$ systems.

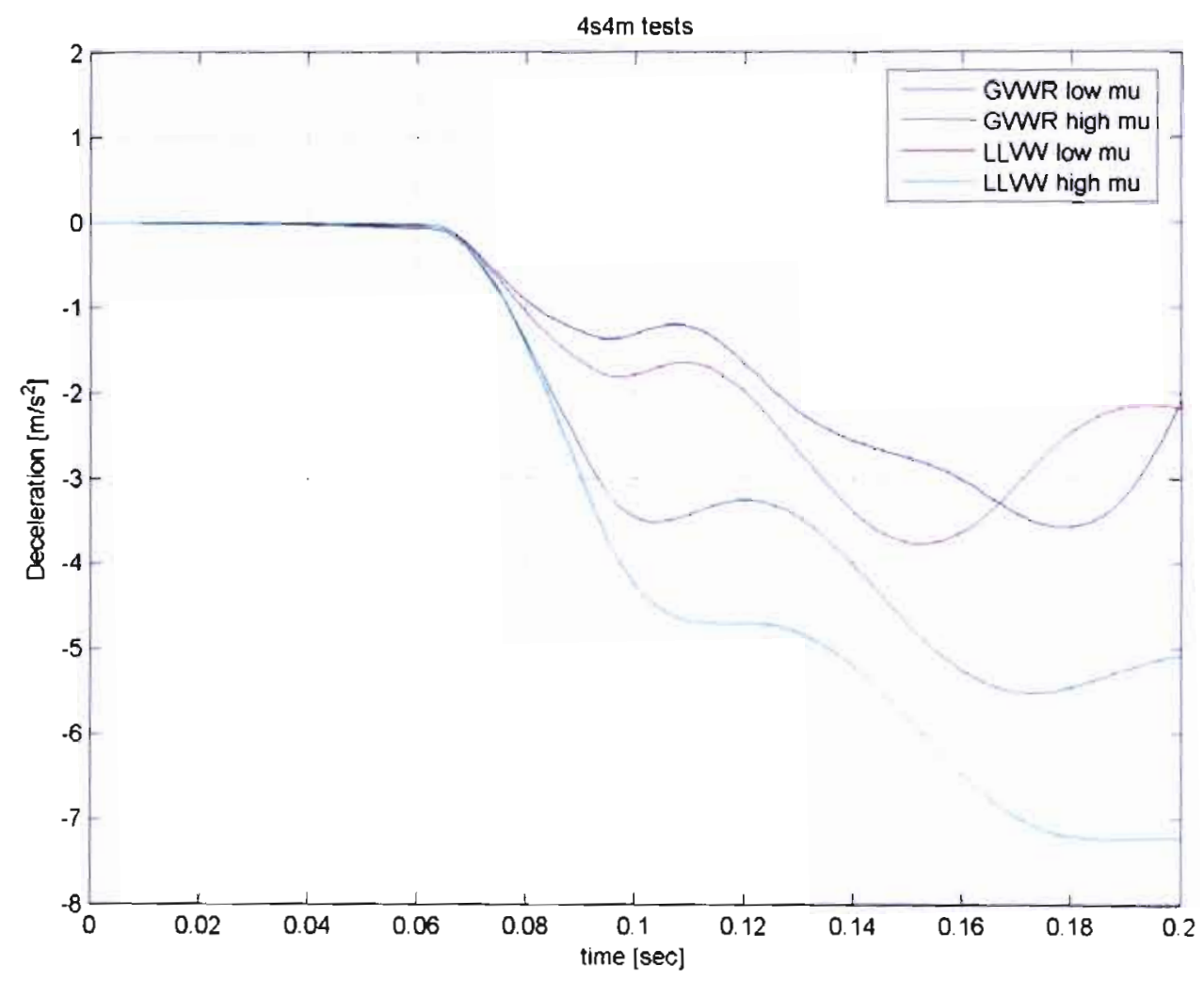

Figure 2.28 - Initial Braking Deceleration of 4s4m System 


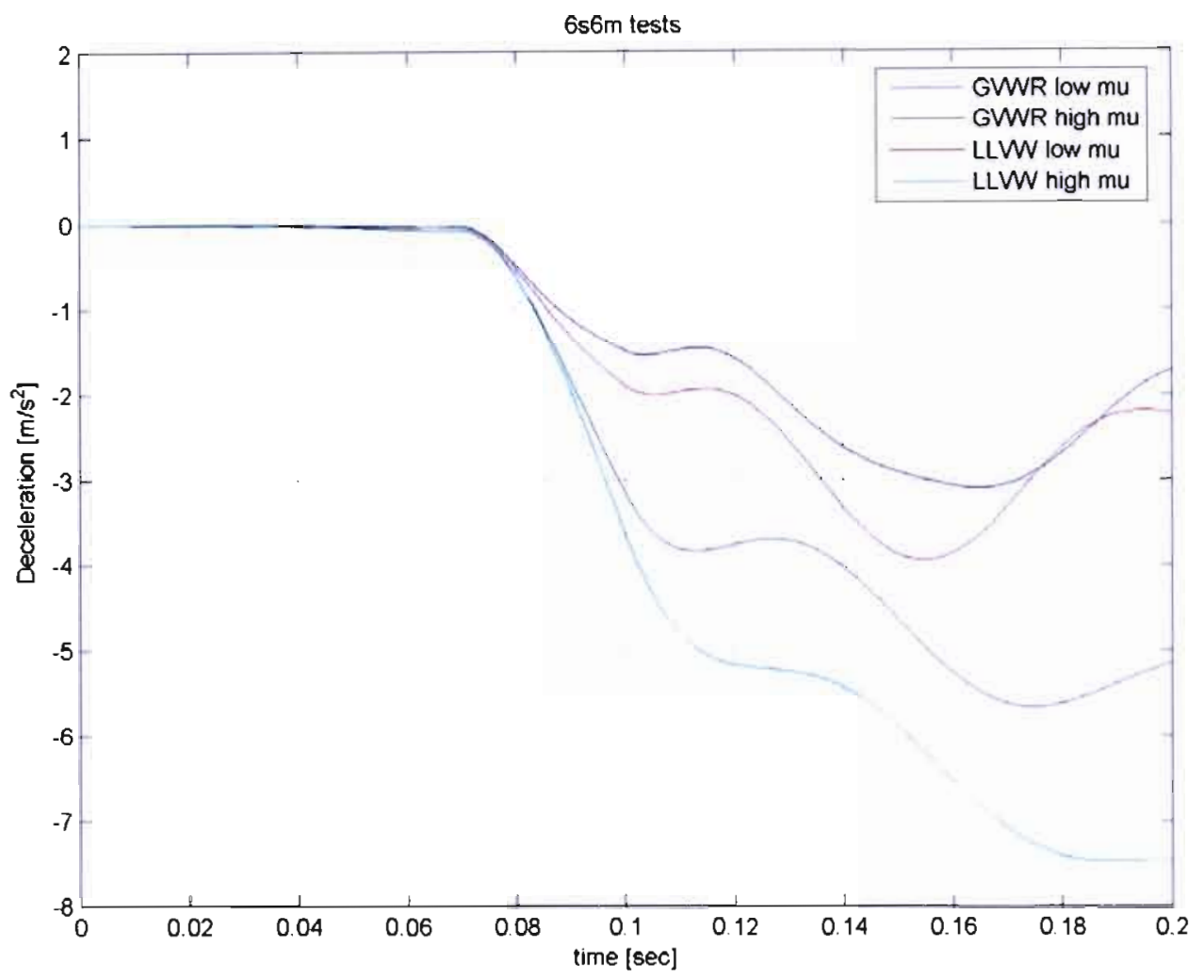

Figure 2.29 - Initial Braking Deceleration of 6s6m System

The preceding figures do in fact show the separation of the low friction and high friction braking cases. These plots were then used in order to choose values of initial_build_cutoff andinitial_build_mu_selector which would be robust in nature and ensure the most efficient determination of controller estimated friction level. Separate values were chosen for the $4 \mathrm{~s} 4 \mathrm{~m}$ and $6 \mathrm{~s} 6 \mathrm{~m}$ cases, and they can be seen in Table 2.9. These were chosen by setting the acceleration threshold level at the earliest time at which the low friction cases separated from the high friction cases. 


\begin{tabular}{|c|c|c|}
\hline & $6 \mathrm{~s} 6 \mathrm{~m}$ & $4 \mathrm{~s} 4 \mathrm{~m}$ \\
\hline Cutoff time [sec] & 0.082 & 0.078 \\
\hline Acceleration Threshold $\left[\mathrm{m} / \mathrm{s}^{\wedge} 2\right]$ & -0.8 & -1.1 \\
\hline
\end{tabular}

Table 2.9 - Friction Estimation Thresholds

\subsection{Model Verification}

In order to check the validity of the modified $6 \mathrm{~s} 6 \mathrm{~m}$ model and the created $4 \mathrm{~s} 4 \mathrm{~m}$ model, simulations were compared to data from experimental field tests, which were conducted on a high friction and on a low friction surface, at both vehicle weight configurations, GVWR and LLVW. The high friction test consisted of a straight-ahead stop from $60 \mathrm{mph}$ on dry Portland cement, which has a nominal peak coefficient of friction of around 0.95 . Low friction behavior was compared by using a brake-in-curve (BIC) maneuver (500 ft. radius) on wet Jennite concrete, which has a nominal peak coefficient of friction around 0.35 .

Because VRTC did not have a $4 \mathrm{~s} 3 \mathrm{~m}$ controller for the Peterbilt truck, no experimental data for this configuration was obtained. This configuration is uncommon for $6 \times 4$ trucks; however, the model is capable of simulating such a system.

\subsubsection{6s6m ABS Model Results}

\subsubsection{6s6m High Friction Stops at GVWR}

The chamber pressure, slip ratio, and acceleration of wheels 1 and 4 can be seen in Figure 2.30 and Figure 2.31, respectively, for the case of straight-ahead braking on the 
high friction surface at GVWR. One can see from these plots that the model accurately mimics the experimental brake chamber pressures. Any discrepancies between the modeled and experimental pressure traces are attributed to the modeling of the treadles as ideal first order systems (see Section 2.3.3). Also, the wheel dynamics are modeled to a reasonably accurate degree. These plots show that the simulated wheel dynamics follow the same trends as the experimental; however, these plots also show just how difficult it is to simulate the actual wheel dynamics on a vehicle. For example, the fluctuations seen in the experimental acceleration trace of Figure 2.30 are not exhibited in the simulated acceleration of wheel 1 . The simulated acceleration remained at a constant value because the simulated chamber pressure remained at a constant value. 
Chanberl
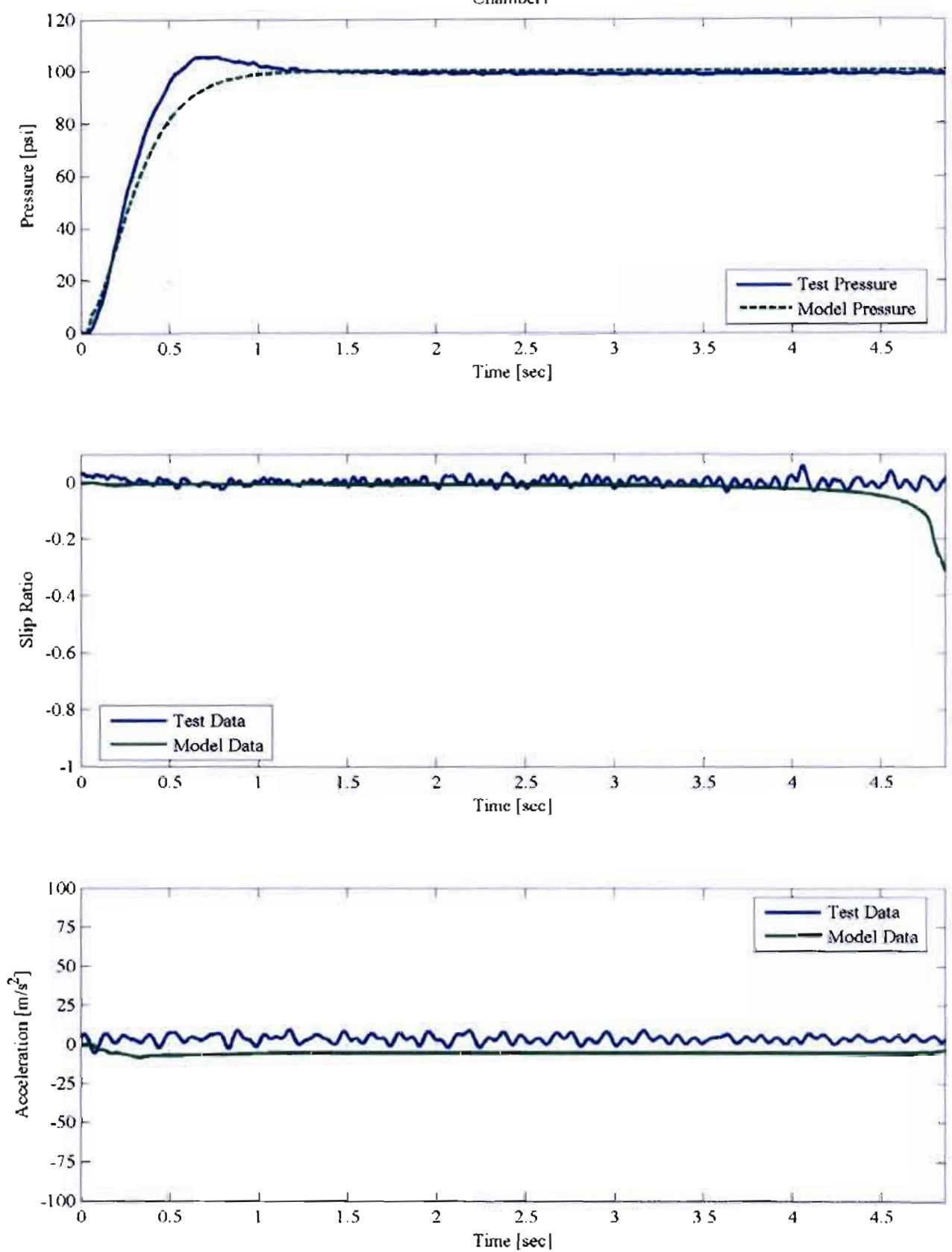

Figure 2.30 - 6s6m High Friction Stops at GVWR - Chamber 1 Dynamics 

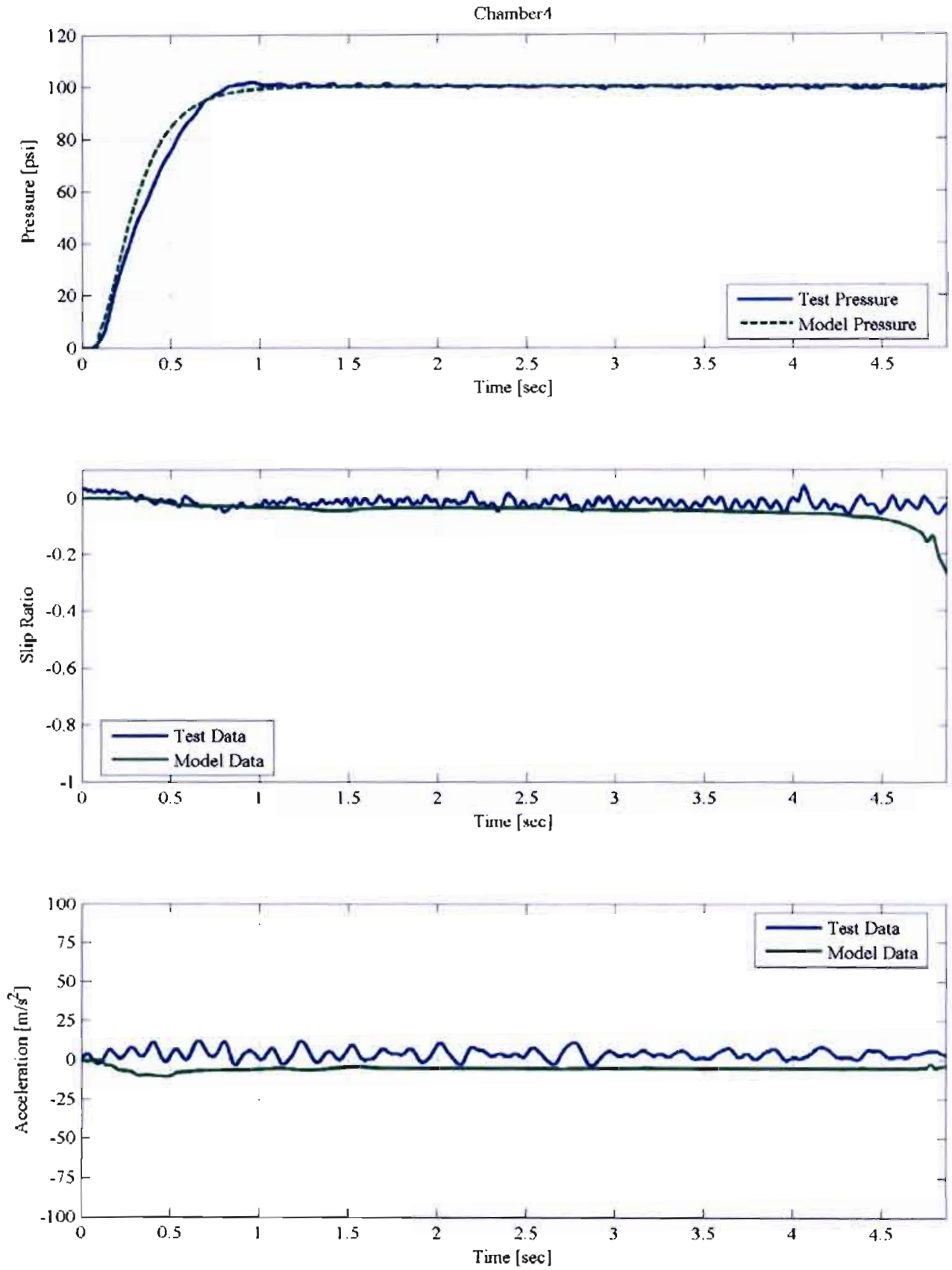

Figure 2.31 - 6s6m High Friction Stops at GVWR - Chamber 4 Dynamics 
Figure 2.34 shows that the ABS controller model is incapable of accurately estimating the Peterbilt track speed for this high friction / high load case. Zaugg also found this behavior in his work [7]. The discrepancy between the simulation and the experiment lies in the torques applied to the S-cam brakes of the Peterbilt. Figure 2.32 shows that the modeled brake torque reach values of about $9000 \mathrm{ft}$-lbs for the steer axle and about $11,000 \mathrm{ft}$-lbs for the drive axles. Upon further investigation of the actual Scam brakes on the Peterbilt, it was discovered that these torques could not be generated. This was verified through the use of dynamometer data taken from one of the drive axle brakes for the Peterbilt. Figure 2.33 shows that for a stop from $60 \mathrm{mph}$, the maximum torque that the drive axle brakes can generate is about $7200 \mathrm{ft}-\mathrm{lbs}$. Similarly, the maximum torque that the steer axle brakes can generate is about $5600 \mathrm{ft}-\mathrm{lbs}$. For a completely accurate simulation of the Peterbilt, under this condition, further research would have to be conducted into the high speed / high pressure output of the S-cam brakes. This factor led to a simulated stopping distance far more optimistic than the experimental set by which it was verified, which can be seen in Table 2.10 even though the brake chamber pressures were accurately modeled. The $95 \%$ confidence intervals were obtained by examining the performance of six different experimental runs of the Peterbilt under the same conditions. 


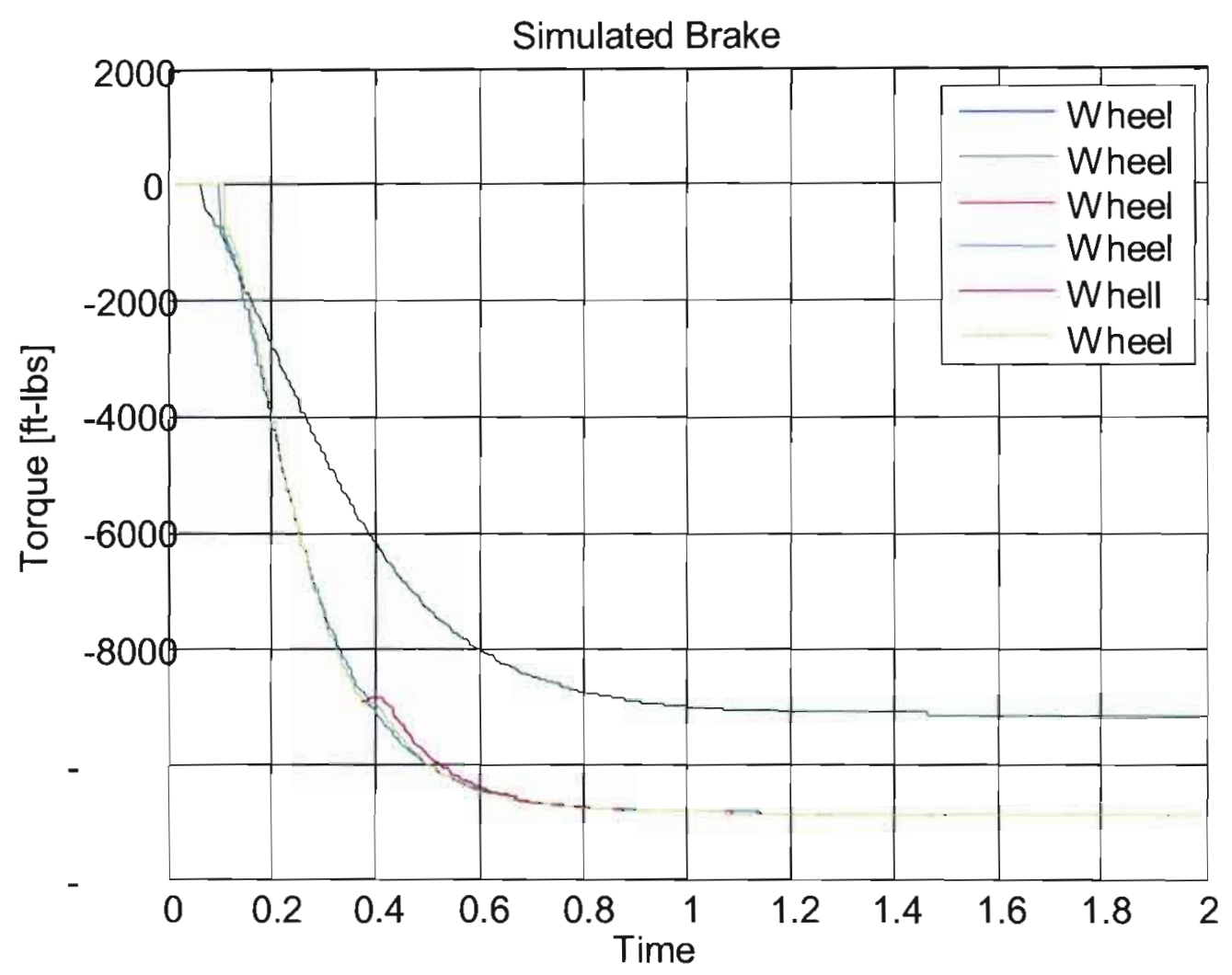

Figure 2.32 - Simulated Brake Torques for $6 \mathrm{~s} 6 \mathrm{~m}$ High Friction Stop 


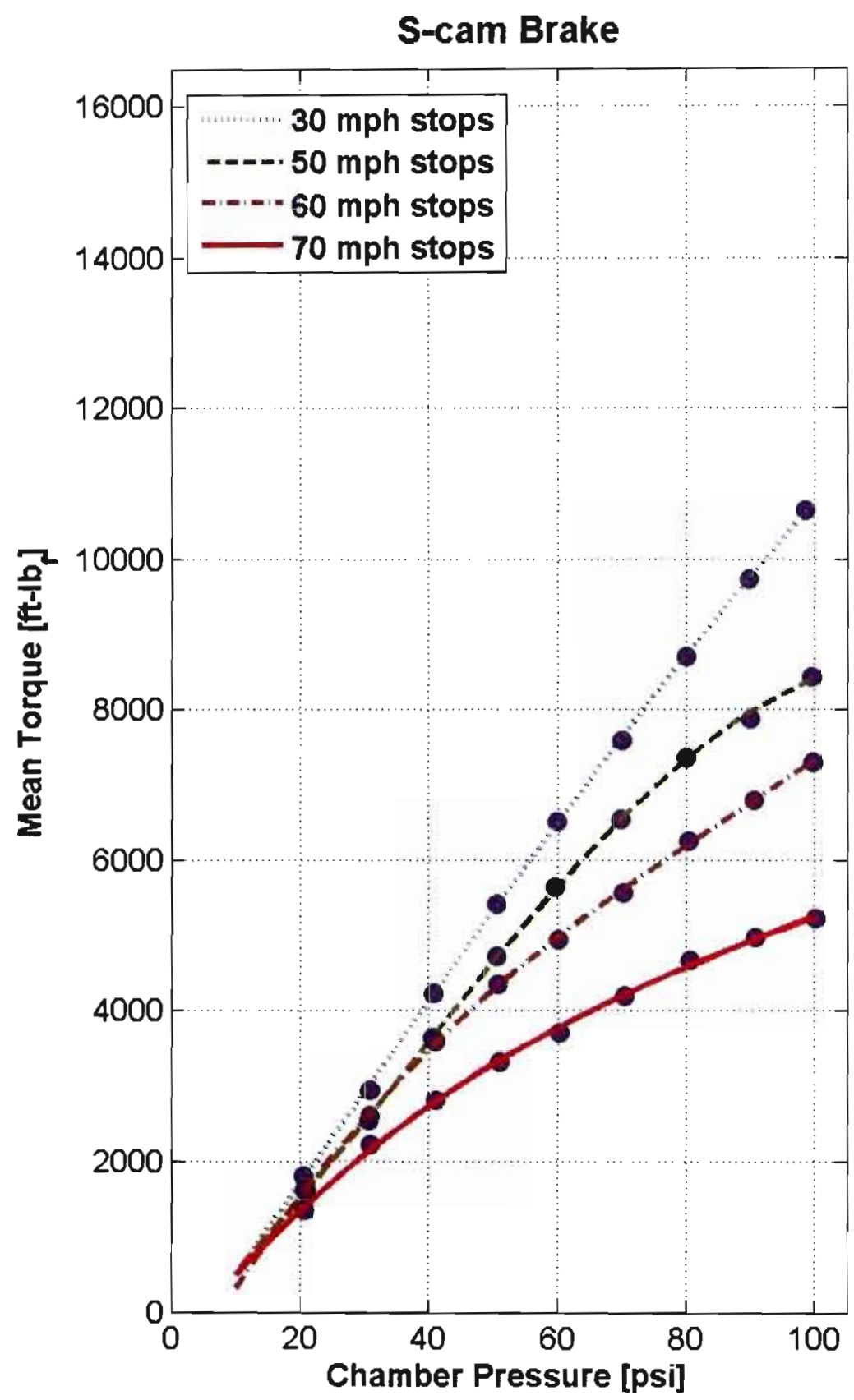

Figure 2.33 - Mean Torque vs. Chamber Pressure for Drive Axle Brakes 


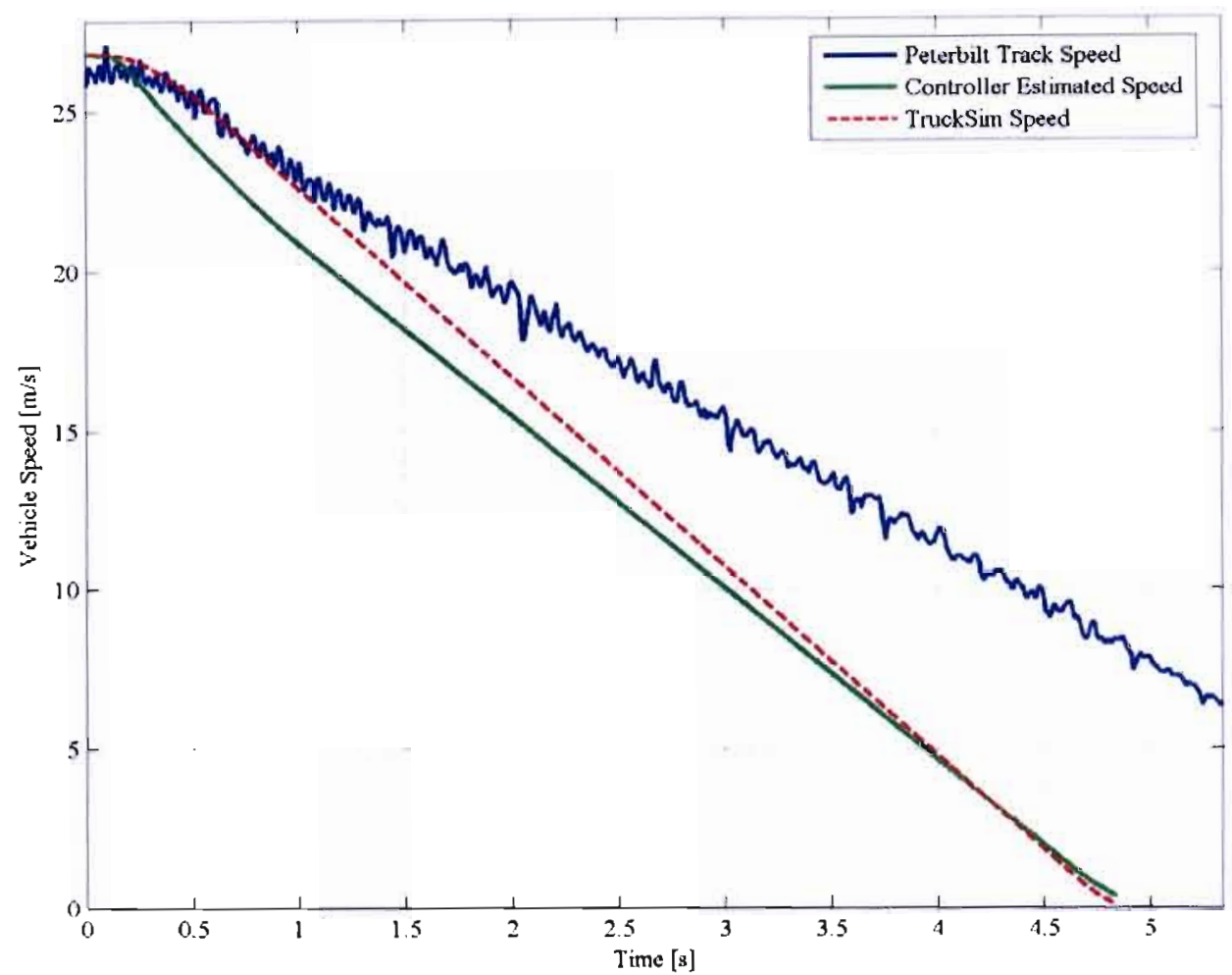

Figure 2.34 - 6s6m High Friction Stops at GVWR - Speed Profiles

\begin{tabular}{|c|c|}
\hline Simulated Stopping Distance $[\mathrm{ft}]$ & 224.2 \\
\hline Lower Bound $(95 \% \mathrm{CI})[\mathrm{ft}]$ & 309.0 \\
\hline Upper Bound $(95 \% \mathrm{CI})[\mathrm{ft}]$ & 322.5 \\
\hline
\end{tabular}

Table 2.10 - Stopping Distances for 6s6m High Friction Stops at GVWR

\subsubsection{6s6m High Friction Stops at LLVW}

High friction stops at LLVW were accurately modeled with the $6 \mathrm{~s} 6 \mathrm{~m}$ ABS configuration. The chamber pressures and dynamics of wheels 1 and 4 , for this case, can 
be seen in Figure 2.35 and Figure 2.36. Because the modeled chamber pressures in these plots generally follow the experimental pressure traces, the results of the following Figure 2.37 and Table 2.11 were expected. These show that the modeled velocity profile well matches that of the experimental stop. Also, the simulated stopping distance for this scenario lies well within the $95 \%$ confidence interval of the experimental data. The slip ratio and wheel acceleration traces for the experimental runs and the simulations follow the same patterns, even though the model was not able to reproduce the exact experimental dynamics. These dynamics are very difficult to exactly model because they could vary due to many experimental factors, such as signal noise and surface variation. 

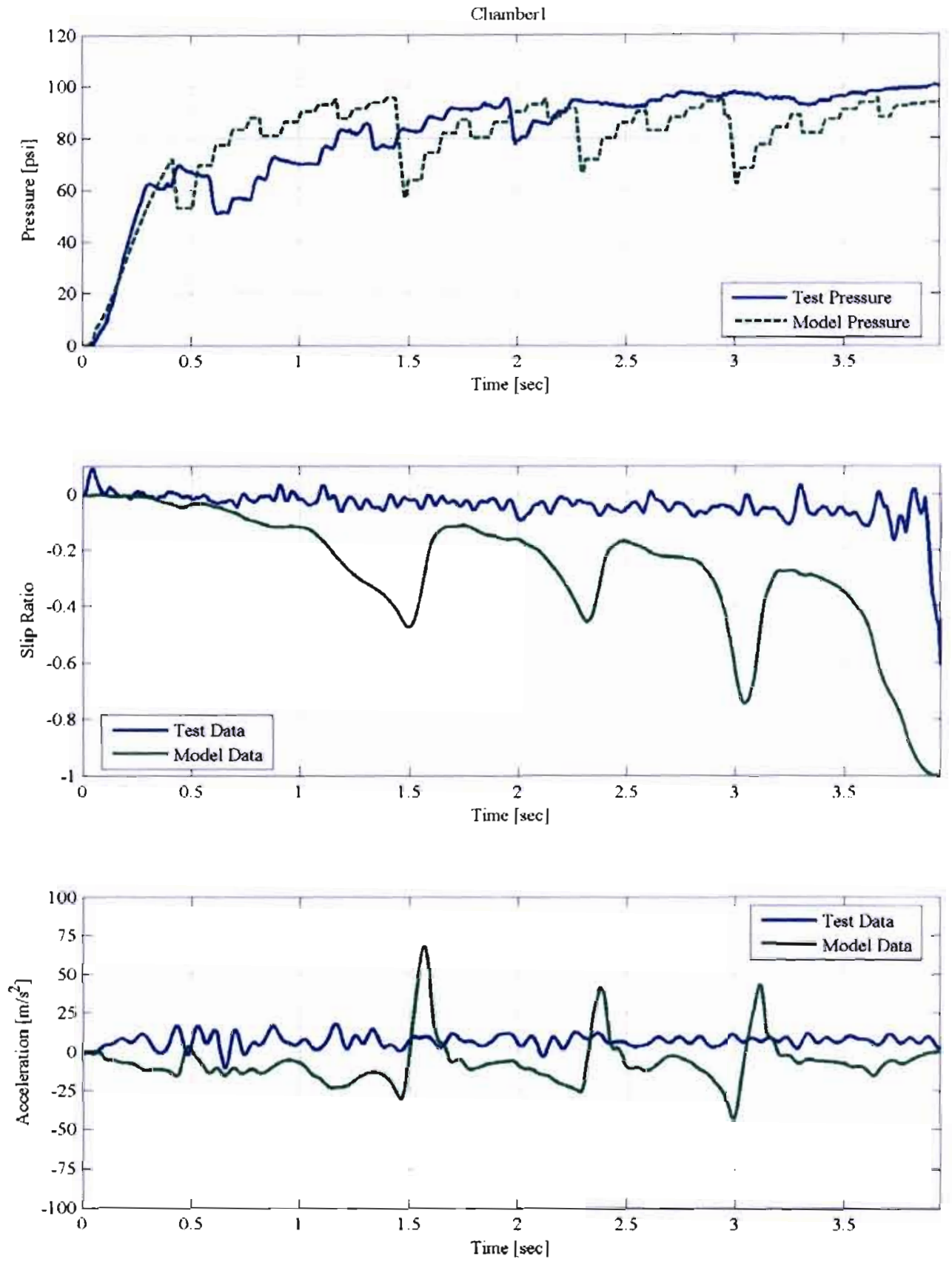

Figure 2.35 - 6s6m High Friction Stops at LLVW - Chamber 1 Dynamics 

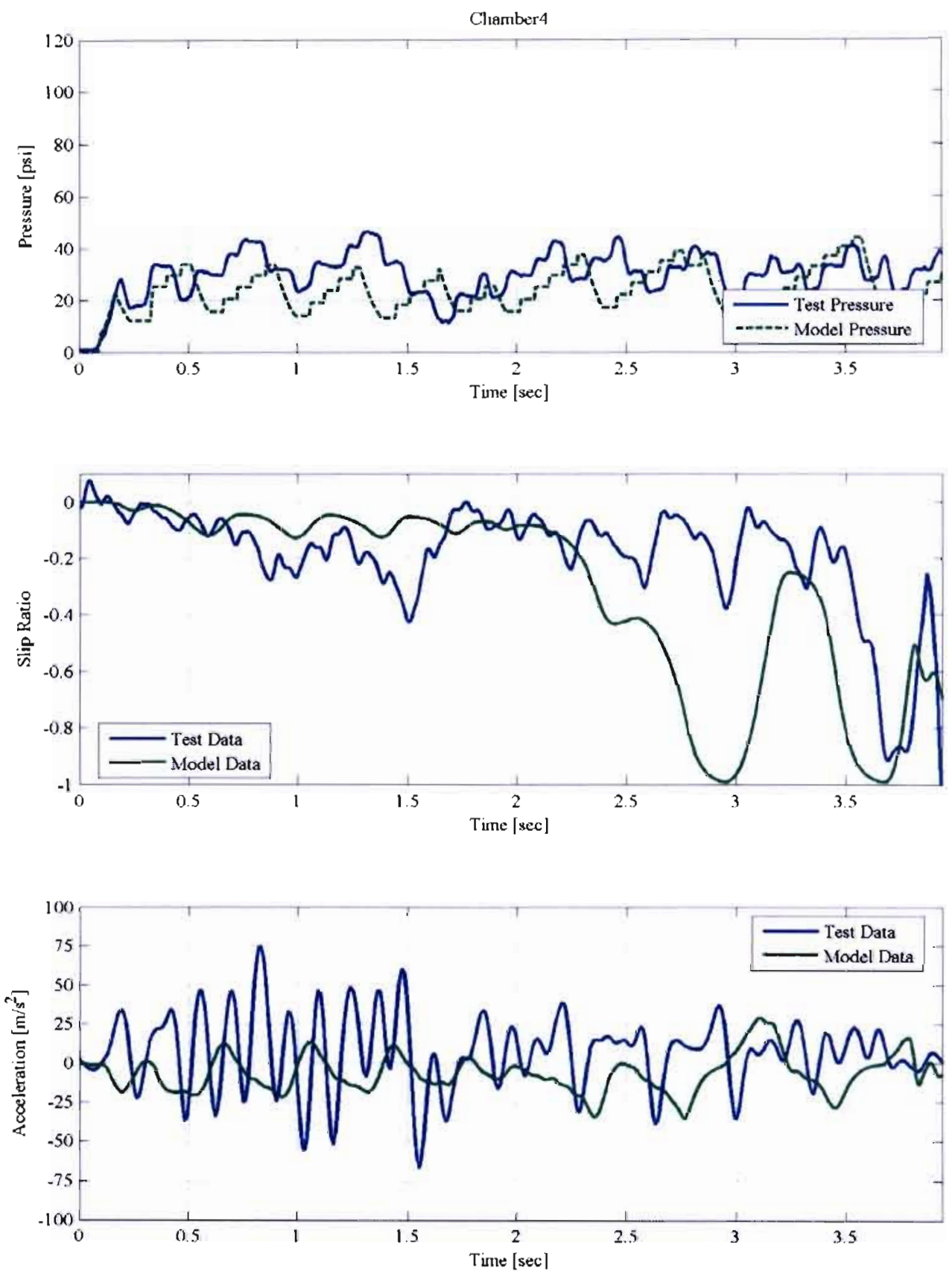

Figure 2.36 - 6s6m High Friction Stops at LLVW - Chamber 4 Dynamics 


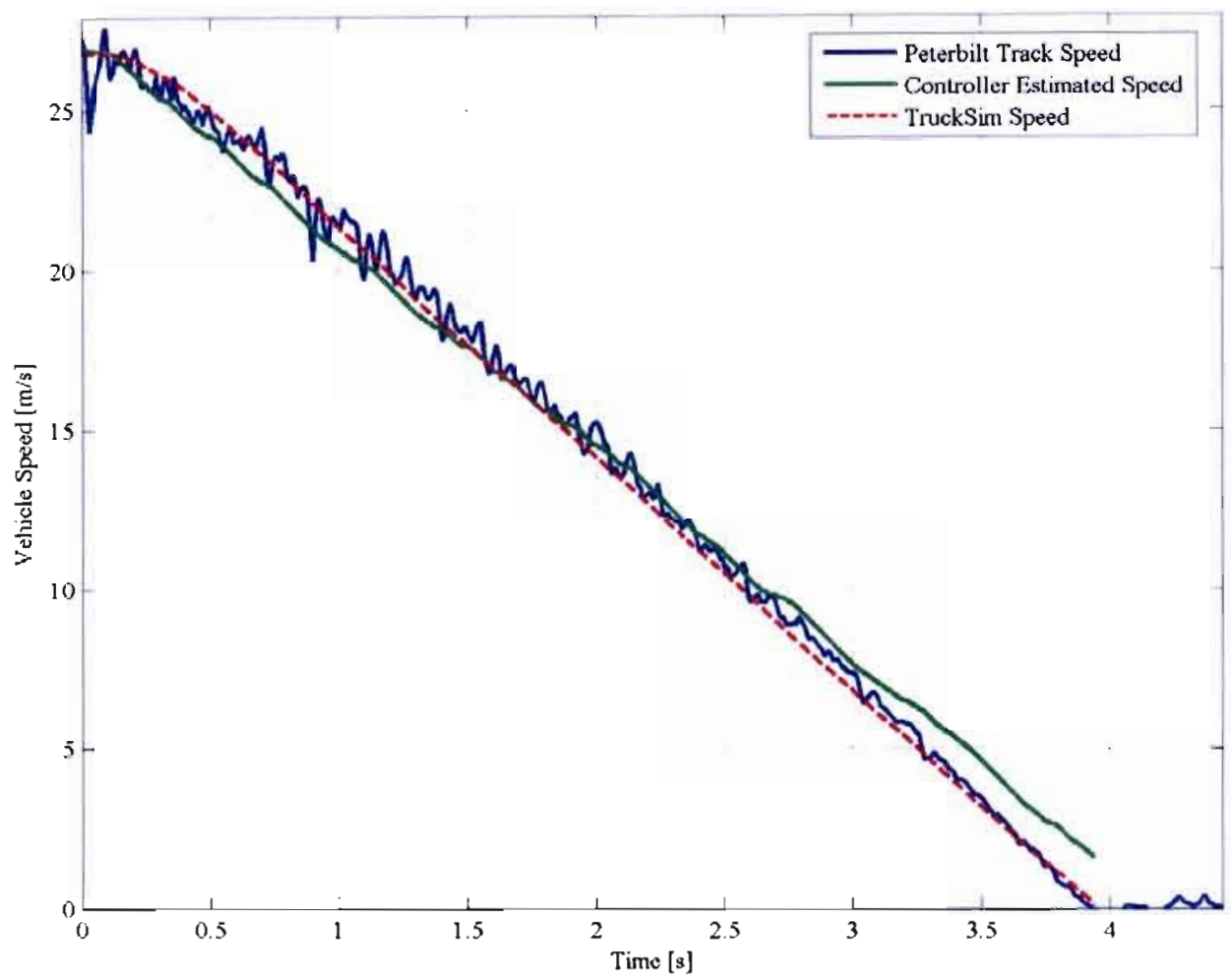

Figure 2.37 - 6s6m High Friction Stops at LLVW - Speed Profiles

\begin{tabular}{|c|c|}
\hline Simulated Stopping Distance $[\mathrm{ft}]$ & 183.9 \\
\hline Lower Bound $(95 \% \mathrm{CI})[\mathrm{ft}]$ & 178.7 \\
\hline Upper Bound $(95 \% \mathrm{CI})[\mathrm{ft}]$ & 188.4 \\
\hline
\end{tabular}

Table 2.11 - Stopping Distances for 6s6m High Friction Stops at LLVW

The model was able to accurately simulate the stop for the lightly-loading vehicle condition, despite the inaccuracies of the brake torque model. This is because the longitudinal stopping force, generated at the tire-road interface, was limited by traction, 
for this case. This was not exhibited in the GVWR simulation of the previous section because the extreme weight condition allowed a much larger longitudinal tractive force in the tires to be generated. This tractive force is dependent on the coefficient of friction of the surface and the normal force at the tire-road interface. During traction-limited braking situations, the brake torques do not have a great effect of the ABS braking performance for this reason.

\subsubsection{6s6m Low Friction Stops at GVWR}

For the low friction, BIC maneuver at gross vehicle weight, the model again was able to accurately predict the braking behavior of the Peterbilt. This can be seen by the close speed relationships of Figure 2.40. Also, the simulated stopping distance falls within the $95 \%$ confidence interval of the experimental data. Upon inspection of Figure 2.38 and Figure 2.39, this result was expected as the modeled pressure traces follow the experimental ones, in general, and similar wheel dynamics can be seen in the modeled and experimental cases. 

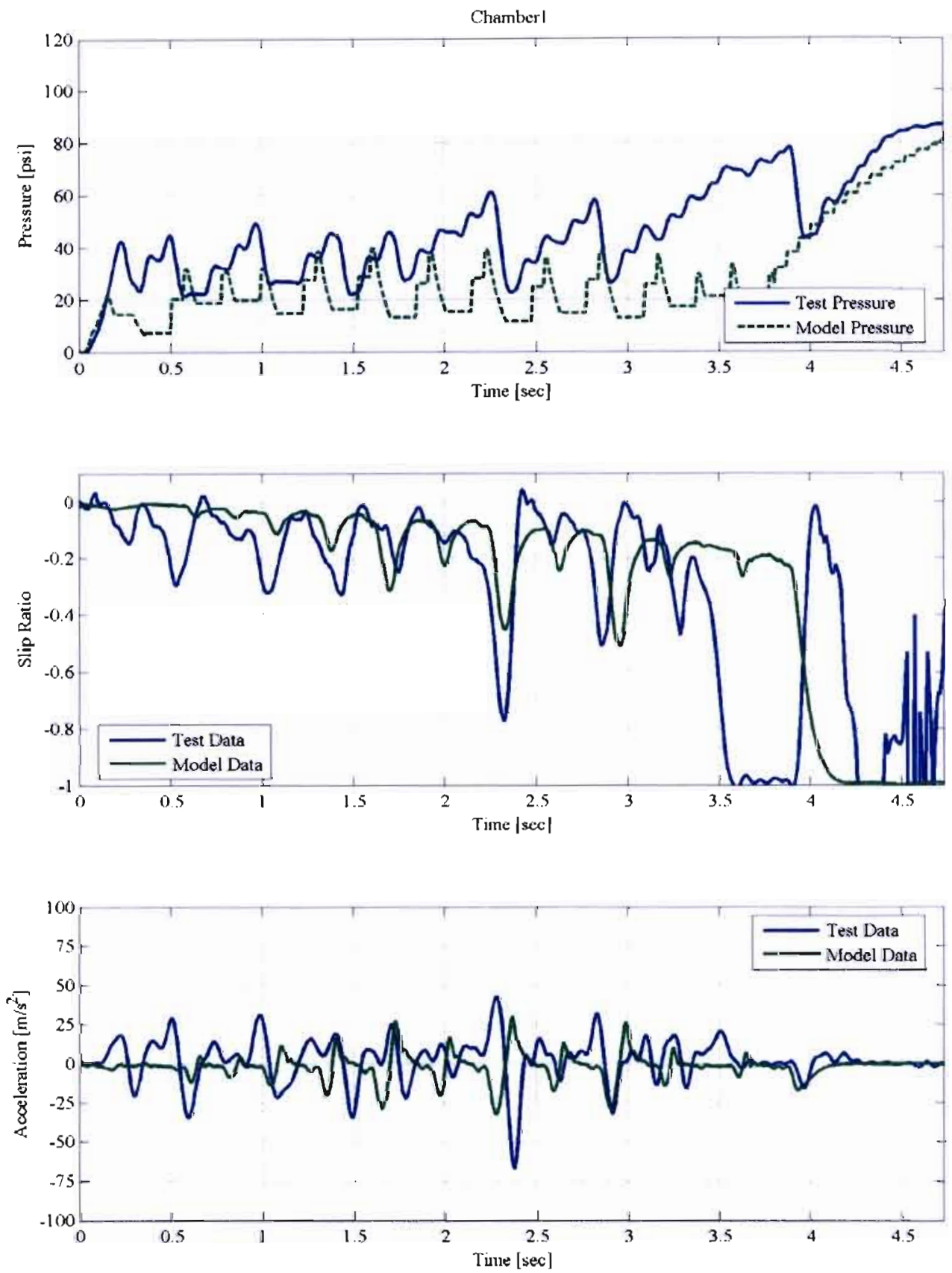

Figure 2.38 - 6s6m Low Friction Stops at GVWR - Chamber 1 Dynamics 

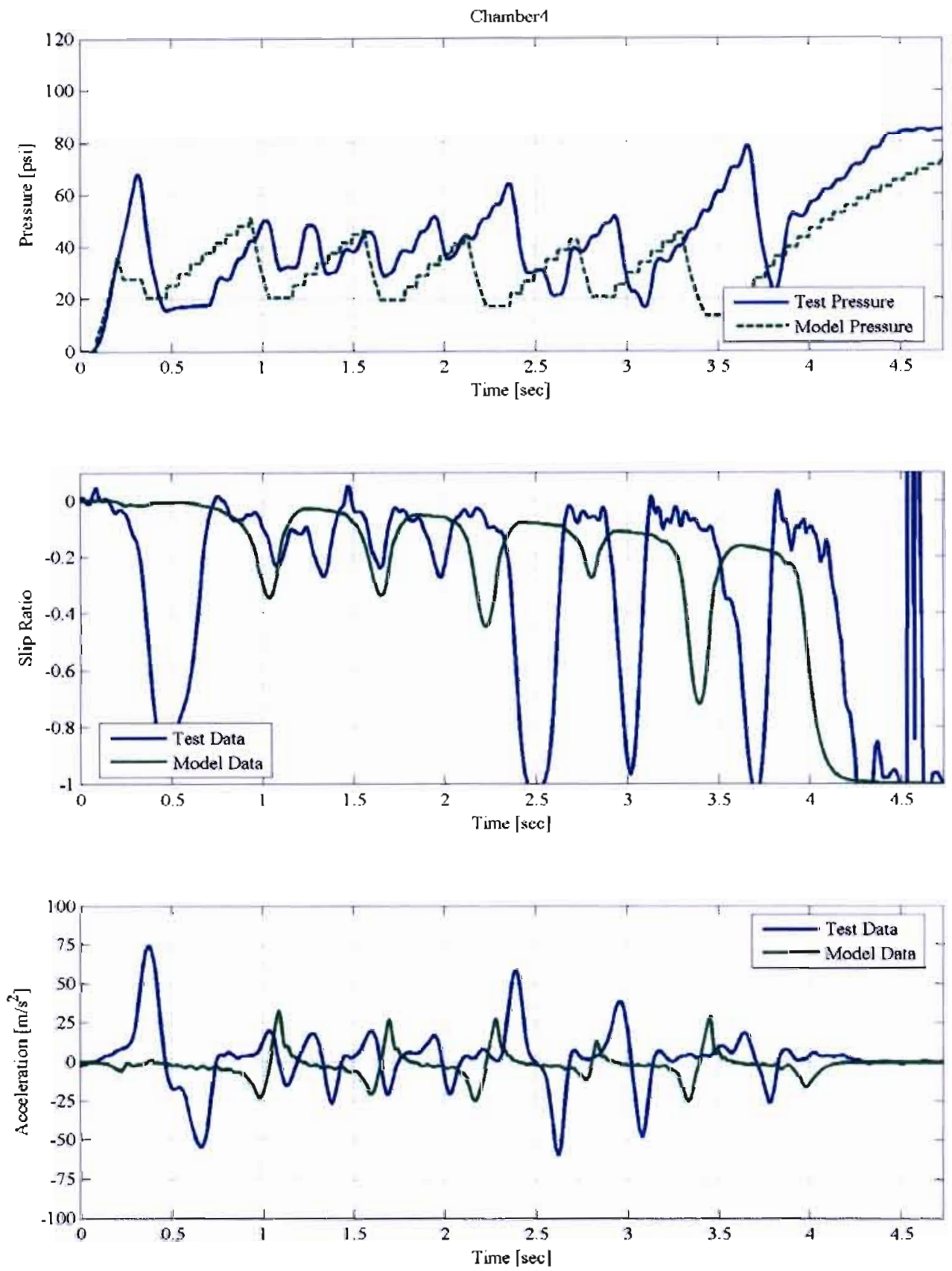

Figure 2.39 - 6s6m Low Friction Stops at GVWR - Chamber 4 Dynamics 


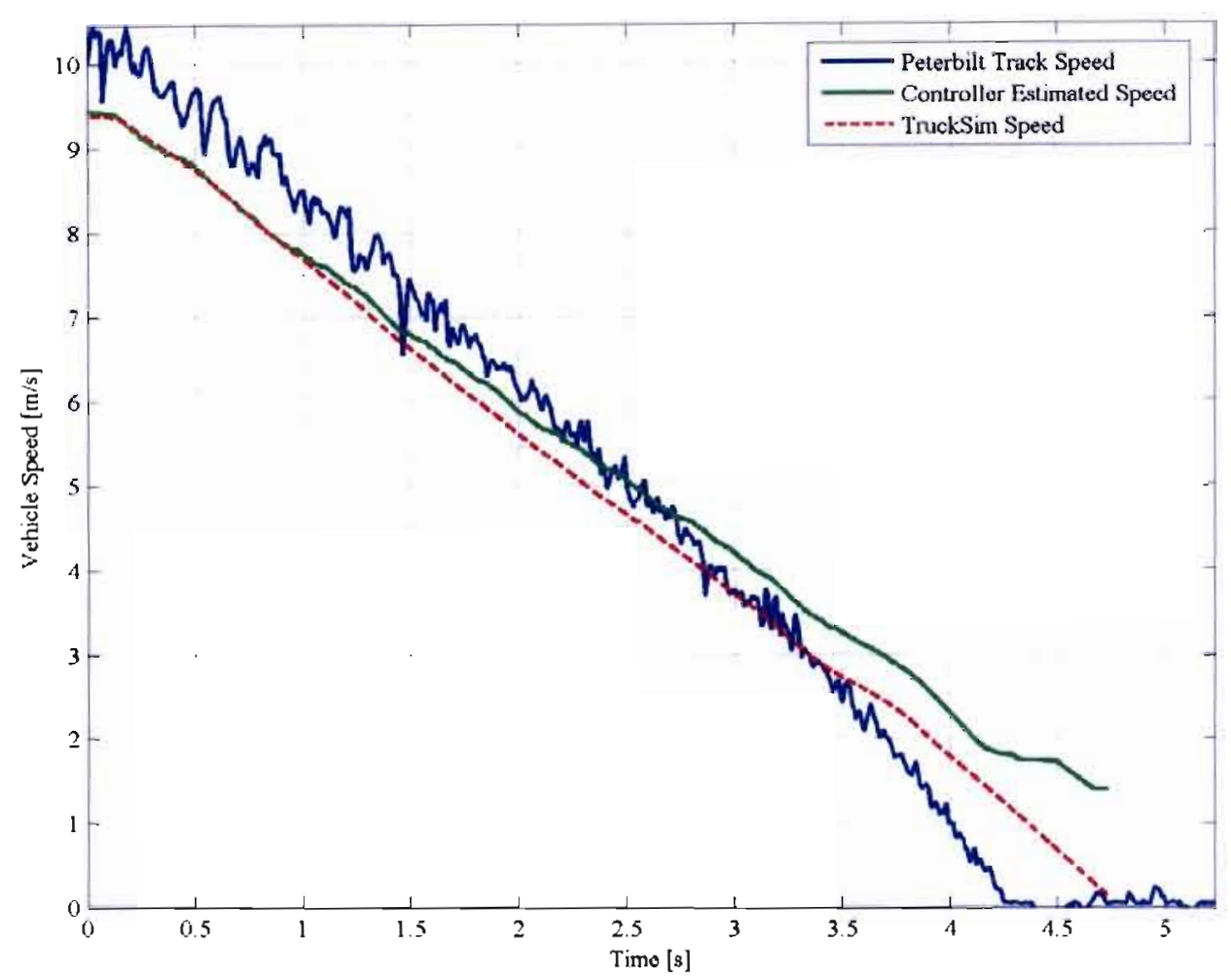

Figure 2.40 - 6s6m Low Friction Stops at GVWR - Speed Profiles

\begin{tabular}{|c|c|}
\hline Simulated Stopping Distance [ft] & 76.8 \\
\hline Lower Bound $(95 \% \mathrm{CI})[\mathrm{ft}]$ & 75.4 \\
\hline Upper Bound $(95 \% \mathrm{CI})[\mathrm{ft}]$ & 81.7 \\
\hline
\end{tabular}

Table 2.12 - Stopping Distances for 6s6m Low Friction Stops at GVWR

\subsubsection{6s6m Low Friction Stops at LLVW}

From the following plots, Figure 2.41 and Figure 2.42, one can see that the LLVW BIC maneuver is simulated to a good degree by the model; however, Table 2.13 
shows that the simulated stopping distance for this case lies just outside the upper bound of the confidence interval. One can see from Figure 2.43 that the experimental track speed comes to a stop before the model (TruckSim) speed does. This is mostly likely attributed to the building behavior of the chamber pressures after about 4 seconds, which can be observed in Figure 2.41 and Figure 2.42. It can be seen from these plots that the experimental chamber pressure builds to a higher level than that of the model as the truck approaches the end of the stop. 

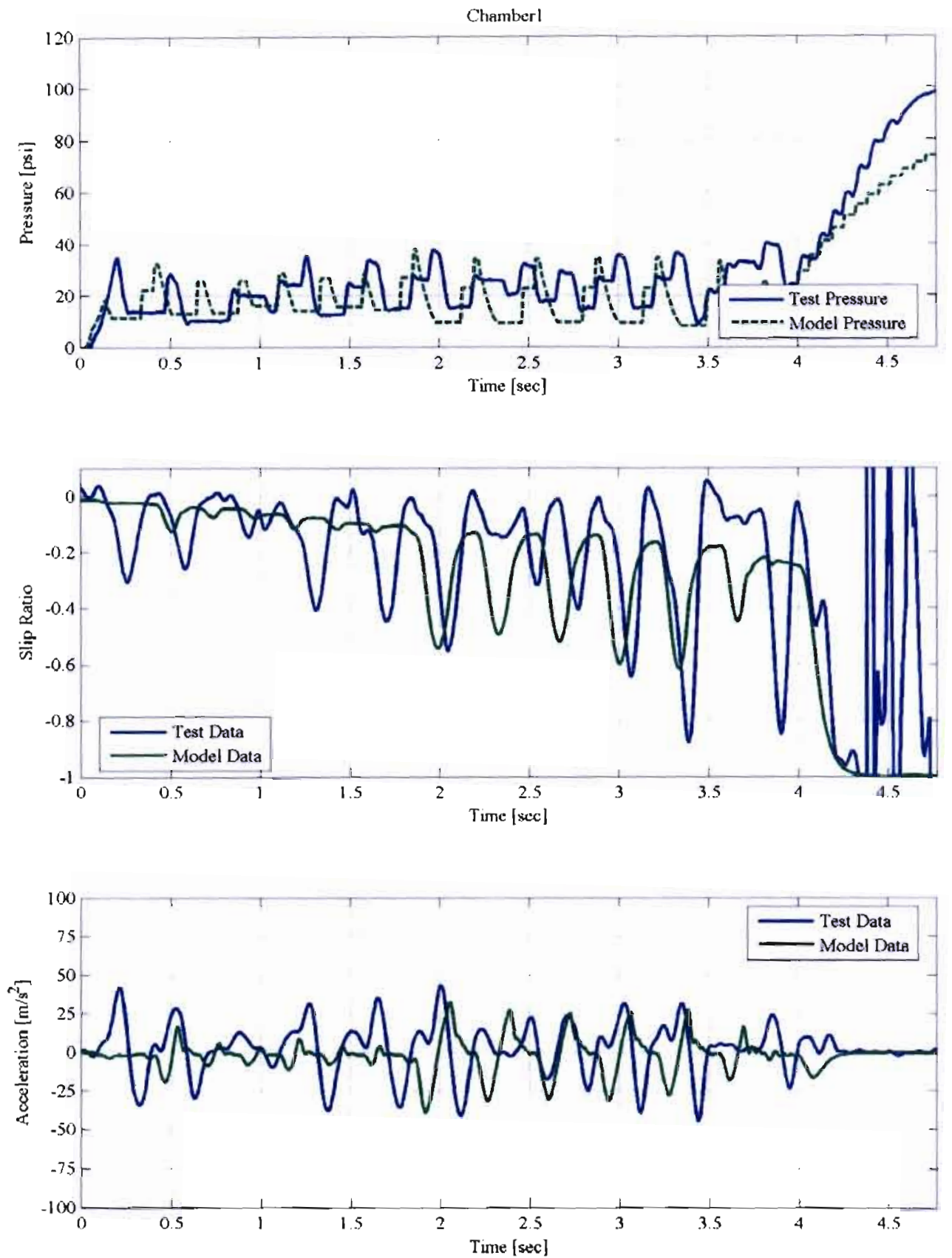

Figure 2.41 - 6s6m Low Friction Stops at LLVW - Chamber 1 Dynamics 

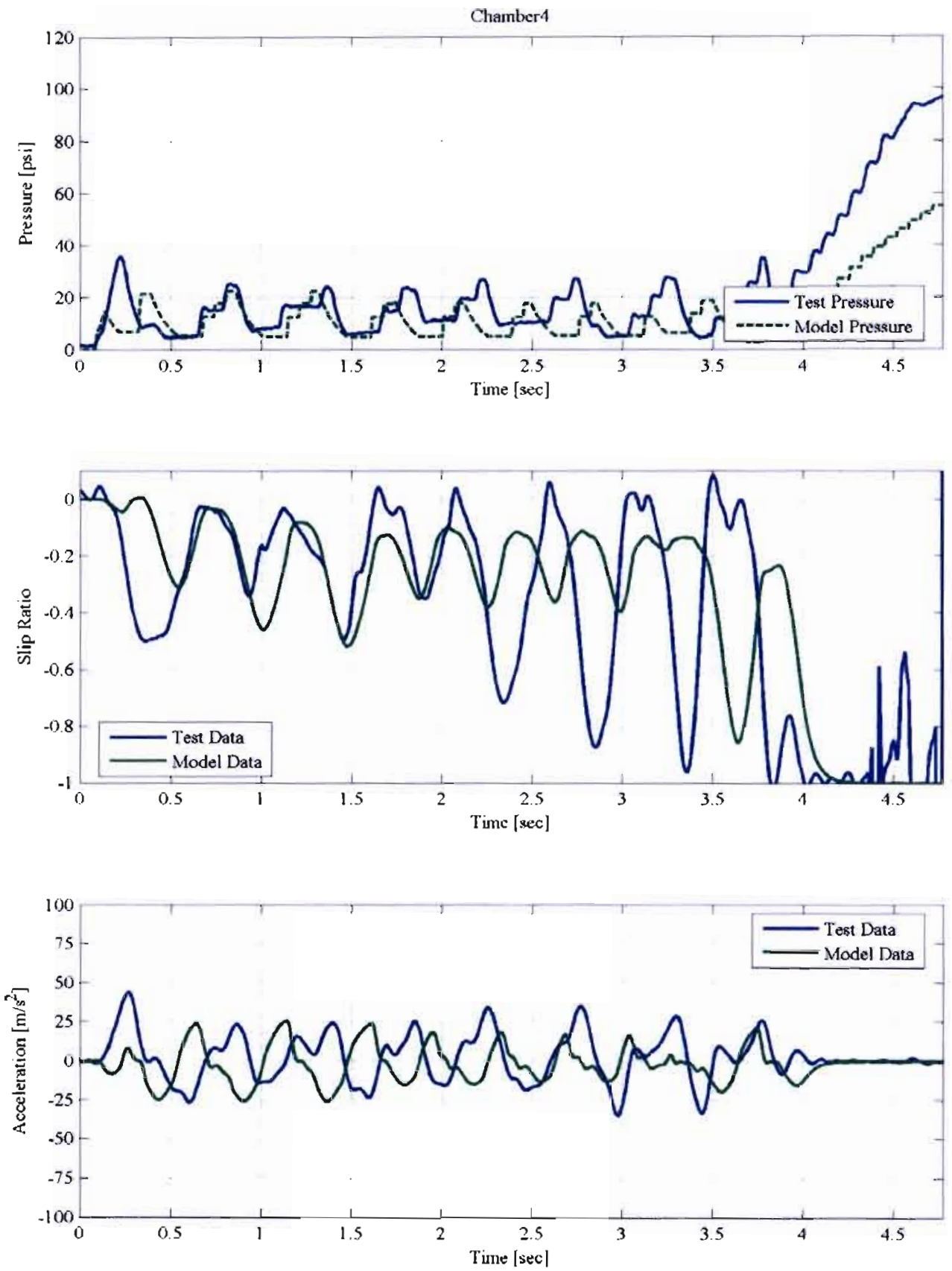

Figure $2.42-6 \mathrm{~s} 6 \mathrm{~m}$ Low Friction Stops at LLVW - Chamber 4 Dynamics 


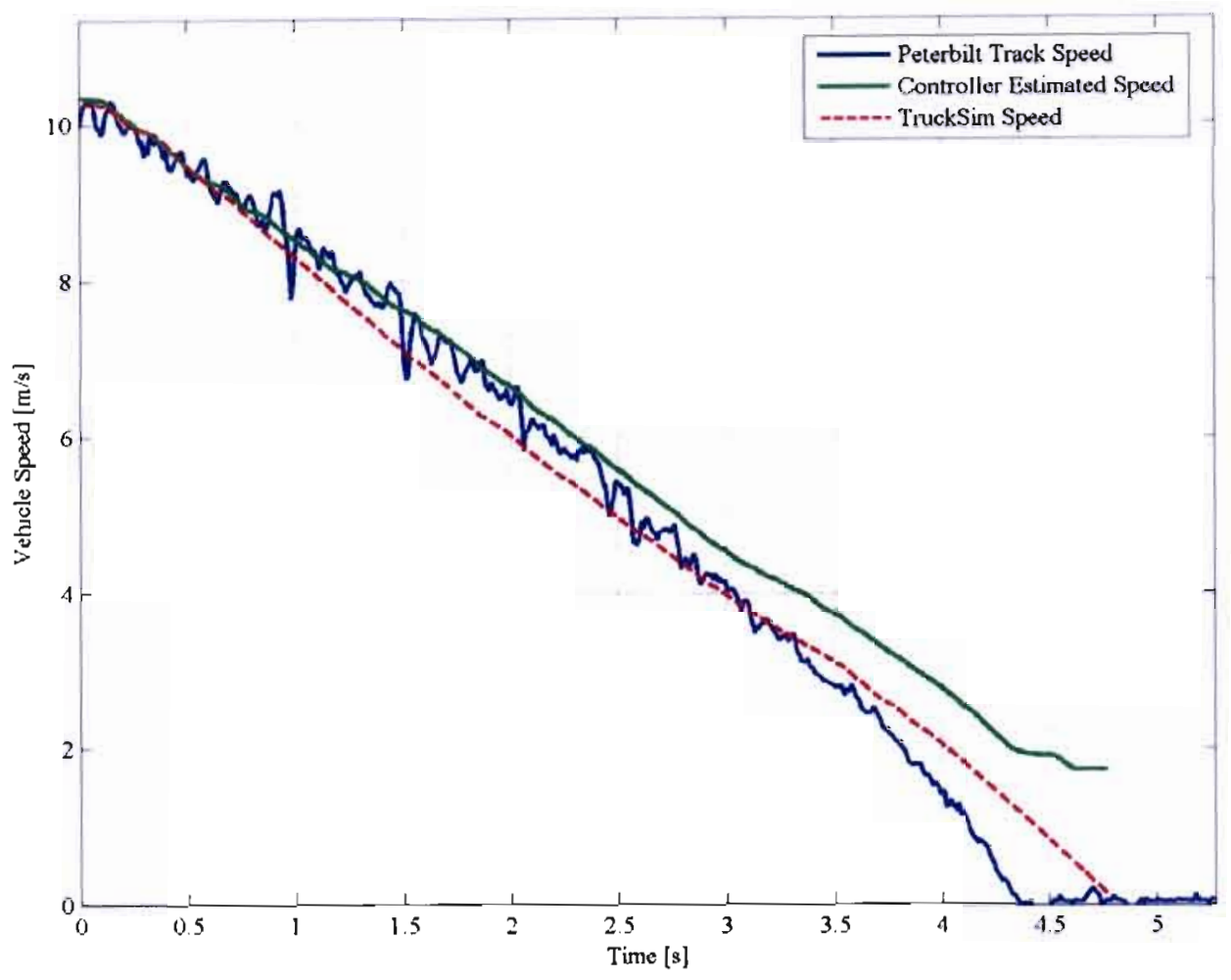

Figure 2.43 - 6s6m Low Friction Stops at LLVW - Speed Profiles

\begin{tabular}{|c|c|}
\hline Simulated Stopping Distance $[\mathrm{ft}]$ & 83.4 \\
\hline Lower Bound $(95 \% \mathrm{CI})[\mathrm{ft}]$ & 78.2 \\
\hline Upper Bound $(95 \% \mathrm{CI})[\mathrm{ft}]$ & 82.3 \\
\hline
\end{tabular}

Table 2.13 - Stopping Distances for 6s6m Low Friction Stops at LLVW

\subsubsection{4s4m Lead Control ABS Model Results}

The acceleration and slip ratio thresholds for the $6 \mathrm{~s} 6 \mathrm{~m}$ controller were determined by Zaugg by co-plotting those traces along with the ABS modulator commands during 
experimental runs. When the experimental runs of the $4 \mathrm{~s} 4 \mathrm{~m}$ systems were completed, the ABS modulator commands were not collected, unfortunately. Therefore, the $4 \mathrm{~s} 4 \mathrm{~m}$ controller was tuned by manually adjusting the thresholds originally developed for the $6 \mathrm{~s} 6 \mathrm{~m}$ system to match the $4 \mathrm{~s} 4 \mathrm{~m}$ experimental results, in the most complete way possible.

\subsubsection{4s4m Lead Control High Friction Stops at GVWR}

In a similar manner to the $6 \mathrm{~s} 6 \mathrm{~m}$ high friction stops at GVWR, Figure 2.44 and Figure 2.45 show a strong correlation between the simulated brake chamber pressures for wheels 1 and 4 and their experimentally determined counterparts. However, for the same reason described in Section 2.5.1.1, the simulation underestimates the true stopping behavior of the Peterbilt truck under the high load / high friction condition. The speed profiles of Figure 2.46 show that the simulation comes to a stop well before the experimental. Because of this, the results of Table 2.14 were expected, as the simulated stopping distance fell well short of the experimental confidence interval. 

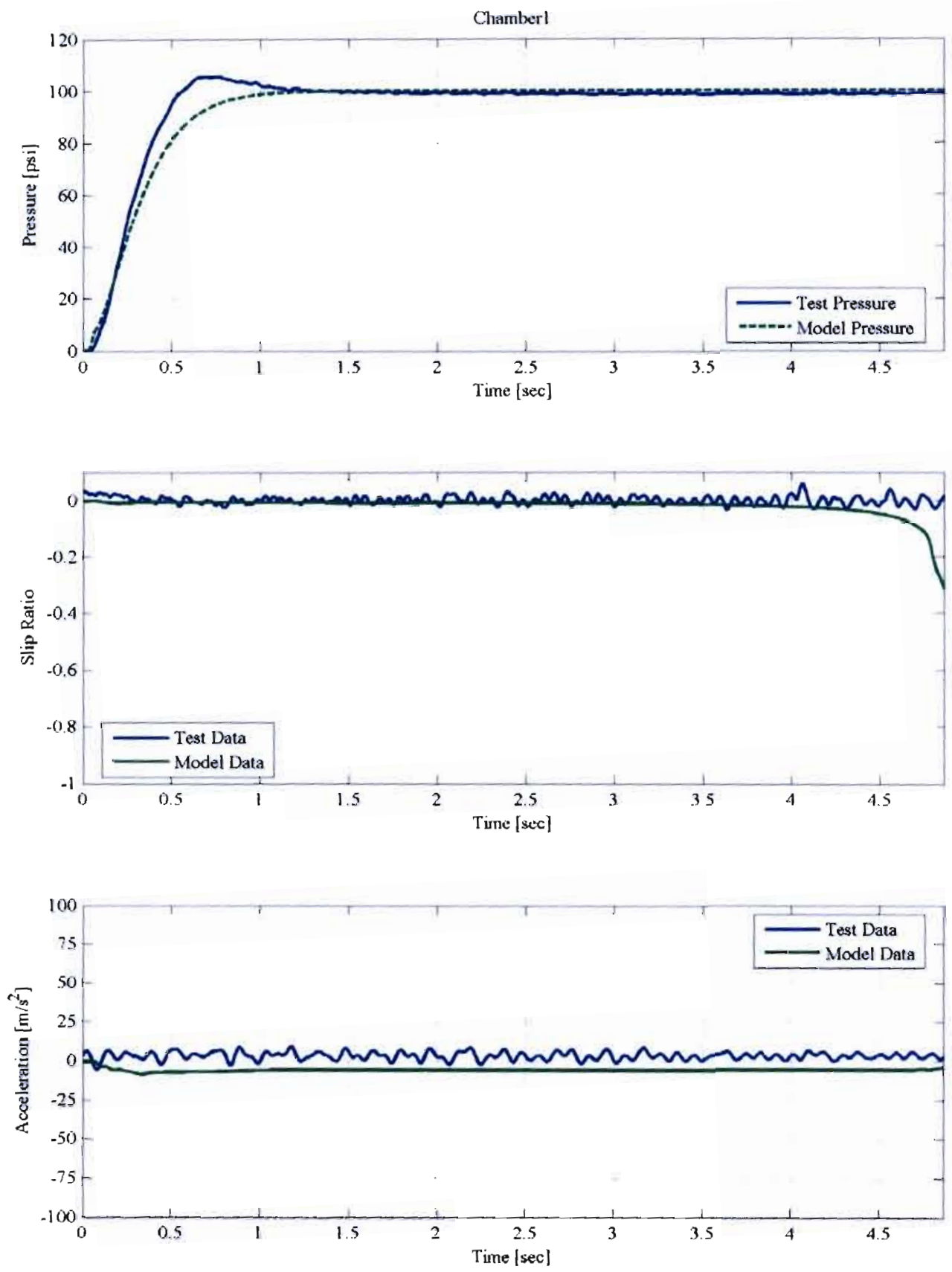

Figure 2.44 - Lead Control High Friction Stops at GVWR - Chamber 1 Dynamics 

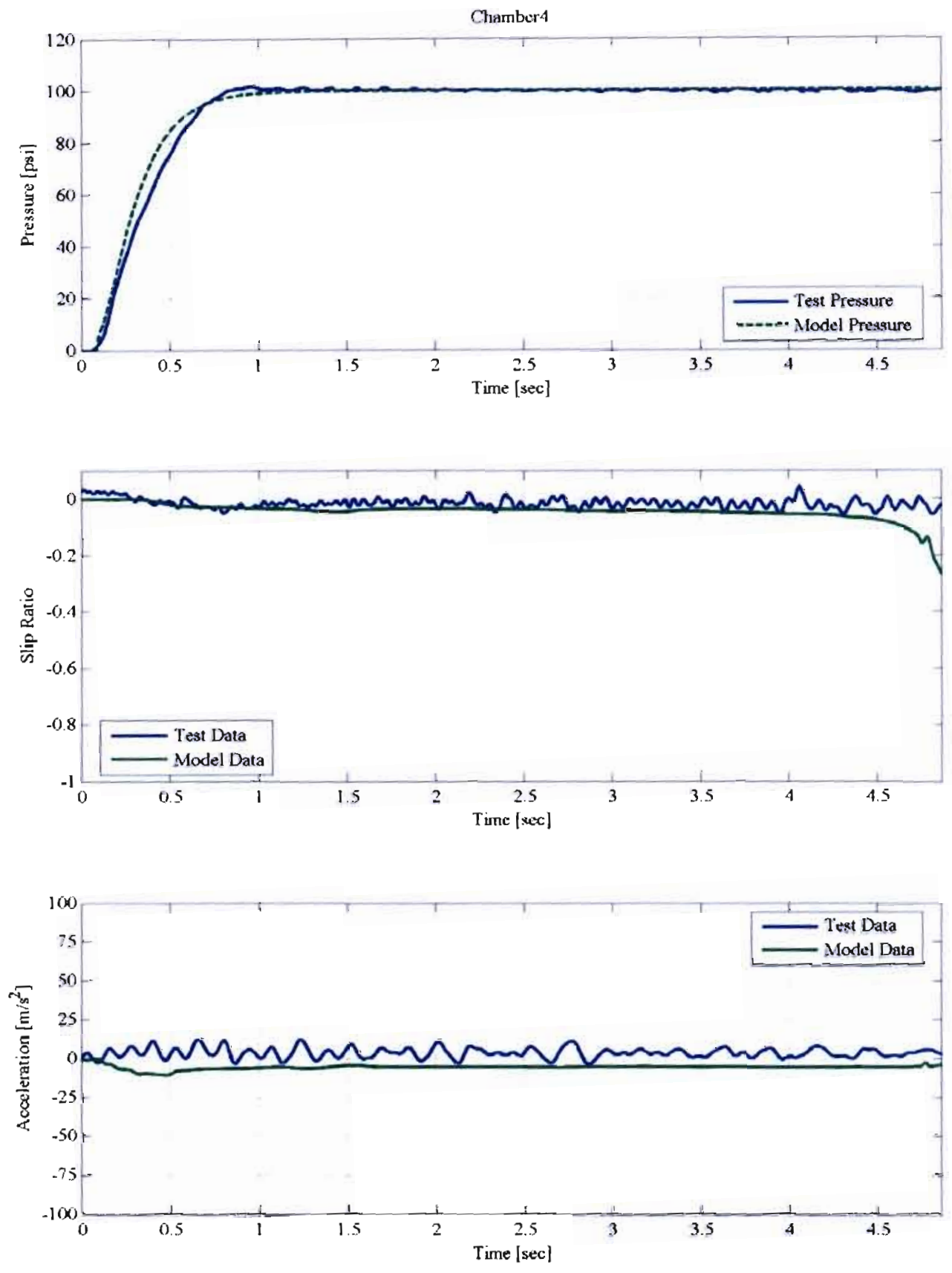

Figure 2.45 - Lead Control High Friction Stops at GVWR - Chamber 4 Dynamics 


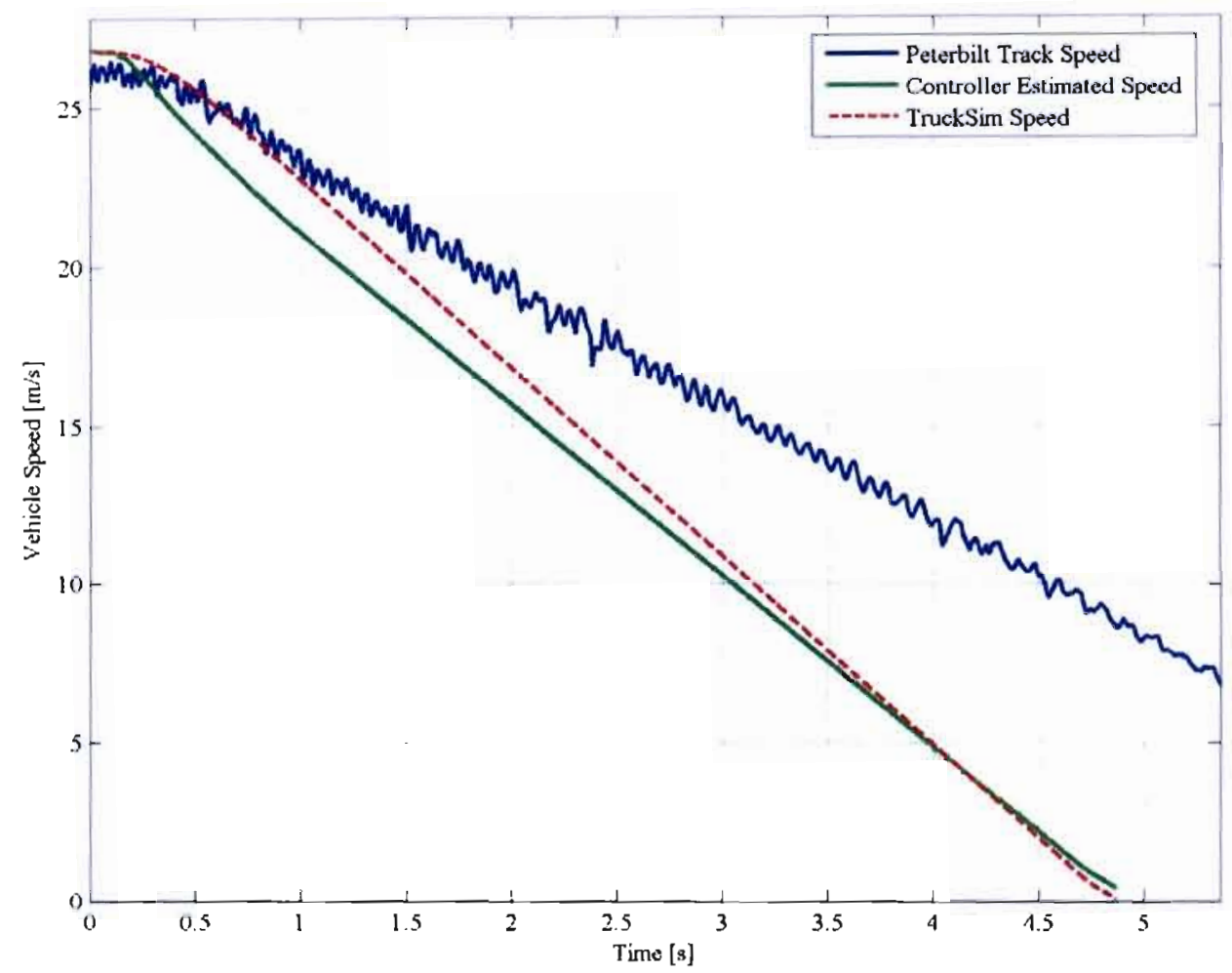

Figure 2.46 - Lead Control High Friction Stops at GVWR - Speed Profiles

\begin{tabular}{|c|c|}
\hline Simulated Stopping Distance $[\mathrm{ft}]$ & 226.0 \\
\hline Lower Bound $(95 \% \mathrm{CI})[\mathrm{ft}]$ & 308.6 \\
\hline Upper Bound $(95 \% \mathrm{CI})[\mathrm{ft}]$ & 332.4 \\
\hline
\end{tabular}

Table 2.14 - Stopping Distances for Lead Control High Friction Stops at GVWR

\subsubsection{4s4m Lead Control High Friction Stops at LLVW}

For the same braking maneuver at the lightly-loaded condition (LLVW), the model was also able to adequately model the dynamics of each brake chamber. 
Representative plots of chambers 1 and 4 can be seen in the following Figure 2.47 and Figure 2.48. Because of the accurately modeled brake chamber pressures, the simulation was able to follow the experimental speed profile, shown in Figure 2.49. From this figure, one can see that the model begins to slightly over-estimate the speed at around 2.5 seconds; therefore, the results of Table 2.15 were expected. The stopping distance for the simulation lies at the upper limit of the experimental confidence interval. 

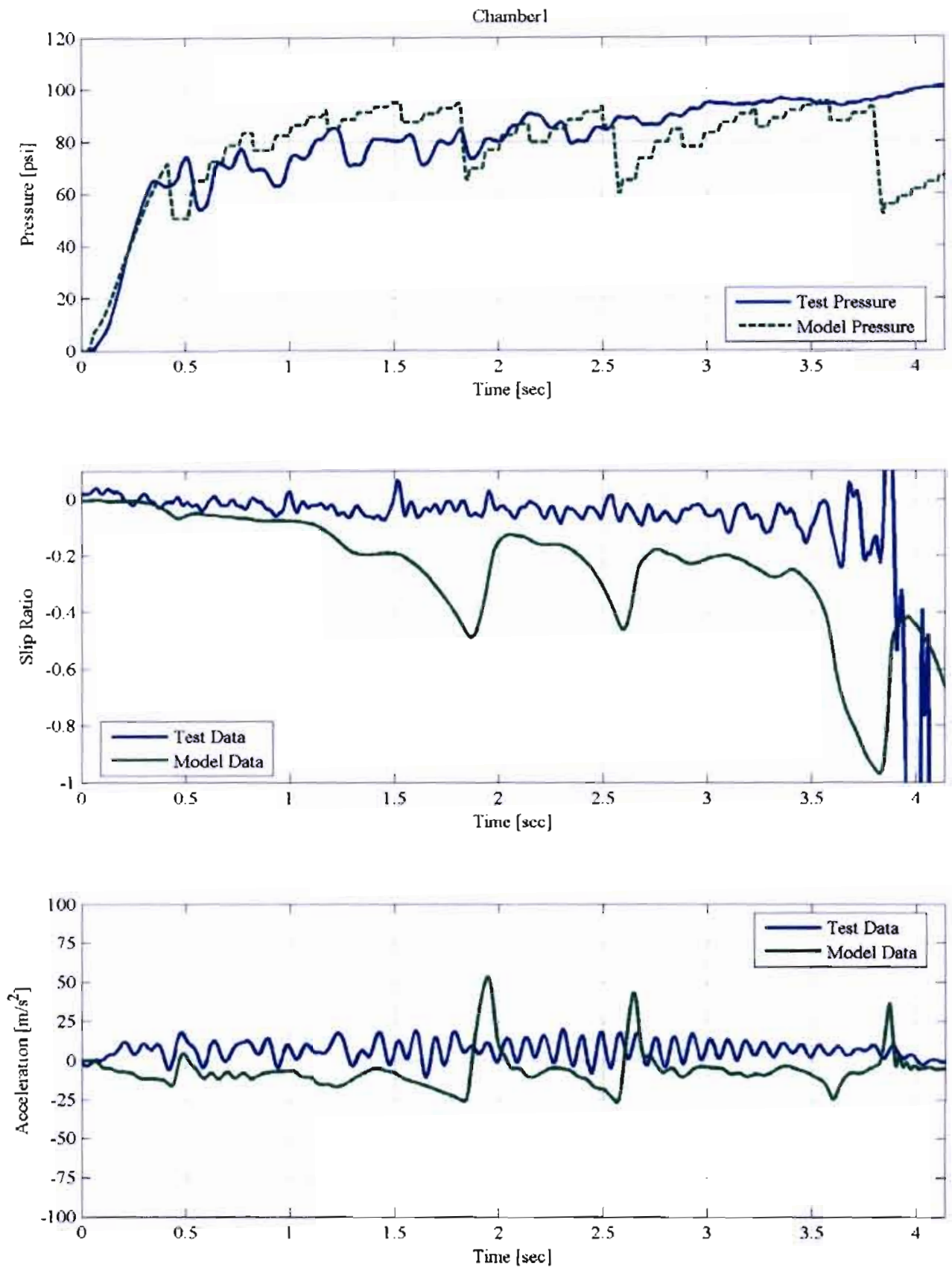

Figure 2.47 - Lead Control High Friction Stops at LLVW - Chamber 1 Dynamics 



Figure 2.48 - Lead Control High Friction Stops at LLVW - Chamber 4 Dynamics 


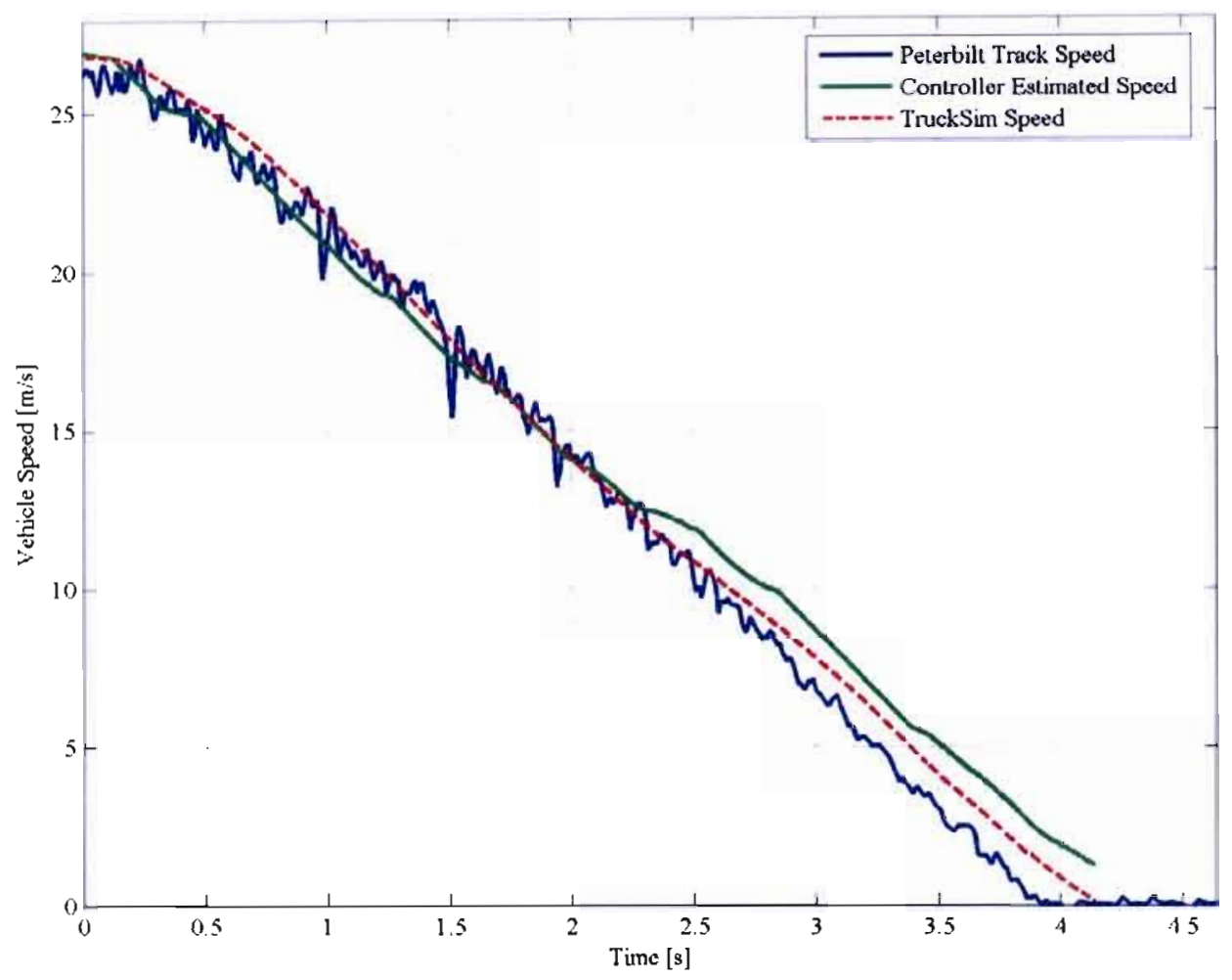

Figure 2.49 - Lead Control High Friction Stops at LLVW - Speed Profiles

\begin{tabular}{|c|c|}
\hline Simulated Stopping Distance $[\mathrm{ft}]$ & 190.2 \\
\hline Lower Bound $(95 \% \mathrm{CI})[\mathrm{ft}]$ & 180.5 \\
\hline Upper Bound $(95 \% \mathrm{CI})[\mathrm{ft}]$ & 190.2 \\
\hline
\end{tabular}

Table 2.15 - Stopping Distances for Lead Control High Friction Stops at LLVW

\subsubsection{4s4m Lead Control Low Friction Stops at GVWR}

The model was found to accurately model the low friction, BIC maneuver at the gross vehicle weight rating (GVWR) of the Peterbilt. Figure 2.50 and Figure 2.51 show 
that the simulated chamber pressures and dynamics for wheels 1 and 4 generally follow the experimental results. The accuracy of the model is verified by examining the speed profiles of Figure 2.52 and noting that the simulated stopping distance lies within the confidence interval of the experimental data, seen in Table 2.16. 

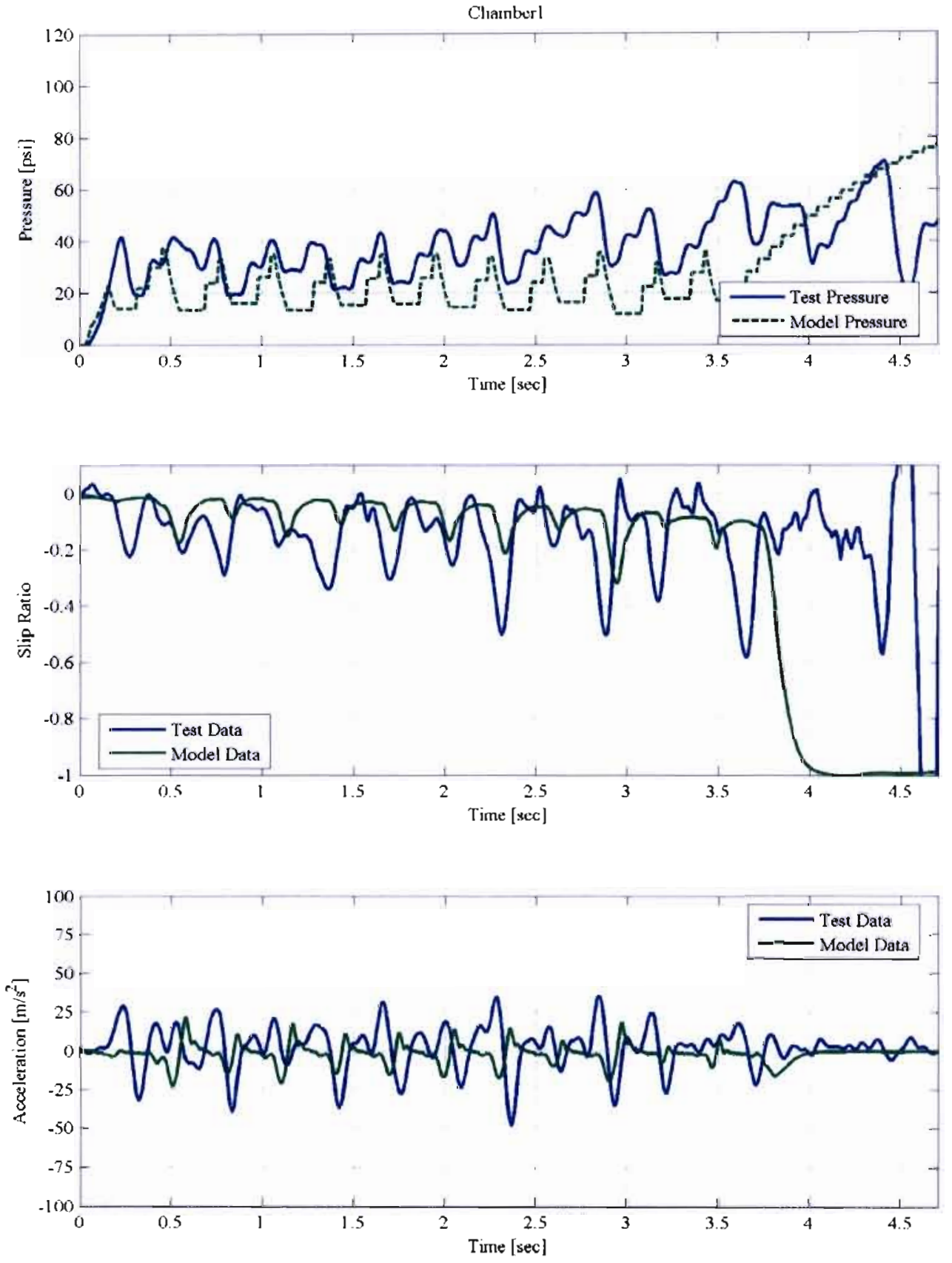

Figure 2.50 - Lead Control Low Friction Stops at GVWR - Chamber 1 Dynamics 

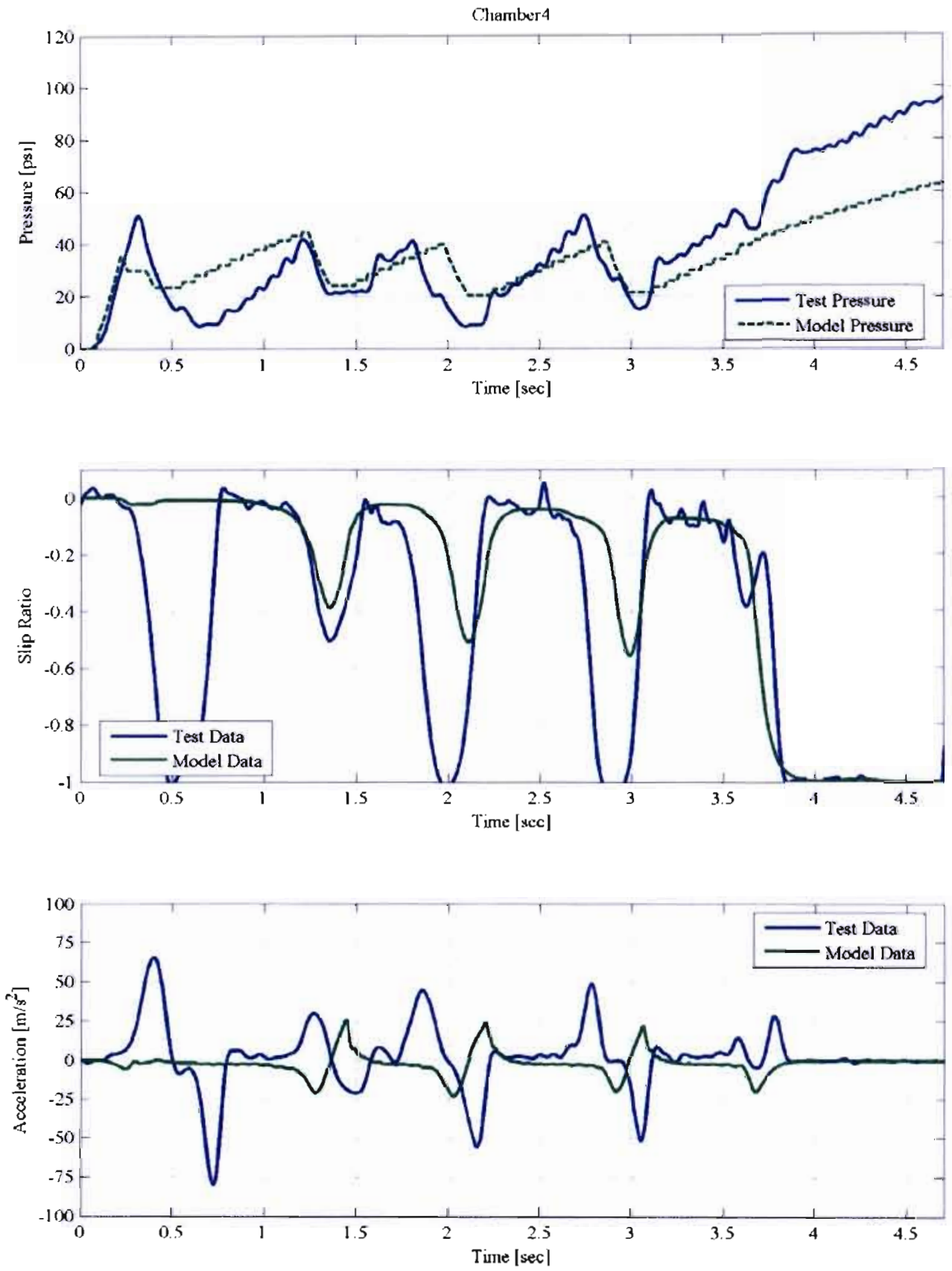

Figure 2.51 - Lead Control Low Friction Stops at GVWR - Chamber 4 Dynamics 


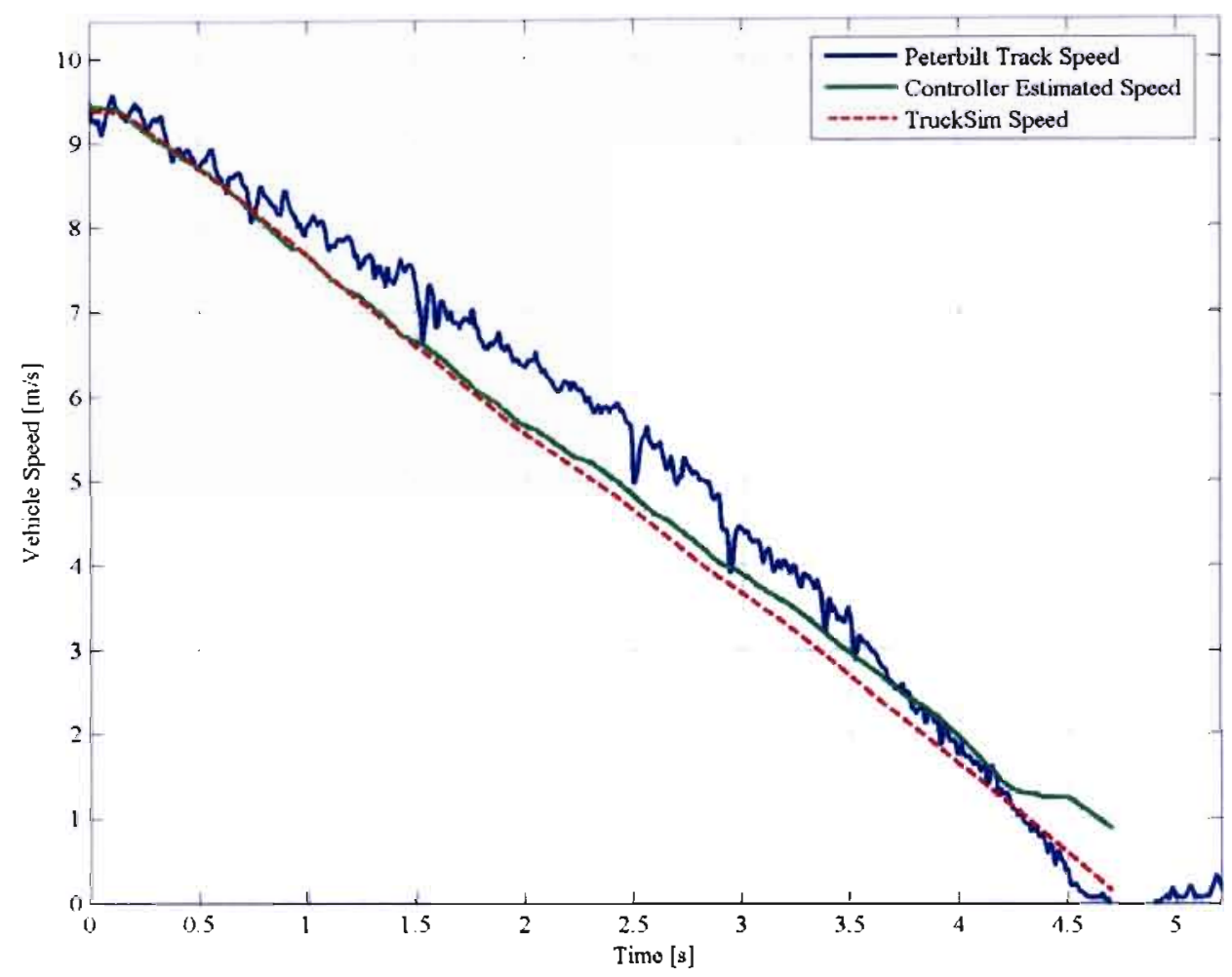

Figure 2.52 - Lead Control Low Friction Stops at GVWR - Speed Profiles

\begin{tabular}{|c|c|}
\hline Simulated Stopping Distance $[\mathrm{ft}]$ & 76.0 \\
\hline Lower Bound $(95 \% \mathrm{CI})[\mathrm{ft}]$ & 73.9 \\
\hline Upper Bound $(95 \% \mathrm{CI})[\mathrm{ft}]$ & 80.5 \\
\hline
\end{tabular}

Table 2.16 - Stopping Distances for Lead Control Low Friction Stops at GVWR

\subsubsection{4s4m Lead Control Low Friction Stops at LLVW}

Just like the BIC stops at GVWR, those at LLVW were also accurately simulated. It can be seen in Figure 2.53 and Figure 2.54 that the wheel dynamics follow the same 
general trend. Also, Figure 2.55 shows that the speed profiles of the simulated and experimental stops are of the same nature, and Table 2.17 shows that the simulated stopping distance is at the lower limit of the experimental confidence interval. It should be noted that the confidence interval of the experimental stops at this condition was very tight ( $2 \mathrm{ft}$ ), so a stopping distance at the lower limit is considered quite acceptable. 

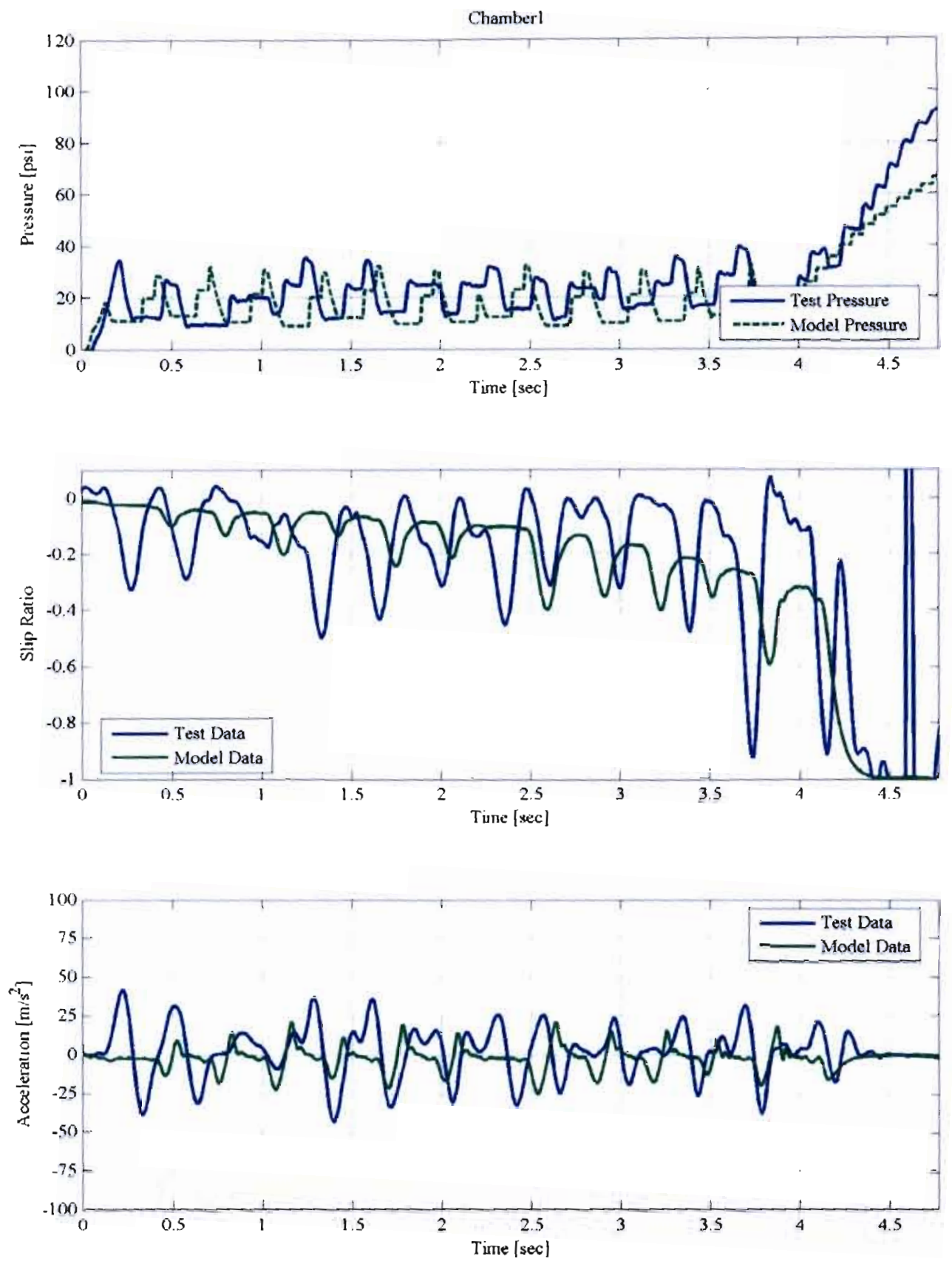

Figure 2.53 - Lead Control Low Friction Stops at LLVW - Chamber 1 Dynamics 

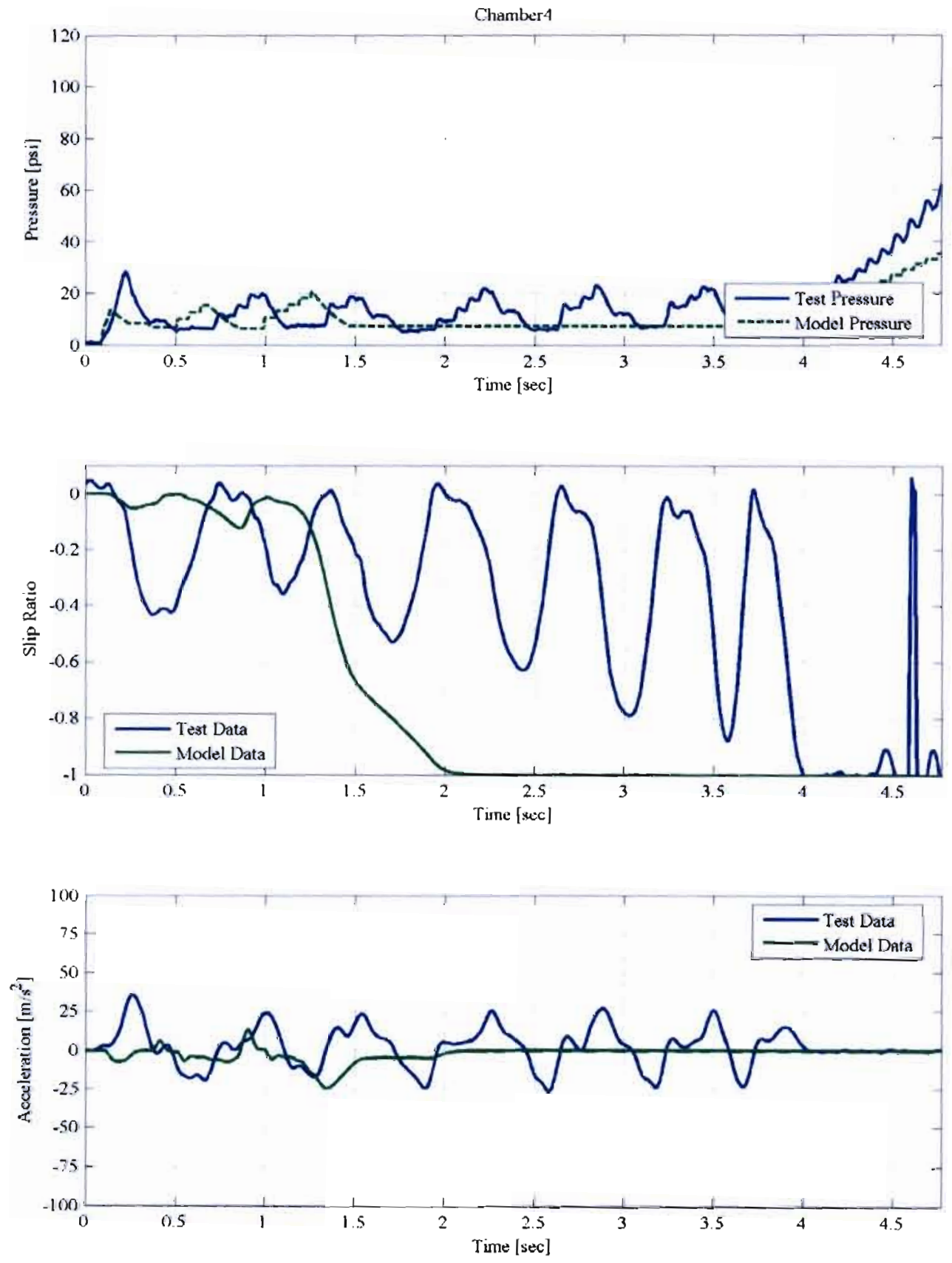

Figure 2.54 - Lead Control Low Friction Stops at LLVW - Chamber 4 Dynamics 


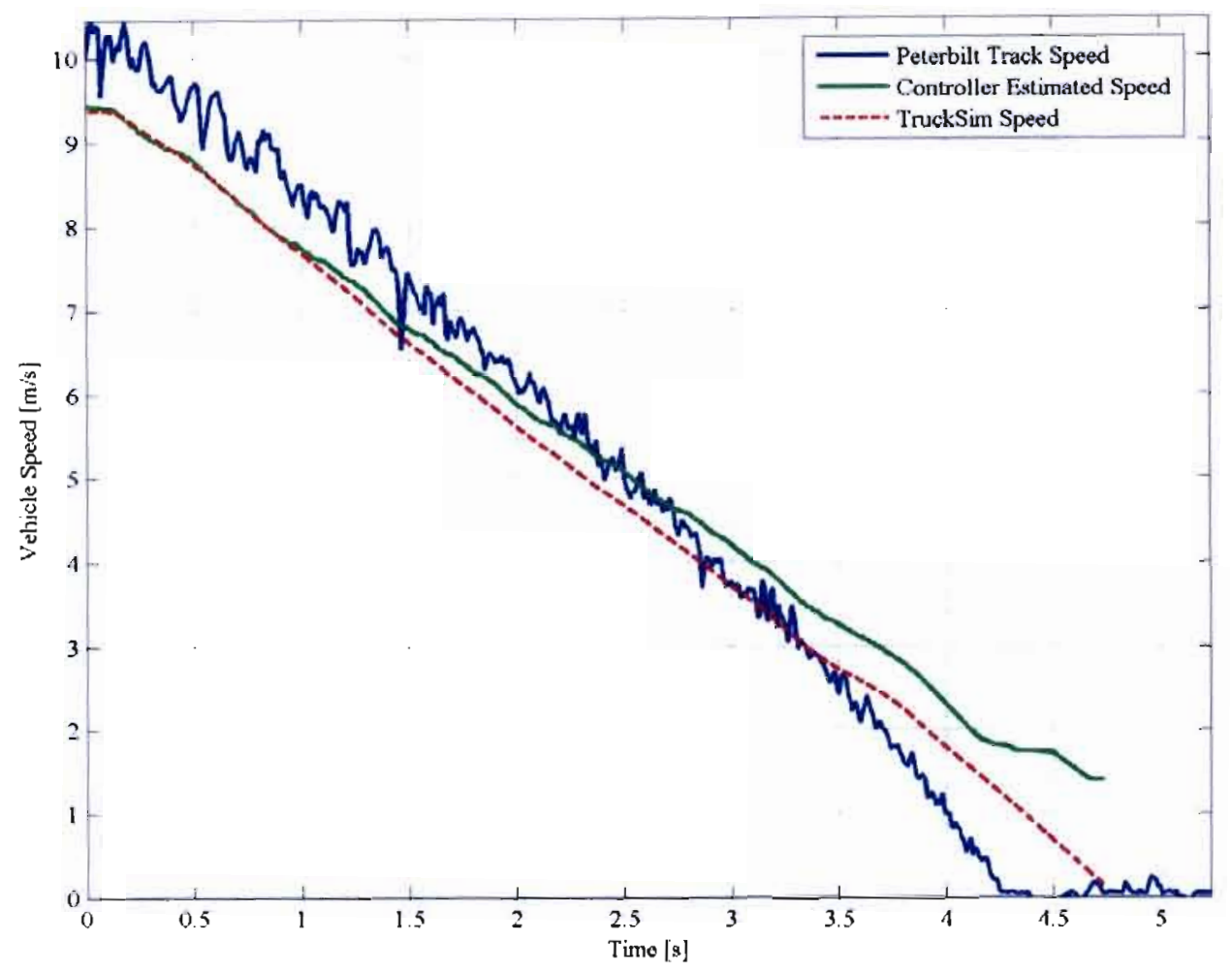

Figure 2.55 - Lead Control Low Friction Stops at LLVW - Speed Profiles

\begin{tabular}{|c|c|}
\hline Simulated Stopping Distance [ft] & 84.2 \\
\hline Lower Bound $(95 \% \mathrm{CI})[\mathrm{ft}]$ & 84.2 \\
\hline Upper Bound $(95 \% \mathrm{CI})[\mathrm{ft}]$ & 86.2 \\
\hline
\end{tabular}

Table 2.17 - Stopping Distances for Lead Control Low Friction Stops at LLVW

\subsubsection{4s4m Trail Control ABS Model Results}

Because the brake chamber dynamics and the speed profile plots for the $4 \mathrm{~s} 4 \mathrm{~m}$ systems with trailing axle control were found to be very similar to those for leading axle 
control, they will not be included in this thesis. However, the following tables of simulated and experimental stopping distances show that the model was capable of accurately modeling the braking behavior of the Peterbilt, equipped with a 4s $4 \mathrm{~m}$ ABS system utilizing trailing axle control, with the exception of the high friction stop at GVWR.

\begin{tabular}{|c|c|}
\hline Simulated Stopping Distance $[\mathrm{ft}]$ & 226.0 \\
\hline Lower Bound $(95 \% \mathrm{CI})[\mathrm{ft}]$ & 319.0 \\
\hline Upper Bound $(95 \% \mathrm{CI})[\mathrm{ft}]$ & 329.6 \\
\hline
\end{tabular}

Table 2.18 - Stopping Distances for Trailing Axle Control High Friction Stops at GVWR

\begin{tabular}{|c|c|}
\hline Simulated Stopping Distance $[\mathrm{ft}]$ & 190.8 \\
\hline Lower Bound $(95 \% \mathrm{CI})[\mathrm{ft}]$ & 175.6 \\
\hline Upper Bound $(95 \% \mathrm{CI})[\mathrm{ft}]$ & 181.9 \\
\hline
\end{tabular}

Table 2.19 - Stopping Distances for Trailing Axle Control High Friction Stops at LLVW

\begin{tabular}{|c|c|}
\hline Simulated Stopping Distance [ft] & 78.8 \\
\hline Lower Bound $(95 \% \mathrm{CI})[\mathrm{ft}]$ & 80.8 \\
\hline Upper Bound $(95 \% \mathrm{CI})[\mathrm{ft}]$ & 88.4 \\
\hline
\end{tabular}

Table 2.20 - Stopping Distances for Trailing Axle Control Low Friction Stops at GVWR 


\begin{tabular}{|c|c|}
\hline Simulated Stopping Distance [ft] & 87.5 \\
\hline Lower Bound $(95 \% \mathrm{CI})[\mathrm{ft}]$ & 90.2 \\
\hline Upper Bound $(95 \% \mathrm{CI})[\mathrm{ft}]$ & 93.9 \\
\hline
\end{tabular}

Table 2.21 - Stopping Distances for Trailing Control Low Friction Stops at LLVW 


\section{CHAPTER 3}

\section{TRACTOR-TRAILER MODEL}

\subsection{Overview}

One of the key areas of interest in heavy truck vehicle dynamics research is the stability of tractor-trailers under extreme braking maneuvers. An extensive catalog of research is being conducted at NHTSA in order to improve the safety of these commercial vehicles and also to refine the set of regulations (FMVSS No. 121) that govern their operation. One such concern is that of anti-lock braking systems (ABS) for semitrailers. Since 1997, ABS control for tractors and semitrailers has been required, by law, in the U.S. [2]; however, performance standards do not yet exist to dictate how effective semitrailer ABS systems must be. Therefore, the research conducted hereafter will be instrumental in updating the FMVSS 121 standards as it will give NHTSA engineers a tool with which to examine different ABS configurations for tractor-trailer vehicle combinations.

Although ABS systems are required for commercial vehicles, some systems in the current U.S. fleet fail to display the level of refinement found in passenger vehicles or 
even that of the Peterbilt straight truck simulated in Chapter 2. This will become more evident in Section 3.4, where the responses of an ABS equipped semitrailer will be used to verify models. An example of this can be seen in Figure 3.1, which shows the brake chamber pressure and vehicle wheel speeds taken from an actual trailer ABS system, during a low friction stop (BIC maneuver on wet Jennite) at the combination vehicle GVWR. In general, these systems allow a significant amount of wheel lock-up, yet because the semitrailer has very large yaw inertia, they adequately remain in the lane during an FMVSS No. 121 brake-in-curve maneuver. Researchers question whether semitrailer ABS systems can be or should be improved such that stopping distances can be reduced and/or greater stability in brake-in-curve maneuvers can be obtained, ultimately leading to safer commercial vehicles. 

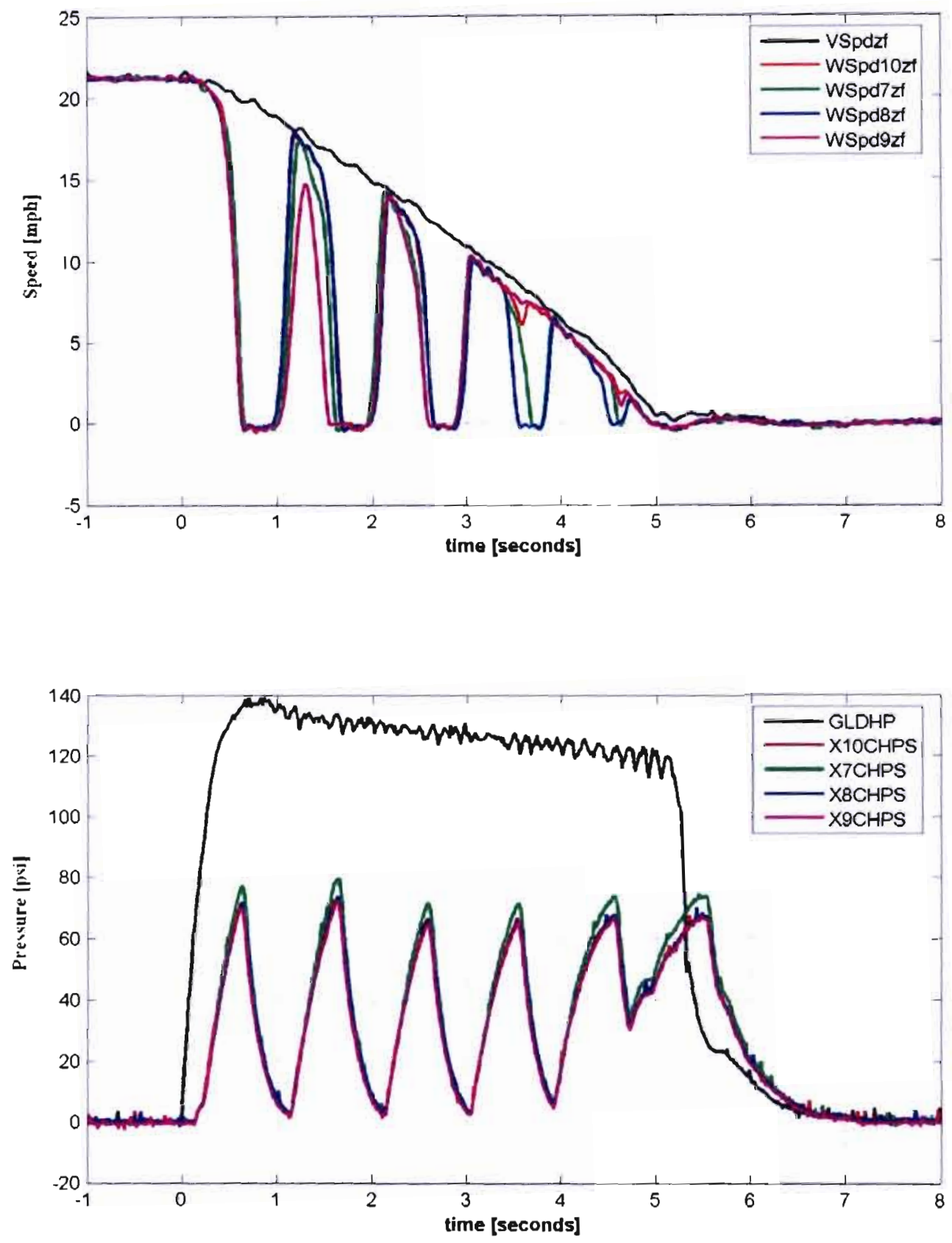

Figure 3.1 - Example Response of Trailer ABS 
In order to study semitrailer ABS effectiveness, a tractor-trailer model of a 48 foot, two axle van trailer connected to NHTSA's Sterling $4 \times 2$ tractor was created. This combination of the Class VIII Sterling and the 48 foot trailer was created in a similar way to the Peterbilt model of Chapter 2. TruckSim was again used as the vehicle dynamics software, in which models of the tractor and trailer were created. ABS controller models were then created in Simulink for the tractor and the trailer, based off of the ABS controller of Zaugg, which were modified in the previously described research.

\subsection{TruckSim Model}

As it was for the simulation of the Peterbilt truck, TruckSim was used as the vehicle dynamics software for the tractor-trailer model. Models of the Sterling tractor and the trailer were created in this environment in order to achieve a full vehicle simulation. TruckSim also provided an animator, which allows each simulation to be observed.

\subsubsection{Sterling Tractor Model}

Zagorski originally created the TruckSim model of the Sterling 2-axle tractor for his study of jackknife stability of Class VIII vehicles with multiple trailers. This model was created by entering masses, coordinates, compliances, and inertias of the elements of the Sterling into the TruckSim user interface, details of which can be found in [5]. The Sterling tractor was chosen for the desired tractor-trailer simulation because its TruckSim model has been verified in the research of Zagorski and because a library of experimental 
test data on the Sterling has been gathered at VRTC. Also, the Sterling is representative of many $4 \times 2$ tractors often seen on America's roadways.

As discussed previously, TruckSim receives friction levels at each wheel and brake torques for each of its pneumatically actuated, S-cam brakes from Simulink. This allows for accurate modeling of the braking behavior of the Sterling by the inclusion of in-depth brake torque models and a simulated ABS controller. More details of the brake torque and ABS controller systems will be given in Section 3.3.

\subsubsection{Trailer Model}

In order to complete the desired tractor-trailer model, a TruckSim model of a 48 foot 2-axle van trailer was used. The model used was one that comes standard with the TruckSim software, which was created by measurement assistance of a NHTSA semitrailer. This trailer model was modified, however, to also receive its surface friction levels and brake system dynamics from Simulink, in the same fashion as the tractor model previously described. For this simulation, the trailer was also equipped with pneumatically controlled S-cam brakes (typical for most trailers) along with an ABS system. The controller for this system was also modeled in the Simulink environment and will be described in Section 3.3.

In order to create various axle weight combinations in the tractor-trailer vehicle, payload weights were added to the trailer model. When loading experimental vehicles for testing, it is common to place ballast weights near the front and rear of the trailer; therefore, one such ballast weight was created and placed nominally above the kingpin of 
the tractor and another was centered above the middle of the two trailer axles. This method of payload placement is often used in experimental testing because it offers a great deal of flexibility, as the mass and location of these weights could then be manipulated in order to create any desired load combination for the vehicle. For this same reason, such a loading scheme was used for the simulated trailer.

\subsubsection{Total Vehicle Model}

The previously described tractor and trailer models were used to create a total vehicle TruckSim vehicle dynamics model, a view of which can be seen in Figure 3.2. This total vehicle TruckSim model was represented mathematically by 121 ordinary differential equations that described the motion of 26 bodies. The software utilized a total of 25 multi-body degrees of freedom in an effort to accurately simulate the dynamic and kinematical behavior of the tractor-trailer combination. 


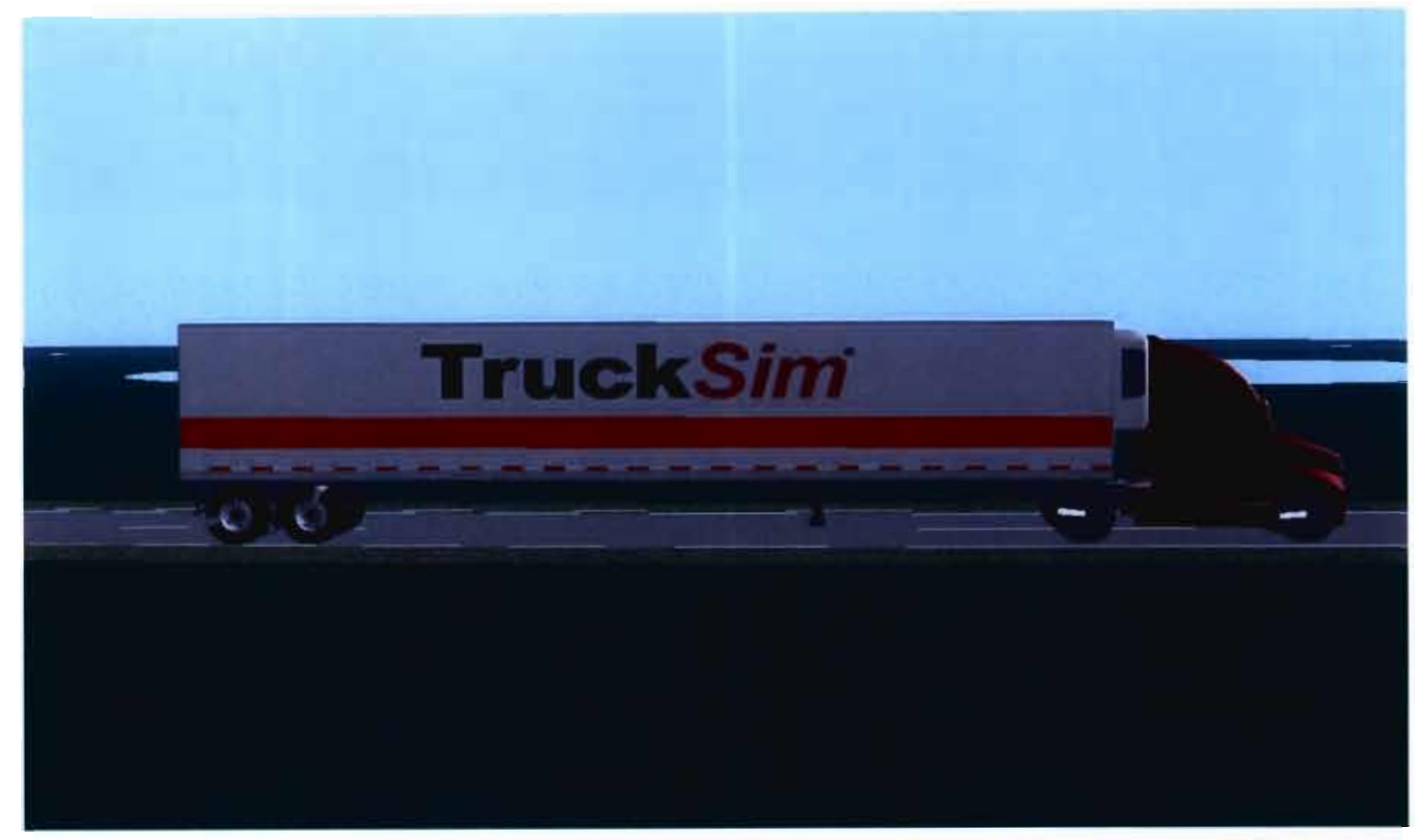

Figure 3.2 - Total Vehicle View

In order to study the effects of vehicle weight on semitrailer ABS performance, two different total vehicle TruckSim models were created. The masses and locations of the trailer payload weights, previously described in Section 3.2.2, were varied in order to create a condition in which the trailer axles received $25 \%$ of their gross axle weight rating (GAWR) and another corresponding to $75 \%$ GAWR. For consistency, the axle weights for the tractor were kept constant at $75 \%$ of their individual axle weight ratings for both trailer load conditions. The payload parameters utilized in order to create these loading conditions are given in Table 3.1. For both cases, the front payload was centered directly over the kingpin of the tractor-trailer combination and the rear payload was located directly above the two trailer axles. 


\begin{tabular}{|c|c|c|}
\hline Trailer Gross Axle Weight Rating Condition & $\mathbf{2 5 \%}$ & $\mathbf{7 5 \%}$ \\
\hline Distance from Kingpin, Front Payload [m] & 0 & 0 \\
\hline Mass of Front Payload [kg] & 2400 & 2200 \\
\hline Distance from Kingpin, Rear Payload [m] & 13.8 & 13.8 \\
\hline Mass of Rear Payload [kg] & 0 & 8400 \\
\hline
\end{tabular}

Table 3.1 - Trailer Payload Masses and Distances from Kingpin

\subsection{Simulink Model}

\subsubsection{Model Environment}

Simulink provided the simulation environment for the tractor-trailer model brake and ABS systems, as it did for the Peterbilt. Within one Simulink environment the TruckSim model was run in parallel with the other models to make up the total vehicle modeling system, such as the Randomly Varied Friction Generator, brake torques and pneumatics models for each axle, and ABS controllers for both the tractor and trailer. The base layer of the Simulink model environment can be seen (in two halves) in Figure 3.3 and Figure 3.4 on the following pages. The top half of the Simulink base layer consists of the inputs to and outputs from the TruckSim s-function module. To the left of the TruckSim module, one can see that the brake torques for the vehicle (tractor and trailer) along with the friction levels for each wheel are the inputs to TruckSim. The brake torques are calculated in the brake torque and pneumatics systems of Figure 3.4, in the same way that they were calculated and utilized for the Peterbilt model. The friction generator is identical to the one used for the Peterbilt (see Section 1.3) with one exception; the friction generator had to be updated to include all four axles and all eight 
wheel positions of the tractor-trailer combination. To the right of the s-function module lie the TruckSim outputs. Included in this set of outputs are the longitudinal wheels speeds of the vehicle (used as the inputs to the ABS controllers), the total vehicle speeds and accelerations, the treadle reference pressure (used to model the primary and secondary treadles), and other dynamic properties for use in post-processing. 


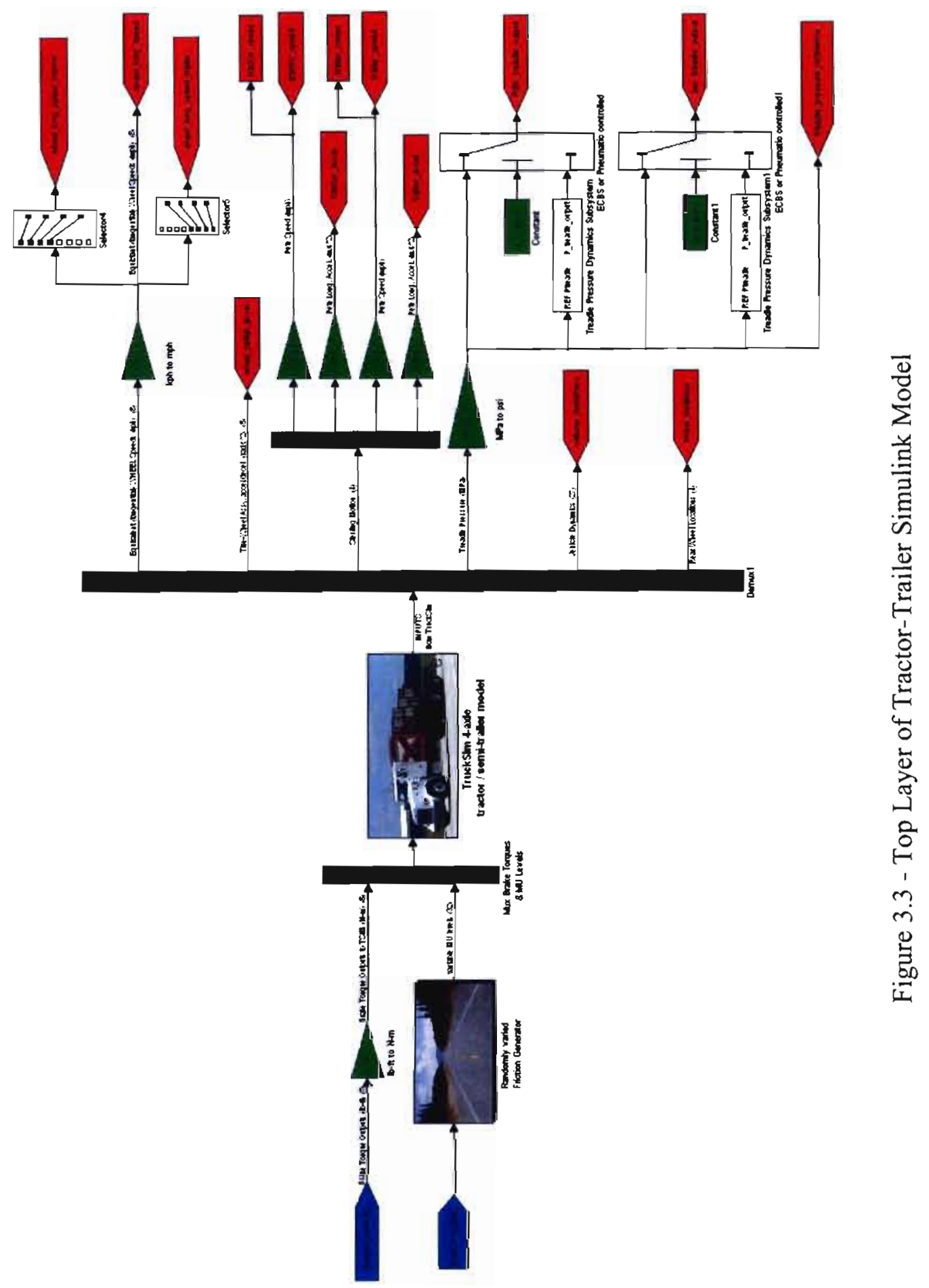




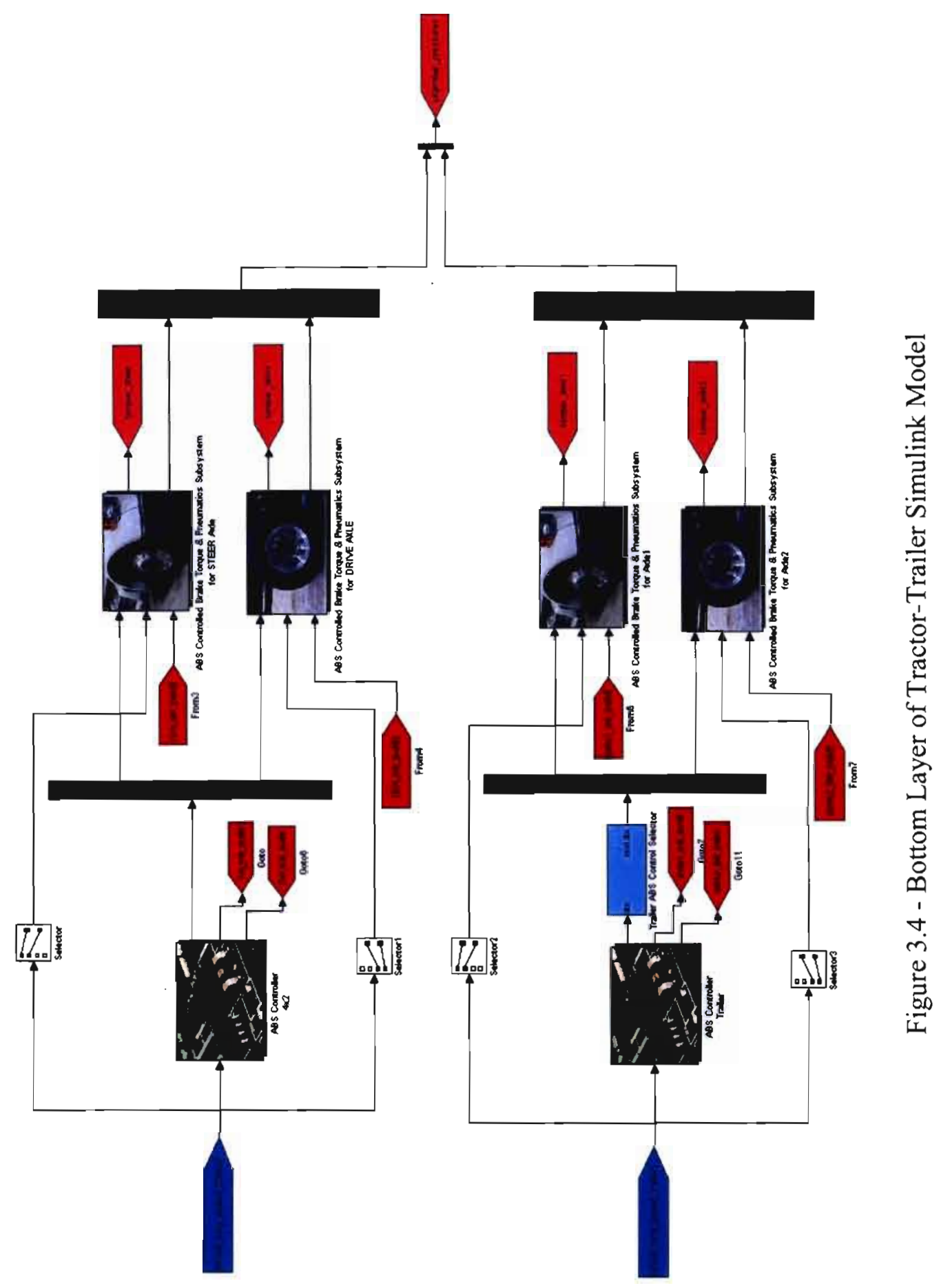


The bottom half of the model base layer (Figure 3.4) consists of the brake behavior modeling of the tractor and trailer. A brake torque and pneumatics subsystem is included in the model for each axle of the vehicle, the parameters of which (such as time constants, delays, and torque characteristics) were determined by Zagorski in [5]. These brake models are identical to the ones used for the Peterbilt model of Chapter 2, with the exception of these parameters. Also included are separate ABS controller models for the tractor (see Section 3.3.2) and trailer (Section 3.3.3). An ABS control selector is also present in the model to enable the simulation of various trailer ABS configurations (Section 3.3.4).

\subsubsection{Tractor ABS Controller Model}

The ABS controller model, developed for the Peterbilt and utilized in Chapter 2 of this thesis, was adapted for use with the $4 \times 2$ Sterling tractor. In essence, the $6 \mathrm{~s} 6 \mathrm{~m}$ model of the Peterbilt was manipulated to be a $4 \mathrm{~s} 4 \mathrm{~m}$ controller for the Sterling. This was accomplished by altering the model to accept four inputs and respond with four outputs. Once the ABS controller model of acceptable form was created, the parameters of the Peterbilt system were adjusted to match those of the Sterling. The slip ratio and acceleration thresholds of the new ABS controller, along with the build, dump, and hold durations, were tuned to create a braking response that was characteristic of the actual ABS system of the Sterling tractor. This braking behavior was validated through comparison to experimental data, which can be seen in the following Section 3.4.1. 


\subsubsection{Trailer ABS Controller Model}

The previously described $4 \mathrm{~s} 4 \mathrm{~m}$ ABS controller model was used for the trailer, as well. However, because the behaviors of the tractor and trailer ABS systems were quite different, a new set of controller thresholds and durations was obtained. This was again accomplished by comparing the results of the model to experimentally obtained results from a similarly equipped van trailer (see Section 3.4.2).

When examining the response of the trailer ABS system, a particular behavior was noticed that was absent from either of the Peterbilt or the Sterling ABS systems. A significant difference during building pressure regimes for low friction and high friction experimental stops was exhibited, and Figure 3.5 shows this behavior by displaying a high friction stop from $60 \mathrm{mph}$ and a low friction stop from $30 \mathrm{mph}$. When examining the high friction stop one can notice that significant holding periods $(200-300 \mathrm{~ms})$ exist over most of the building pressure regions. This behavior is not exhibited, however, for the majority of the building regions of the low friction stop. If this building behavior was found exclusively in the high friction stop, then different holding durations could be used in the controller for the different friction levels. This behavior was not exclusive; therefore further examination was necessary. 

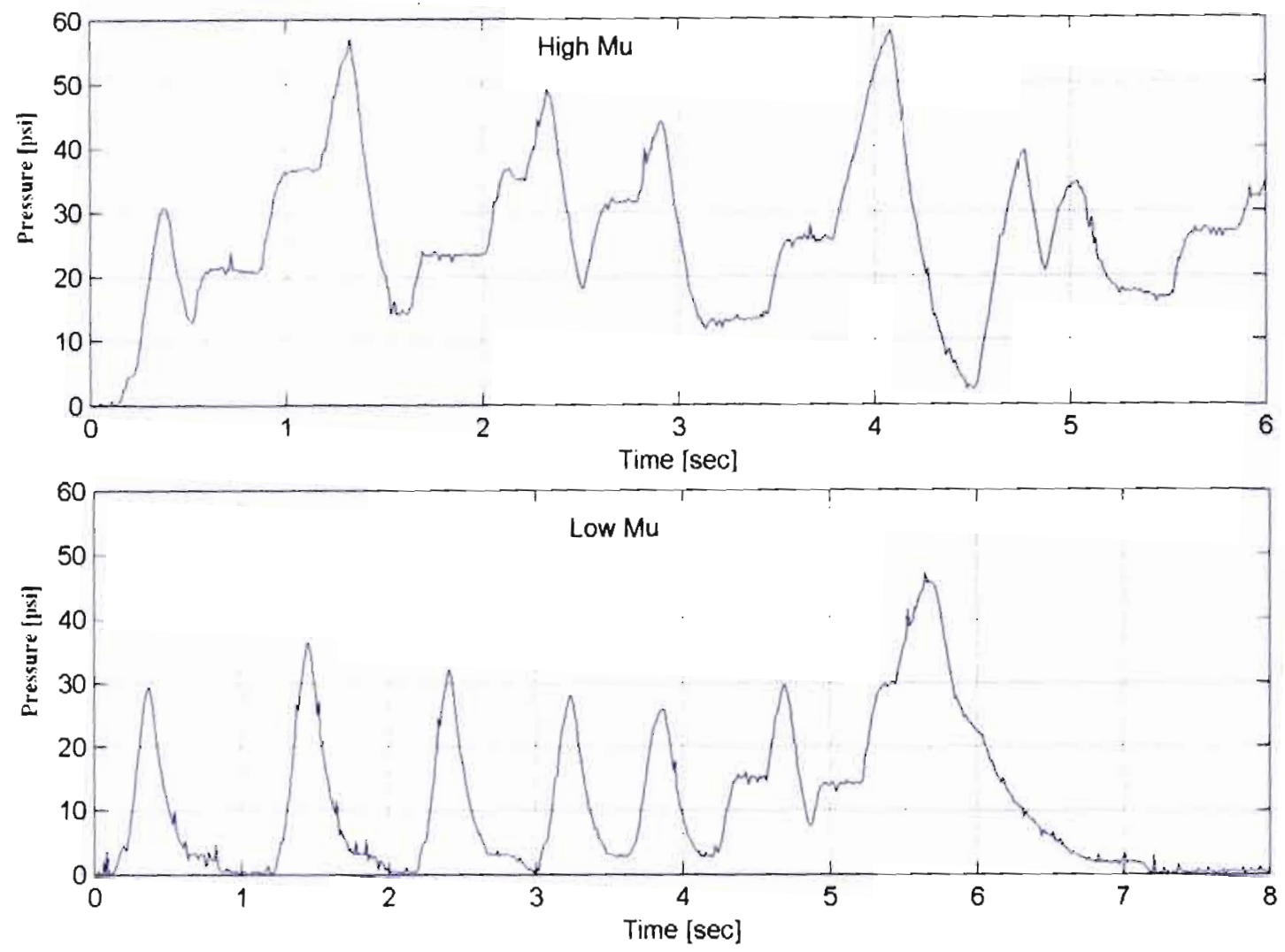

Figure 3.5 - Low and High Friction Stops for Experimental Trailer

Upon further examination of these stops, a noticeable difference in the slip ratio traces between the two became evident. One can see from Figure 3.6 that the slip ratios for the high friction stop remained relatively low $(10-30 \%)$ up until about 4 seconds. Between 4 and 5 seconds on that same plot, very high levels of slip were seen. When examining those regions on the high friction pressure plot of Figure 3.5, one can see that the long hold duration building behavior was exhibited up to around 4 seconds. Also, the minimal hold duration building sequence can be seen between 4 and 5 seconds. When examining the slip ratio trace of the low friction stop, one can see that very high slip 
ratios were exhibited from 0 to about 4 seconds and relatively low values (10 to 30\%) are seen from around 4 to 4.5 seconds. Therefore, it was hypothesized that the ABS controller would not allow significant holding periods for chamber pressure builds initiating during periods of high wheel slip. If the logic previously described holds, then the minimal hold building sequence should be seen in the low friction plot of Figure 3.5 up until around 4 seconds and the other building behavior should be seen thereafter. It is evident from the plots that this behavior was in fact exhibited.
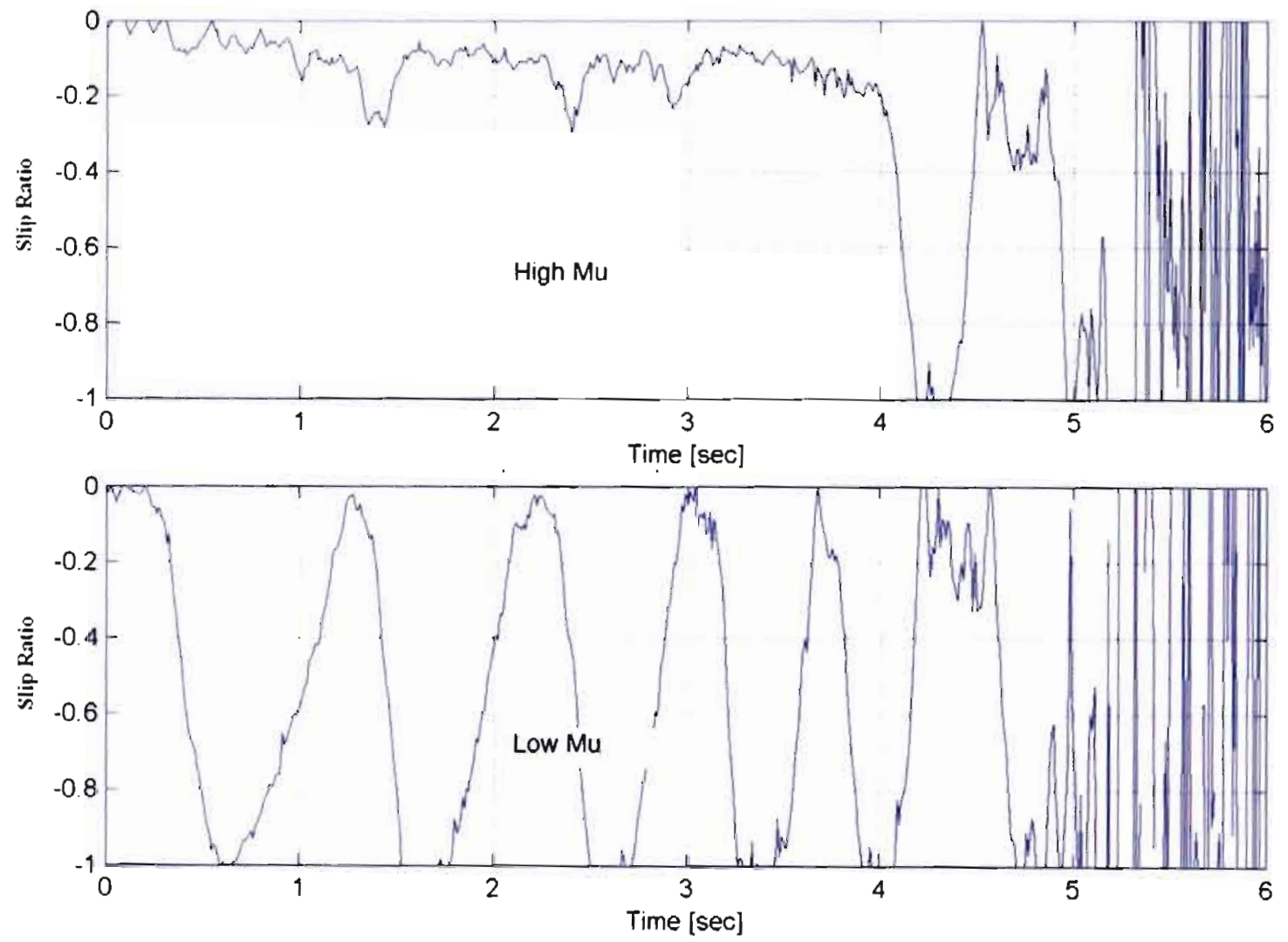

Figure 3.6 - Experimental Slip Ratios for High and Low Friction Stops 
Using this information, the trailer ABS model was updated to include the variable build durations. Figure 3.7 shows the Slip Ratio Dump System of the trailer's ABS controller model. This system accepts the slip ratios of each wheel of the trailer and outputs a command to dump pressure when those slip ratio levels deem it necessary. When a slip ratio dump is initiated, the value for trailer_SR_dump_on, seen in Figure 3.7, becomes equal to 1 . Therefore, this value could be used in the model as a flag between the two different building behaviors. More information on this subsystem can be seen in Section 4.4.4.2 of [7].

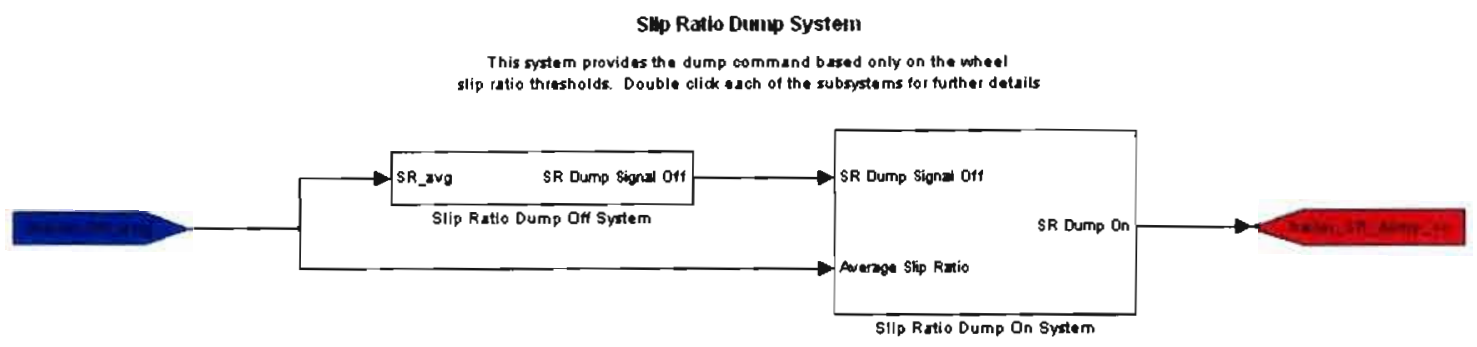

Figure 3.7 - Slip Ratio Dump System of Trailer ABS Model

Also in the model is a section in the building module for each axle that dictates the exhibited stair-step building behavior (see Section 4.5 .1 of [7]). In this subsystem, the holding duration for this building sequence is determined at each instant of time, based on the current friction level, in the Mu Threshold Selector. A close-up of the hold timing section of the Lead Axle Stair-Step Building system can be seen in Figure 3.8. In the Peterbilt and Sterling ABS models, the only input to this selector module was the friction level of the vehicle; however, for the trailer ABS model, an additional input was 
included. The previously described controller parameter, which signifies the presence of a dump command initiated by the passing of a slip ratio threshold, is used as a trigger for the selector module. If a slip ratio dump has been initiated in either of the two lead axle wheels, then a value of ' 1 ' is passed to the selector module, which can be seen in Figure 3.9. In this module, the appropriate holding duration is selected for the corresponding friction and slip ratio levels. An identical system was created for the trailing axle, with the obvious exception of the selection of the monitored wheels.

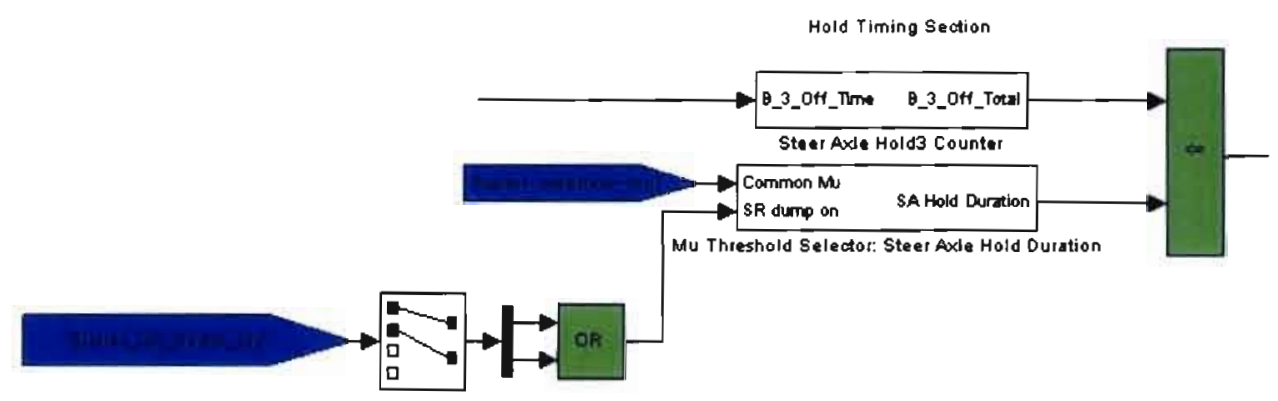

Figure 3.8 - Hold Timing Section of Lead Axle Stair-Step Build System 


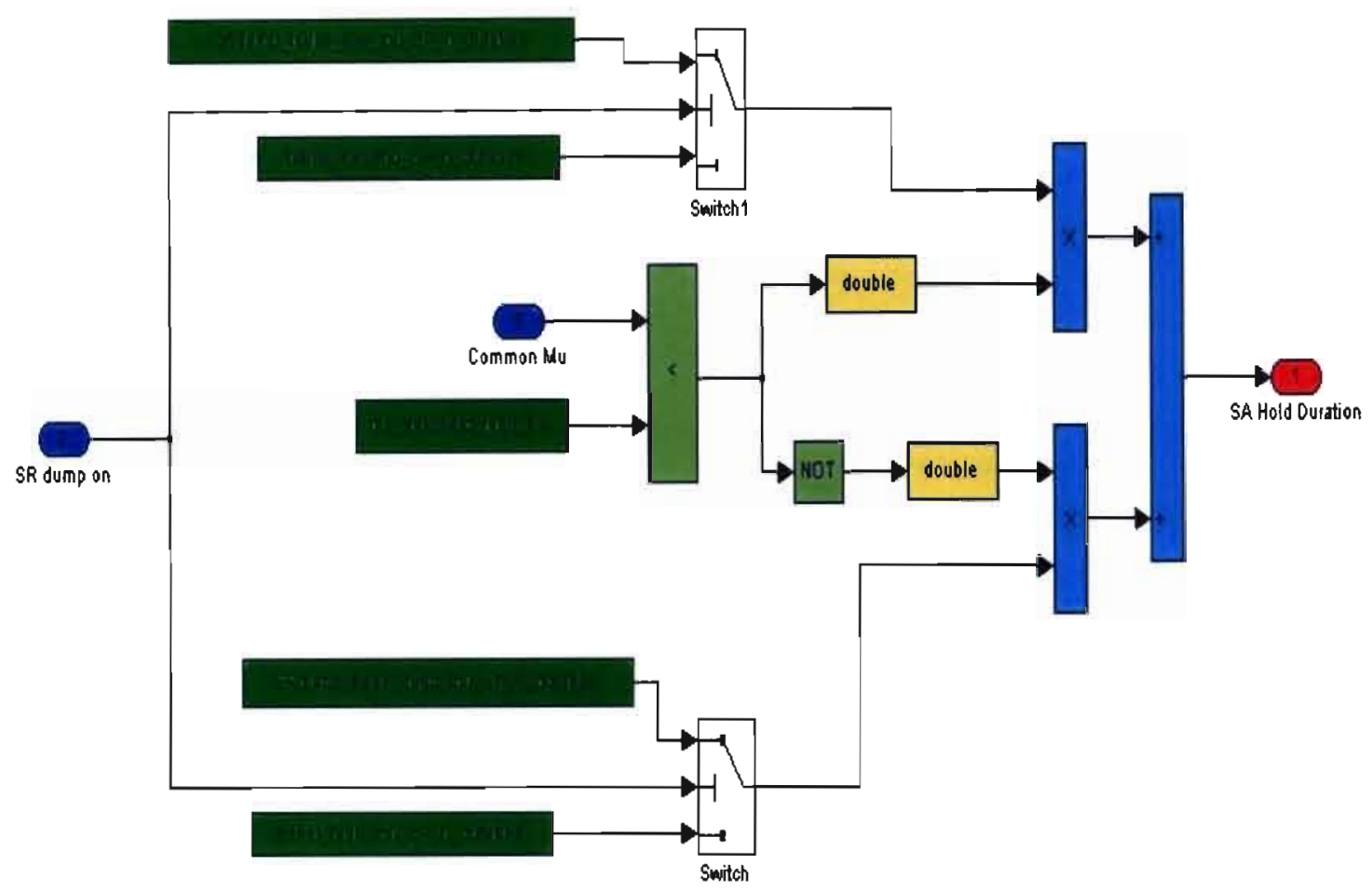

Figure 3.9 - Lead Axle Hold Duration Selector

\subsubsection{Trailer ABS Control Selector}

Because the speed of each of the four trailer wheels was monitored and the brake chamber of each wheel could be independently modulated, the previously described ABS system for the trailer resulted in a $4 \mathrm{~s} 4 \mathrm{~m}$ configuration; however, it was desired to study other configurations. In order to do this, the Trailer ABS Control Selector module was created, which was very similar to the selector created for the Peterbilt model. At each instance of time, the module accepted the ABS commands for the four individual wheels of the trailer and output the appropriate sequence of commands, depending on the desired configuration. For this study, $4 \mathrm{~s} 2 \mathrm{~m}$ and $2 \mathrm{~s} 1 \mathrm{~m}$ ABS configurations were studied in 
addition to $4 \mathrm{~s} 4 \mathrm{~m}$. The Control Selector made it possible to simulate the desired configuration based on a series of inputs (by the user) to Simulink.

The base layer for the Control Selector module can be seen in Figure 3.10. The key element in the module is a switch that passes the appropriate control scheme to the brake models depending on the value of the input, abs_config, which is determined in Matlab based on a set of user inputs. If a value of ' 1 ' is input to the selector, then a $4 \mathrm{~s} 4 \mathrm{~m}$ configuration is simulated by passing the inputs from the ABS controller model directly through to the brake models. In the same way, a value of ' 2 ' corresponds to $4 \mathrm{~s} 2 \mathrm{~m}$ control and a value of ' 3 ' to $2 \mathrm{~s} 1 \mathrm{~m}$ control.

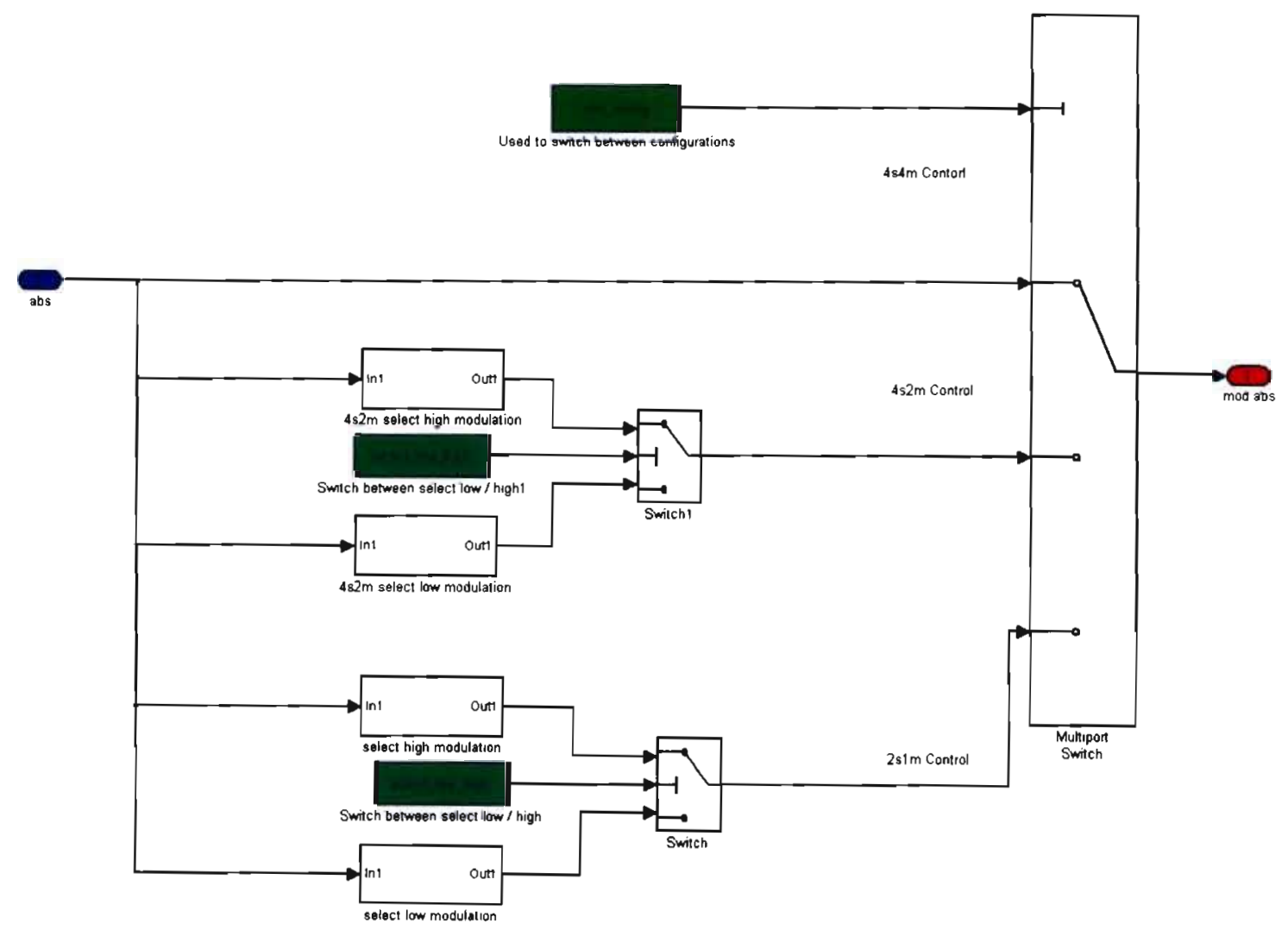

Figure 3.10 - Base Layer of Trailer ABS Control Selector 
A $4 \mathrm{~s} 2 \mathrm{~m}$ ABS configuration implies that the speeds of all four of the trailer wheels are being monitored and that two independent modulators exist. For this configuration each side of the trailer has its own modulator, meaning that the left-front and left-rear wheels are modulated together and the right-front and right-rear are modulated together. Because a decision on the collective modulation of 2 wheels needed to be made based on the speeds of those two wheels, select-low and select-high logic schemes were implemented in the controller. The logic schemes used for the tractor-trailer model are the same as those used for the Peterbilt (see Section 2.2).

When the simulation of a $4 \mathrm{~s} 2 \mathrm{~m}$ ABS system is desired, the control selector passes the appropriate select-low or select-high logic output to the brake models depending on the value of the input, select_low_high. This constant has either a value of ' 0 ' or ' 1 ', corresponding to the desired simulation of a select-low or select-high system, respectively. The 4s $2 \mathrm{~m}$ Select-High Module can be seen in Figure 3.11. In this module, the ABS controls for the wheels are de-multiplexed so that the individual commands for the left side (wheels 1 and 3 ) and the right side (wheels 2 and 4) can be modulated together. The select-high logic used in the modules of this figure is identical to that used for the Peterbilt $4 \mathrm{~s} 3 \mathrm{~m}$ system, which can be again in Figure 2.8. Figure 3.12 shows the select-low module for the $4 \mathrm{~s} 2 \mathrm{~m}$ system, which is identical to the select-high system, with the exception that select-low logic is used. The select-low logic that was implemented in this module is the same as that which was used for the Peterbilt $4 \mathrm{~s} 3 \mathrm{~m}$ system, and can be viewed in Figure 2.10. 


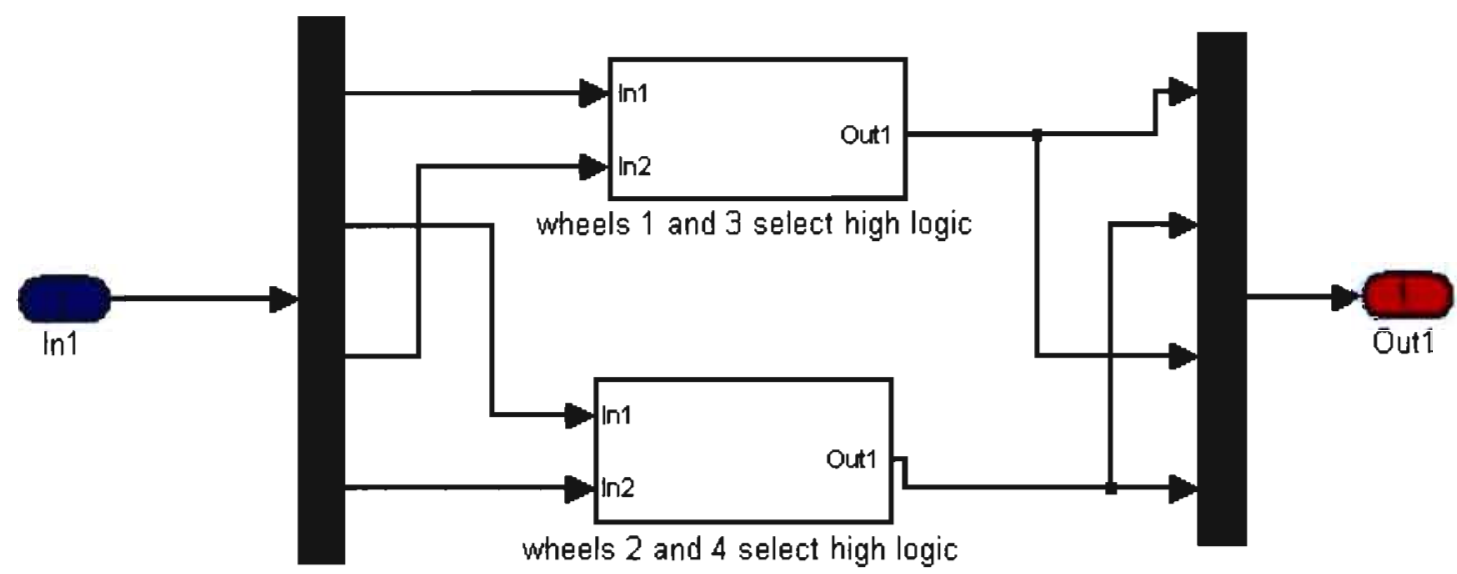

Figure $3.11-4 \mathrm{~s} 2 \mathrm{~m}$ Select-High Module

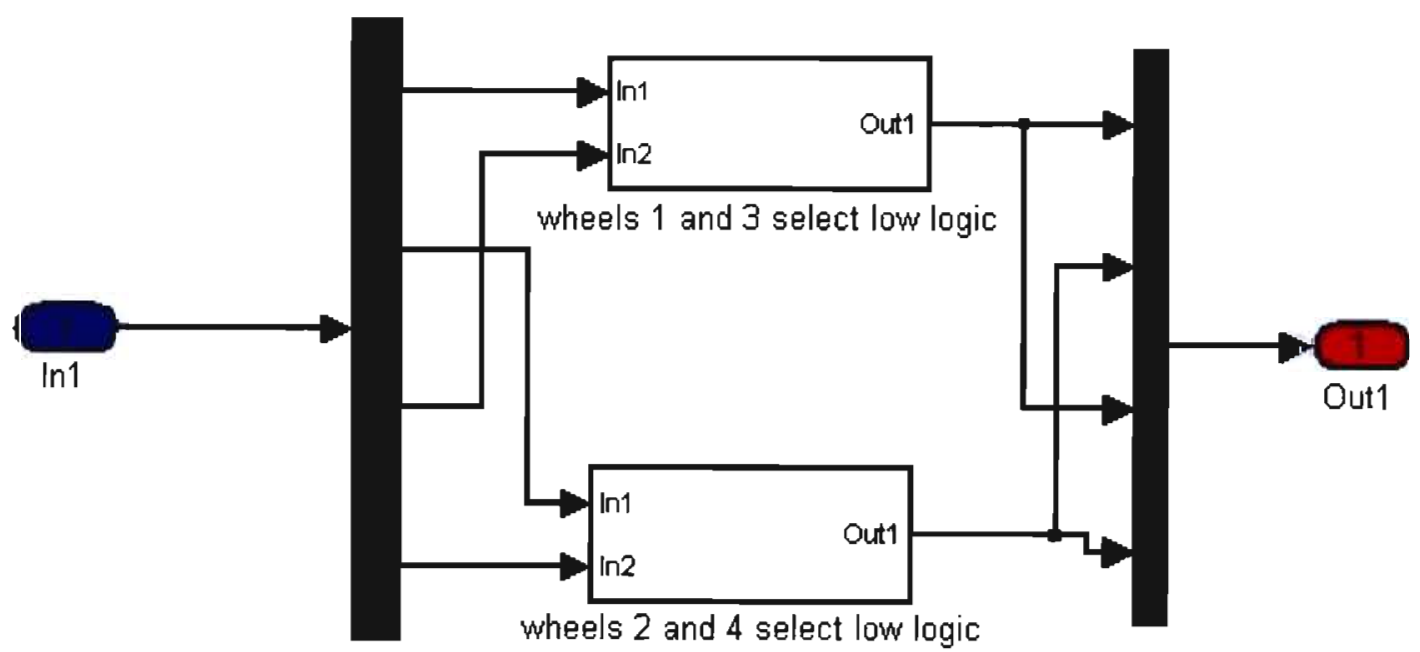

Figure 3.12 - 4s2m Select-Low Module 
$2 \mathrm{~s} 1 \mathrm{~m}$ control is implemented in a similar fashion to that of the $4 \mathrm{~s} 2 \mathrm{~m}$ configuration. Because the speeds of two wheels are monitored in order to control a single modulator, the same select-low or select-high logic needs to be installed into the model, which can be seen in Figure 3.10. The $2 \mathrm{~s} 1 \mathrm{~m}$ select-low and the $2 \mathrm{~s} 1 \mathrm{~m}$ select-high modules are slightly different from those corresponding to $4 \mathrm{~s} 2 \mathrm{~m}$ control because they are fundamentally different as far as which wheels are monitored. For a $2 \mathrm{~s} 1 \mathrm{~m}$ system (on a 2-axle trailer) one of the axles is chosen to be the control axle. The wheel speeds of that particular axle are then monitored in order to control all four brakes. Figure 3.13 shows how a Matlab input variable, control_axle, is used to switch between a select-high logic scheme using the leading trailer axle as the control and a select-high logic scheme using the trailing axle as the control. The same method is used for the select-low module seen in Figure 3.14. These figures show that if the lead axle is to the control, then the commands of two lead axle wheels (wheels 1 and 2) are sent into the appropriate logic scheme, with the opposite being true for trailing axle control. 


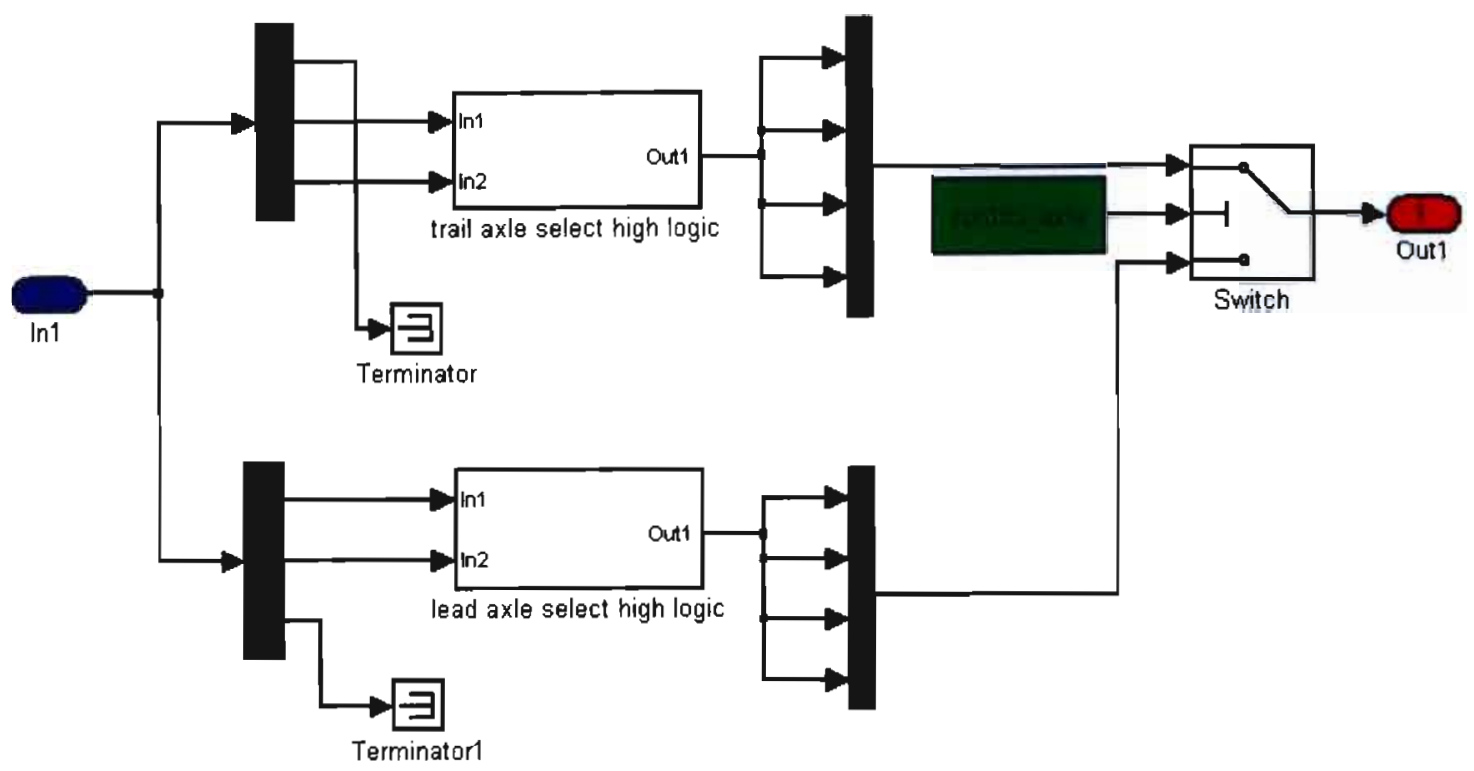

Figure 3.13 - 2s $1 \mathrm{~m}$ Select-High Module

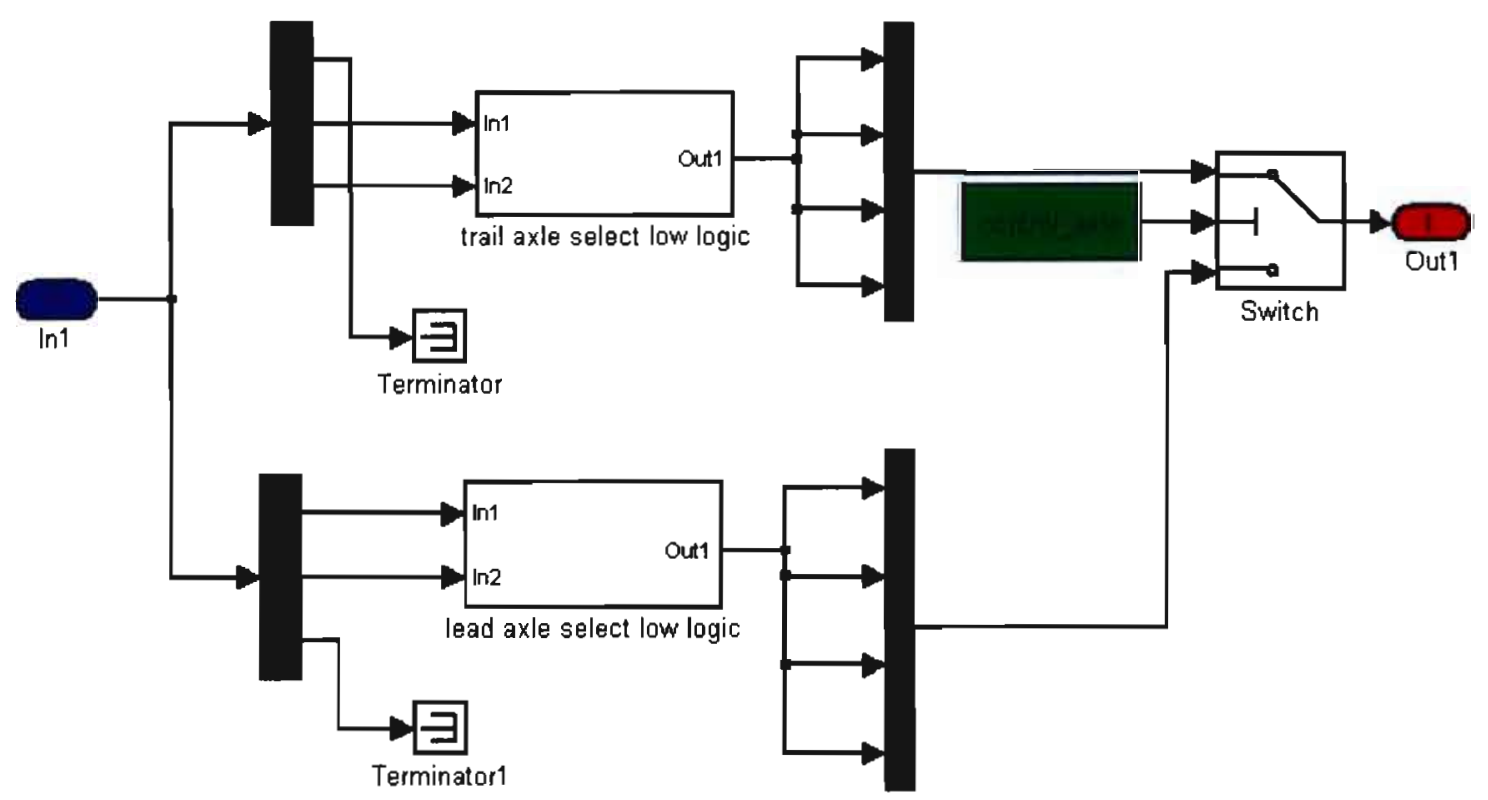

Figure 3.14 - 2s $1 \mathrm{~m}$ Select-Low Module 


\subsection{Model Validation}

Validation using experimental data is a very important step in any modeling project, as it gives credibility to simulated results. In order to accomplish this, the response of the previously described tractor-trailer model was compared to experimental data, collected by NHTSA engineers and technicians at VRTC. The Sterling $4 \times 2$ tractor was chosen as the model of choice because a great deal of experimental data on this truck has been gathered. The tractor was equipped with an Applied Bendix 4s4m ABS system (2000 model year). For validation of the semitrailer models, extensive data existed for a 53' Fruehaf van trailer, equipped with a 2s $1 \mathrm{~m}$ ABS system. The ABS system was manufactured by Wabash (2001 model year) and used the front trailer axle for control feedback. Even though the model used a 48' trailer, it was desired to create a trailer ABS model that acted in a similar manner to the ABS controller of the 53' trailer.

It should be noted that although experimental data existed for the Sterling tractor and the 53' trailer individually, no set of data existed in which the two were used together. The Sterling data was collected with a control trailer and data on the Fruehaf semitrailer was collected while the trailer was being pulled by a Volvo $6 \times 4$ tractor.

\subsubsection{Sterling Tractor Validation}

To start the tractor-trailer model validation process, it was necessary to ensure accurate modeling of the Sterling $4 \times 2$ tractor. Experimental data was collected for the Sterling under the following maneuvers: a straight ahead stop from $60 \mathrm{mph}$ on a high friction surface at LLVW and a brake-in-curve maneuver at GVWR on a low friction 
surface from $30 \mathrm{mph}$. TruckSim models were created for the Sterling at the two loading conditions, tractor LLVW and GVWR. The parameters of the tractor ABS controller model were then varied, and then compared to experimental data, to create a tractor model that accurately simulated the behavior of the actual Sterling. The experimental and simulated brake chamber pressures for the steer and drive axles can be seen in Figure 3.15 and Figure 3.16, respectively, for the BIC maneuver on the low friction (wet Jennite) surface. Likewise, the chamber pressures for the high friction stop at LLVW can be seen in Figure 3.17 and Figure 3.18. These plots show that the simulated tractor adequately follows the behavior of the experimentally tested Sterling. 

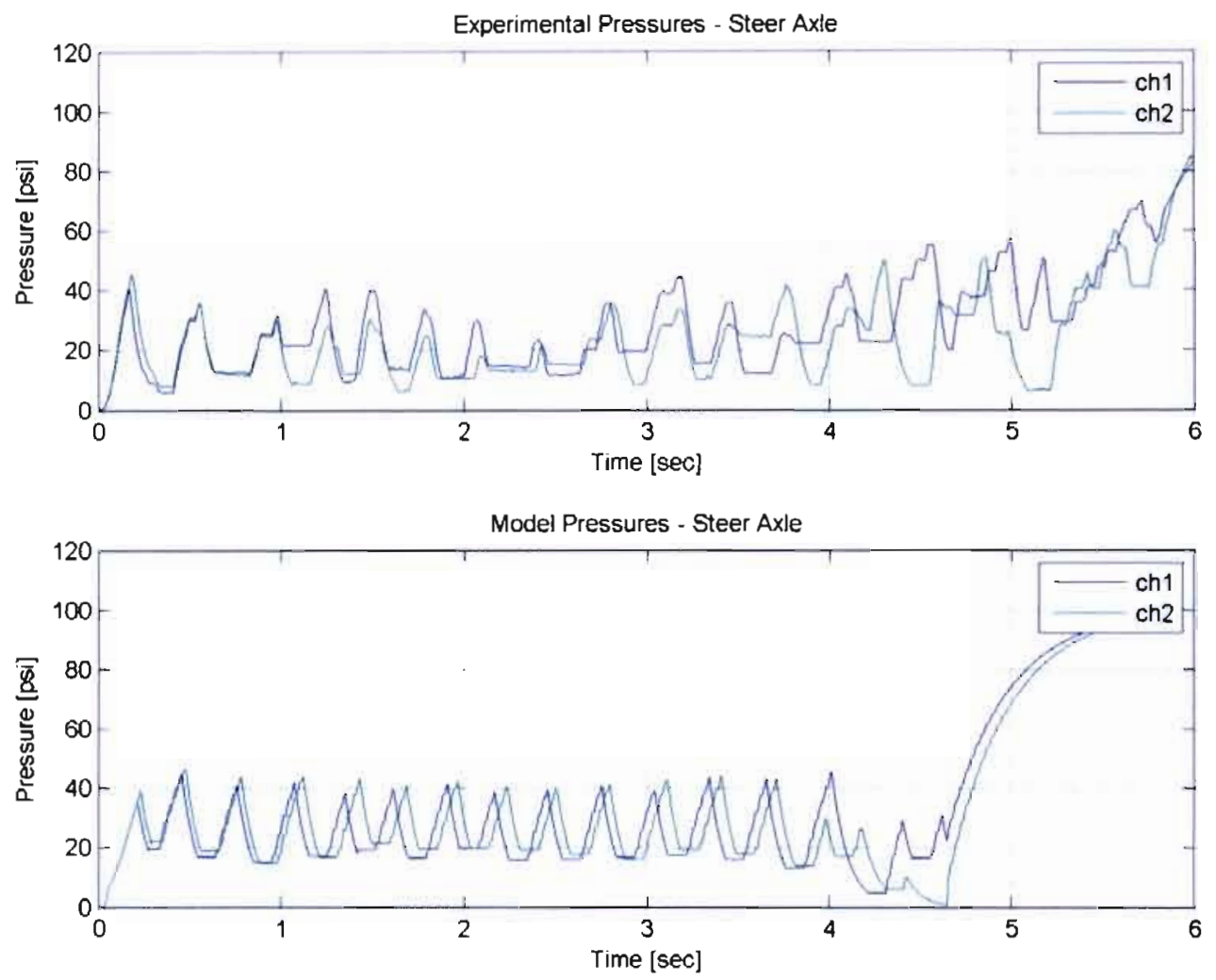

Figure 3.15 - Steer Axle Brake Chamber Pressures, Tractor at GVWR, BIC on Low Friction Surface 

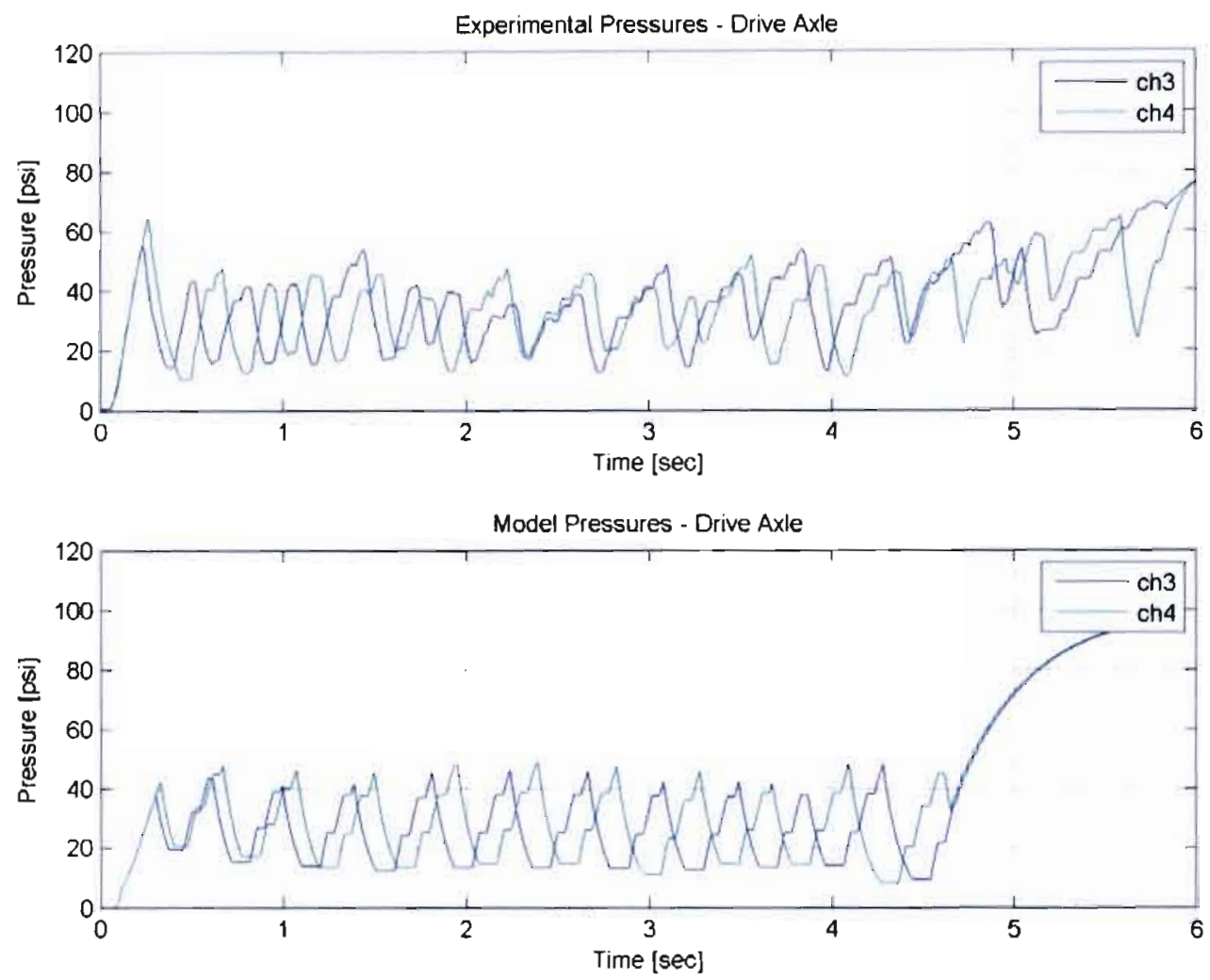

Figure 3.16 - Drive Axle Brake Chamber Pressures, Tractor at GVWR, BIC on Low Friction Surface 

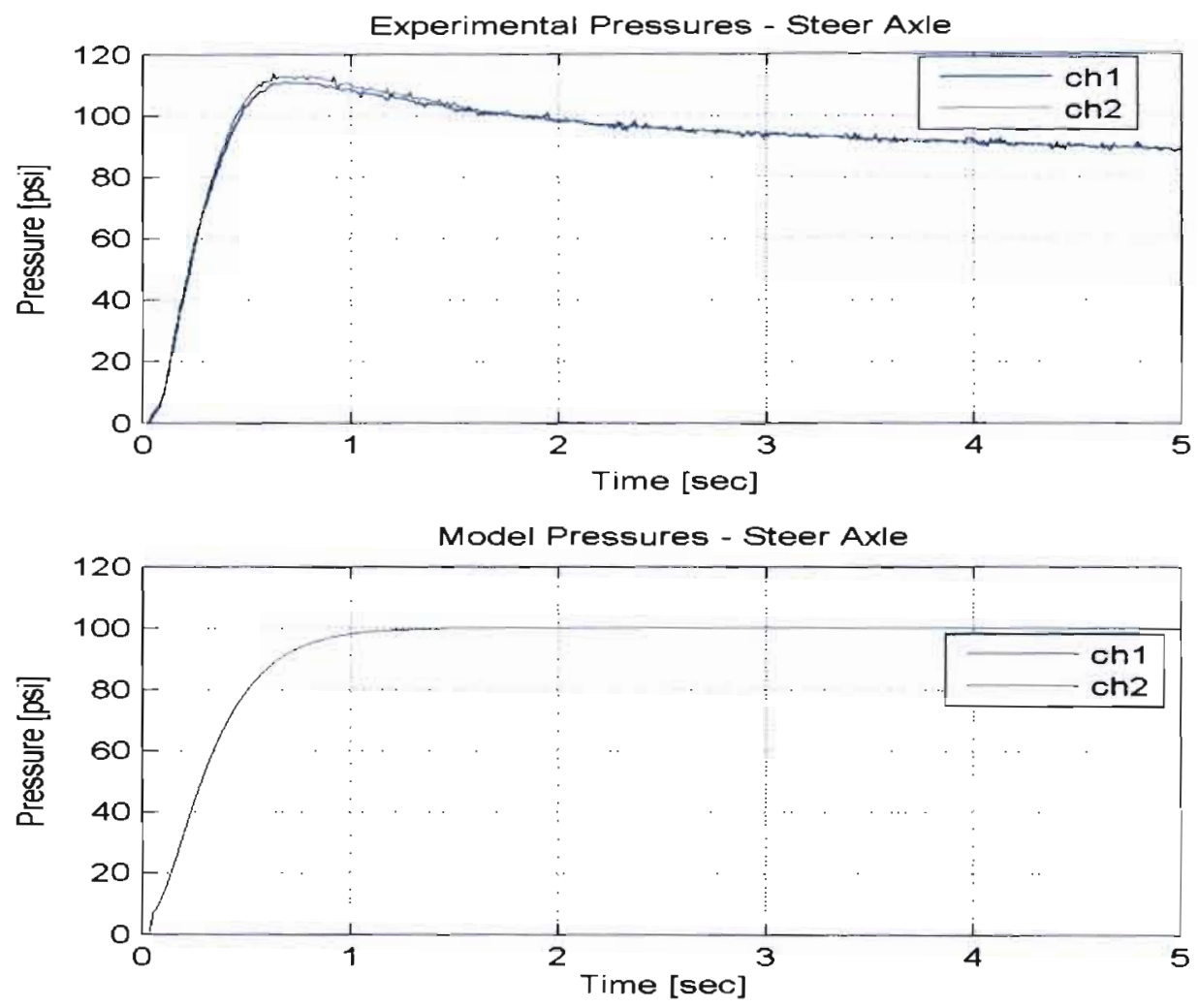

Figure 3.17 - Steer Axle Brake Chamber Pressures, Tractor at LLVW, Straight-ahead Stop from $60 \mathrm{mph}$ on High Friction Surface 

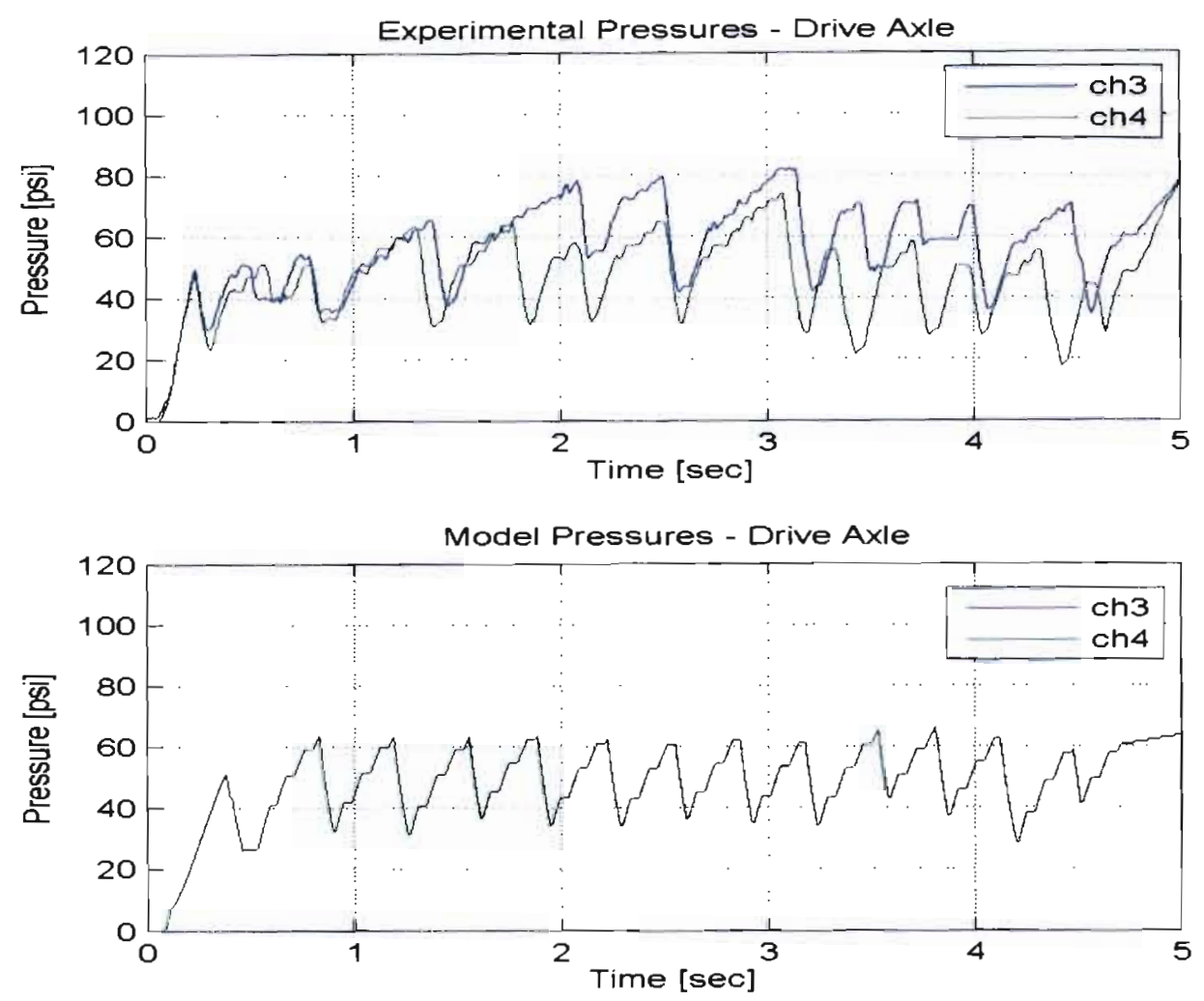

Figure 3.18 - Drive Axle Brake Chamber Pressures, Tractor at LLVW, Straight-ahead Stop from $60 \mathrm{mph}$ on High Friction Surface

\subsubsection{Trailer Validation}

As it was stated earlier, since no data set existed in which the studied trailer is being pulled by the Sterling tractor, the aim of the trailer verification process was to ensure that the modeled trailer ABS system acted in a manner resembling the experimental data while being towed by another tractor. This was accomplished by examining brake chamber pressures and slip ratios of the modeled and experimental stops. The following two data sets were available for use in validation: a low friction 
BIC maneuver and a high friction stop from $60 \mathrm{mph}$, both at the LLVW condition for the trailer.

Figure 3.19 shows the brake chamber 1 pressure for the experimental and modeled trailers, for the high friction stop at LLVW. One can see from this plot that the brake chamber responses are similar to experimental data. Further validation can be seen in Figure 3.20, which is a plot of the experimental and simulated slip ratios for wheel location 1. These plots are not identical, of course, because of the unavoidable differences in the experimental and modeled test conditions, as described previously.
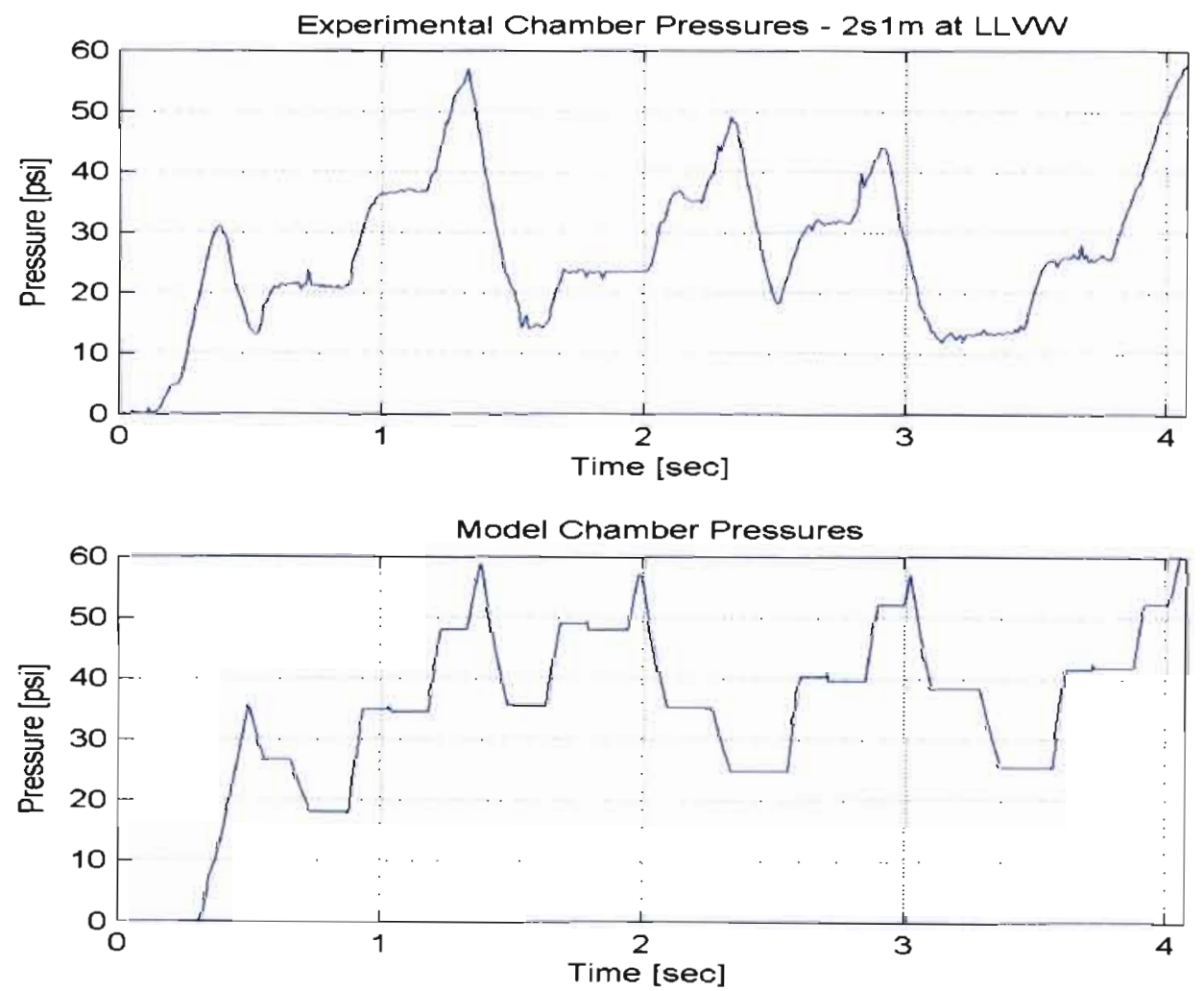

Figure 3.19 - Chamber 1 Brake Pressures for Trailer, High Friction Stop from $60 \mathrm{mph}$ at LLVW 

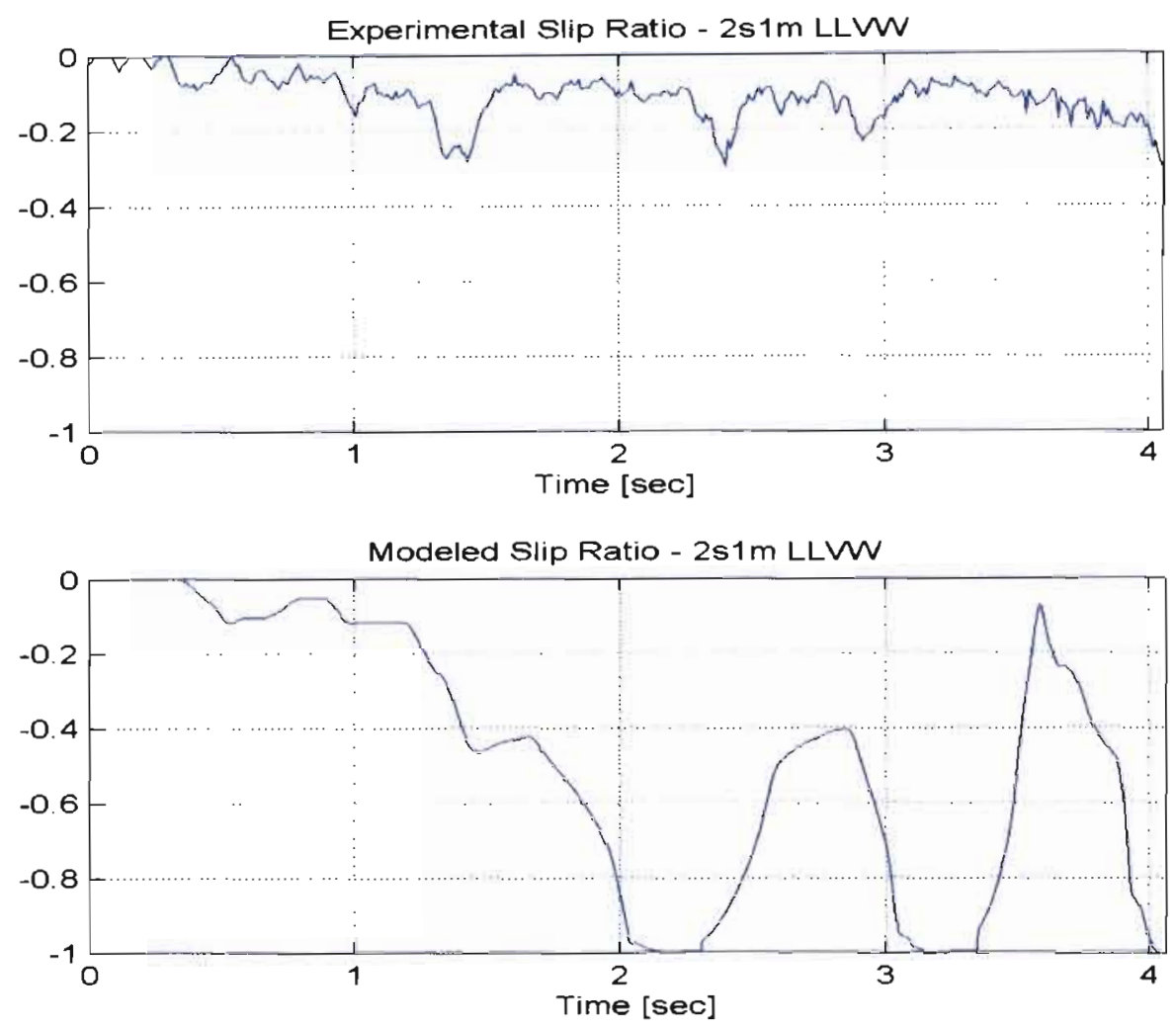

Figure 3.20 - Chamber 1 Slip Ratio for Trailer, High Friction Stop from $60 \mathrm{mph}$ at LLVW

Examination of Figure 3.20 - Chamber 1 Slip Ratio for Trailer, High Friction Stop from $60 \mathrm{mph}$ at LLVW shows that the experimental stop consisted of a large number of instances of slip ratios in the $10-30 \%$ range. This behavior is exhibited as well for the modeled trace until around 2 seconds, when the difference in tractors, along with other differences, may come into play. To further study the slip ratio characteristics, histograms were created for the experimental and simulated stops, which can be seen in Figure 3.21 and Figure 3.22, respectively. These were created by placing the TruckSim calculated slip ratios of each run into a series of bins, so that the number of occurrences 
of individual slip ratio values could be observed. It can be seen from these plots that a significant percentage of the total slip ratio occurrences can be found in the $10-30 \%$ range for both cases. Figure 3.22 shows a cluster of slip ratio occurrences in the range of 40 to $60 \%$ that was not exhibited in the experimental data of Figure 3.21 . This is again most likely attributed to the differences in tractors, as described before. 
Average Histogram Bar Plots for Wheel Slip Levels
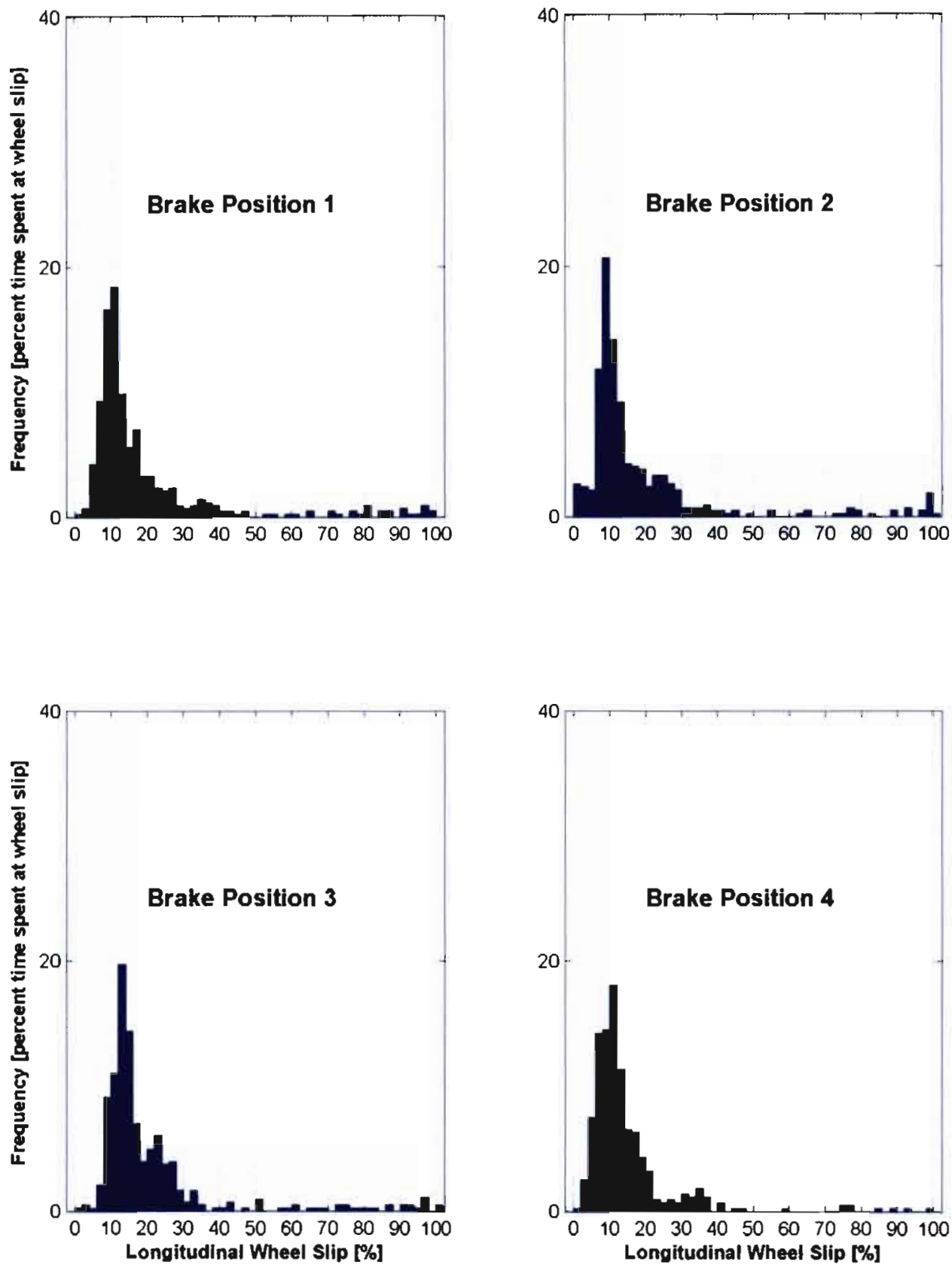

Figure 3.21 - Experimental Slip Ratio Histograms for High Friction Stop 
Average Histogram Bar Plots for Wheel Slip Levels
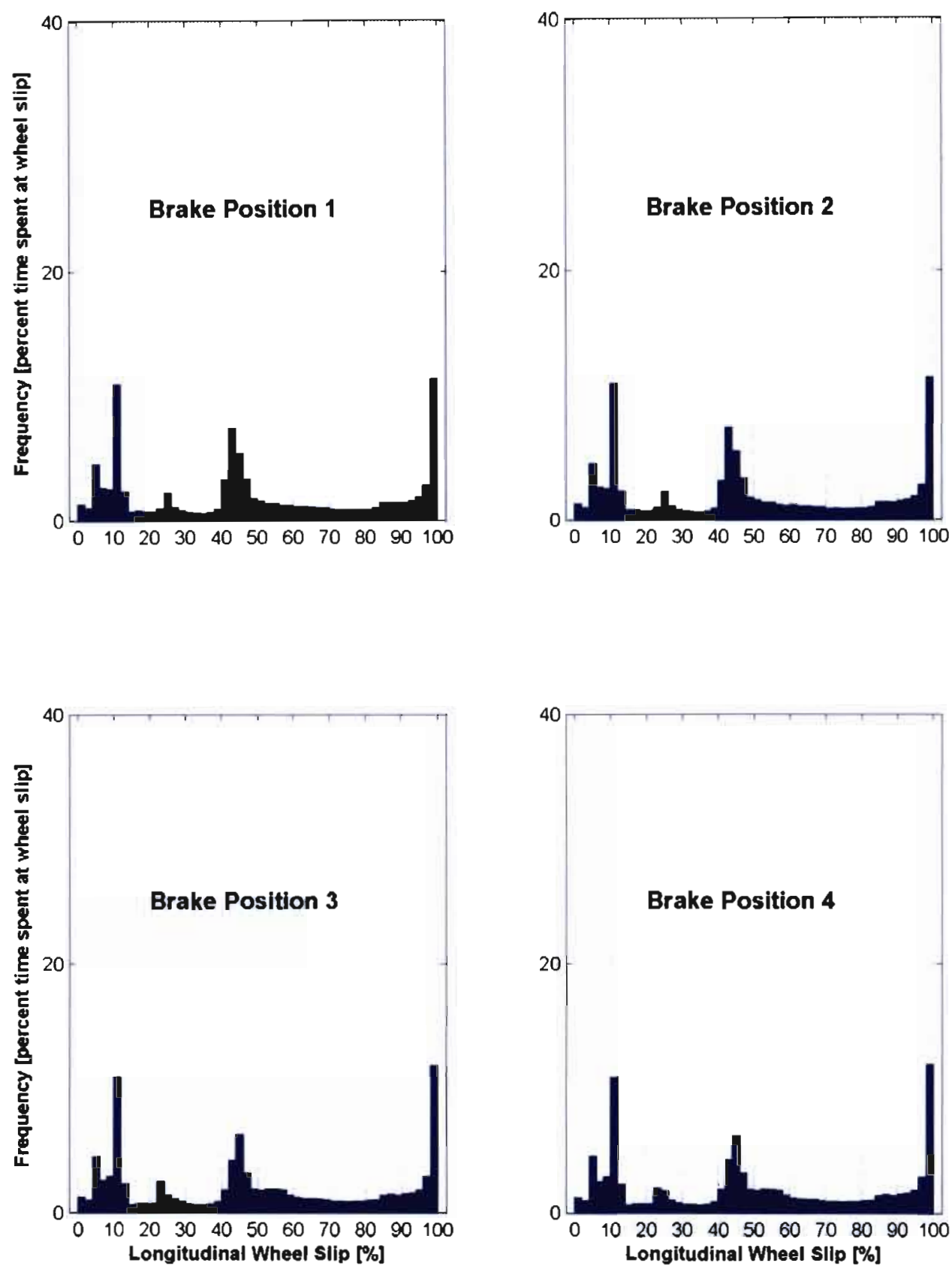

Figure 3.22 - Simulated Slip Ratio Histograms for High Friction Stop 
A similar analysis was conducted for the low friction, brake-in-curve stop. One can see from Figure 3.23 and Figure 3.24 that the pressure and wheel slip responses of the trailer for the low friction were accurately modeled, as the brake pressures and slip ratios follow the same trends. This is further verified by the slip ratio histograms of Figure 3.25 and Figure 3.26. The author believes that the experimental trailer braking situation under the low friction condition was more easily modeled because the effects of the different tractor behaviors would be minimized under low friction conditions, because differences in high-end braking torques between the Volvo (used in experiment) and the Sterling (used in model) tractors would not be realized due to the low brake pressures existing in low friction ABS-enabled stops and because the vehicle is traction-limited in this case. 

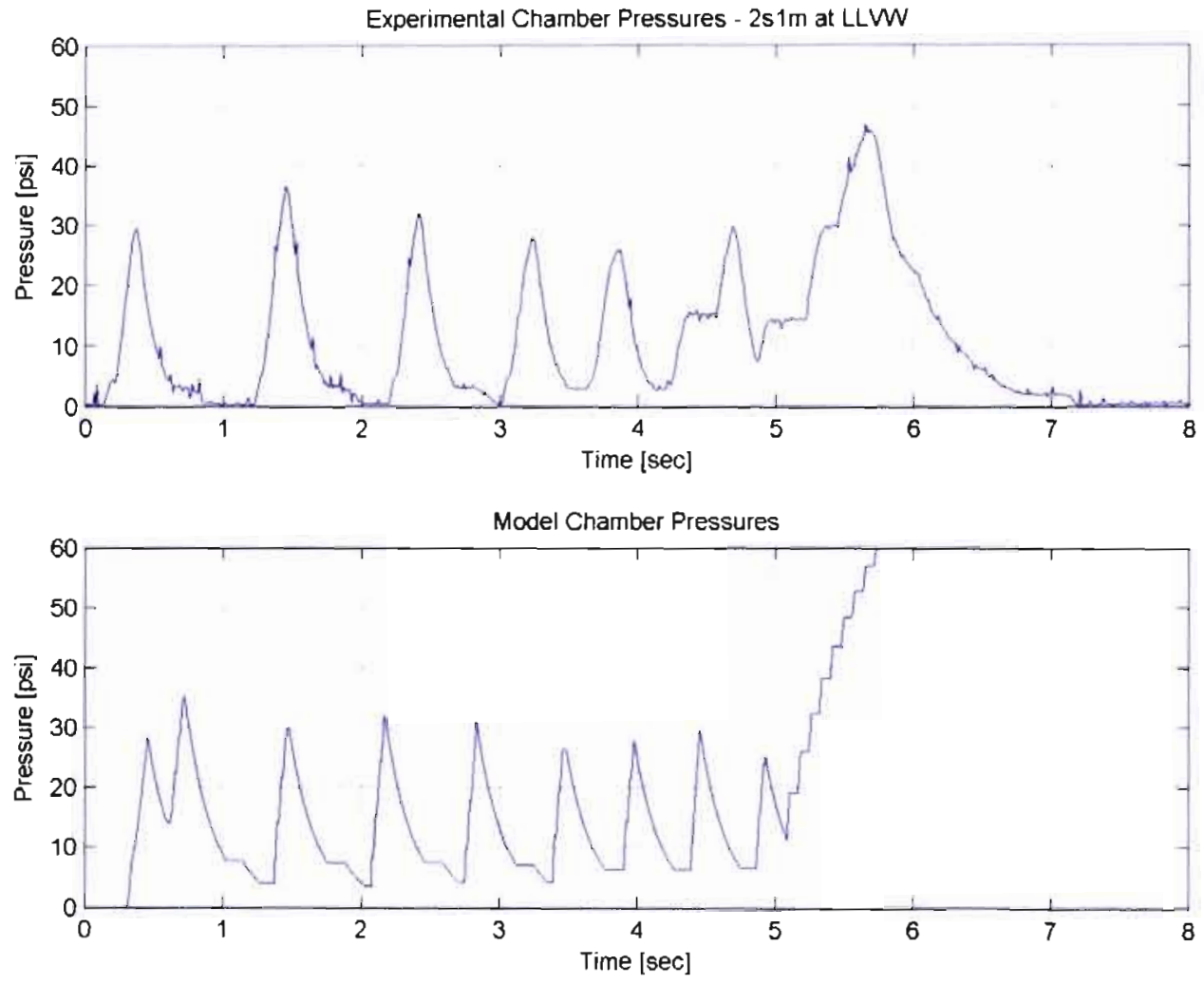

Figure 3.23 - Chamber l Brake Pressures for Trailer, Low Friction BIC at LLVW 

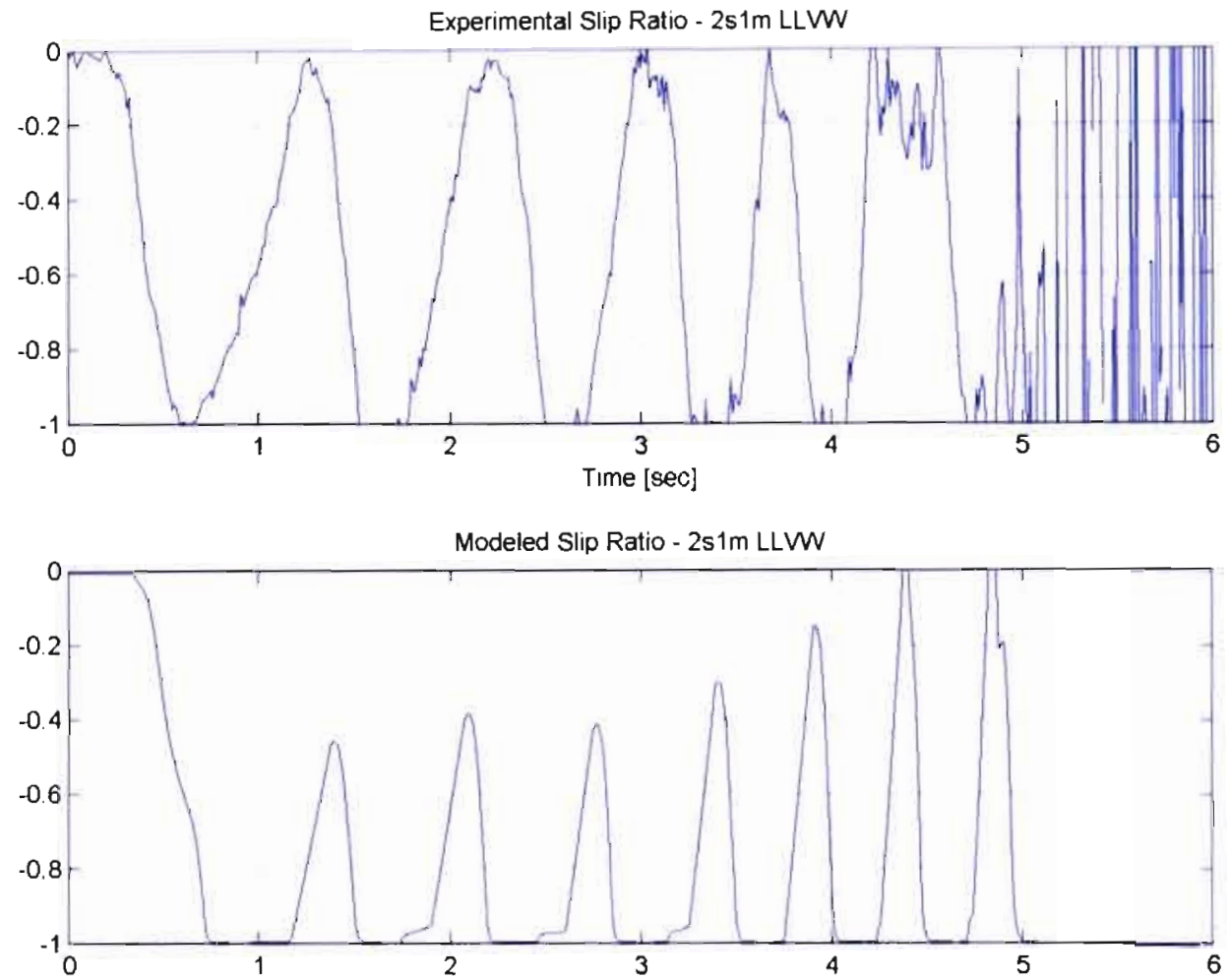

Figure 3.24 - Chamber 1 Slip Ratios for Trailer, Low Friction BIC at LLVW 
Average Histogram Bar Plots for Wheel Slip Levels
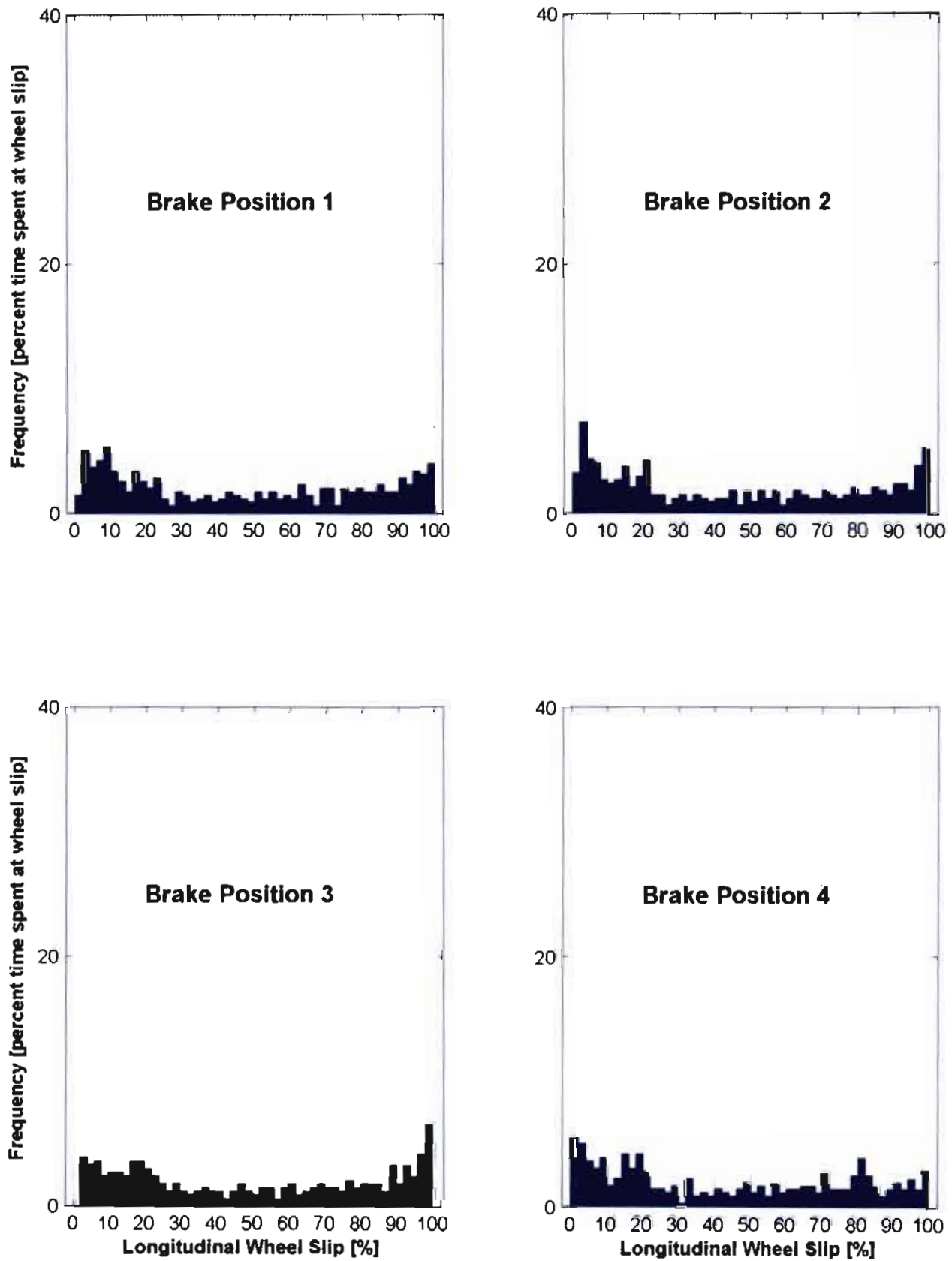

Figure 3.25 - Experimental Slip Ratio Histograms for Low Friction Stop 
Average Histogram Bar Plots for Wheel Slip Levels
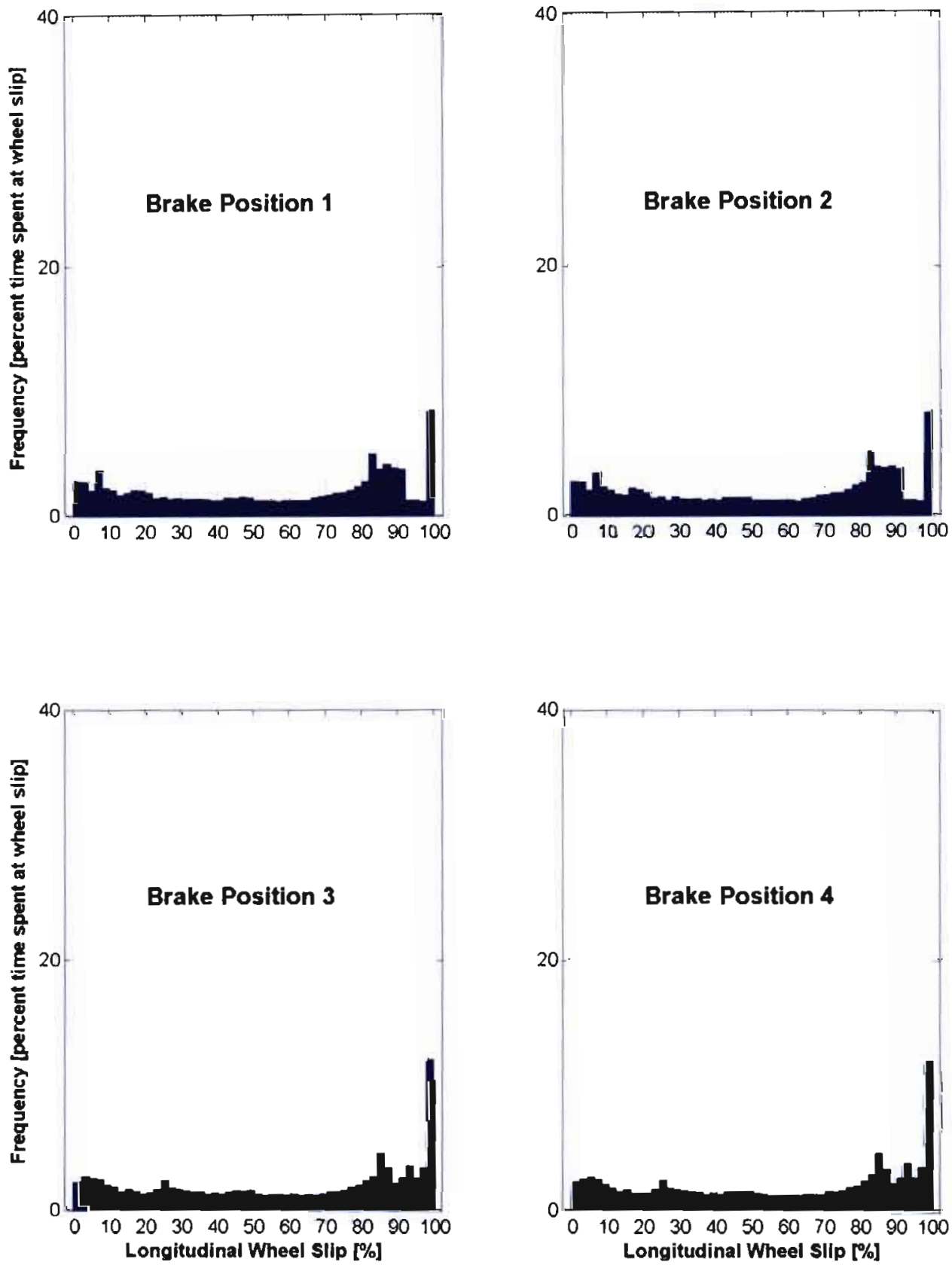

Figure 3.26 - Simulated Slip Ratio Histograms for Low Friction Stop 


\subsection{Semi-Trailer Model Test Plan}

With the completion and validation of the tractor-trailer model, a test plan was developed to study the effects that different ABS configurations may have on a trailer's braking performance and to study possible trade-offs between longitudinal and lateral effectiveness when varying ABS controller parameters. In order to study this, five different ABS systems were developed which were subjected to two simulated test maneuvers.

\subsubsection{ABS Configurations}

Five different ABS configurations were developed representing three basic architectures: $2 \mathrm{~s} 1 \mathrm{~m}, 4 \mathrm{~s} 2 \mathrm{~m}$, and $4 \mathrm{~s} 4 \mathrm{~m}$. These basic $4 \mathrm{~s} 4 \mathrm{~m}, 4 \mathrm{~s} 2 \mathrm{~m}$, and $2 \mathrm{~s} 1 \mathrm{~m}$ systems were created by using the ABS controller model discussed in Section 3.3.3 along with the ABS Control Selector described in Section 3.3.4. The other two are based off of the previously described $2 \mathrm{~s} 1 \mathrm{~m}$ model; however, their parameters were varied in order to create alternatively performing systems.

Forces in the tires are essential to braking performance, as T.D. Gillespie wrote in [12], "In modern highway vehicles all the primary control and disturbance forces which are applied to the vehicle, with the exception of aerodynamic forces, are generated in the tire-road contact patch." It follows that all tractive (longitudinal) braking and cornering (lateral) forces are highly dependant upon the mechanics of the tires. Upon further examination, it was found that the longitudinal friction force at the tire-road contact patch varies as a function of slip ratio. At $0 \%$ slip, the tire friction force is negligible, because 
braking forces in the tire are generated from the difference in wheel and vehicle speeds. Longitudinal wheel slip is calculated according to Equation 1.

$$
\kappa=\frac{v_{i}-v_{\text {vehicle }}}{v_{\text {vehicle }}}
$$

Typically on pavement, the tractive force reaches a peak between 10 and $30 \%$ slip (depending on the tire, surface, load, and speed) and typically reaches an asymptotic value of $70-80 \%$ of its maximum value as slip ratios approach lock-up (100\% slip). This information can be seen graphically in Figure 10.7 of [12], which shows representative tire traction data. Conversely, it is widely known that lateral, or cornering, forces in the tire are at their maximum value at $0 \%$ longitudinal slip, and that the magnitude decreases to a value near 0 as the wheel approaches lock-up (see Figure 10.22 of [12]). This behavior was illustrated for heavy truck tires by Dunn in [1] with tire traction data collected at VRTC. This information can be seen graphically in Figure 3.27. 


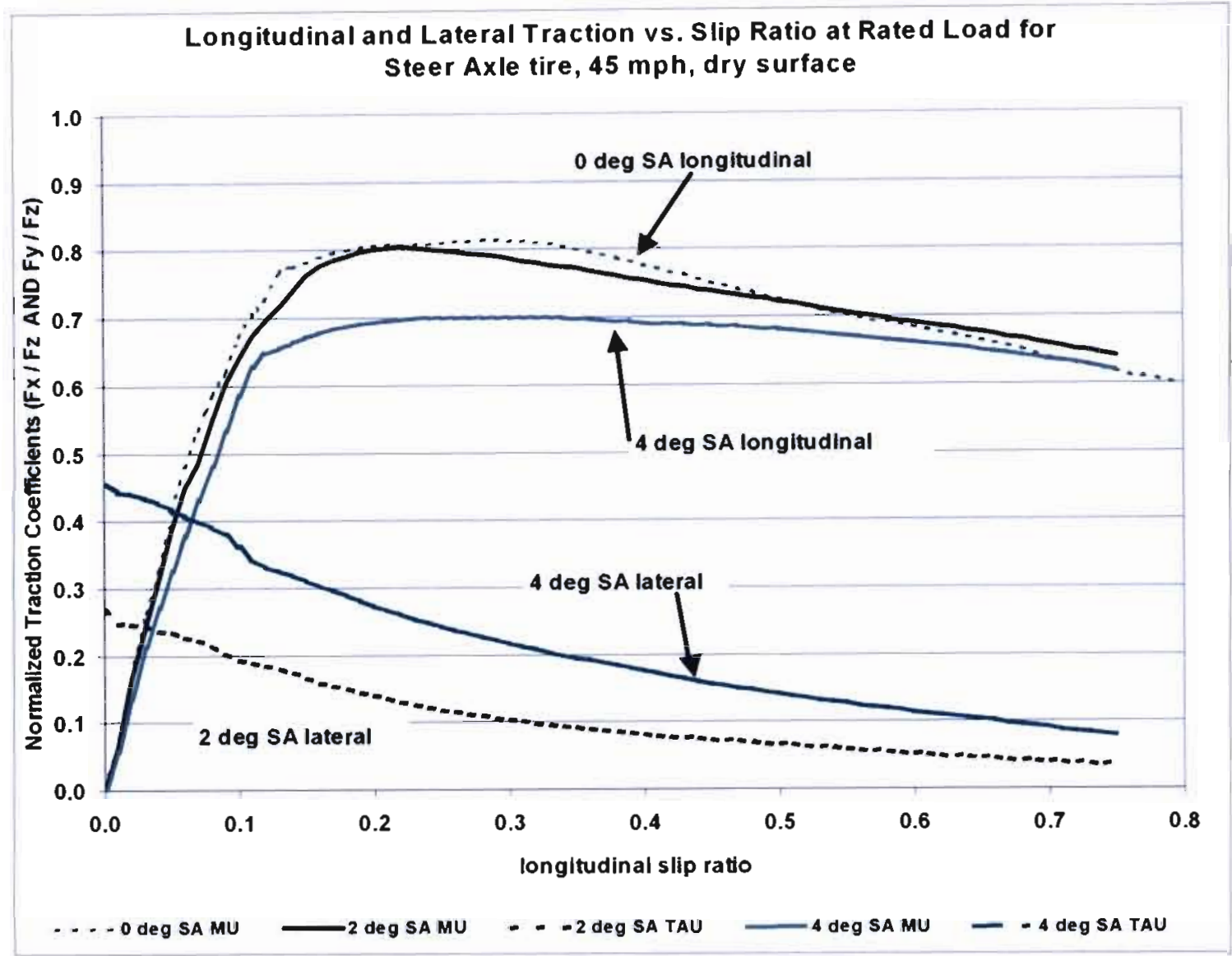

Figure 3.27 - Normalized Tire Longitudinal and Lateral Force vs. Slip Ratio at Different Slip Angles [1] for Steer Axle Heavy Truck Tire

Figure 3.27 illustrates that at certain slip ratio values, it is possible to have a tire in a region of good longitudinal effectiveness and at the same time be in a region of poor lateral effectiveness, and vice versa. This basic trade-off was used as an inspiration for two additional $2 \mathrm{~s} 1 \mathrm{~m}$ controller models, the first of which aimed to keep slip ratios unrealistically close to $0 \%$ slip throughout the duration of the stop. An ABS system which keeps the slip ratio close to $0 \%$ at all times will undoubtedly have poor longitudinal performance, and high lateral performance. Alternatively, another ABS 
controller model was created which keeps slip ratio values unrealistically close to $100 \%$; this system will certainly display very poor lateral performance, but will have fairly high longitudinal performance. The "optimally tuned" $2 \mathrm{~s} 1 \mathrm{~m}$ ABS system from Section 3.3.4 and the "poor longitudinal" and "poor lateral" $2 \mathrm{~s} 1 \mathrm{~m}$ ABS systems previously described were termed " $2 \mathrm{~s} 1 \mathrm{~mA}$ ", " $2 \mathrm{~s} 1 \mathrm{mB}$ ", and " $2 \mathrm{~s} 1 \mathrm{mC}$ ", respectively, for the simulations described in Chapter 4. The ABS controller parameters of the $2 \mathrm{~s} 1 \mathrm{~mA}$ system were varied (primarily the slip ratio and acceleration dump on and dump off thresholds) in order to create the $2 \mathrm{~s} 1 \mathrm{mB}$ and $2 \mathrm{~s} 1 \mathrm{mC}$ systems. Also, the $2 \mathrm{~s} 1 \mathrm{~mA}$ (or optimally tuned) system implemented select-low logic when it sensed that it is on a low friction surface and switched to select-high logic when it sensed that it is on a high friction surface. It is believed that many $2 \mathrm{~s} 1 \mathrm{~m}$ systems in use today may utilize such a scheme because selectlow logic would be helpful under a low friction braking situation (i.e., dump when either sensed wheel says to do so). Also, select-high logic would be more beneficial on high friction stops, in which a more aggressive scheme could be used (i.e., only dump when both sensed wheels deem it necessary). This capability was also included into the $4 \mathrm{~s} 2 \mathrm{~m}$ and $4 \mathrm{~s} 4 \mathrm{~m}$ control schemes. Due to the nature of the select-low and select-high schemes, it is believed that a select-low system would perform worse than a select-high system for straight ahead stops, and the opposite would be true for brake-in-curve maneuvers. Therefore, the $2 \mathrm{~s} 1 \mathrm{mB}$ system, designed to have poor longitudinal performance, used select-low logic at all times and the $2 \mathrm{~s} 1 \mathrm{mC}$ system, designed to have poor lateral performance, used select-high logic at all times. The desired behavior of these "poor longitudinal" and "poor lateral" systems can be seen from the slip ratio histograms of 
each system. The plots Figure 3.28 though Figure 3.33 show these histograms for each system under two different simulations: a low friction stop from $30 \mathrm{mph}$ and a high friction stop from $60 \mathrm{mph}$. These plots show the TruckSim calculated slip at each wheel for each case. One can see from these plots that the desired behavior is exhibited in these $2 \mathrm{~s} 1 \mathrm{~m}$ systems and will be beneficial to the study of trailer ABS systems in Chapter 4 . 
Low Friction Stop from $30 \mathrm{mph}, 251 \mathrm{~mA}$
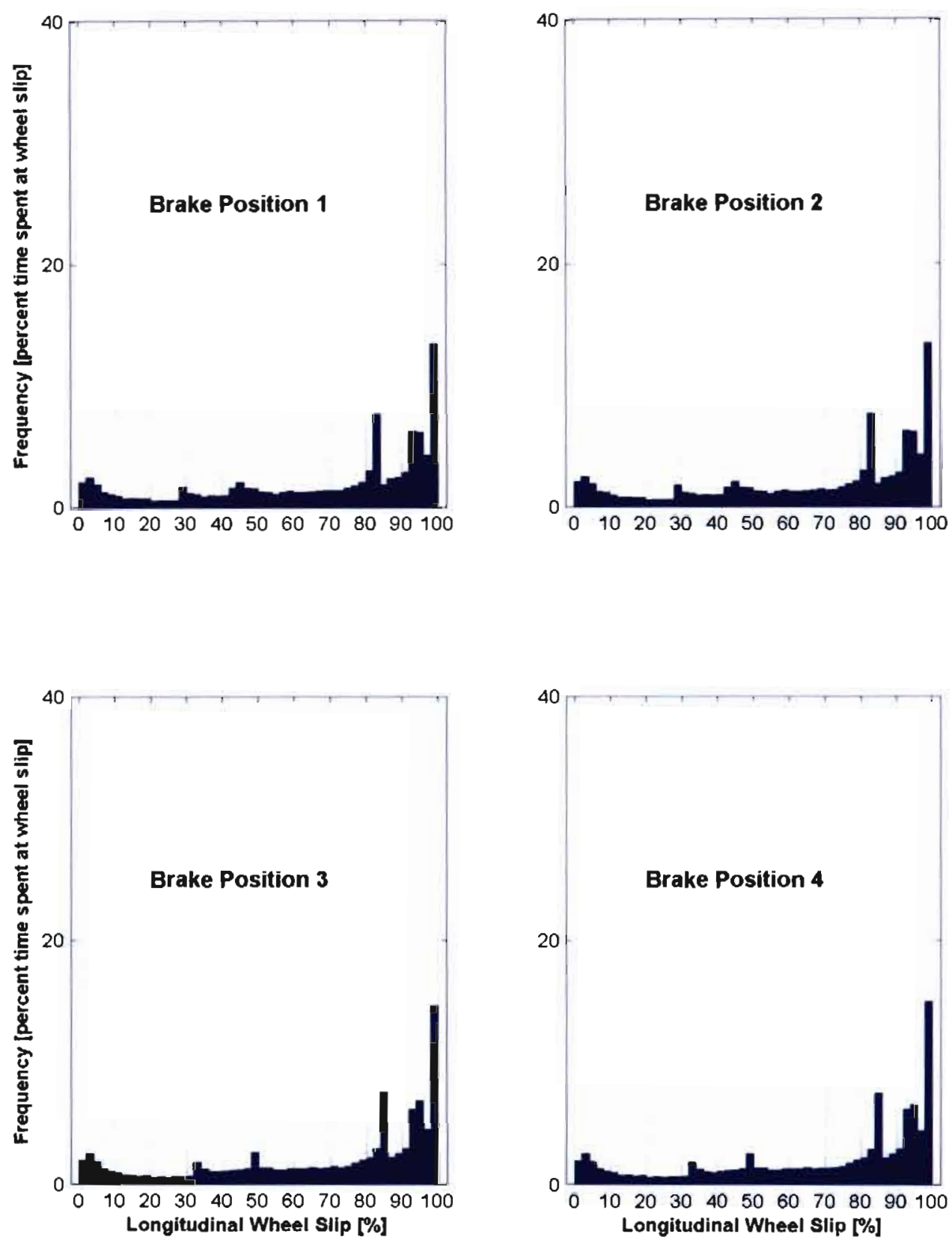

Figure 3.28 - Histogram of Optimally Tuned 2s1m, Low Friction Stop 
Low Friction stop from $30 \mathrm{mph}, 251 \mathrm{mB}$
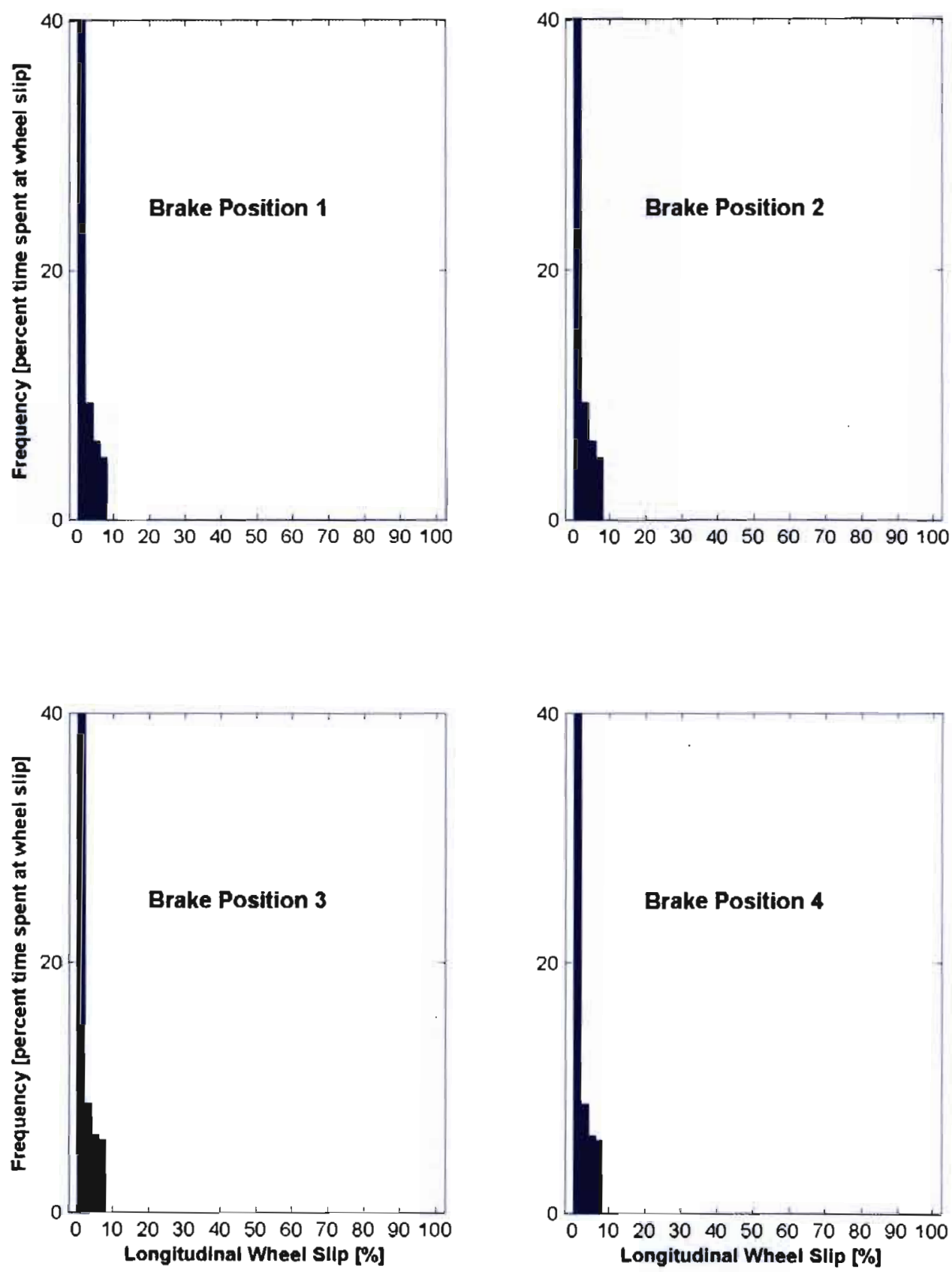

Figure 3.29 - Poor Longitudinal 2s $1 \mathrm{~m}$, Low Friction Stop 
Low Friction Stop from $30 \mathrm{mph}, 2 \mathrm{~s} 1 \mathrm{mC}$
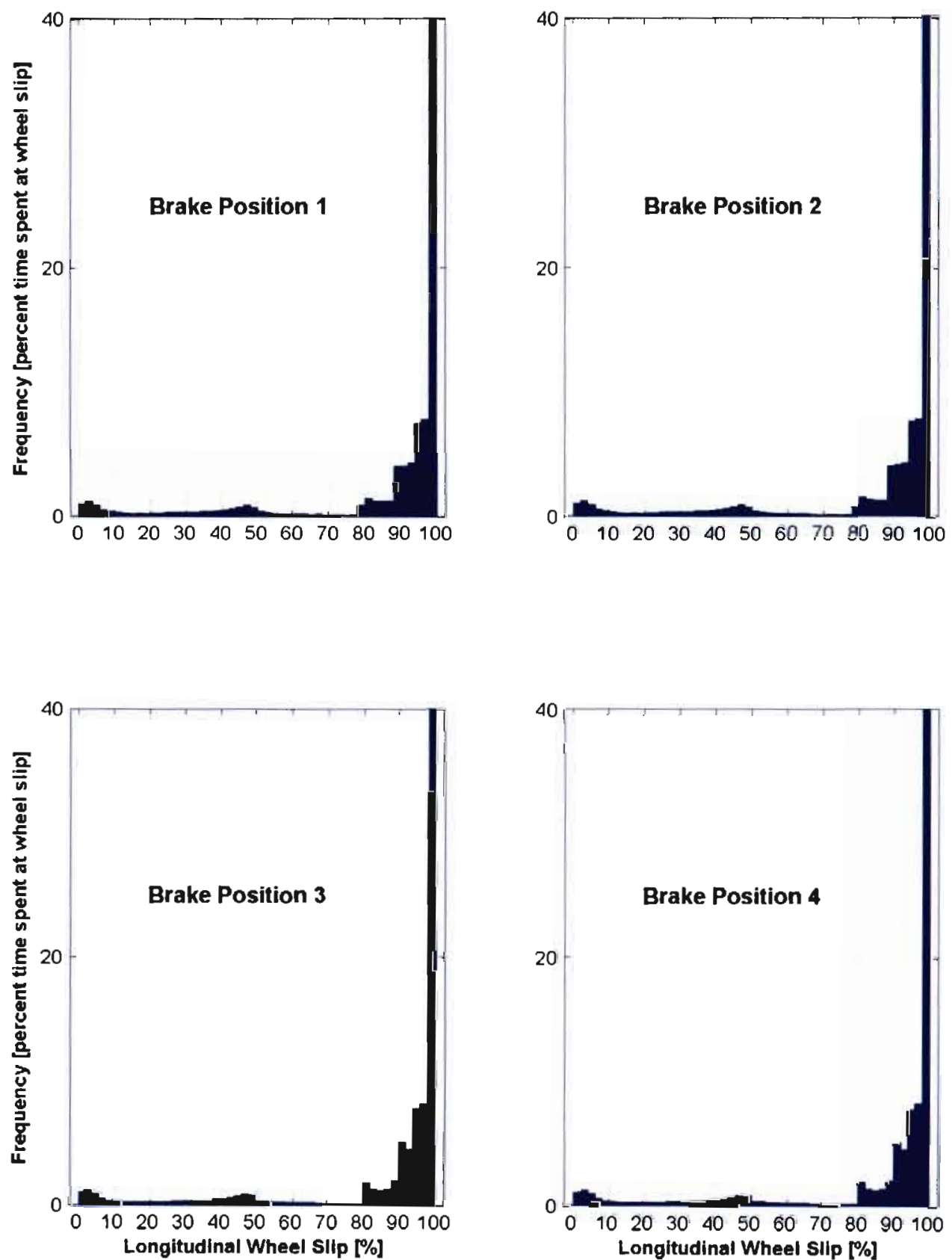

Figure 3.30 - Poor Lateral 2s1m, Low Friction Stop 
High Friction Stop from $60 \mathrm{mph}, 2 \mathrm{~s} 1 \mathrm{~mA}$
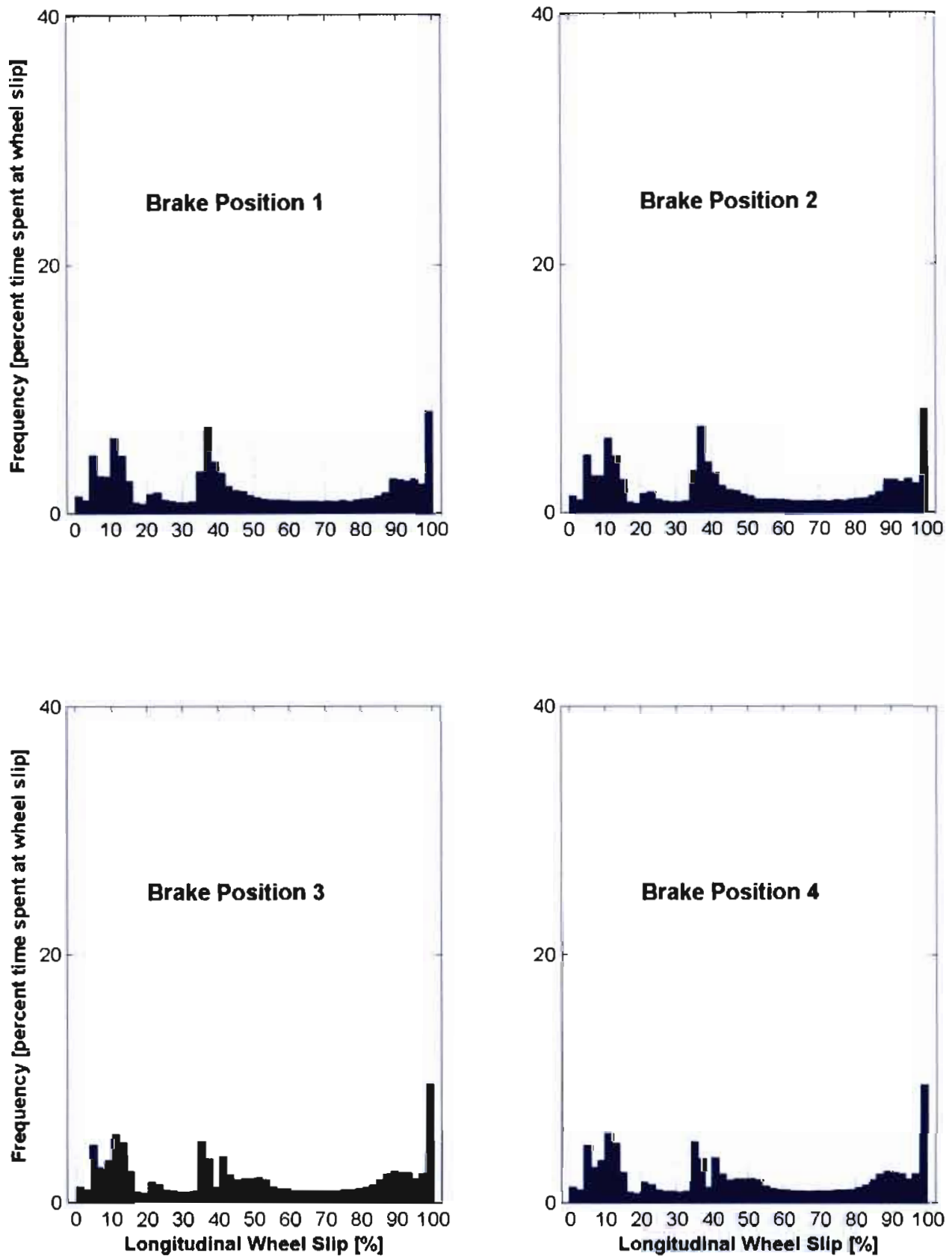

Figure 3.31 - Histogram of Optimally Tuned $2 \mathrm{~s} 1 \mathrm{~m}$, High Friction Stop 
High Friction Stop from $60 \mathrm{mph}, 2 \mathrm{~s} 1 \mathrm{mB}$
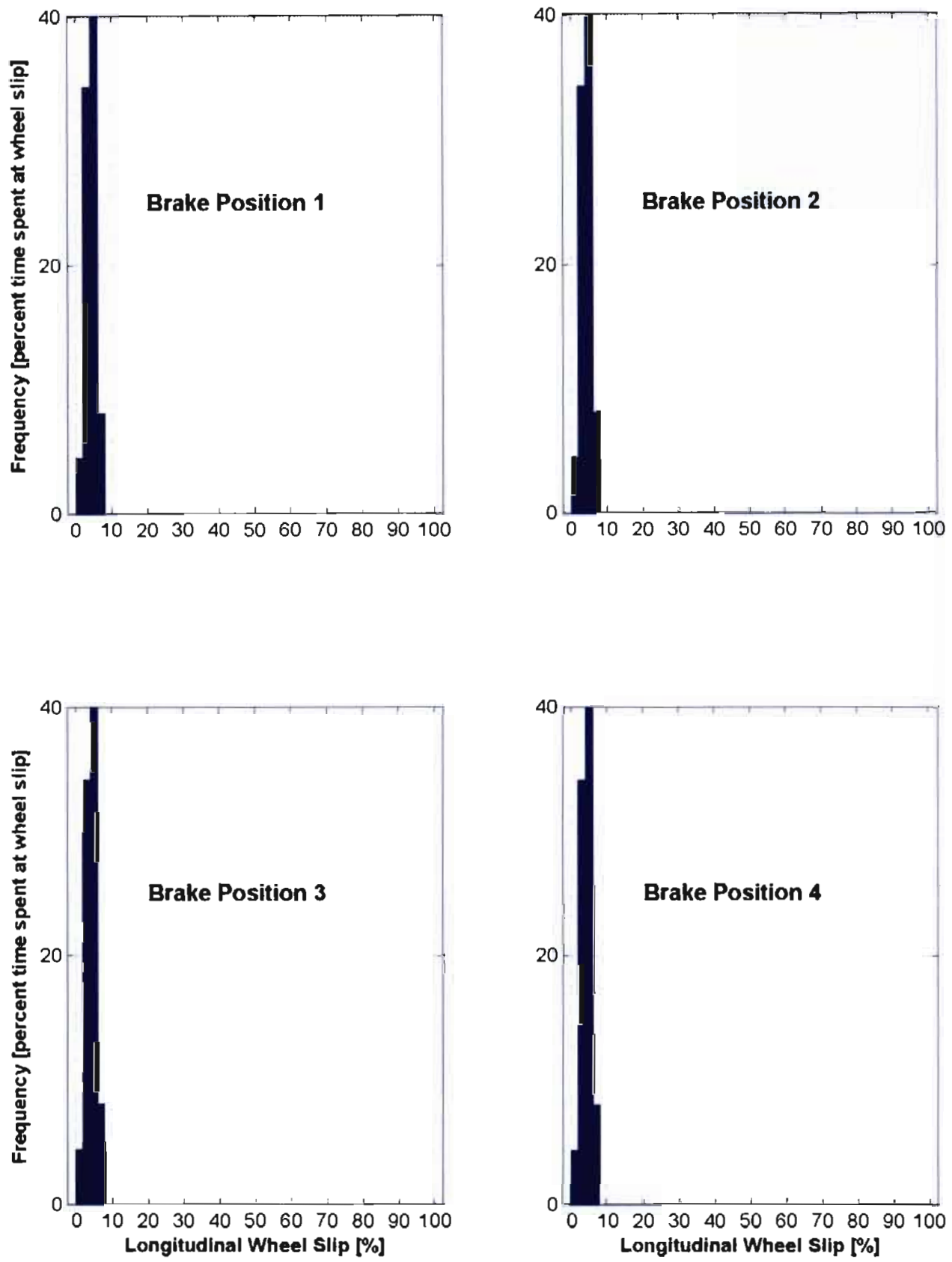

Figure 3.32 - Poor Longitudinal 2s1m, High Friction Stop 
High Friction Stop from $60 \mathrm{mph}, 2 \mathrm{~s} 1 \mathrm{mC}$
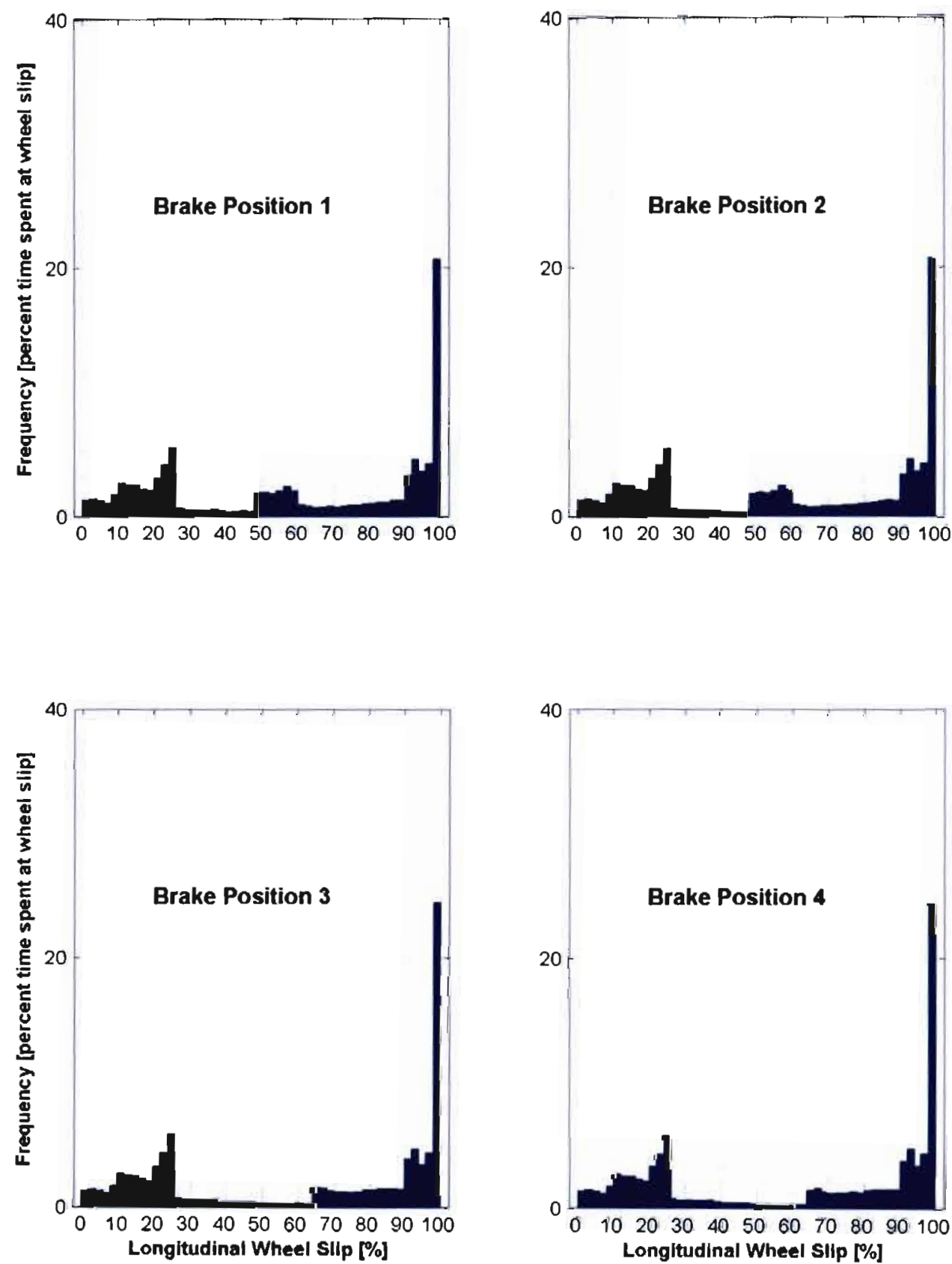

Figure 3.33 - Poor Lateral 2s1 m, High Friction Stop 


\subsubsection{Straight Braking Test}

In order to study longitudinal braking effectiveness, a test plan was developed around a straight-ahead braking maneuver in TruckSim. At each of the previously described trailer axle loading conditions, tests were run for each of the five ABS configurations. Simulations were conducted at a high and a low friction level and stops were initiated from starting speeds of 60 and $30 \mathrm{mph}$. Also, tests were conducted for full vehicle (tractor and trailer) braking as well as the situation of trailer only braking. This test plan is summarized in Table 3.2 .

\begin{tabular}{|c|c|c|}
\hline Trailer Axle Loads & $25 \%$ GAWR & $75 \%$ GAWR \\
\hline Surface Coefficient of Friction & 0.35 & 0.85 \\
\hline Vehicle Braking Condition & Tractor \& Trailer & Trailer Only \\
\hline Initial Speed & $30 \mathrm{mph}$ & $60 \mathrm{mph}$ \\
\hline
\end{tabular}

Table 3.2 - Straight-Ahead Braking Test Plan

Longitudinal performance was graded based on the stopping distance of each test as well as a parameter known as surface utilization, or S.U. (see Equation 2). This parameter was calculated by dividing the average deceleration of a particular run by the average deceleration of a locked-wheel (or no ABS) stop, at identical conditions.. These average deceleration values were calculated (in g) by taking a linear regression of the trailer speed trace. This parameter illustrates how well an ABS system performs in straight-ahead stops, by comparing its response to a system which allows full lock-up.

$$
S . U .=\frac{\operatorname{decel}_{A B S}}{\text { decel }_{\text {locked }- \text { wheel }}}
$$




\subsubsection{Brake-In-Curve Test}

In order to test for lateral performance, a test utilizing a 500 foot brake-in-curve (BIC) maneuver in TruckSim was used. For each load condition, the maximum drivethough speed for the tractor-trailer combination will first be determined. The maximum drive-through speed is the highest speed at which the vehicle can maneuver through the curve without leaving the lane. Then, the limit-handling speed for each ABS configuration will be determined by finding the maximum speed at which the vehicle stays in lane under a full treadle braking application. Lateral performance will be graded based a metric called the Lateral Acceleration Performance Quotient, or LAPQ, which is calculated according to Equation 3, as defined in $[3,4]$.

$$
L A P Q=\frac{V_{\text {limit-braking }}^{2}}{V_{\text {drive-though }}^{2}}
$$




\section{CHAPTER 4}

\section{TRACTOR-TRAILER MODEL SIMULATION RESULTS}

\subsection{Straight-Ahead Stops - Full Vehicle Braking}

In order to study longitudinal braking performance of the modeled tractor-trailer, straight-ahead braking simulations were conducted. Simulations were completed at a variety of conditions, outlined in Section 3.5.2, and the results of all tests involving full vehicle braking (tractor and trailer) are included in this section. Simulated stops from 60 and $30 \mathrm{mph}$ down to $6 \mathrm{mph}$ were included for this study of full vehicle braking.

The first step for each simulated case was to obtain the average deceleration and stopping distance for the vehicle without ABS braking on the trailer. For these tests, ABS was active on the tractor, however, so that its activity would be a constant throughout the entire full vehicle braking tests. 


\subsubsection{5\% GAWR, Low Friction}

The results of the longitudinal performance testing of the tractor-trailer, with the trailer axles at $25 \%$ of their gross axle weight rating, under full vehicle braking on a low friction surface, are tabulated in Table 4.1. This table shows the longitudinal performance of the vehicle, for different trailer ABS controller models, as characterized by the surface utilization and stopping distance corresponding to each ABS configuration, at each of the two initial speeds ( 30 and $60 \mathrm{mph}$ ). Table 4.1 shows that for each initial speed, for this test condition, the $2 \mathrm{~s} 1 \mathrm{~mA}, 2 \mathrm{~s} 1 \mathrm{mC}, 4 \mathrm{~s} 2 \mathrm{~m}$, and $4 \mathrm{~s} 4 \mathrm{~m}$ systems perform to a relatively equal degree. This information is also shown graphically in Figure 4.1, which also shows that the $2 \mathrm{~s} 1 \mathrm{mB}$ system (designed to perform poorly longitudinally) had the smallest S.U. and the longest stopping distance. 


\begin{tabular}{|c|c|c|c|c|}
\hline \multicolumn{5}{|c|}{ Full Braking, 25\% Axle Load, $\mu=0.35$} \\
\hline Speeds & ABS System & $\begin{array}{c}\text { decel } \\
{[\text { ABS] }}\end{array}$ & S.U. & $\begin{array}{c}\text { S.D. } \\
{[\mathrm{ft}]}\end{array}$ \\
\hline \multirow{5}{*}{$60-6$} & none & 0.296 & - & 434.9 \\
\cline { 2 - 5 } & $2 \mathrm{~s} 1 \mathrm{~m}-\mathrm{A}$ & 0.293 & $98.8 \%$ & 435.1 \\
\cline { 2 - 5 } & $2 \mathrm{~s} 1 \mathrm{~m}-\mathrm{B}$ & 0.276 & $93.3 \%$ & 449.1 \\
\cline { 2 - 5 } & $2 \mathrm{~s} 1 \mathrm{~m}-\mathrm{C}$ & 0.293 & $99.0 \%$ & 432.9 \\
\cline { 2 - 5 } & $4 \mathrm{~s} 2 \mathrm{~m}$ & 0.291 & $98.1 \%$ & 437.0 \\
\hline \multirow{5}{*}{$30-6$} & $4 \mathrm{~s} 4 \mathrm{~m}$ & 0.292 & $98.6 \%$ & 438.3 \\
\hline & none & 0.279 & - & 114.2 \\
\cline { 2 - 5 } & $2 \mathrm{~s} 1 \mathrm{~m}-\mathrm{A}$ & 0.279 & $99.8 \%$ & 114.2 \\
\cline { 2 - 5 } & $2 \mathrm{~s} 1 \mathrm{~m}-\mathrm{B}$ & 0.214 & $76.5 \%$ & 138.4 \\
\cline { 2 - 5 } & $2 \mathrm{~s} 1 \mathrm{~m}-\mathrm{C}$ & 0.281 & $100.6 \%$ & 113.6 \\
\hline & $4 \mathrm{~s} 2 \mathrm{~m}$ & 0.282 & $101.0 \%$ & 113.1 \\
\hline & $4 \mathrm{~s} 4 \mathrm{~m}$ & 0.279 & $100.1 \%$ & 114.1 \\
\hline
\end{tabular}

Table 4.1 - Longitudinal Performance of Full Vehicle Braking, 25\% GAWR, Low Friction

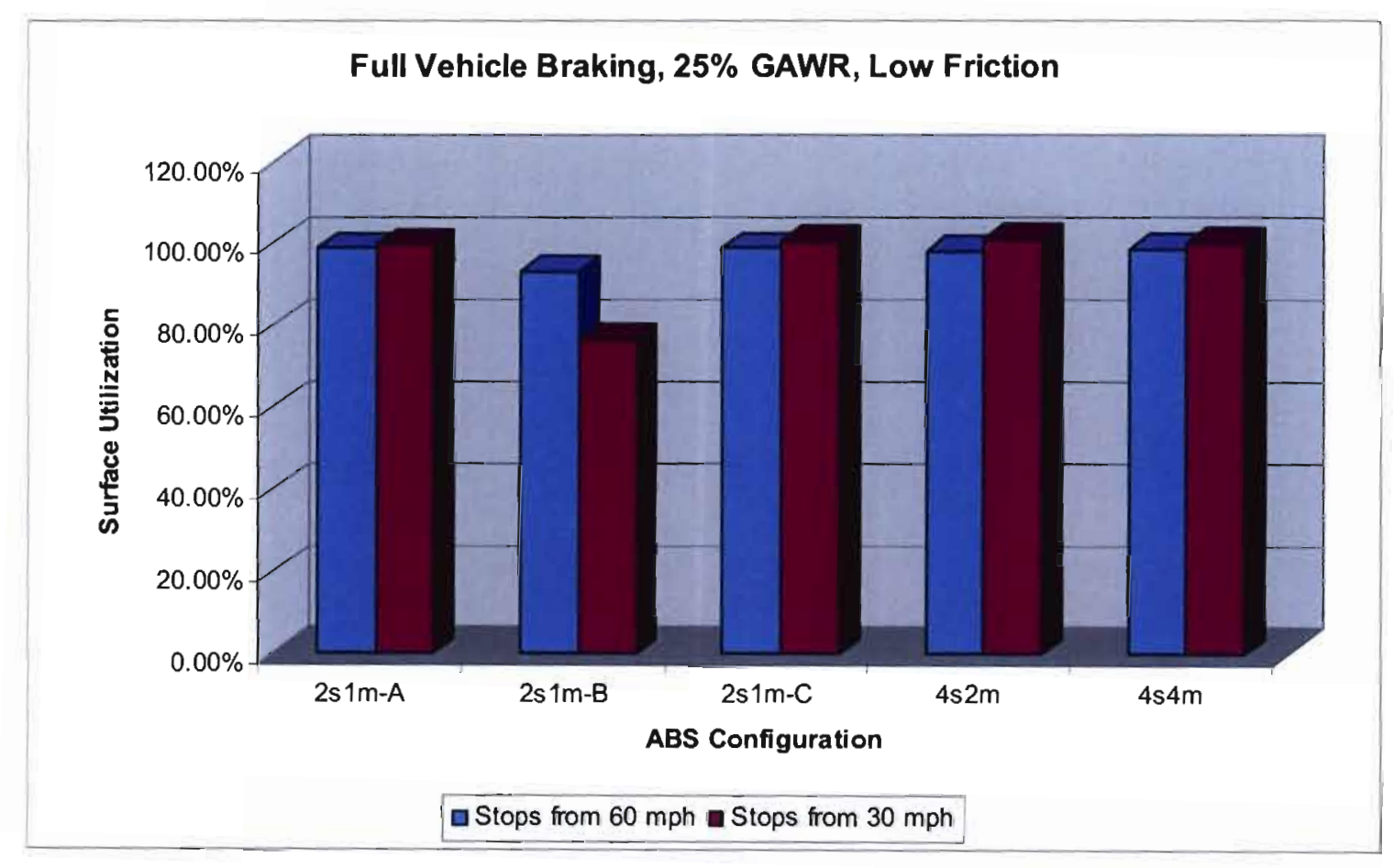

Figure 4.1 - Surface Utilization of Full Vehicle Braking, 25\% GAWR, Low Friction 
Because the $4 \mathrm{~s} 2 \mathrm{~m}$ and $4 \mathrm{~s} 4 \mathrm{~m}$ systems were created from the same controller parameters as the $2 \mathrm{~s} 1 \mathrm{~mA}$ system, it is understandable that those three systems would perform in a similar manner for this test. Because the $2 \mathrm{~s} 1 \mathrm{mC}$ controller was tuned to have parameters different than the $2 \mathrm{~s} 1 \mathrm{~mA}$ controller, further examination was conducted into these two tests. Figure 4.2 shows the brake chamber pressure and slip ratio at each wheel position for the $2 \mathrm{~s} 1 \mathrm{~mA}$ system, and Figure 4.3 illustrates the same information for the $2 \mathrm{~s} 1 \mathrm{mC}$ system. Showing relatively low pressures (about $10-30 \mathrm{psi}$ ) and relatively deep slip ratio cycles, the $2 \mathrm{~s} 1 \mathrm{~mA}$ system responded as expected. Because the designed $2 \mathrm{~s} 1 \mathrm{mC}$ system aims to keep the slip ratio of each wheel close to $100 \%$ at all times, the response seen in Figure 4.3 was expected as the majority of the slip ratios for this case are between 85 and $100 \%$. It should be noted that higher brake chamber pressures were exhibited for the $2 \mathrm{~s} 1 \mathrm{mC}$ case because of the higher slip ratio thresholds. The $2 \mathrm{~s} 1 \mathrm{~mA}$ and $2 \mathrm{~s} 1 \mathrm{mC}$ systems perform longitudinally to a relatively equal degree because for instances in which the $2 \mathrm{~s} 1 \mathrm{mC}$ has higher brake chamber pressures the $2 \mathrm{~s} 1 \mathrm{~mA}$ system has more locations where the tires lie in the range of slip ratios that allow the maximum tractive braking force (see Figure 3.27). This balance of higher chamber pressures versus more optimum slip ratios at the tires will be exhibited in many other instances of this study. 

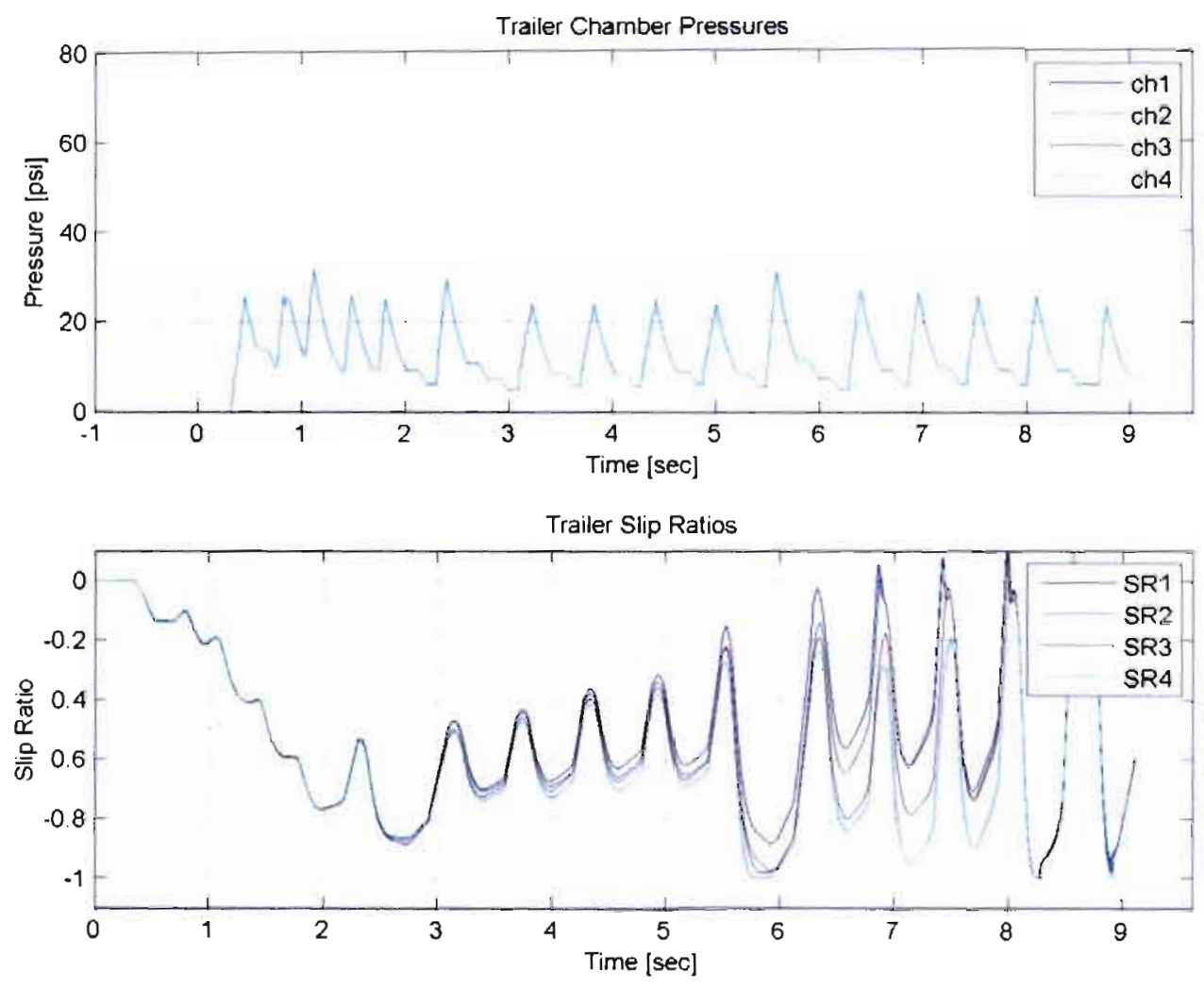

Figure 4.2 - Response of 2s $1 \mathrm{~mA}$ system, 25\% GAWR, Low Friction 

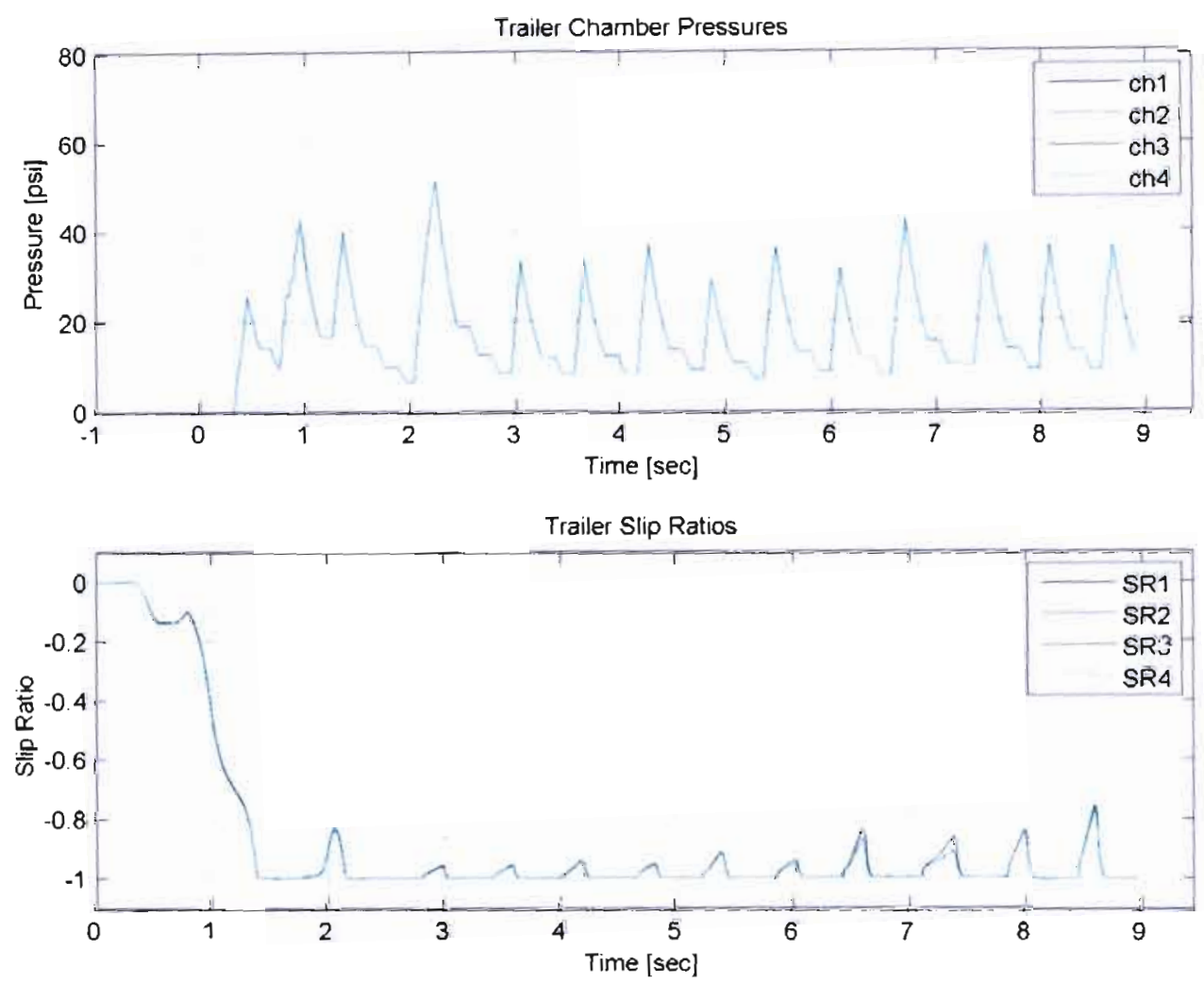

Figure 4.3 - Response of $2 \mathrm{~s} I \mathrm{mC}$ system, 25\% GAWR, Low Friction

In a surprising result, the $2 \mathrm{~s} 1 \mathrm{mB}$ system (designed to perform poor longitudinally) yielded results that were not far inferior to the other systems, for the $60 \mathrm{mph}$ case. Figure 4.4 shows the response of this system, and it can be seen from this plot that many of the resulting slip ratios lie in the optimum range of $20-30 \%$. Even though it was designed to keep the slip ratios of the trailer wheels at lower levels, the situation of low load, low friction, and high speed made higher slip ratios inevitable. As dictated by physics, slip initiates at a wheel whenever the torque request applied from the brake exceeds the amount of torque available at the tire road interface, as dictated by the surface coefficient 
of friction and parameters of the tire. This fact helps to explain why the performance of the $2 \mathrm{~s} 1 \mathrm{mB}$ system was far inferior to the others for the $30 \mathrm{mph}$ case, even though it was not for $60 \mathrm{mph}$, as lower slip ratios would most likely develop in the case of the lower initial speed.
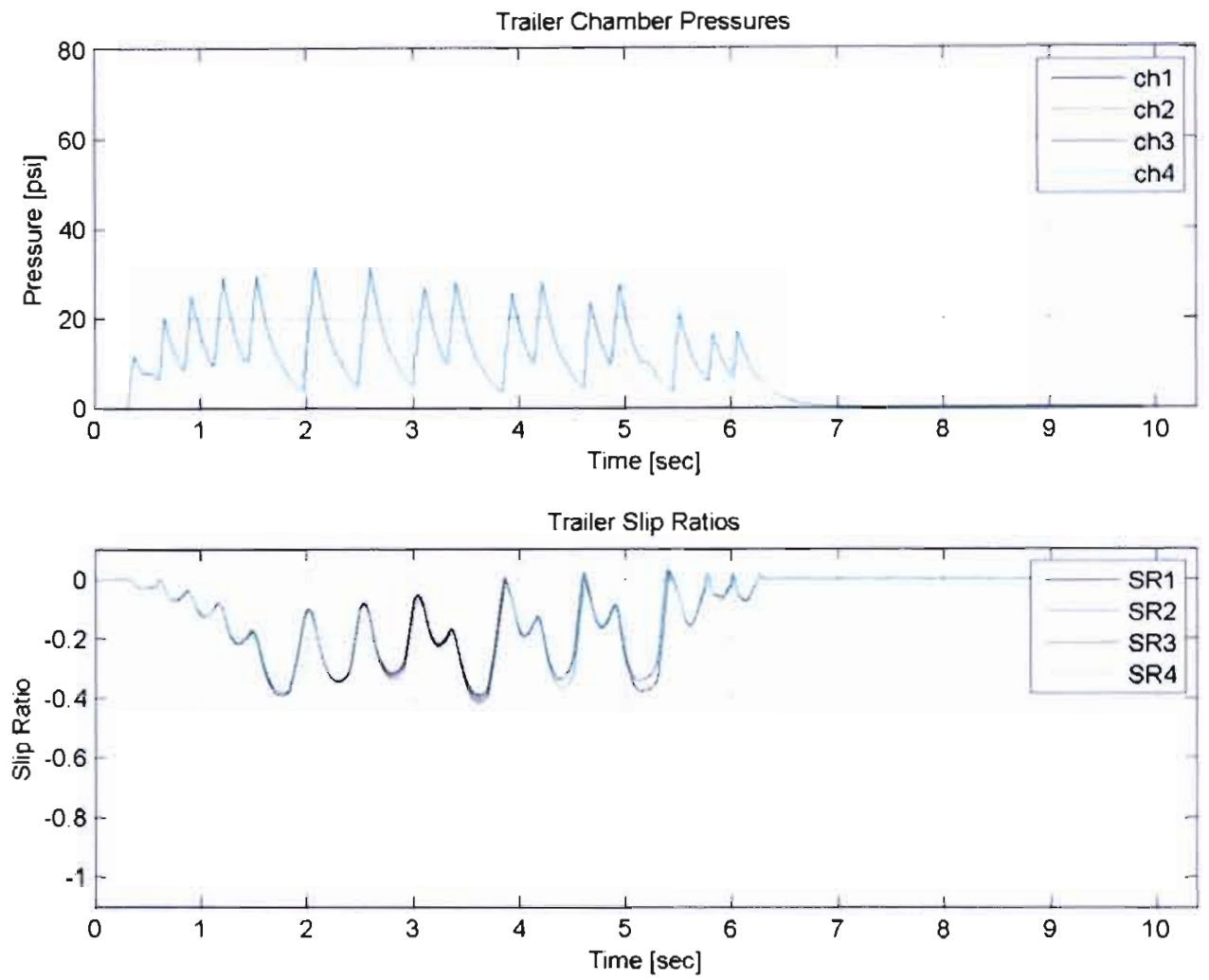

Figure 4.4 - Response of $2 \mathrm{~s} 1 \mathrm{mB}$ system, 25\% GAWR, Low Friction

\subsubsection{5\% GAWR, High Friction}

The results of the simulated tractor-trailer under full vehicle braking, at $25 \%$ of the trailer's GAWR, on a high friction surface, can be seen in Table 4.2 and graphically in Figure 4.5. These show that again, for this case, that the $2 \mathrm{~s} 1 \mathrm{~mA}, 2 \mathrm{~s} 1 \mathrm{mC}, 4 \mathrm{~s} 2 \mathrm{~m}$, and 
$4 \mathrm{~s} 4 \mathrm{~m}$ systems performed equally well, for the same reasons that were explained in Section 4.1.1. The $2 \mathrm{~s} 1 \mathrm{mB}$ system had the poorest performance, and Figure 4.6 shows just why. This figure shows that under this condition, the ABS controller was able to keep the slip ratios of each wheel in the range of 0 to $5 \%$, by keeping brake chamber pressures to values around $20 \mathrm{psi}$. Because of this combination of low brake chamber pressures and slip ratios in the range of lowest tire tractive force, the fact that the $2 \mathrm{~s} 1 \mathrm{mB}$ system performed worse than the others was expected. To show how the other systems performed better, Figure 4.7 illustrates that the $2 \mathrm{~s} 1 \mathrm{~mA}$ system allowed for higher brake chamber pressures and more slip ratios in the optimum range. 


\begin{tabular}{|c|c|c|c|c|}
\hline \multicolumn{5}{|c|}{ Full Braking, 25\% Axle Load, $\mu=0.85$} \\
\hline Speeds & ABS System & $\begin{array}{c}\text { decel } \\
\text { [ABS] }\end{array}$ & S.U. & $\begin{array}{c}\text { S.D. } \\
{[\mathrm{ft}]}\end{array}$ \\
\hline \multirow{4}{*}{$60-6$} & none & 0.626 & - & 218.4 \\
\cline { 2 - 5 } & $2 \mathrm{~s} 1 \mathrm{~m}-\mathrm{A}$ & 0.679 & $108.5 \%$ & 210.0 \\
\cline { 2 - 5 } & $2 \mathrm{~s} 1 \mathrm{~m}-\mathrm{B}$ & 0.519 & $82.9 \%$ & 261.0 \\
\cline { 2 - 5 } & $2 \mathrm{~s} 1 \mathrm{~m}-\mathrm{C}$ & 0.666 & $106.3 \%$ & 208.3 \\
\cline { 2 - 5 } & $4 \mathrm{~s} 2 \mathrm{~m}$ & 0.664 & $106.0 \%$ & 211.0 \\
\cline { 2 - 5 } & $4 \mathrm{~s} 4 \mathrm{~m}$ & 0.674 & $107.6 \%$ & 210.8 \\
\hline \multirow{5}{*}{$30-6$} & none & 0.691 & - & 56.2 \\
\cline { 2 - 5 } & $2 \mathrm{~s} 1 \mathrm{~m}-\mathrm{A}$ & 0.702 & $101.6 \%$ & 55.0 \\
\cline { 2 - 5 } & $2 \mathrm{~s} 1 \mathrm{~m}-\mathrm{B}$ & 0.580 & $83.9 \%$ & 63.7 \\
\cline { 2 - 5 } & $2 \mathrm{~s} 1 \mathrm{~m}-\mathrm{C}$ & 0.710 & $102.8 \%$ & 54.6 \\
\cline { 2 - 5 } & $4 \mathrm{~s} 2 \mathrm{~m}$ & 0.702 & $101.6 \%$ & 55.2 \\
\cline { 2 - 5 } & $4 \mathrm{~s} 4 \mathrm{~m}$ & 0.696 & $100.6 \%$ & 55.4 \\
\hline
\end{tabular}

Table 4.2 - Longitudinal Performance of Full Vehicle Braking, 25\% GAWR, High Friction

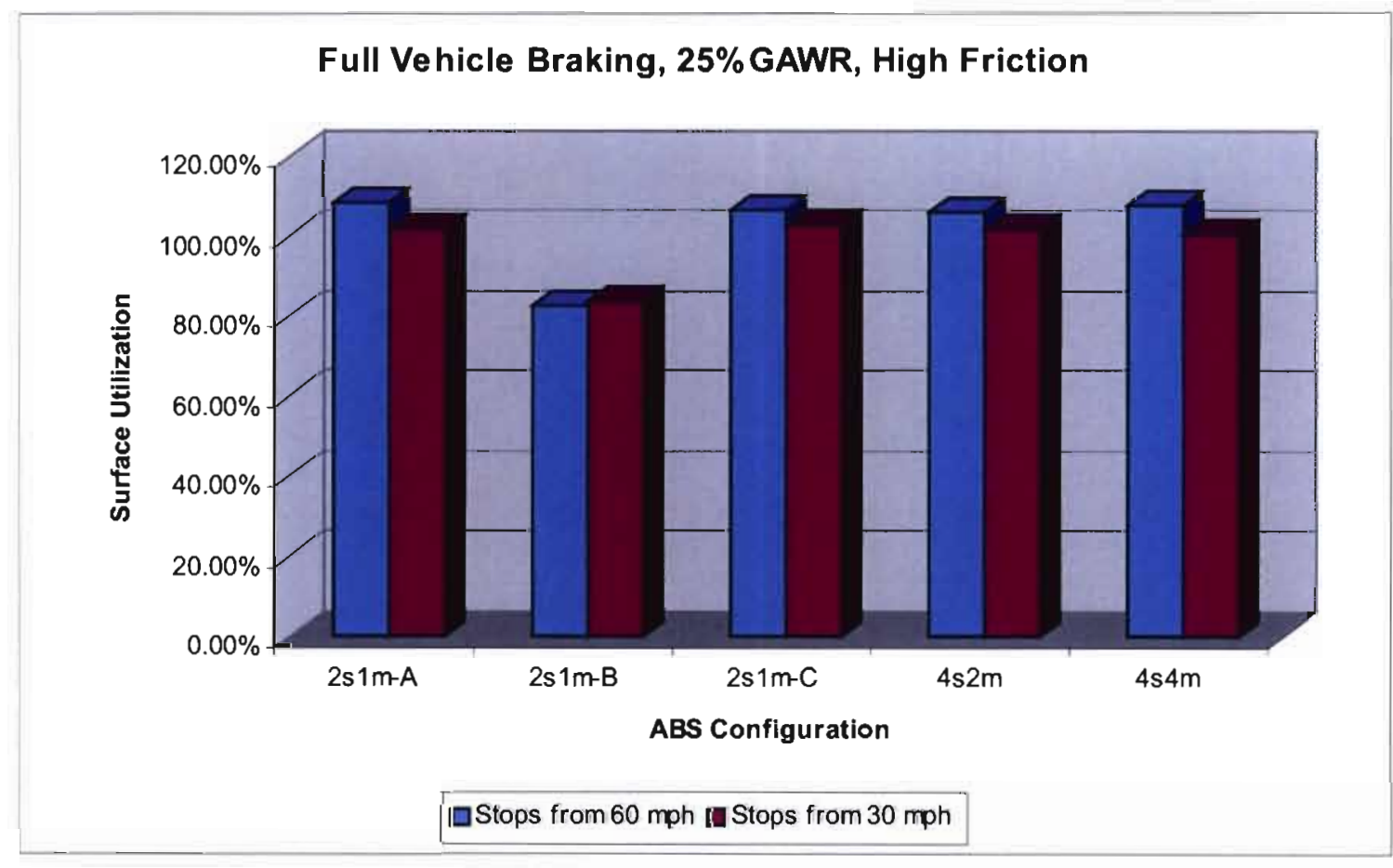

Figure 4.5 - Surface Utilization of Full Vehicle Braking, 25\% GAWR, High Friction 


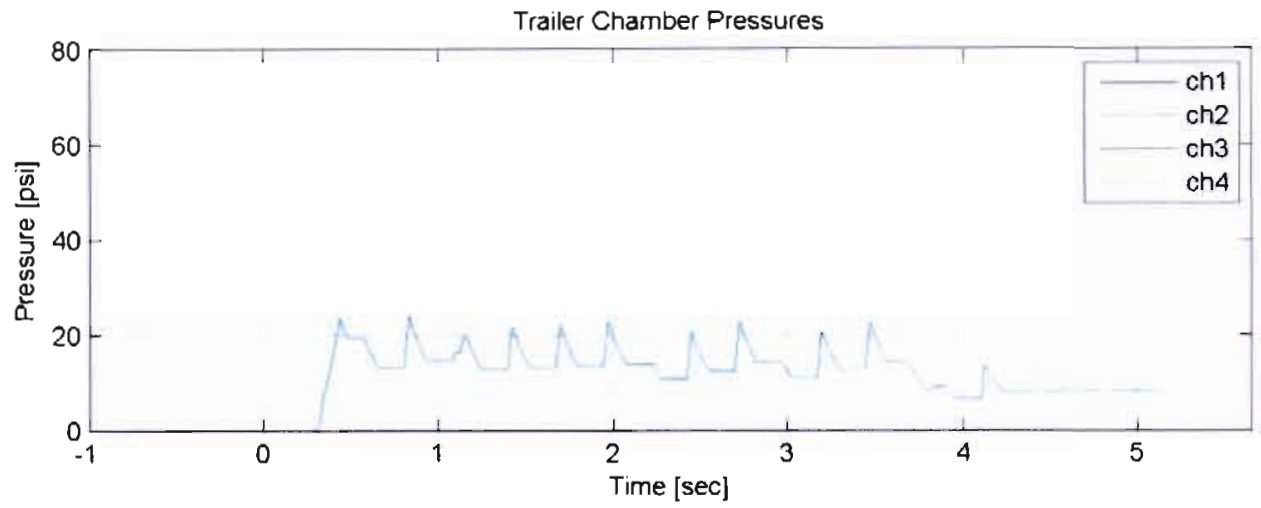

Trailer Slip Ratios

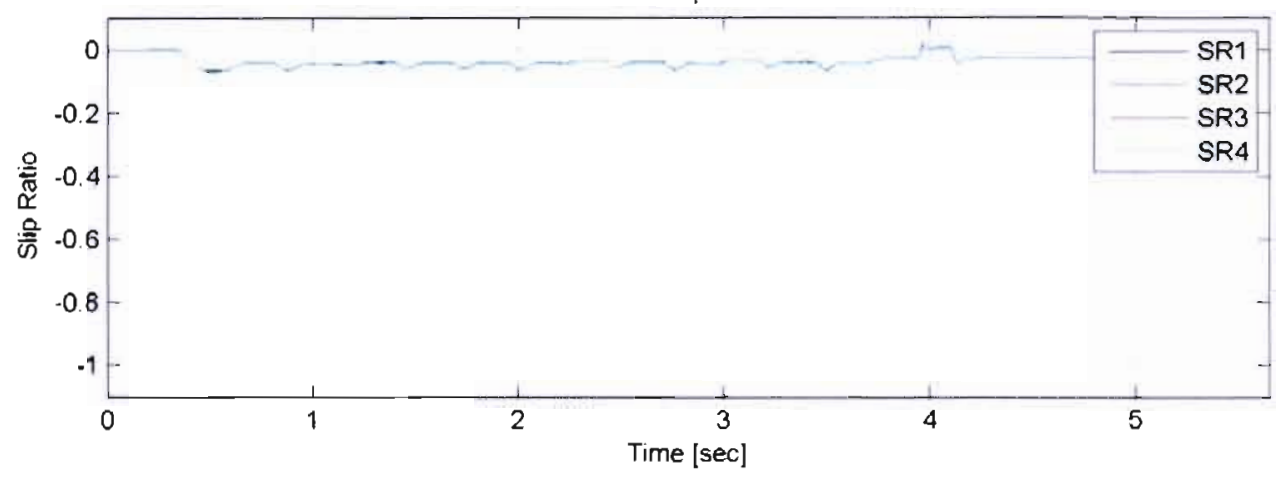

Figure 4.6 - Response of $2 \mathrm{~s} 1 \mathrm{mB}$ system, $25 \%$ GAWR, High Friction 

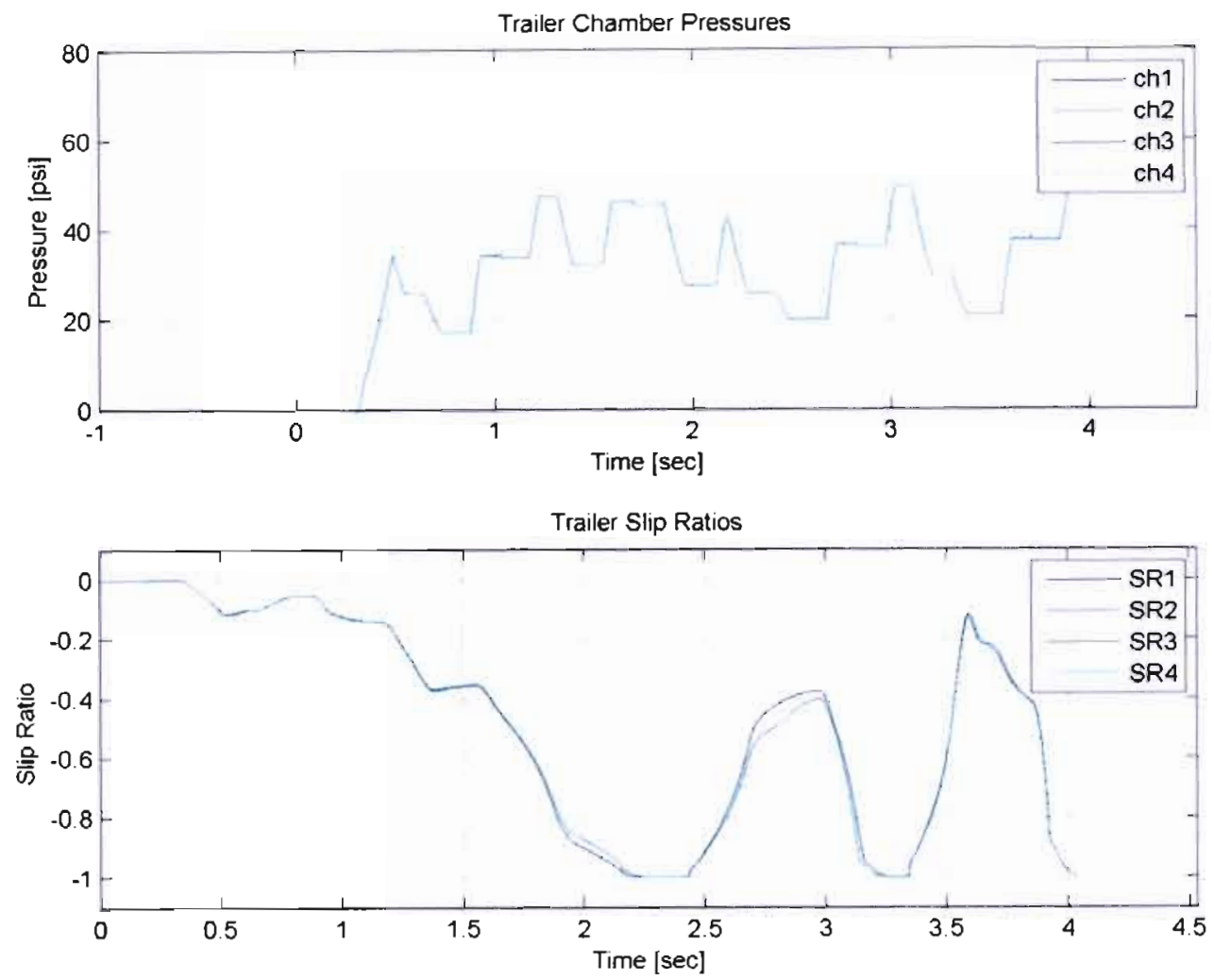

Figure 4.7 - Response of 2s1mA System, 25\% GAWR, High Friction

\subsubsection{5\% GAWR, Low Friction}

Similar results were obtained for the tractor-trailer at $75 \%$ GAWR on the low friction surface as were obtained for the same situation at 25\% GAWR. Again, the $2 \mathrm{~s} 1 \mathrm{~mA}, 2 \mathrm{~s} 1 \mathrm{mC}, 4 \mathrm{~s} 2 \mathrm{~m}$, and $4 \mathrm{~s} 4 \mathrm{~m}$ systems performed to a relatively equal effectiveness. Also, the $2 \mathrm{~s} 1 \mathrm{mB}$ system had the poorest performance; however, the separation between this and the other systems was much larger for this case. The $2 \mathrm{~s} 1 \mathrm{mB}$ system was less effective for this case because under the high axle load condition, the controller was able 
to keep the trailer wheel slip ratios near $0 \%$, which can be seen in Figure 4.9, as the system underutilizes the available traction.

\begin{tabular}{|c|c|c|c|c|}
\hline \multicolumn{5}{|c|}{ Full Braking, 75\% Axle Load, $\mu=0.35$} \\
\hline Speeds & ABS System & $\begin{array}{c}\text { decel } \\
{[\text { ABS] }}\end{array}$ & S.U. & $\begin{array}{c}\text { S.D. } \\
\text { [ft] }\end{array}$ \\
\hline \multirow{4}{*}{60 - 6 } & none & 0.307 & - & 419.0 \\
\cline { 2 - 5 } & $2 \mathrm{~s} 1 \mathrm{~m}-\mathrm{A}$ & 0.309 & $100.9 \%$ & 411.3 \\
\cline { 2 - 5 } & $2 \mathrm{~s} 1 \mathrm{~m}-\mathrm{B}$ & 0.205 & $66.9 \%$ & 617.8 \\
\cline { 2 - 5 } & $2 \mathrm{~s} 1 \mathrm{~m}-\mathrm{C}$ & 0.306 & $99.8 \%$ & 416.2 \\
\cline { 2 - 5 } & $4 \mathrm{~s} 2 \mathrm{~m}$ & 0.311 & $101.3 \%$ & 402.4 \\
\cline { 2 - 5 } & $4 \mathrm{~s} 4 \mathrm{~m}$ & 0.309 & $100.9 \%$ & 418.2 \\
\hline \multirow{4}{*}{30 - 6 } & none & 0.294 & - & 111.2 \\
\cline { 2 - 5 } & $2 \mathrm{~s} 1 \mathrm{~m}-\mathrm{A}$ & 0.310 & $105.3 \%$ & 108.4 \\
\cline { 2 - 5 } & $2 \mathrm{~s} 1 \mathrm{~m}-\mathrm{B}$ & 0.199 & $67.6 \%$ & 156.1 \\
\cline { 2 - 5 } & $2 \mathrm{~s} 1 \mathrm{~m}-\mathrm{C}$ & 0.307 & $104.5 \%$ & 108.6 \\
\cline { 2 - 5 } & $4 \mathrm{~s} 2 \mathrm{~m}$ & 0.310 & $105.4 \%$ & 108.1 \\
\cline { 2 - 5 } & $4 \mathrm{~s} 4 \mathrm{~m}$ & 0.307 & $104.3 \%$ & 108.7 \\
\hline
\end{tabular}

Table 4.3 - Longitudinal Performance of Full Vehicle Braking, 75\% GAWR, Low Friction 


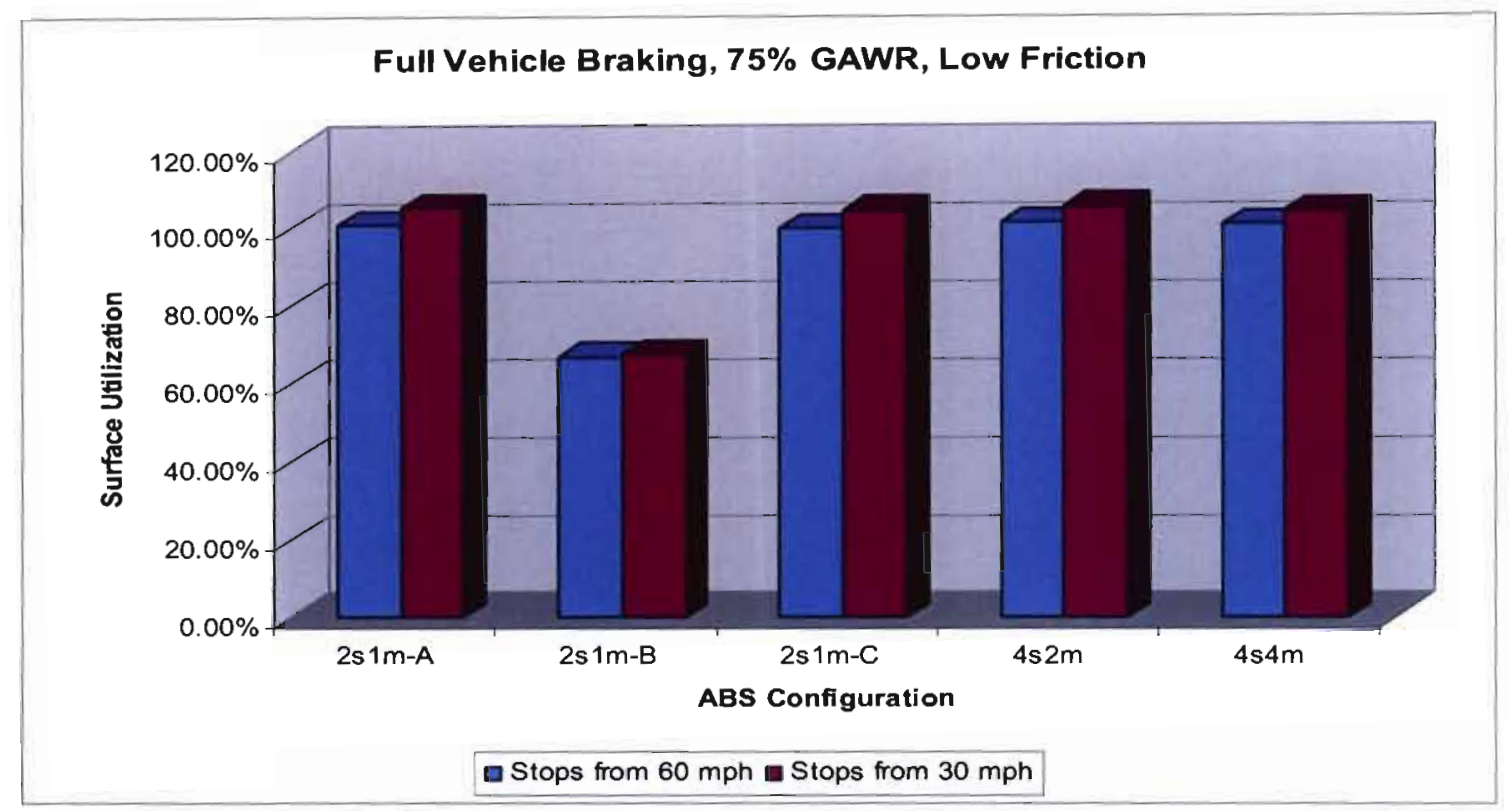

Figure 4.8 - Surface Utilization of Full Vehicle Braking, 75\% GAWR, Low Friction
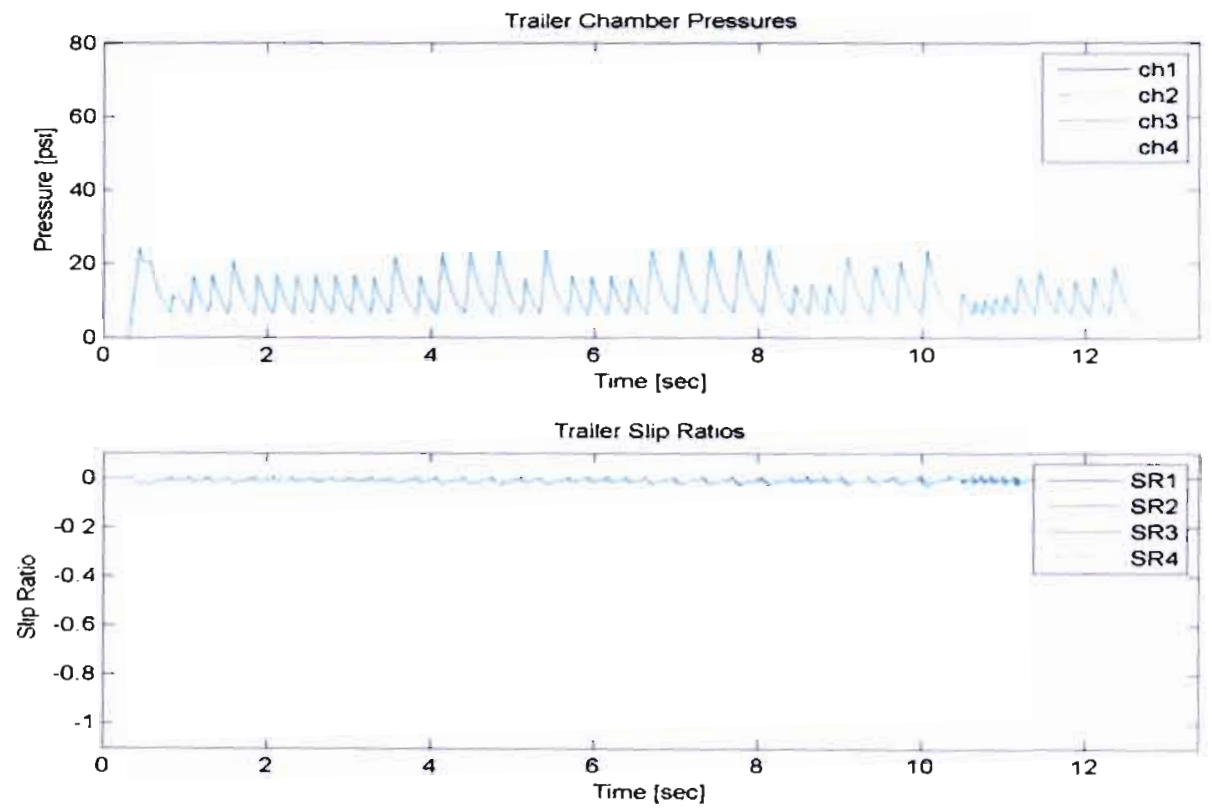

Figure 4.9 - Response of $2 \mathrm{~s} 1 \mathrm{mB}$ system, 75\% GAWR, Low Friction 


\subsubsection{5\% GAWR, High Friction}

Table 4.4 and Figure 4.10 show the performance of the vehicle at $75 \%$ GAWR for stops on a high friction surface. These graphics show that all five systems performed to an equal level of effectiveness, as characterized by the tabulated surface utilization factors and stopping distances. This result is due to the fact that virtually no ABS activity was exhibited in these stops. In the same manner as the GVWR stops for the Peterbilt on a high friction surface, the wheel slip and/or acceleration failed to reach levels high enough to indicate pressure dumps under this loading and surface condition.

\begin{tabular}{|c|c|c|c|c|}
\hline \multicolumn{5}{|c|}{ Full Braking, 75\% Axle Load, $\mu=0.85$} \\
\hline Speeds & ABS System & $\begin{array}{c}\text { decel } \\
{[\text { ABS] }}\end{array}$ & S.U. & $\begin{array}{c}\text { S.D. } \\
\text { [ft] }\end{array}$ \\
\hline \multirow{4}{*}{60 - 6 } & none & 0.681 & - & 216.9 \\
\cline { 2 - 5 } & $2 \mathrm{~s} 1 \mathrm{~m}-\mathrm{A}$ & 0.684 & $100.4 \%$ & 213.9 \\
\cline { 2 - 5 } & $2 \mathrm{~s} 1 \mathrm{~m}-\mathrm{B}$ & 0.666 & $97.9 \%$ & 222.6 \\
\cline { 2 - 5 } & $2 \mathrm{~s} 1 \mathrm{~m}-\mathrm{C}$ & 0.670 & $98.4 \%$ & 217.2 \\
\cline { 2 - 5 } & $4 \mathrm{~s} 2 \mathrm{~m}$ & 0.684 & $100.4 \%$ & 213.9 \\
\cline { 2 - 5 } & $4 \mathrm{~s} 4 \mathrm{~m}$ & 0.684 & $100.4 \%$ & 213.9 \\
\hline \multirow{4}{*}{30 - 6 } & none & 0.804 & - & 57.1 \\
\cline { 2 - 5 } & $2 \mathrm{~s} 1 \mathrm{~m}-\mathrm{A}$ & 0.797 & $99.1 \%$ & 56.4 \\
\cline { 2 - 5 } & $2 \mathrm{~s} 1 \mathrm{~m}-\mathrm{B}$ & 0.767 & $95.8 \%$ & 58.5 \\
\cline { 2 - 5 } & $2 \mathrm{~s} 1 \mathrm{~m}-\mathrm{C}$ & 0.786 & $97.7 \%$ & 56.4 \\
\cline { 2 - 5 } & $4 \mathrm{~s} 2 \mathrm{~m}$ & 0.797 & $99.1 \%$ & 56.3 \\
\cline { 2 - 5 } & $4 \mathrm{~s} 4 \mathrm{~m}$ & 0.790 & $98.3 \%$ & 56.4 \\
\hline
\end{tabular}

Table 4.4 - Longitudinal Performance of Full Vehicle Braking, 75\% GAWR, High Friction 


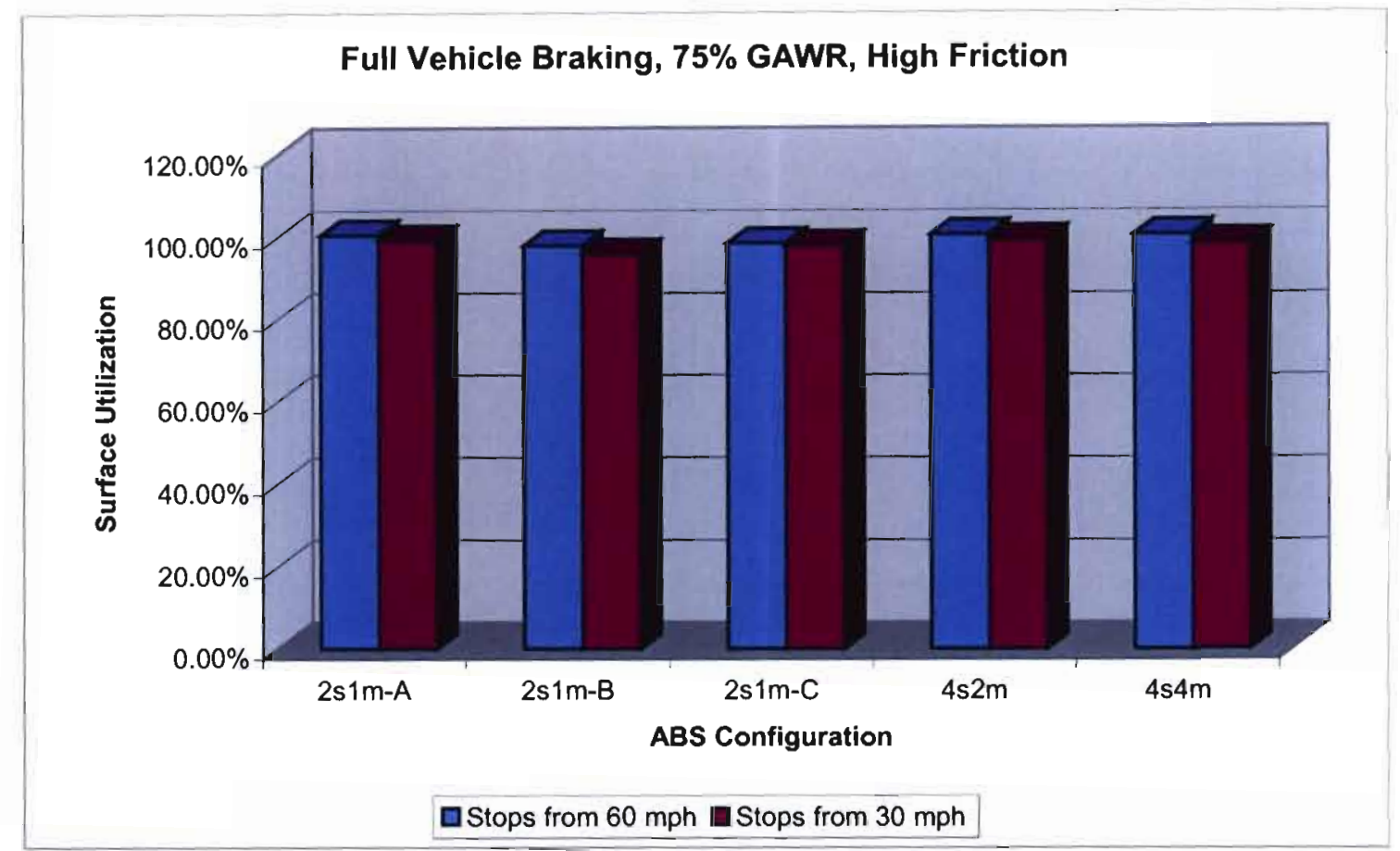

Figure 4.10 - Surface Utilization of Full Vehicle Braking, 75\% GAWR, High Friction

\subsection{Straight-Ahead Snubs - Trailer-Only Braking}

In an effort to eliminate the influence of the braking dynamics of the Sterling tractor, the tests of Section 4.1 were again simulated; however, for these tests, only the brakes on the trailer were activated. Such a braking situation is relevant not only because the response of the trailer, braking by itself, could be studied but also because this is a practice that may occur for tractor-trailers on roads. When a driver needs to moderately decrease the speed of his or her vehicle, he or she has the option to activate a valve known as the gladhand, which allows pneumatic brake signals to be sent to the brake 
chambers of the trailer and not to those of the tractor. It should be noted, however, that this would not be done in an emergency braking situation.

The results of these simulations were quite interesting and somewhat unexpected. Some interesting factors came into play when the speed of the vehicle was decreased (from 60 to $40 \mathrm{mph}$ and from 30 to $15 \mathrm{mph}$ ) without the assistance of the tractor brakes, which will be seen throughout this section.

\subsubsection{5\% GAWR, Low Friction}

The simulated results at this testing scenario, as seen in Table 4.5 and Figure 4.11, show that again the $2 \mathrm{~s} 1 \mathrm{~mA}, 2 \mathrm{~s} 1 \mathrm{mC}, 4 \mathrm{~s} 2 \mathrm{~m}$, and $4 \mathrm{~s} 4 \mathrm{~m}$ systems yielded relatively equal longitudinal performance. The brake chamber pressures and slip ratios of the $2 \mathrm{~s} 1 \mathrm{~mA}$ and $2 \mathrm{~s} 1 \mathrm{mC}$ systems, seen in Figure 4.12 and Figure 4.13, show the familiar compromise between higher brake chamber pressures and optimum slip ratios, also exhibited in the full vehicle braking scenarios. One can see from these graphics that the $2 \mathrm{~s} 1 \mathrm{mB}$ system actually performed higher than the other systems for this test; this fact resulted in a detailed analysis into the behavior of the simulated ABS controllers under the trailer-only braking condition. 


\begin{tabular}{|c|c|c|c|c|}
\hline \multicolumn{5}{|c|}{ Trailer Only Braking, $25 \%$ Axle Load, $\mu=0.35$} \\
\hline Speeds & $\begin{array}{c}\text { ABS } \\
\text { System }\end{array}$ & $\begin{array}{c}\text { decel } \\
\text { [ABS] }\end{array}$ & S.U. & $\begin{array}{c}\text { S.D. } \\
{[\mathrm{ft}]}\end{array}$ \\
\hline \multirow{5}{*}{$60-40$} & none & 0.0868 & - & 795.5 \\
\cline { 2 - 5 } & $2 \mathrm{~s} 1 \mathrm{~m}-\mathrm{A}$ & 0.0872 & $100.46 \%$ & 783.2 \\
\cline { 2 - 5 } & $2 \mathrm{~s} 1 \mathrm{~m}-\mathrm{B}$ & 0.0896 & $103.23 \%$ & 782.9 \\
\cline { 2 - 5 } & $2 \mathrm{~s} 1 \mathrm{~m}-\mathrm{C}$ & 0.0868 & $100.00 \%$ & 788.4 \\
\cline { 2 - 5 } & $4 \mathrm{~s} 2 \mathrm{~m}$ & 0.0873 & $100.58 \%$ & 782.9 \\
\cline { 2 - 5 } & $4 \mathrm{~s} 4 \mathrm{~m}$ & 0.0868 & $100.00 \%$ & 787.9 \\
\hline \multirow{5}{*}{$30-15$} & none & 0.0866 & - & 276.6 \\
\cline { 2 - 5 } & $2 \mathrm{~s} 1 \mathrm{~m}-\mathrm{A}$ & 0.0866 & $100.00 \%$ & 276.4 \\
\cline { 2 - 5 } & $2 \mathrm{~s} 1 \mathrm{~m}-\mathrm{B}$ & 0.0888 & $102.54 \%$ & 270.4 \\
\cline { 2 - 5 } & $2 \mathrm{~s} 1 \mathrm{~m}-\mathrm{C}$ & 0.0866 & $100.00 \%$ & 276.4 \\
\cline { 2 - 5 } & $4 \mathrm{~s} 2 \mathrm{~m}$ & 0.0866 & $100.00 \%$ & 276.4 \\
\cline { 2 - 5 } & $4 \mathrm{~s} 4 \mathrm{~m}$ & 0.0867 & $100.12 \%$ & 276.3 \\
\hline
\end{tabular}

Table 4.5 - Longitudinal Performance of Trailer-Only Braking, 25\% GAWR, Low Friction

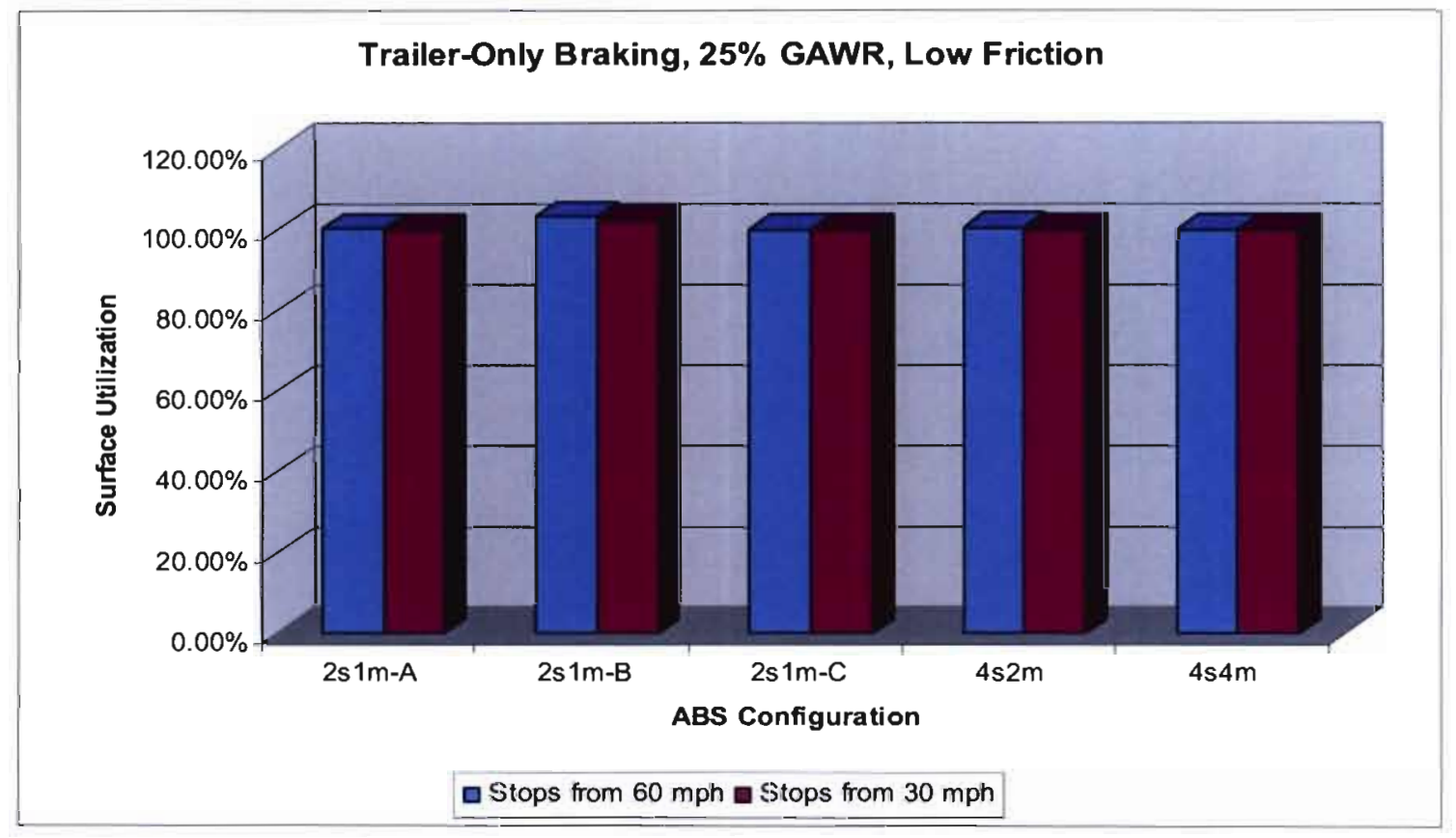

Figure 4.11 - Surface Utilization of Trailer-Only Braking, 25\% GAWR, Low Friction 

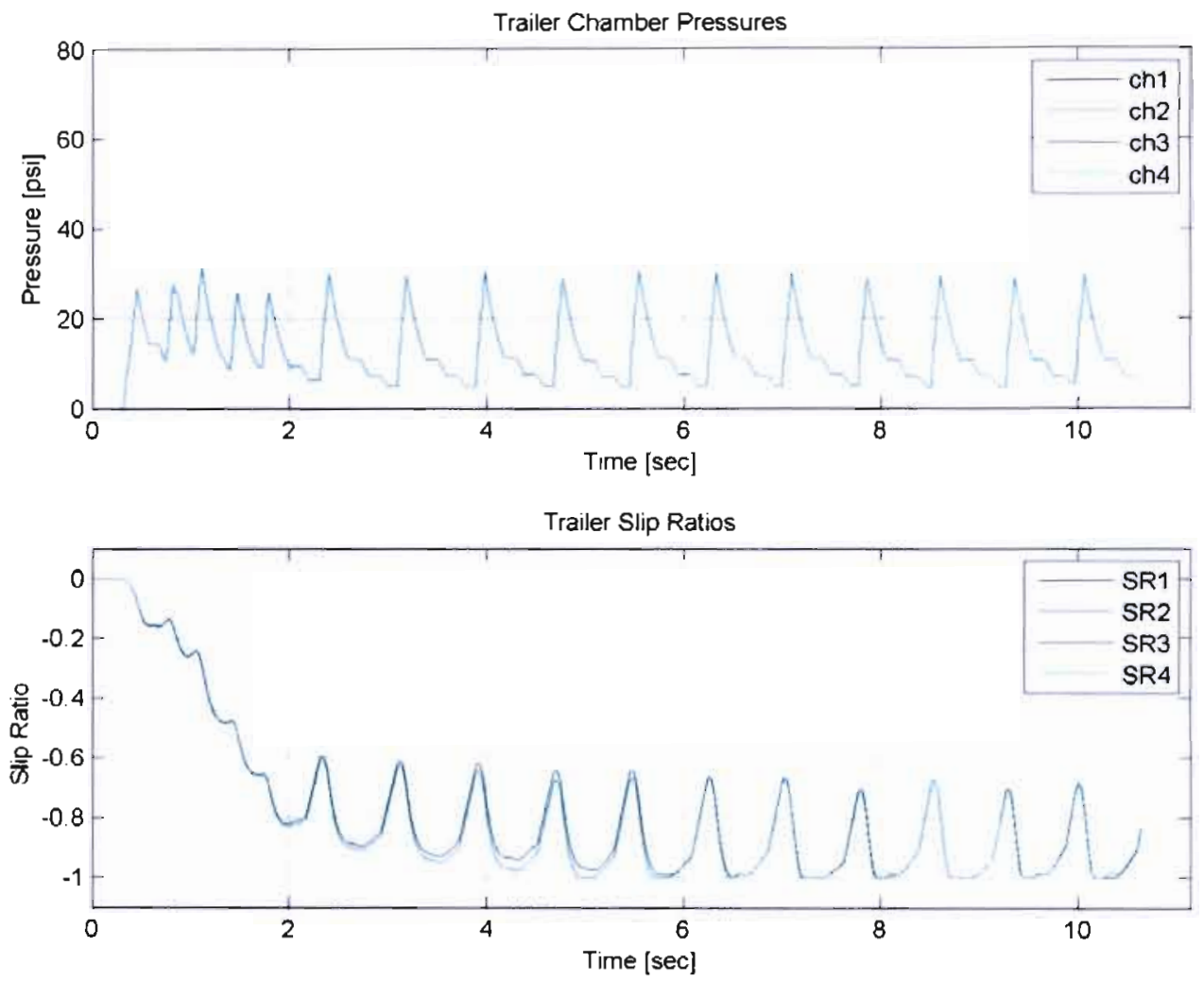

Figure 4.12 - Trailer-Only Braking Response of 2s $1 \mathrm{~mA}$ system, 25\% GAWR, Low Friction 

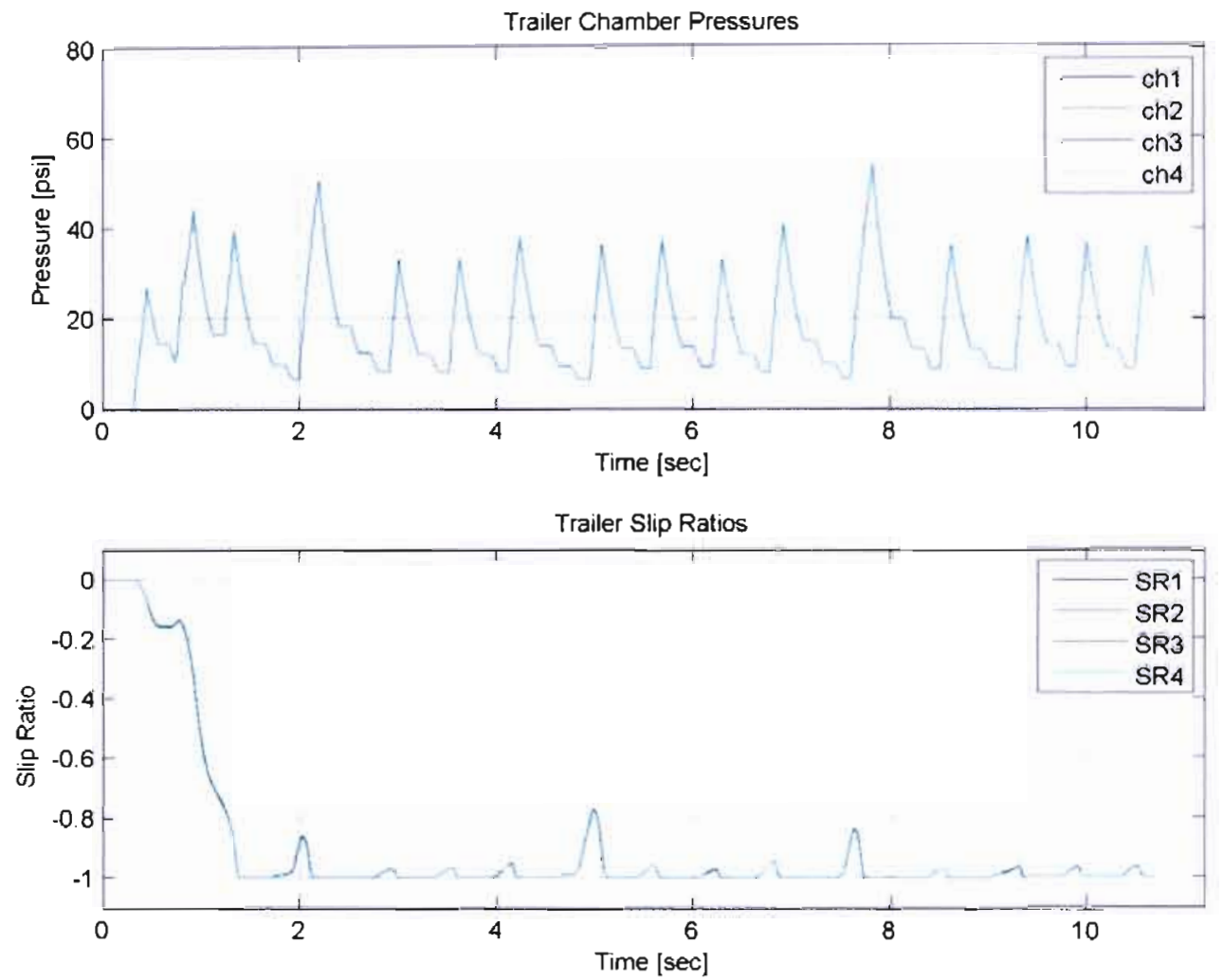

Figure 4.13 - Trailer-Only Braking Response of 2s $1 \mathrm{mC}$ system, 25\% GAWR, Low Friction

Because the $2 \mathrm{~s} 1 \mathrm{mB}$ system was easily the poorest performing system for the full vehicle braking tests of Section 4.1, it was odd that it performed the best for this case. Figure 4.14 and Figure 4.15 show the brake chamber pressures and slip ratios for each trailer wheel location for the $2 \mathrm{~s} 1 \mathrm{mB}$ snubs from 60 and $30 \mathrm{mph}$, respectively. The snub from 60 mph shows a chamber pressure response characteristic of those found for the $2 \mathrm{~s} 1 \mathrm{mB}$ system under full vehicle braking; however, the resulting wheel slip ratios are at higher levels than those found in the full vehicle case (see Figure 4.4). Figure 4.15 again shows high slip ratios along with an interesting building characteristic from 5 seconds 
until the end of the stop. It was unexpected to find building behavior like this because it is characteristic of low velocity (near $0 \mathrm{mph}$ ) building behavior of many ABS systems. For this and previous $\mathrm{ABS}$ controller models, the controller allows the brake chambers to build, in a continuous, stair-step fashion from $6 \mathrm{mph}$ until the end of the stop. These commands should not have been possible outputs from the ABS controller model as the speed of the tractor-trailer was being reduced only to $15 \mathrm{mph}$ from $30 \mathrm{mph}$.
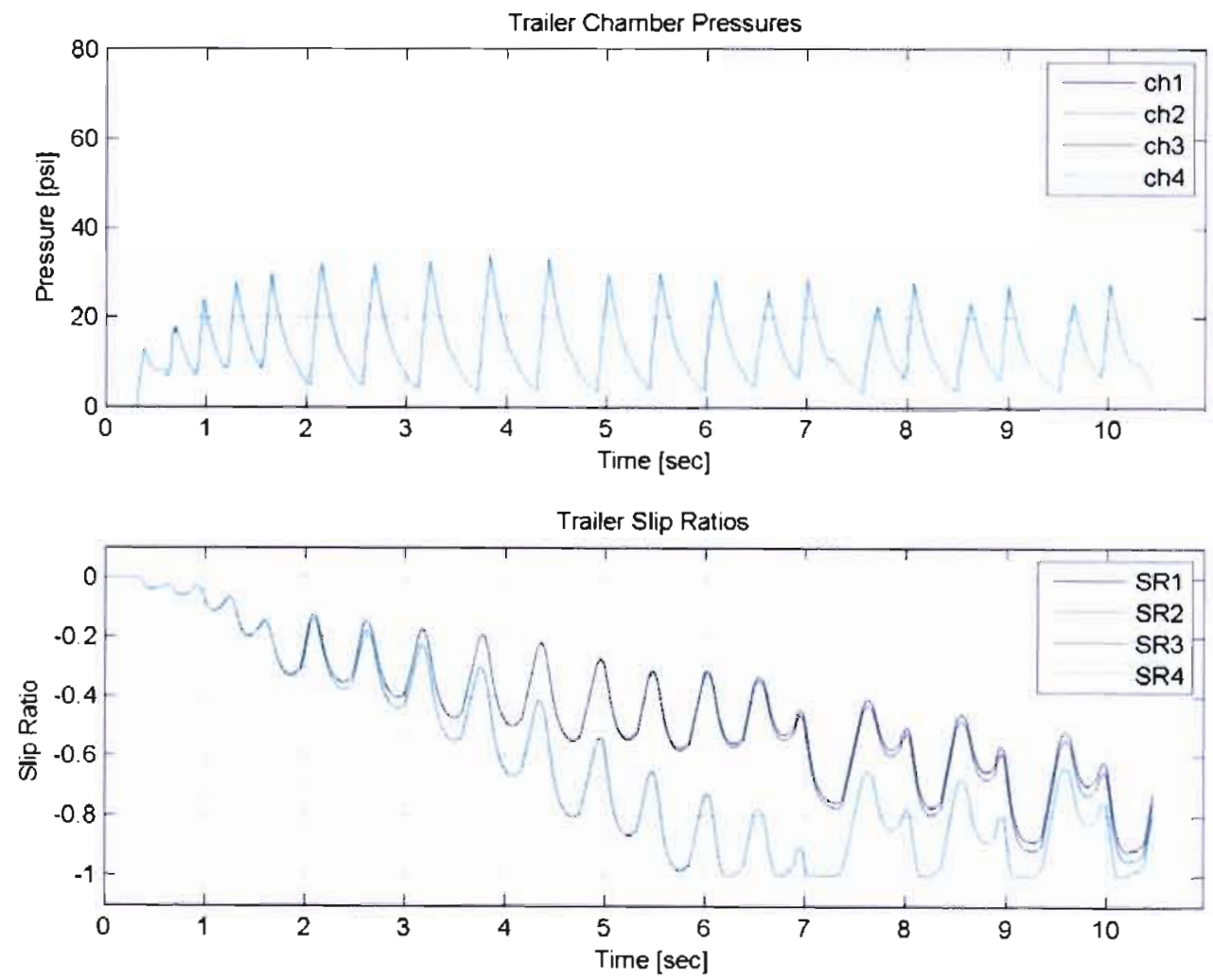

Figure 4.14 - Trailer-Only Braking Response of $2 \mathrm{~s} 1 \mathrm{mB}$ system, 25\% GAWR, Low Friction, from $60 \mathrm{mph}-40 \mathrm{mph}$ 

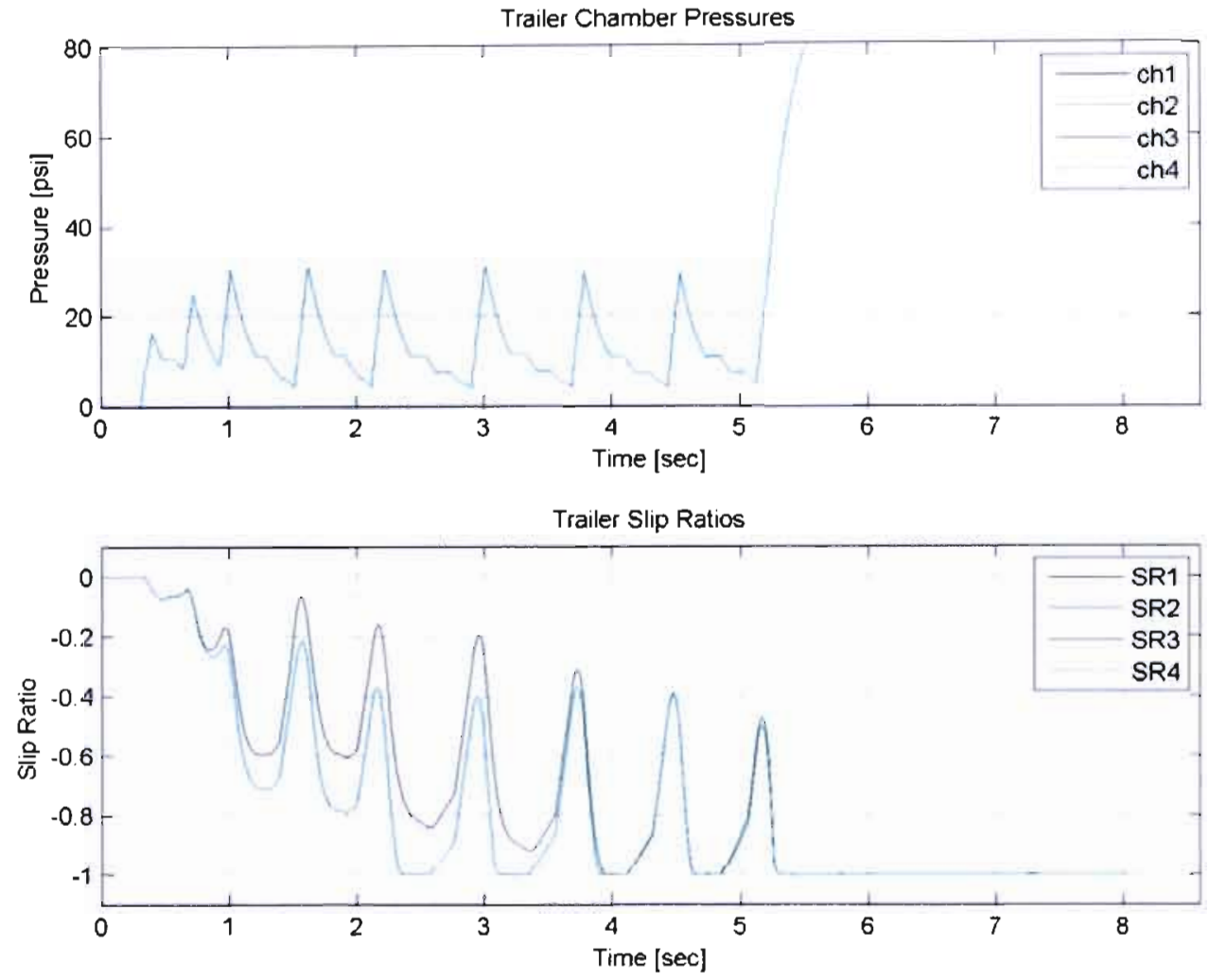

Figure 4.15 - Trailer-Only Braking Response of $2 \mathrm{~s} 1 \mathrm{mB}$ system, 25\% GAWR, Low Friction, from $30 \mathrm{mph}-15 \mathrm{mph}$

Due to this strange activity, the vehicle speed of the tractor-trailer was examined. Because the trailer's ABS controller model accepts only the sensed wheel speeds as inputs, it must use those wheel speeds to estimate the vehicle speed of the trailer. This procedure is outlined in Section 4.2.1 of Zaugg [7]. In short, the vehicle speed is estimated by taking the previous vehicle speed and subtracting from it the maximum change in wheel speeds. The change in vehicle speed over a given time period is limited by friction, however, so that the speed of the vehicle cannot decrease faster than what is physically possible under the current tire-road interface. Under the situation of trailer- 
only braking, it was hypothesized that the wheels of the trailer would decelerate at a much faster rate than the total vehicle; this would lead to the ABS controller model "thinking" that the trailer was slowing down at a faster rate than it actually was. To examine this further, the actual speed of the trailer (calculated in TruckSim) was plotted against the estimated speed of the trailer's ABS controller. Figure 4.16 shows that while the actual vehicle slows from 30 to $15 \mathrm{mph}$ over the 8 second snub, the ABS controller estimated that the trailer had come to a complete stop over that duration. It can be seen from Figure 4.15 that the low velocity stair-step building behavior begins at around 5.2 seconds, and it can be seen in Figure 4.16 that at this time the controller estimated trailer speed crosses the $6 \mathrm{mph}$ threshold. 


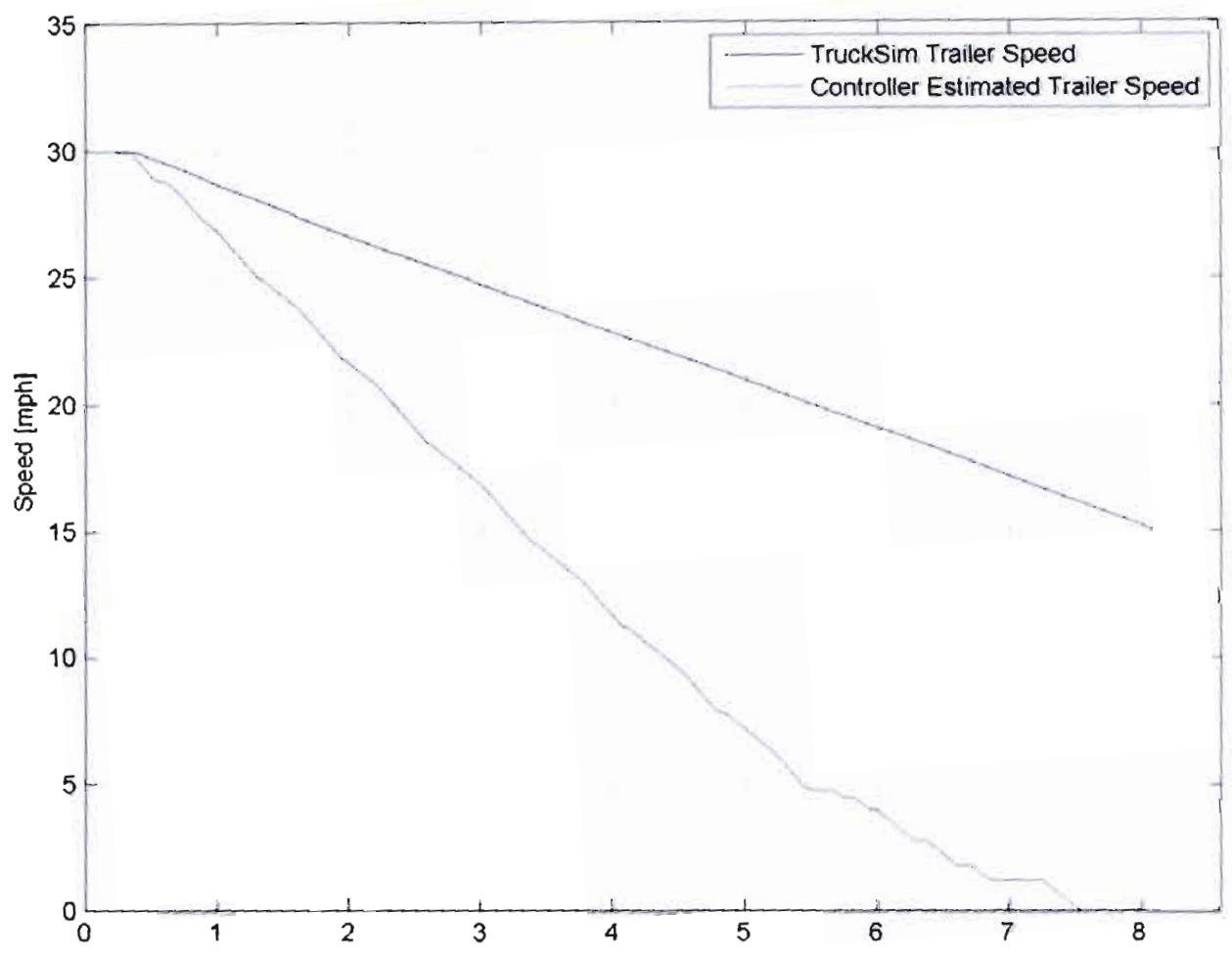

Figure 4.16 - Actual and Controller Estimated Trailer Speeds for $2 \mathrm{~s} 1 \mathrm{mB}$ system from 30 $\mathrm{mph}$

Inadequate vehicle speed estimation not only affects the building behavior of the simulated trailer, it is also essential to the estimation of slip ratio internal to the ABS controller. The ABS controller uses the internally estimated vehicle speed, along with the four independent wheel speeds, to estimate the slip ratio at each wheel according to Equation 1, where $v_{i}$ is the longitudinal speed of the wheel ' $i$ ', and $v_{\text {vehicle }}$ is the overall vehicle speed. Because the estimated vehicle speed is an essential part to the calculation of slip ratio for the sensed wheels, it is probable that the difference in the actual values 
for each sensed wheel (as seen in Figure 4.15) and those expected can be attributed to the vehicle speed estimation.

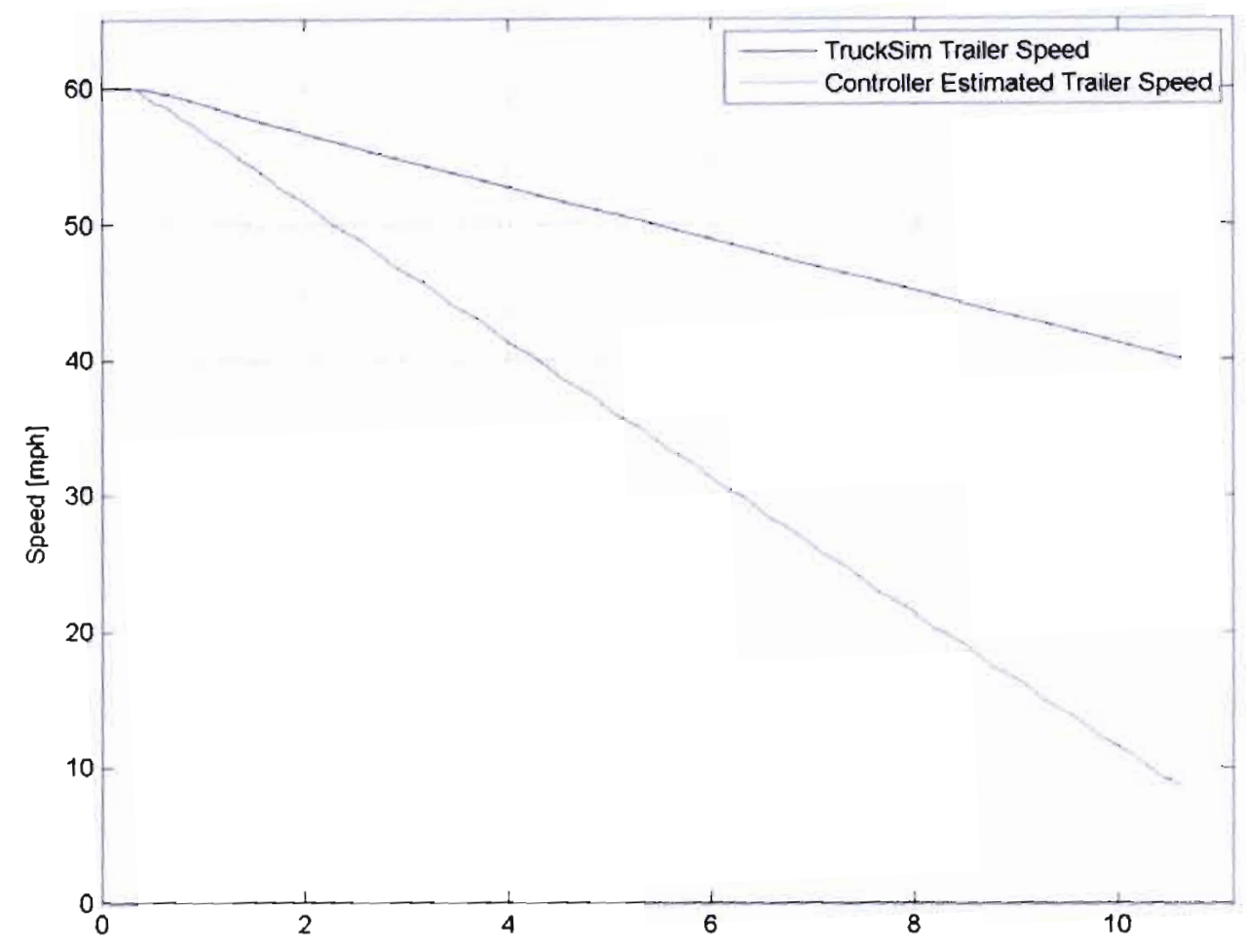

Figure 4.17 - Actual and Controller Estimated Trailer Speeds for $2 \mathrm{~s} 1 \mathrm{mB}$ system from 60 mph

To examine this further, the stop from $60 \mathrm{mph}$ was examined. The actual and controller estimated trailer speeds for this simulation can be seen in Figure 4.17. It can be seen from this plot that the estimated speed does in fact deviate greatly from the actual (TruckSim calculated) speed. Questioning whether a large discrepancy would exist, the actual slip ratios for each wheel were plotted along with those estimated by the ABS 
controller model in Figure 4.18. This presents an interesting result; from the estimated slip ratios, the $2 \mathrm{~s} 1 \mathrm{mB}$ controller model appeared to be acting as it should, when the actual slip ratio traces show that much larger values. In other words, the controller estimated that it was keeping the wheels as close to $0 \%$ slip as possible when in actuality, due to poor vehicle speed estimation, the slip ratios of the tires remained in the range of 40 to $80 \%$.
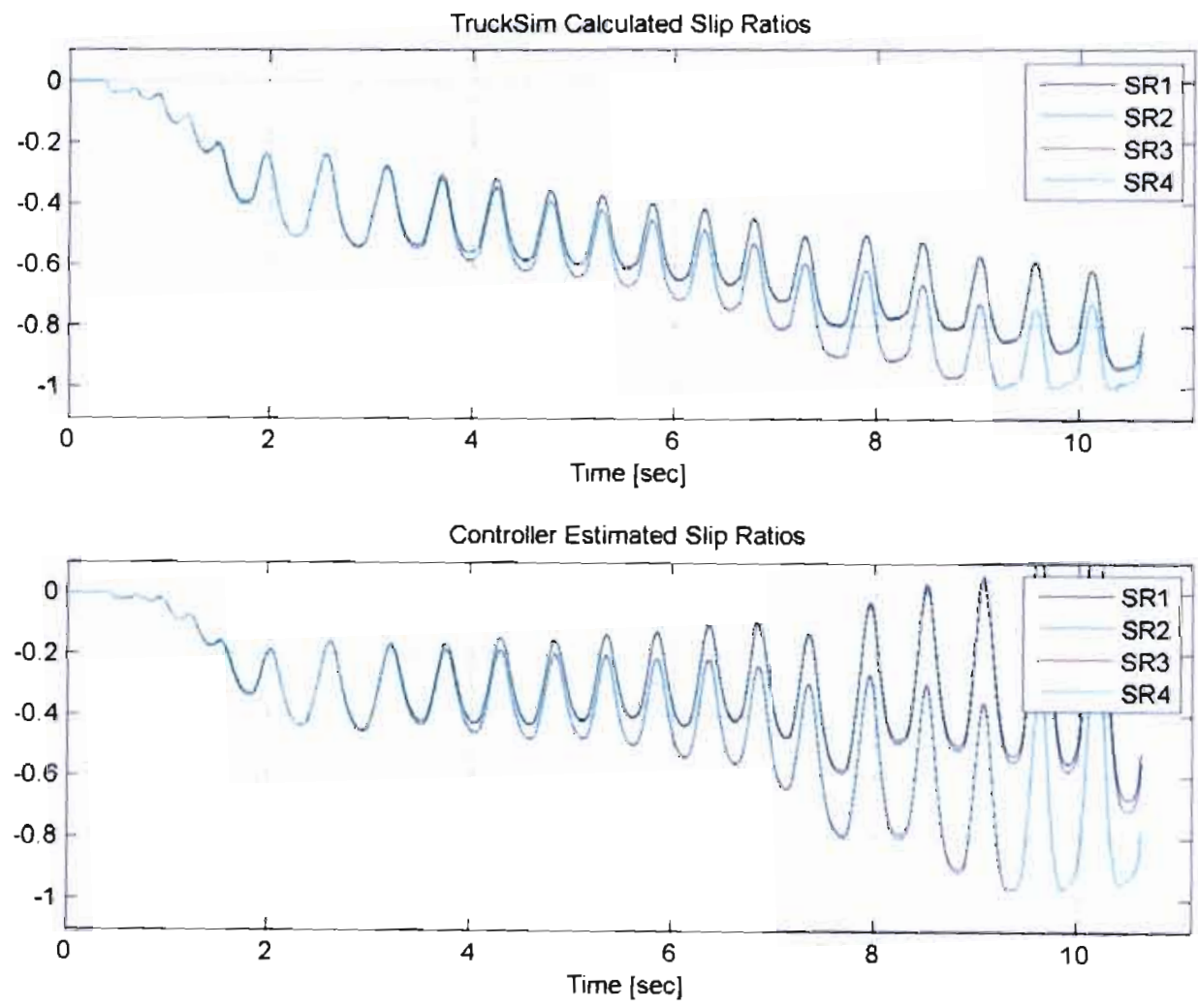

Figure 4.18 - Actual and Controller Calculated Slip Ratios for $2 \mathrm{~s} 1 \mathrm{mB}$ system from 60 mph 


\subsubsection{5\% GAWR, High Friction}

For the high friction stop at $25 \%$ GAWR, the $2 \mathrm{~s} 1 \mathrm{mB}$ system again performed closely to the other systems, even though they performed much better than $2 \mathrm{~s} 1 \mathrm{mB}$ under the equivalent, full vehicle braking situation (see Section 4.1.2). This result is again attributed to inaccurate estimation of vehicle speed by the trailer ABS controller under the trailer-only braking condition. Figure 4.20 shows that due to poor calculation of slip ratio in the controller, the actual resulting slip ratios for the $2 \mathrm{~s} 1 \mathrm{mB}$ system for the high friction case vary between 10 and $20 \%$; because these values are in the optimum range for longitudinal performance, it can be deduced that the $2 \mathrm{~s} 1 \mathrm{mB}$ system performs similarly to the other systems because of this fact. That figure also shows that some low velocity building behavior is seen in the $2 \mathrm{~s} 1 \mathrm{mB}$ system, after about 4.4 seconds. Figure 4.21 shows that even though the initial speed of the stop was $60 \mathrm{mph}$, the speed estimated by the controller does drop below the $6 \mathrm{mph}$ speed threshold. 


\begin{tabular}{|c|c|c|c|c|}
\hline \multicolumn{5}{|c|}{ Trailer Only Braking, 25\% Axle Load, $\mu=0.85$} \\
\hline Speeds & $\begin{array}{c}\text { ABS } \\
\text { System }\end{array}$ & $\begin{array}{c}\text { decel } \\
\text { [ABS] }\end{array}$ & S.U. & $\begin{array}{c}\text { S.D. } \\
\text { [f] }\end{array}$ \\
\hline \multirow{5}{*}{$60-40$} & none & 0.1957 & - & 373.9 \\
\cline { 2 - 5 } & $2 \mathrm{~s} 1 \mathrm{~m}-\mathrm{A}$ & 0.2082 & $106.39 \%$ & 361.5 \\
\cline { 2 - 5 } & $2 \mathrm{~s} 1 \mathrm{~m}-\mathrm{B}$ & 0.2066 & $105.57 \%$ & 370.1 \\
\cline { 2 - 5 } & $2 \mathrm{~s} 1 \mathrm{~m}-\mathrm{C}$ & 0.2026 & $103.53 \%$ & 362.0 \\
\cline { 2 - 5 } & $4 \mathrm{~s} 2 \mathrm{~m}$ & 0.2026 & $103.53 \%$ & 368.0 \\
\hline \multirow{5}{*}{$30-15$} & $4 \mathrm{~s} 4 \mathrm{~m}$ & 0.2098 & $107.20 \%$ & 359.8 \\
\hline & none & 0.1956 & - & 132.7 \\
\cline { 2 - 5 } & $2 \mathrm{~s} 1 \mathrm{~m}-\mathrm{A}$ & 0.1967 & $100.56 \%$ & 128.2 \\
\cline { 2 - 5 } & $2 \mathrm{~s} 1 \mathrm{~m}-\mathrm{B}$ & 0.2009 & $102.71 \%$ & 128.4 \\
\cline { 2 - 5 } & $2 \mathrm{~s} 1 \mathrm{~m}-\mathrm{C}$ & 0.1982 & $101.33 \%$ & 126.7 \\
\cline { 2 - 5 } & $4 \mathrm{~s} 2 \mathrm{~m}$ & 0.1981 & $101.28 \%$ & 128.6 \\
\cline { 2 - 5 } & $4 \mathrm{~s} 4 \mathrm{~m}$ & 0.1979 & $101.18 \%$ & 128.1 \\
\hline
\end{tabular}

Table 4.6 - Longitudinal Performance of Trailer-Only Braking, 25\% GAWR, High Friction

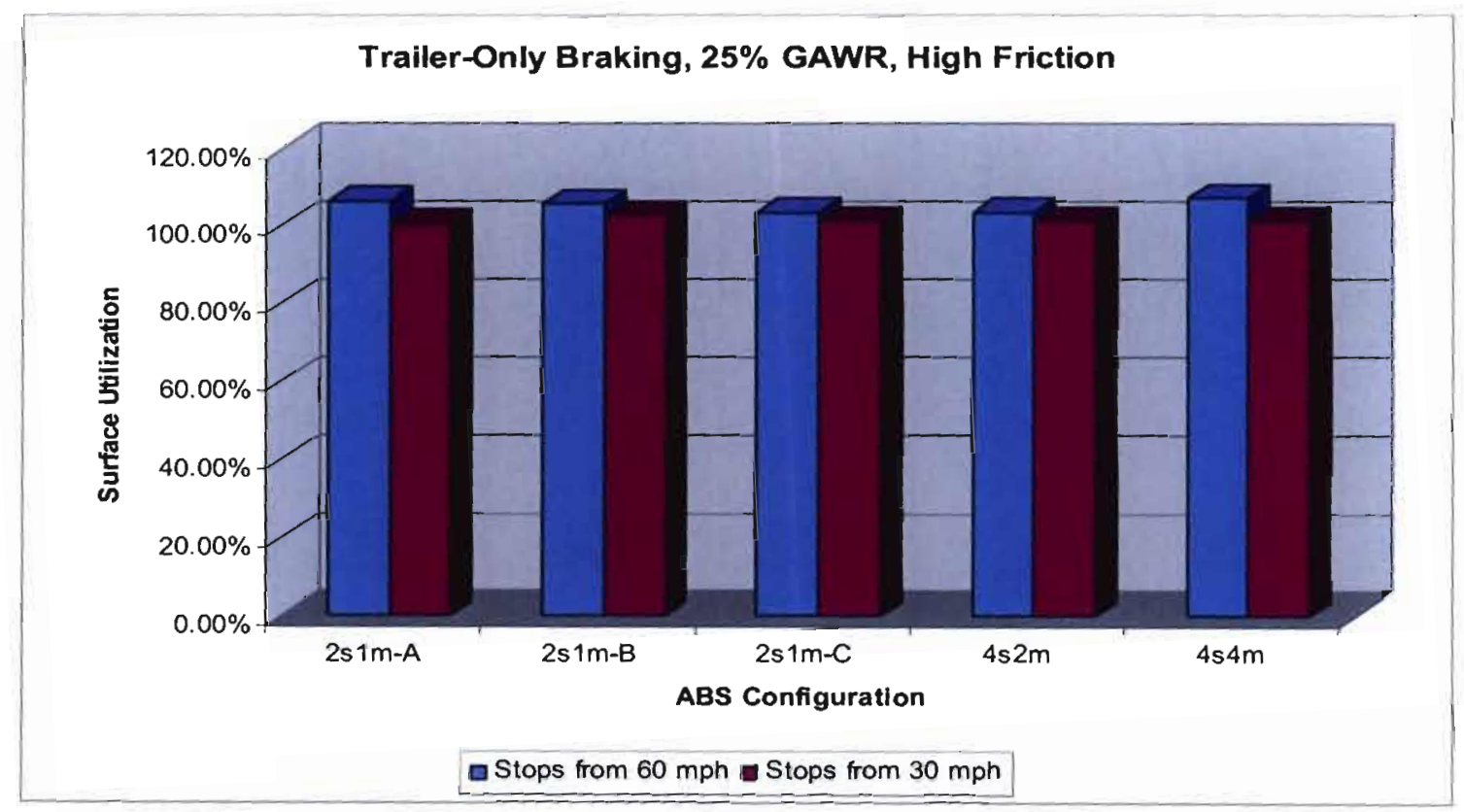

Figure 4.19 - Surface Utilization of Trailer-Only Braking, 25\% GAWR, Low Friction 

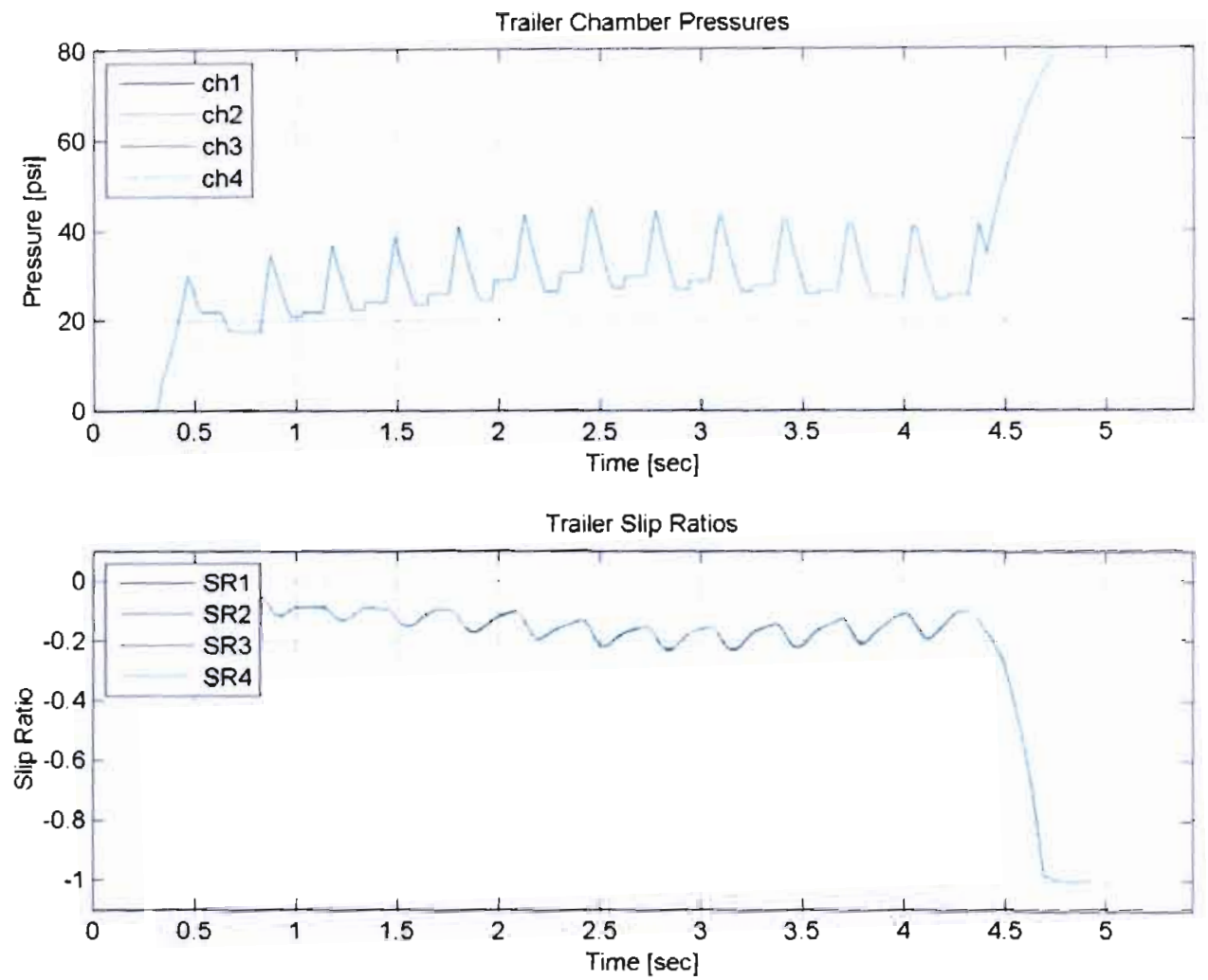

Figure 4.20 - Trailer-Only Braking Response of $2 \mathrm{~s} 1 \mathrm{mB}$ system, 25\% GAWR, High Friction, from $60 \mathrm{mph}$ 


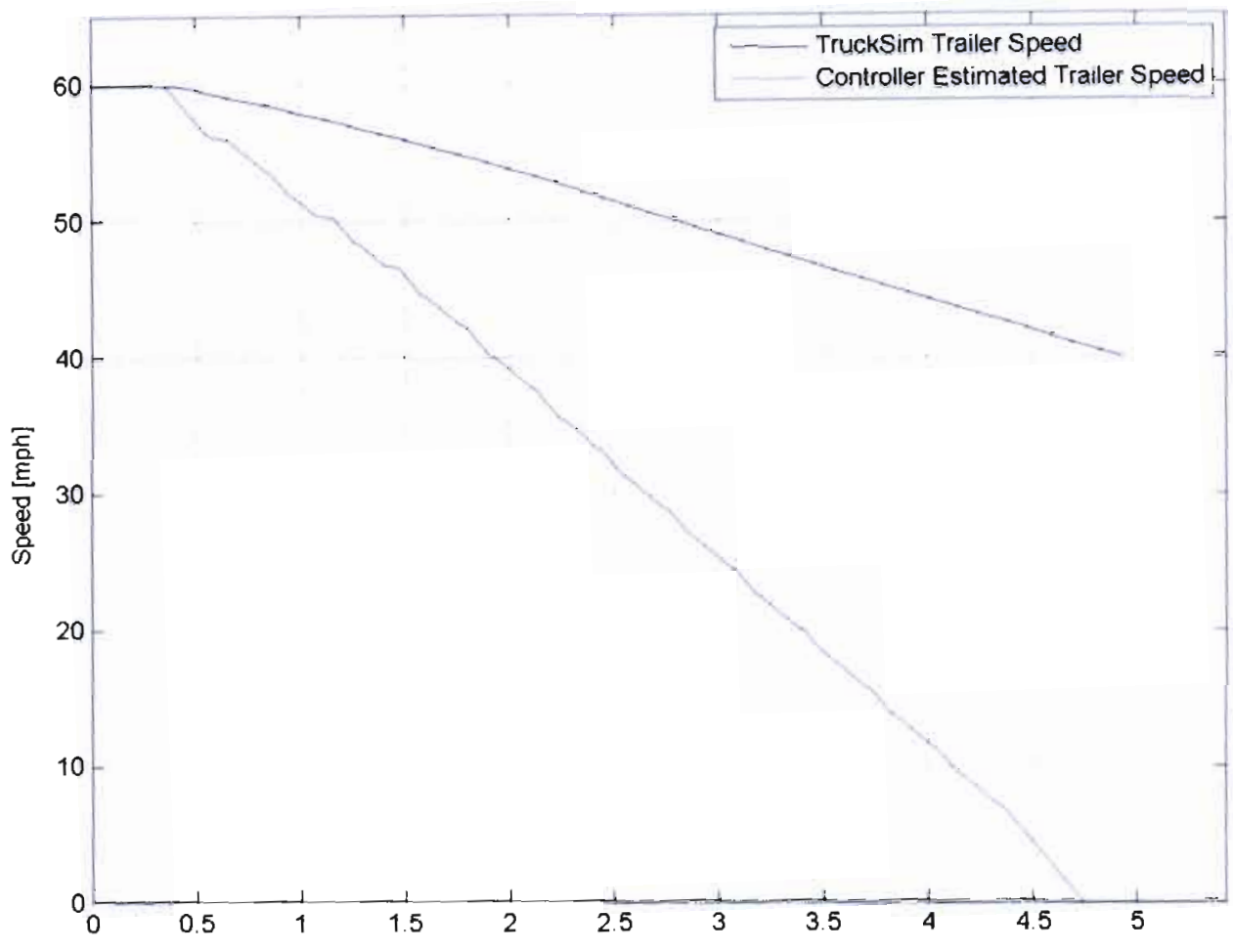

Figure 4.21 - Actual and Controller Estimated Trailer Speeds for $2 \mathrm{~s} 1 \mathrm{mB}$ system from 60 mph, 25\% GAWR, High Friction

\subsubsection{5\% GAWR, Low Friction}

The results of Section 4.2.1 showed that all five ABS systems performed in a similar manner for the low friction, trailer-only braking stops at 25\% GAWR. Table 4.7 and Figure 4.22 show the same to be true for the same scenario at $75 \%$ GAWR, for the most part. The interesting result from this set of simulations can be seen in Figure 4.23, which shows the actual speed of the trailer and the controller estimated speed for the $2 \mathrm{~s} 1 \mathrm{~mA}$ system, snubbed from 60 to $40 \mathrm{mph}$. When comparing this to the corresponding 
plot for the 25\% GAWR case (Figure 4.17), one can see that the controller is able to estimate the trailer's speed more accurately. This is attributed to the higher axle weights for the $75 \%$ GAWR case, which prohibit the wheel speeds from decreasing as rapidly as the $25 \%$ GAWR case due to the extra load.

\begin{tabular}{|c|c|c|c|c|}
\hline \multicolumn{5}{|c|}{ Trailer Only Braking, 75\% Axle Load, $\mu=0.35$} \\
\hline Speeds & $\begin{array}{c}\text { ABS } \\
\text { System }\end{array}$ & $\begin{array}{c}\text { decel } \\
{[A B S]}\end{array}$ & S.U. & $\begin{array}{c}\text { S.D. } \\
\text { [ft] }\end{array}$ \\
\hline \multirow{4}{*}{$60-40$} & none & 0.1671 & - & 429.2 \\
\cline { 2 - 5 } & $2 \mathrm{~s} 1 \mathrm{~m}-\mathrm{A}$ & 0.1701 & $101.80 \%$ & 422.3 \\
\cline { 2 - 5 } & $2 \mathrm{~s} 1 \mathrm{~m}-\mathrm{B}$ & 0.1693 & $101.32 \%$ & 437.4 \\
\cline { 2 - 5 } & $2 \mathrm{~s} 1 \mathrm{~m}-\mathrm{C}$ & 0.1672 & $100.06 \%$ & 426.3 \\
\cline { 2 - 5 } & $4 \mathrm{~s} 2 \mathrm{~m}$ & 0.1745 & $104.43 \%$ & 416.4 \\
\cline { 2 - 5 } & $4 \mathrm{~s} 4 \mathrm{~m}$ & 0.1693 & $101.32 \%$ & 423.3 \\
\hline \multirow{4}{*}{$30-15$} & none & 0.1697 & - & 151.7 \\
\cline { 2 - 5 } & $2 \mathrm{~s} 1 \mathrm{~m}-\mathrm{A}$ & 0.1715 & $101.06 \%$ & 150.3 \\
\cline { 2 - 5 } & $2 \mathrm{~s} 1 \mathrm{~m}-\mathrm{B}$ & 0.1816 & $107.01 \%$ & 143.8 \\
\cline { 2 - 5 } & $2 \mathrm{~s} 1 \mathrm{~m}-\mathrm{C}$ & 0.1697 & $100.00 \%$ & 151.4 \\
\cline { 2 - 5 } & $4 \mathrm{~s} 2 \mathrm{~m}$ & 0.1712 & $100.88 \%$ & 149.8 \\
\cline { 2 - 5 } & $4 \mathrm{~s} 4 \mathrm{~m}$ & 0.1727 & $101.77 \%$ & 149.5 \\
\hline
\end{tabular}

Table 4.7 - Longitudinal Performance of Trailer-Only Braking, 75\% GAWR, Low Friction 


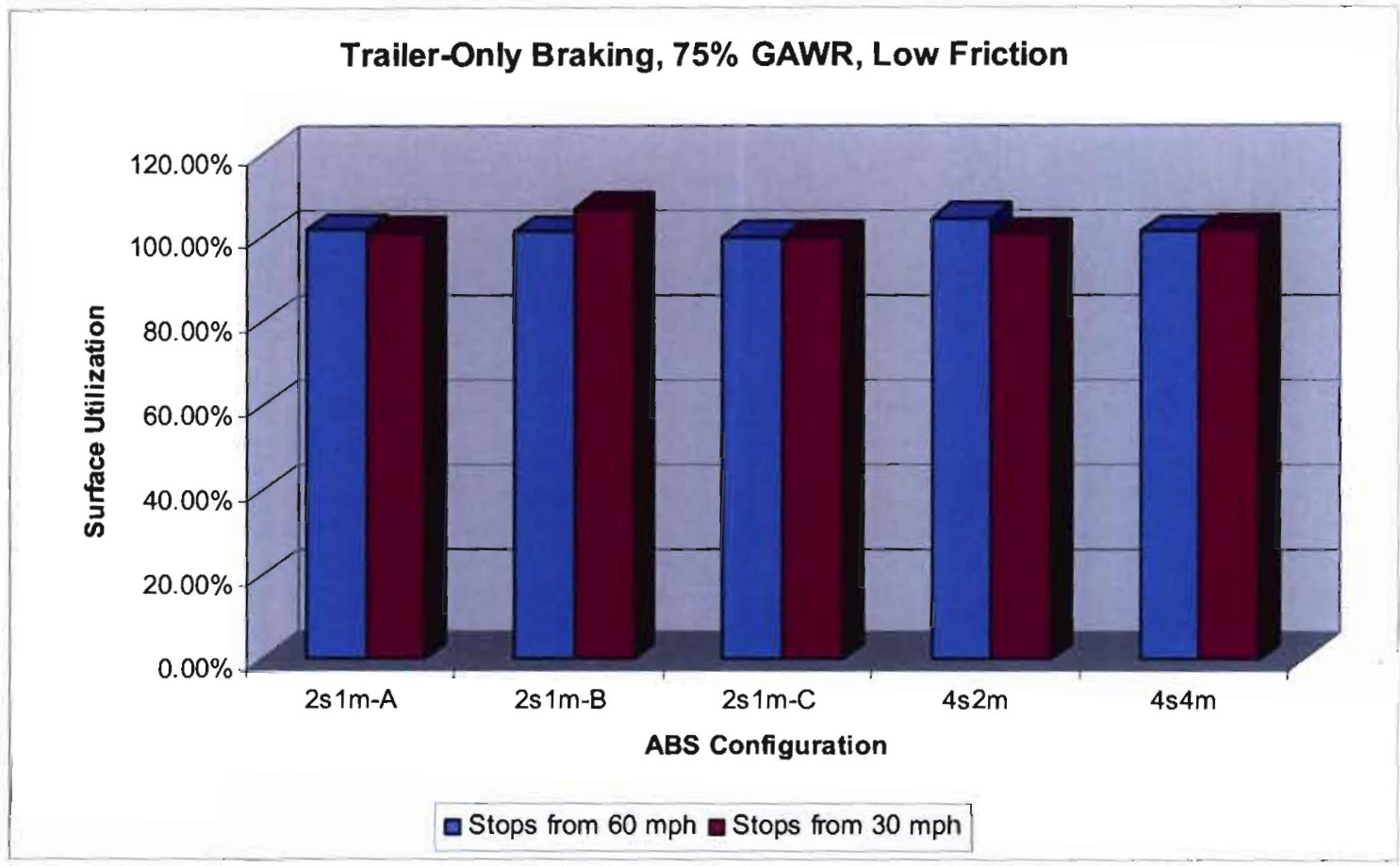

Figure 4.22 - Surface Utilization of Trailer-Only Braking, 75\% GAWR, Low Friction 


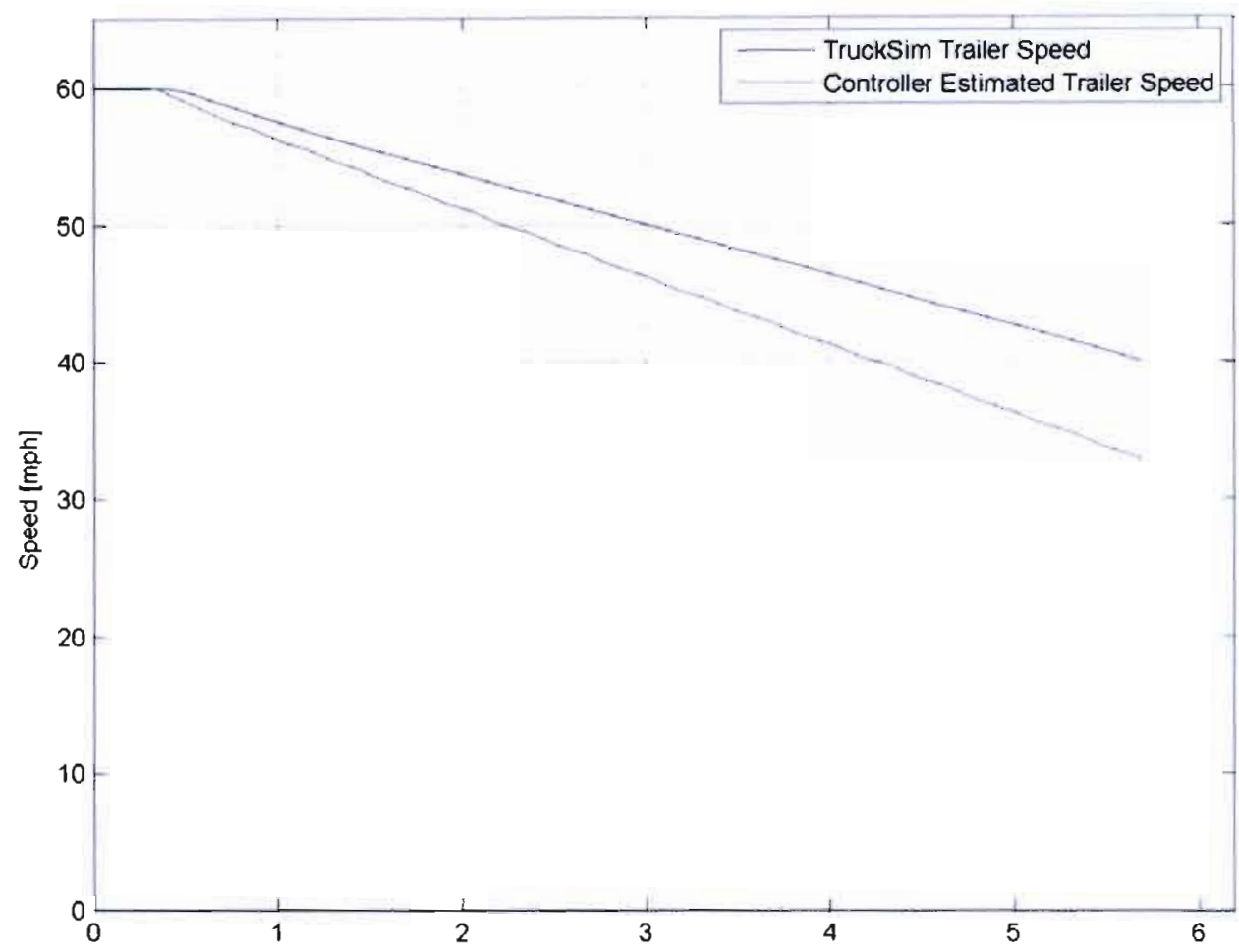

Figure 4.23 - Actual and Controller Estimated Trailer Speeds for $2 \mathrm{~s} 1 \mathrm{~mA}$ system from 60 mph, $75 \%$ GAWR, Low Friction

\subsubsection{5\% GAWR, High Friction}

For the high friction stops at $75 \%$ GAWR, no ABS modulation took place; therefore Table 4.8 and Figure 4.24 show identical responses between the five ABS systems. 


\begin{tabular}{|c|c|c|c|c|}
\hline \multicolumn{5}{|c|}{ Trailer Only Braking, $75 \%$ Axle Load, $\mu=0.85$} \\
\hline Speeds & $\begin{array}{c}\text { ABS } \\
\text { System }\end{array}$ & $\begin{array}{c}\text { decel } \\
{[\text { ABS] }}\end{array}$ & S.U. & $\begin{array}{c}\text { S.D. } \\
{[\mathrm{ft}]}\end{array}$ \\
\hline \multirow{5}{*}{$60-40$} & none & 0.3611 & - & 239.0 \\
\cline { 2 - 5 } & $2 \mathrm{~s} 1 \mathrm{~m}-\mathrm{A}$ & 0.3614 & $100.08 \%$ & 233.4 \\
\cline { 2 - 5 } & $2 \mathrm{~s} 1 \mathrm{~m}-\mathrm{B}$ & 0.3614 & $100.08 \%$ & 233.4 \\
\cline { 2 - 5 } & $2 \mathrm{~s} 1 \mathrm{~m}-\mathrm{C}$ & 0.3614 & $100.08 \%$ & 233.4 \\
\cline { 2 - 5 } & $4 \mathrm{~s} 2 \mathrm{~m}$ & 0.3614 & $100.08 \%$ & 233.4 \\
\cline { 2 - 5 } & $4 \mathrm{~s} 4 \mathrm{~m}$ & 0.3614 & $100.08 \%$ & 233.4 \\
\hline \multirow{5}{*}{$30-15$} & none & 0.4448 & - & 78.0 \\
\cline { 2 - 5 } & $2 \mathrm{~s} 1 \mathrm{~m}-\mathrm{A}$ & 0.4360 & $98.02 \%$ & 76.2 \\
\cline { 2 - 5 } & $2 \mathrm{~s} 1 \mathrm{~m}-\mathrm{B}$ & 0.4360 & $98.02 \%$ & 76.2 \\
\cline { 2 - 5 } & $2 \mathrm{~s} 1 \mathrm{~m}-\mathrm{C}$ & 0.4360 & $98.02 \%$ & 76.2 \\
\cline { 2 - 5 } & $4 \mathrm{~s} 2 \mathrm{~m}$ & 0.4360 & $98.02 \%$ & 76.2 \\
\cline { 2 - 5 } & $4 \mathrm{~s} 4 \mathrm{~m}$ & 0.4394 & $98.79 \%$ & 75.9 \\
\hline
\end{tabular}

Table 4.8 - Longitudinal Performance of Trailer-Only Braking, 75\% GAWR, High Friction

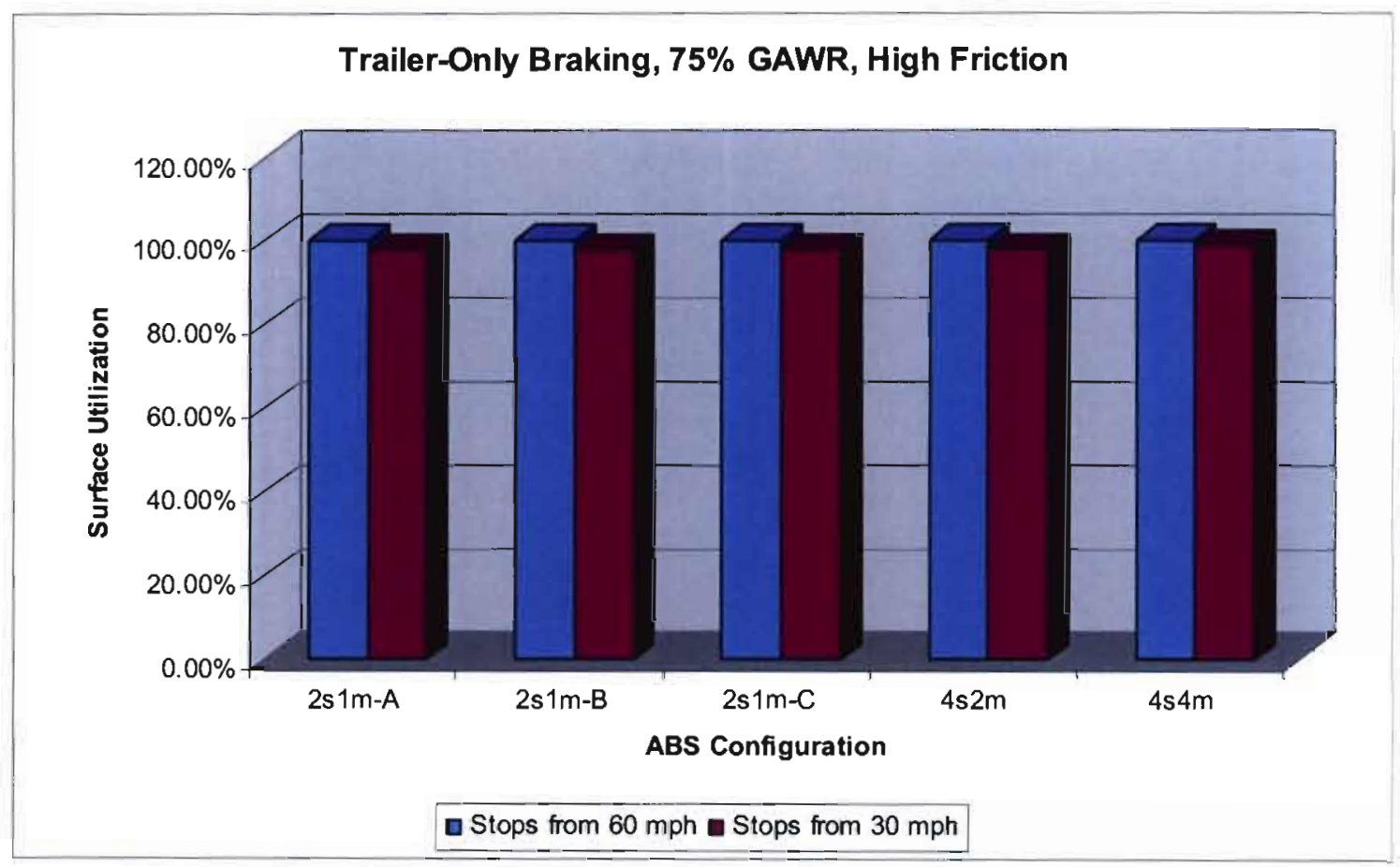

Figure 4.24 - Surface Utilization of Trailer-Only Braking, 75\% GAWR, High Friction 


\subsection{Brake-In-Curve Tests}

At each loading condition, lateral performance was studied by simulating the tractor-trailer with each ABS condition subjected to a brake-in-curve (BIC) maneuver. The maximum speed in which the tractor-trailer could remain in lane through the $500 \mathrm{ft}$ radius circle was recorded for each loading condition. This speed, known as the drivethrough speed, was then compared to the maximum speed in which the vehicle could remain in lane under full treadle, ABS enabled, braking (the limit braking speed). An ABS system which performs well laterally would then have a ratio of limit braking speed to drive-through speed close to (or sometimes exceeding) $100 \%$.

\subsubsection{5\% GAWR, BIC Results}

The results of the BIC tests for the trailer at $25 \%$ GAWR can be seen in Table 4.9. This table shows the drive-through speed for the tractor-trailer under this loading condition as well as the speed at which the first axle of the tractor-trailer axle left the lane for the BIC maneuver utilizing each ABS system. This table also displays which axle was the first to leave the lane, given by a number representing each of the four axles of the vehicle, where the steer axle of the tractor is denoted by ' 1 ' and the leading axle of the trailer is given by ' 4 '. From this table, one can see that the $2 \mathrm{~s} 1 \mathrm{mB}$ system performed fairly well and the $2 \mathrm{~s} 1 \mathrm{mC}$ system performed poorly. These results were expected, because the $2 \mathrm{~s} 1 \mathrm{mB}$ system was designed to keep wheel slip ratios as close to $0 \%$ as possible and the $2 \mathrm{~s} 1 \mathrm{mC}$ system was designed to keep them as close to lock-up ( $100 \%$ slip) as possible. Recall Section 3.5.1 in which the longitudinal and lateral performance 
of tires was discussed. Figure 3.27 shows that tires generate the maximum possible lateral force at $0 \%$ longitudinal slip and the effectiveness of lateral force goes to nearly 0 at $100 \%$ slip; therefore, the results of the $2 \mathrm{~s} 1 \mathrm{mB}$ and $2 \mathrm{~s} 1 \mathrm{mC}$ systems were expected. One can see the difference in wheel slip ratio response for the two systems in Figure 4.25 and Figure 4.26 . For the $25 \%$ GAWR case, the trailing axle of the trailer was the first leave the lane with the exception of the $2 \mathrm{~s} 1 \mathrm{mB}$ case. In this case, jack-knifing occurred.

\begin{tabular}{|c|c|c|c|c|c|}
\hline \multicolumn{2}{|c|}{$25 \%$ GAWR } & {$[\mathrm{kph}]$} & {$[\mathrm{mph}]$} & LAPQ & $\begin{array}{c}\text { Axle Left } \\
\text { Lane }\end{array}$ \\
\hline $\begin{array}{c}\text { Maximum Drive-Through } \\
\text { Speed }\end{array}$ & 55.0 & 34.2 & - & 2 \\
\hline \multirow{4}{*}{$\begin{array}{c}\text { Limit Braking } \\
\text { Test Speed }\end{array}$} & $2 \mathrm{~s} 1 \mathrm{~mA}$ & 33.8 & 21.0 & $37.77 \%$ & 4 \\
\cline { 2 - 6 } & $2 \mathrm{~s} 1 \mathrm{mB}$ & 39.0 & 24.2 & $50.28 \%$ & 1 \\
\cline { 2 - 6 } & $2 \mathrm{~s} 1 \mathrm{mC}$ & 32.4 & 20.1 & $34.70 \%$ & 4 \\
\cline { 2 - 6 } & $4 \mathrm{~s} 2 \mathrm{~m}$ & 35.7 & 22.2 & $42.13 \%$ & 4 \\
\cline { 2 - 6 } & $4 \mathrm{~s} 4 \mathrm{~m}$ & 33.3 & 20.7 & $36.66 \%$ & 4 \\
\hline
\end{tabular}

Table 4.9 - Brake-In-Curve Results, 25\% GAWR 

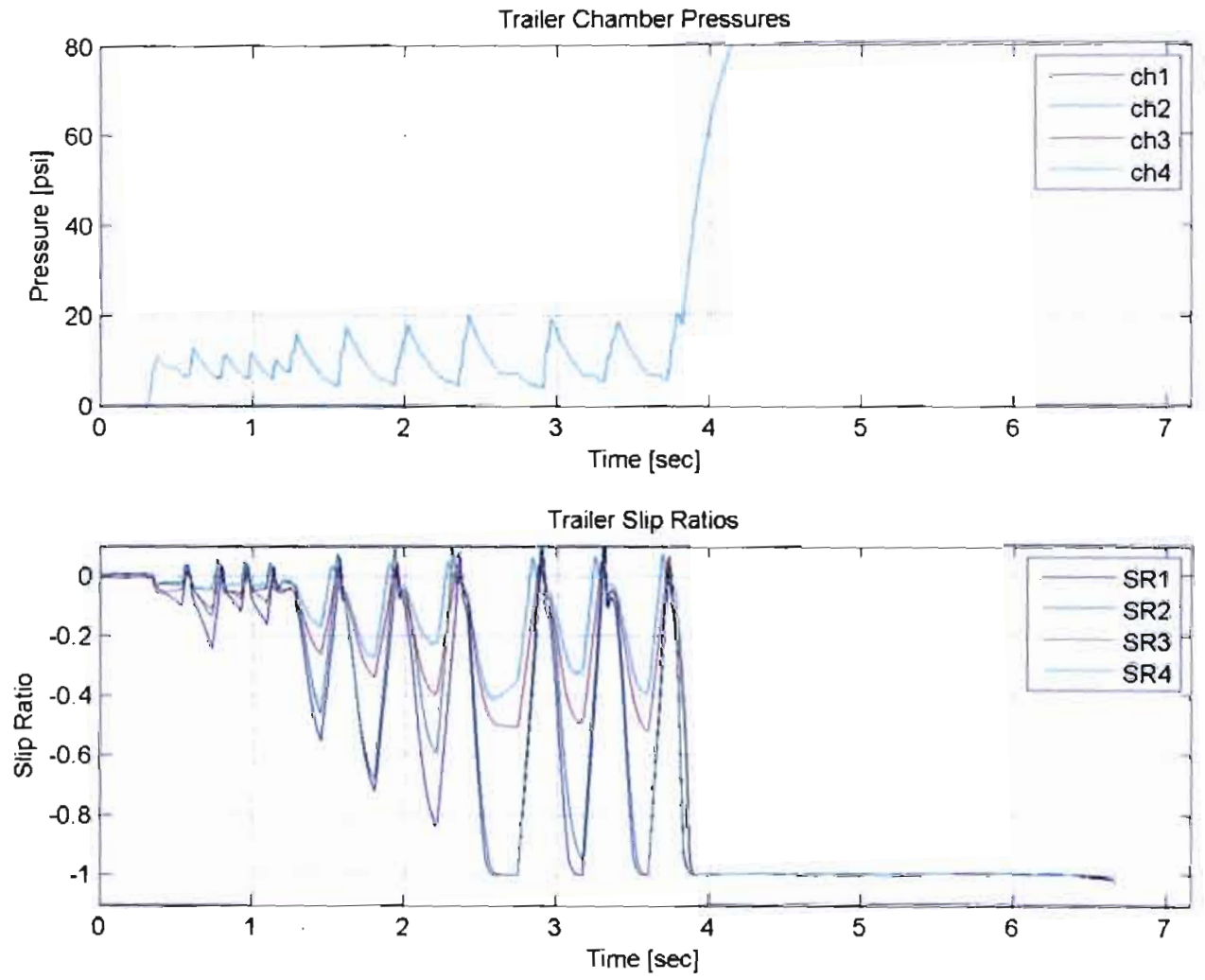

Figure 4.25 - Response to BIC Maneuver, $2 \mathrm{~s} 1 \mathrm{mB}$ System at $25 \%$ GAWR 

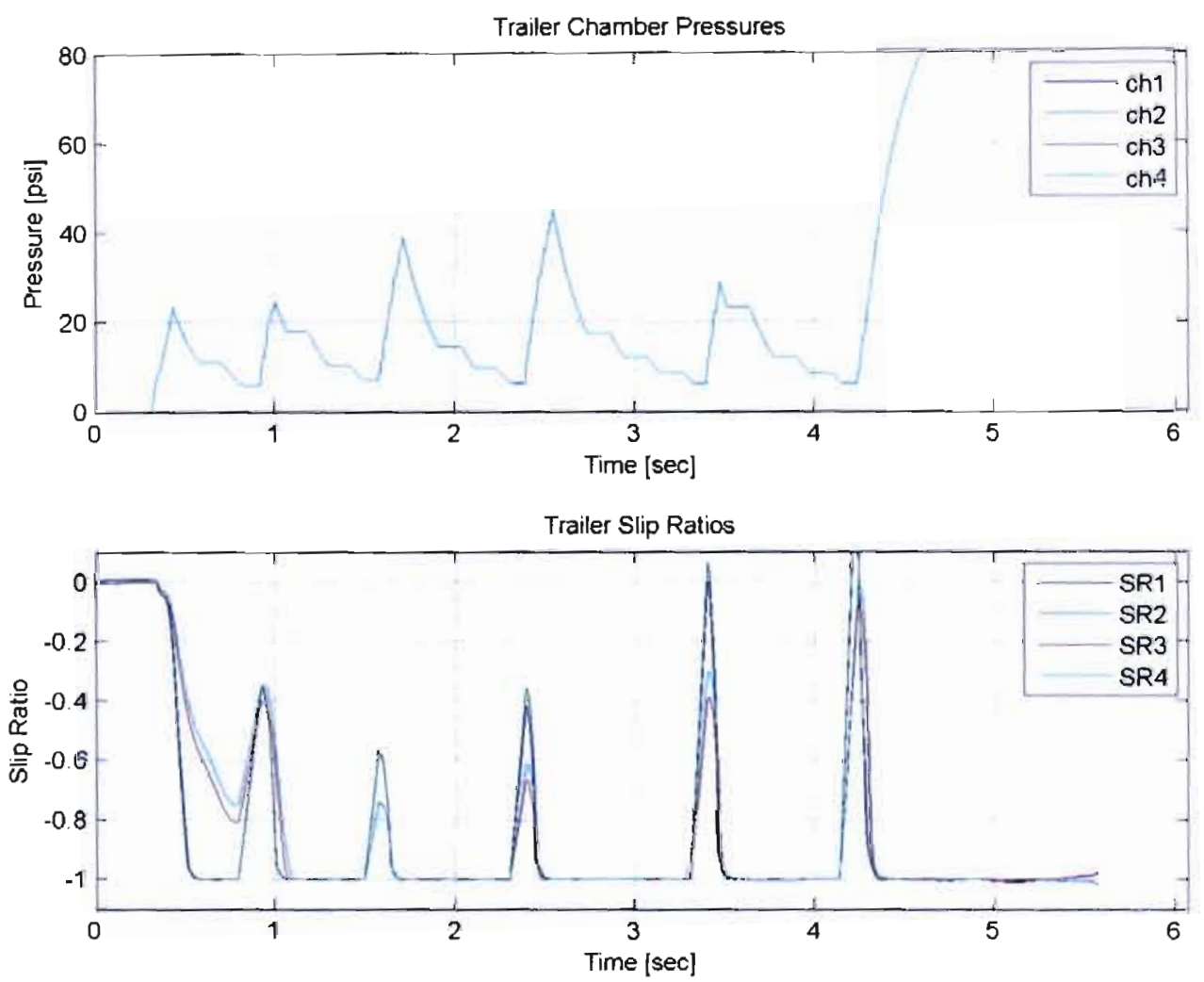

Figure 4.26 - Response to BIC Maneuver, 2s1 mC System at 25\% GAWR

Although the three ABS system models performed similarly for longitudinal tests, Table 4.9 shows some separation between the performances of the $2 \mathrm{~s} 1 \mathrm{~mA}, 4 \mathrm{~s} 2 \mathrm{~m}$, and $4 \mathrm{~s} 4 \mathrm{~m}$ systems for the BIC simulation. Figure 4.27 shows that a greater amount of longitudinal wheel slip is developed in the leading axle wheels of the trailer than in the trailing axle. The $4 \mathrm{~s} 2 \mathrm{~m}$ system monitors trailer wheels 1 and 3 together and wheels 2 and 4 together, and for this low friction BIC maneuver, the system utilized select-low logic. Therefore, the $4 \mathrm{~s} 2 \mathrm{~m}$ system could act upon wheels 3 and 4 as if they were experiencing the high slip ratios that are exhibited in wheels 1 and 2 . In theory, the $4 \mathrm{~s} 2 \mathrm{~m}$ system 
would then outperform the $2 \mathrm{~s} 1 \mathrm{~mA}$ system, which does not have the previously described capability, and this result is seen in Table 4.9. Figure 4.28 shows that this behavior did occur, as the simulation resulted in more slip ratio values near the optimum range for lateral stability. Because each wheel was independently modulated for the $4 \mathrm{~s} 4 \mathrm{~m}$ system, the benefits of select-low logic were not realized; therefore, the $4 \mathrm{~s} 4 \mathrm{~m}$ system did not perform as high as the $2 \mathrm{~s} 1 \mathrm{~mA}$ and $4 \mathrm{~s} 2 \mathrm{~m}$ systems. One can see how each brake chamber is independently modulated in the following Figure 4.29.
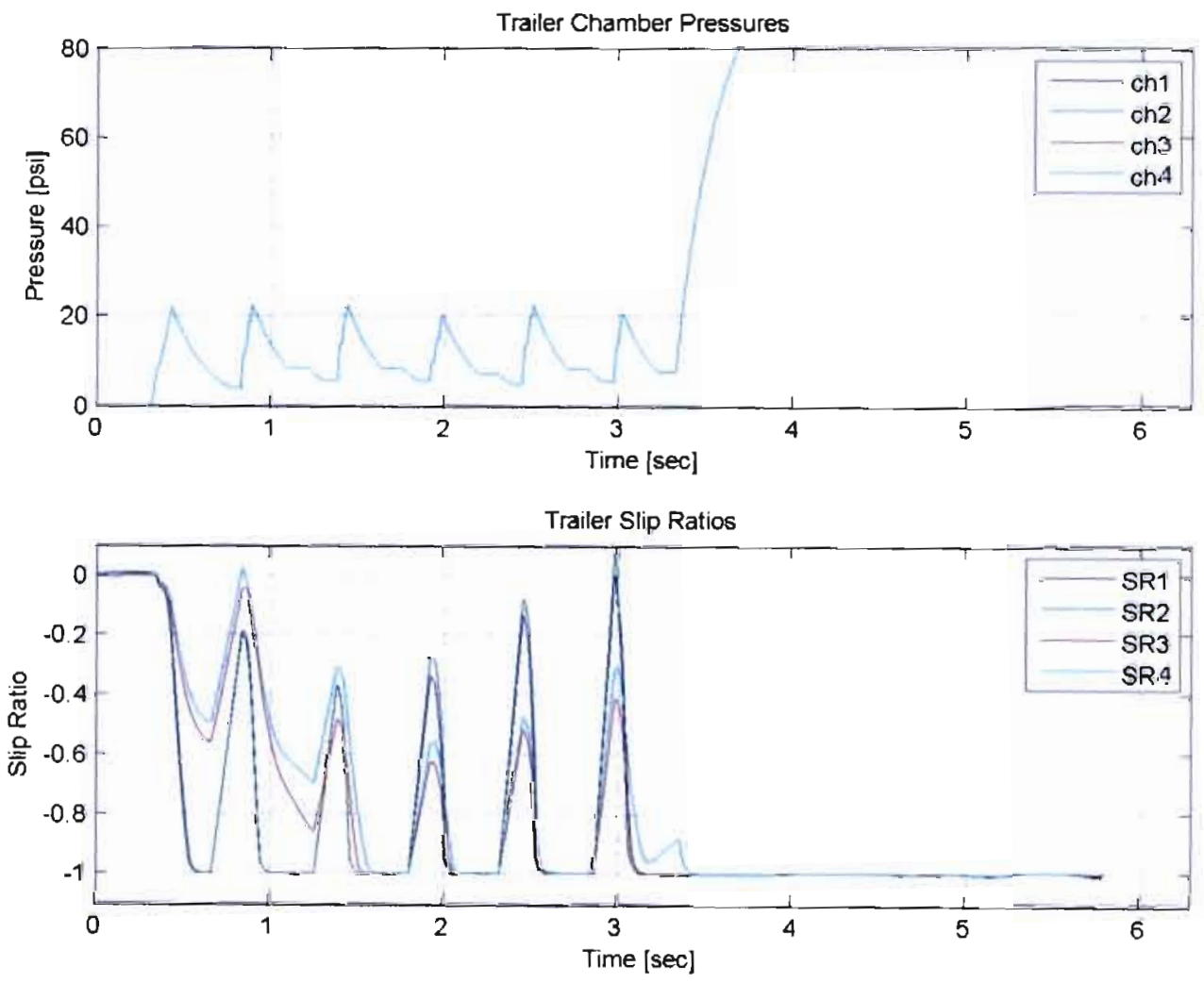

Figure 4.27 - Response to BIC Maneuver, 2s $1 \mathrm{~mA}$ System at 25\% GAWR 

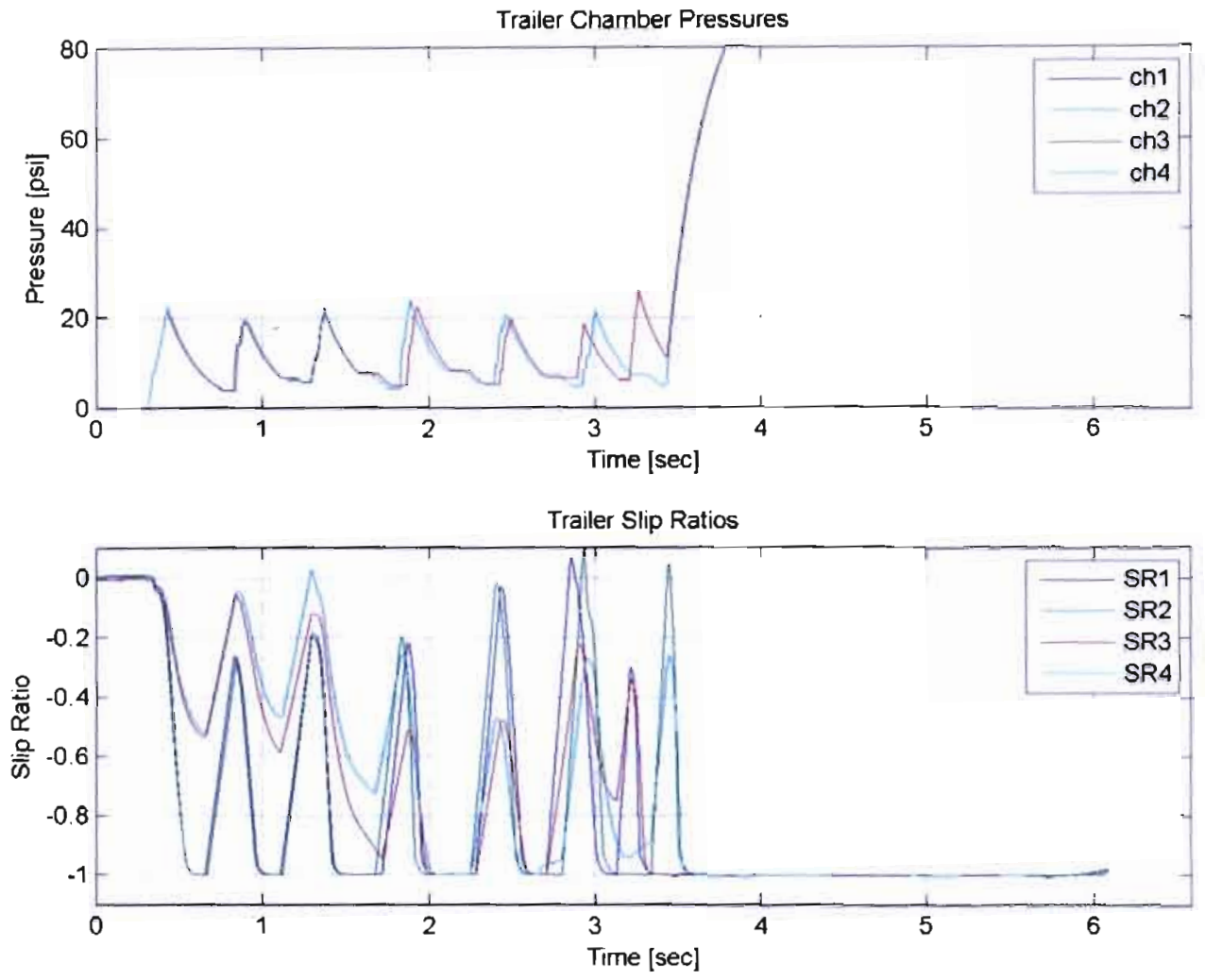

Figure 4.28 - Response to BIC Maneuver, 4s2m System at 25\% GAWR 

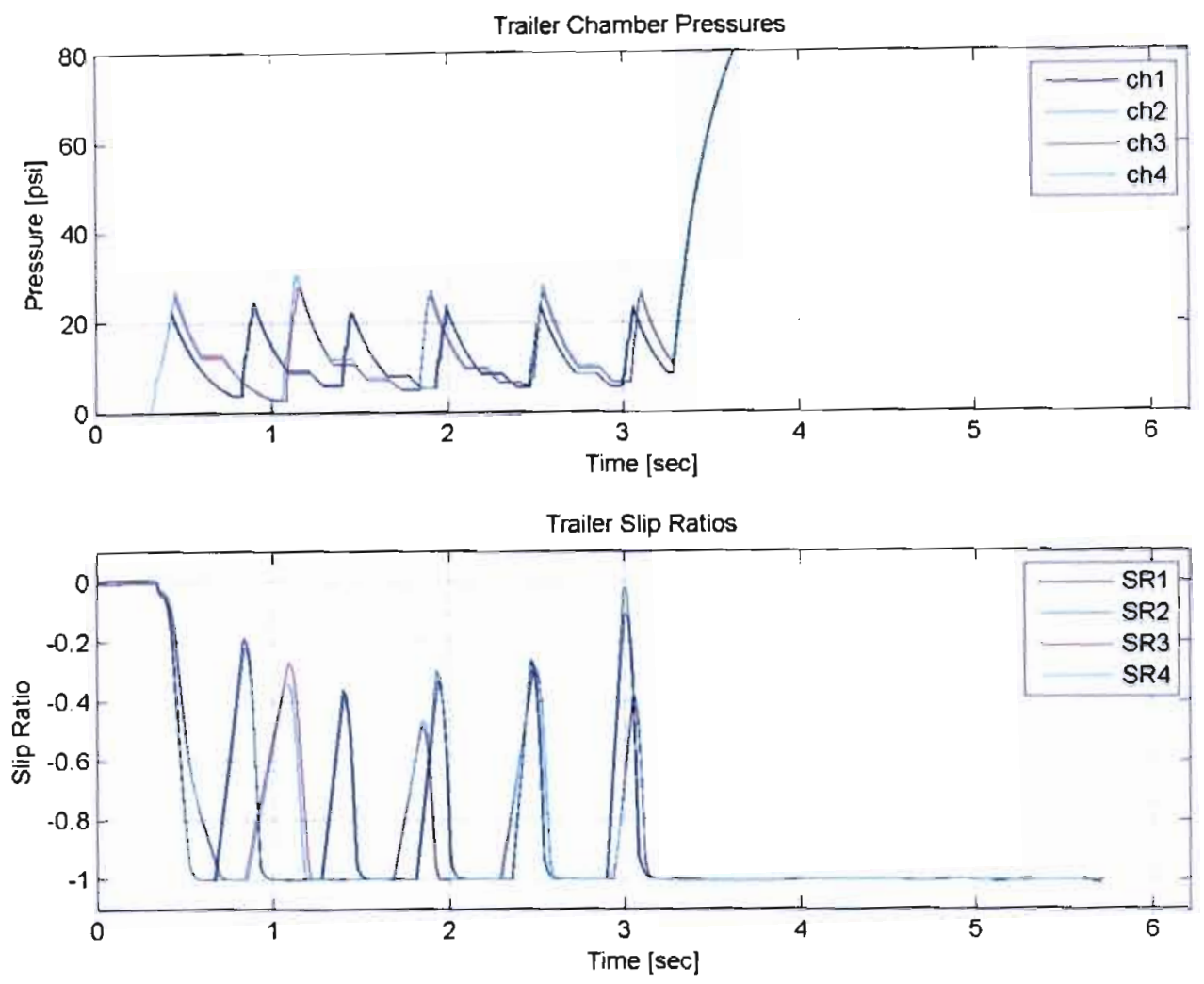

Figure 4.29 - Response to BIC Maneuver, $4 s 4 \mathrm{~m}$ System at 25\% GAWR

\subsubsection{5\% GAWR, BIC Results}

Table 4.10 shows that again, for the $75 \%$ GAWR simulations, the $2 \mathrm{~s} 1 \mathrm{mB}$ system performed to the highest level. For this high trailer load condition, the $2 \mathrm{~s} 1 \mathrm{mB}$ system was able to keep the slip ratios of the four trailer wheels at relatively low values, as evidenced by Figure 4.30. Figure 4.31 and Figure 4.32 show that the select-low behavior of the previous section is also exhibited for the $2 \mathrm{~s} 1 \mathrm{~mA}$ and $4 \mathrm{~s} 2 \mathrm{~m}$ systems at this loading condition. From these three plots, it would appear that the $2 \mathrm{~s} 1 \mathrm{mB}$ system would greatly 
outperform the $2 \mathrm{~s} 1 \mathrm{~mA}$ and $4 \mathrm{~s} 2 \mathrm{~m}$ systems, because the later systems allow significant lock-up during the BIC stop. However, the LAPQ values for these systems were quite similar due to the fact that the limit braking speed was affected by jack-knifing. For this scenario, the rear axle of the tractor was the first to leave the lane; therefore it was not able to test the lateral performance of these systems to their full extent.

\begin{tabular}{|c|c|c|c|c|c|}
\hline \multicolumn{2}{|c|}{$75 \%$ GAWR } & [kph] & [mph] & LAPQ & $\begin{array}{l}\text { Axle Left } \\
\text { Lane }\end{array}$ \\
\hline \multicolumn{2}{|c|}{$\begin{array}{l}\text { Maximum Drive-Through } \\
\text { Speed }\end{array}$} & 55.5 & 34.5 & - & 2 \\
\hline \multirow{5}{*}{$\begin{array}{l}\text { Limit Braking } \\
\text { Test Speed }\end{array}$} & $2 \mathrm{~s} 1 \mathrm{~mA}$ & 34.2 & 21.3 & $37.97 \%$ & 2 \\
\hline & $2 \mathrm{~s} 1 \mathrm{mB}$ & 35.0 & 21.7 & $39.77 \%$ & 2 \\
\hline & $2 \mathrm{~s} 1 \mathrm{mC}$ & 31.0 & 19.3 & $31.20 \%$ & 4 \\
\hline & $4 \mathrm{~s} 2 \mathrm{~m}$ & 34.5 & 21.4 & $38.64 \%$ & 2 \\
\hline & $4 \mathrm{~s} 4 \mathrm{~m}$ & 32.1 & 19.9 & $33.45 \%$ & 4 \\
\hline
\end{tabular}

Table 4.10 - Brake-In-Curve Results, 75\% GAWR 

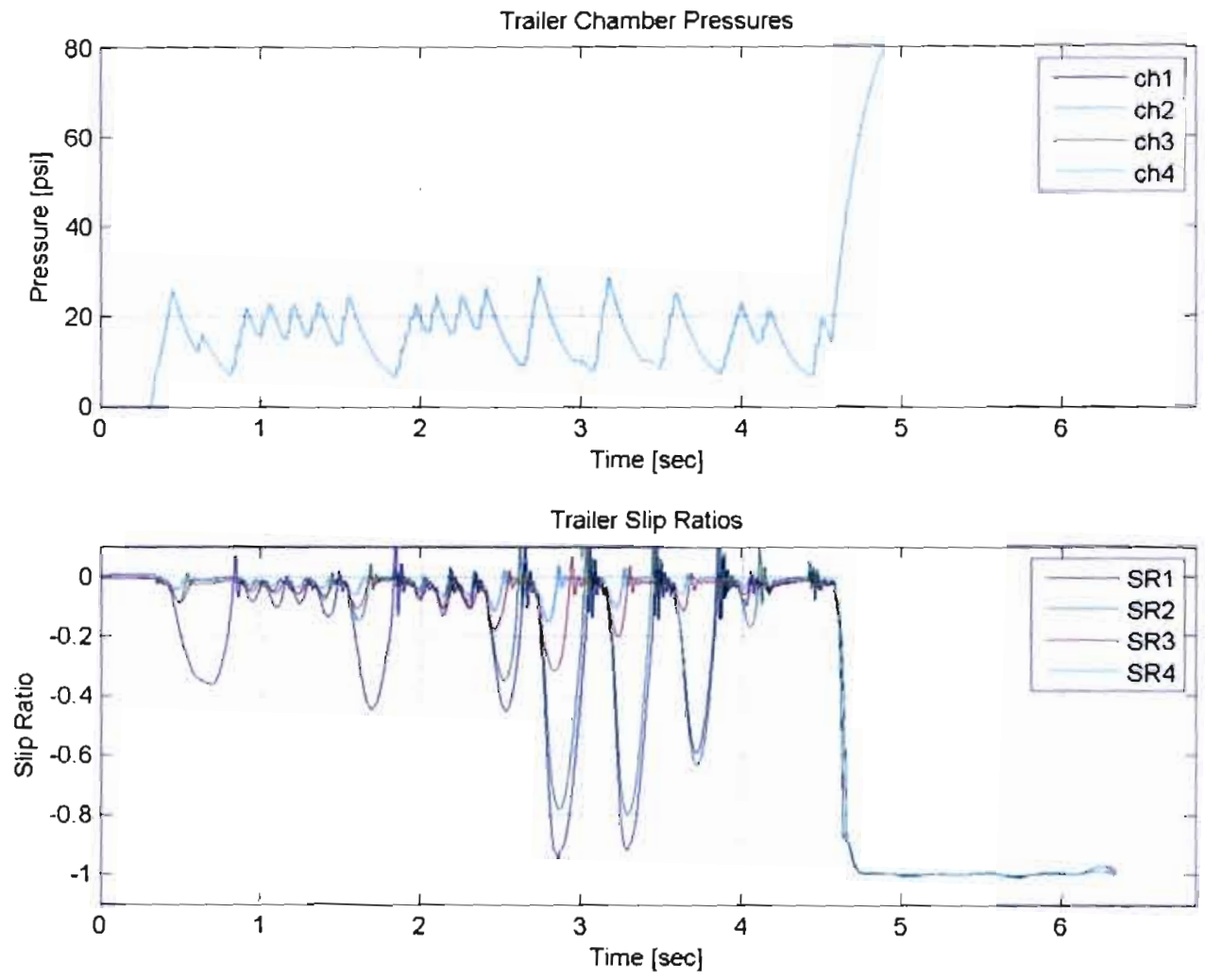

Figure 4.30 - Response to BIC Maneuver, 2s $1 \mathrm{mB}$ System at 75\% GAWR 

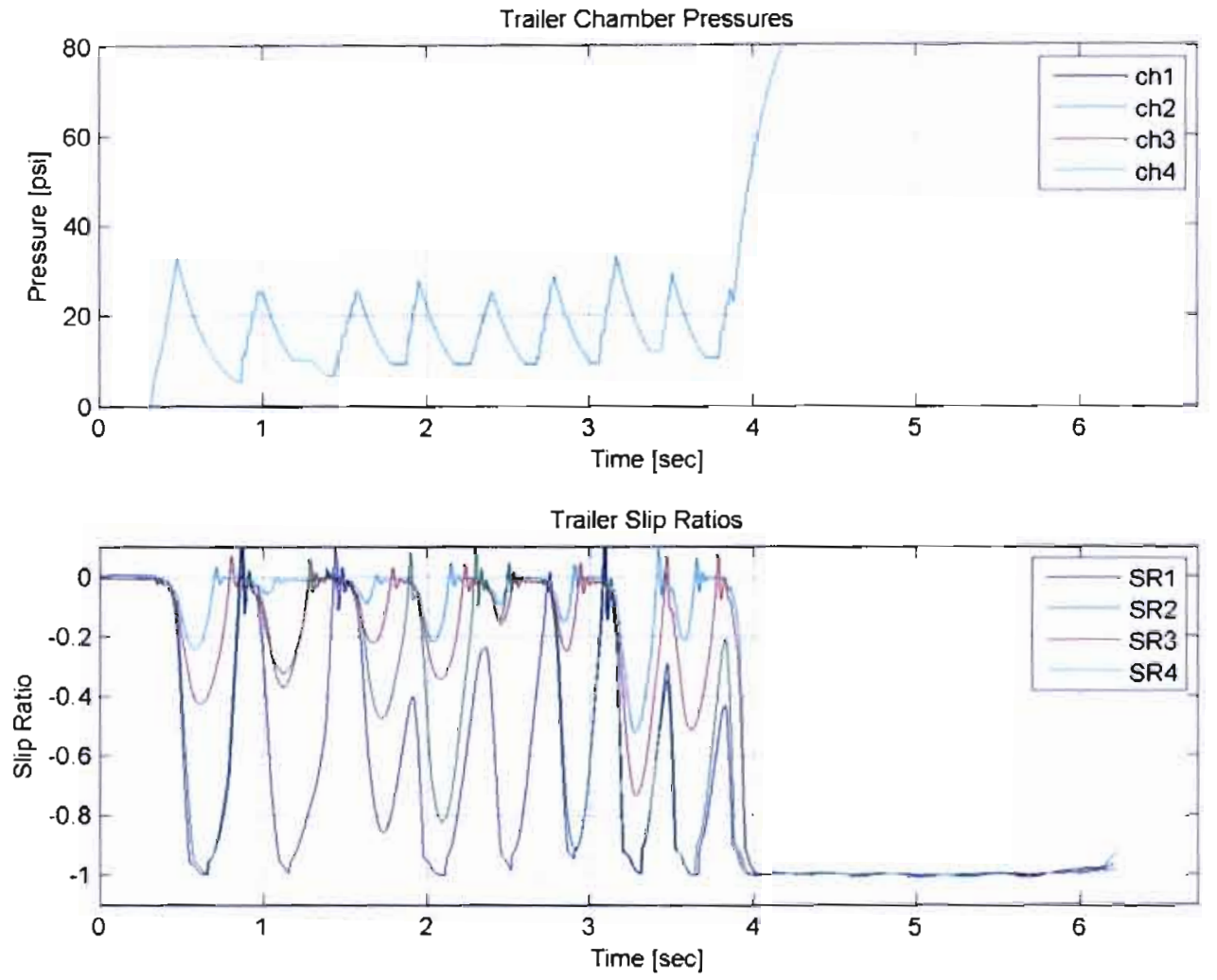

Figure 4.31 - Response to BIC Maneuver, 2s1mA System at 75\% GAWR 

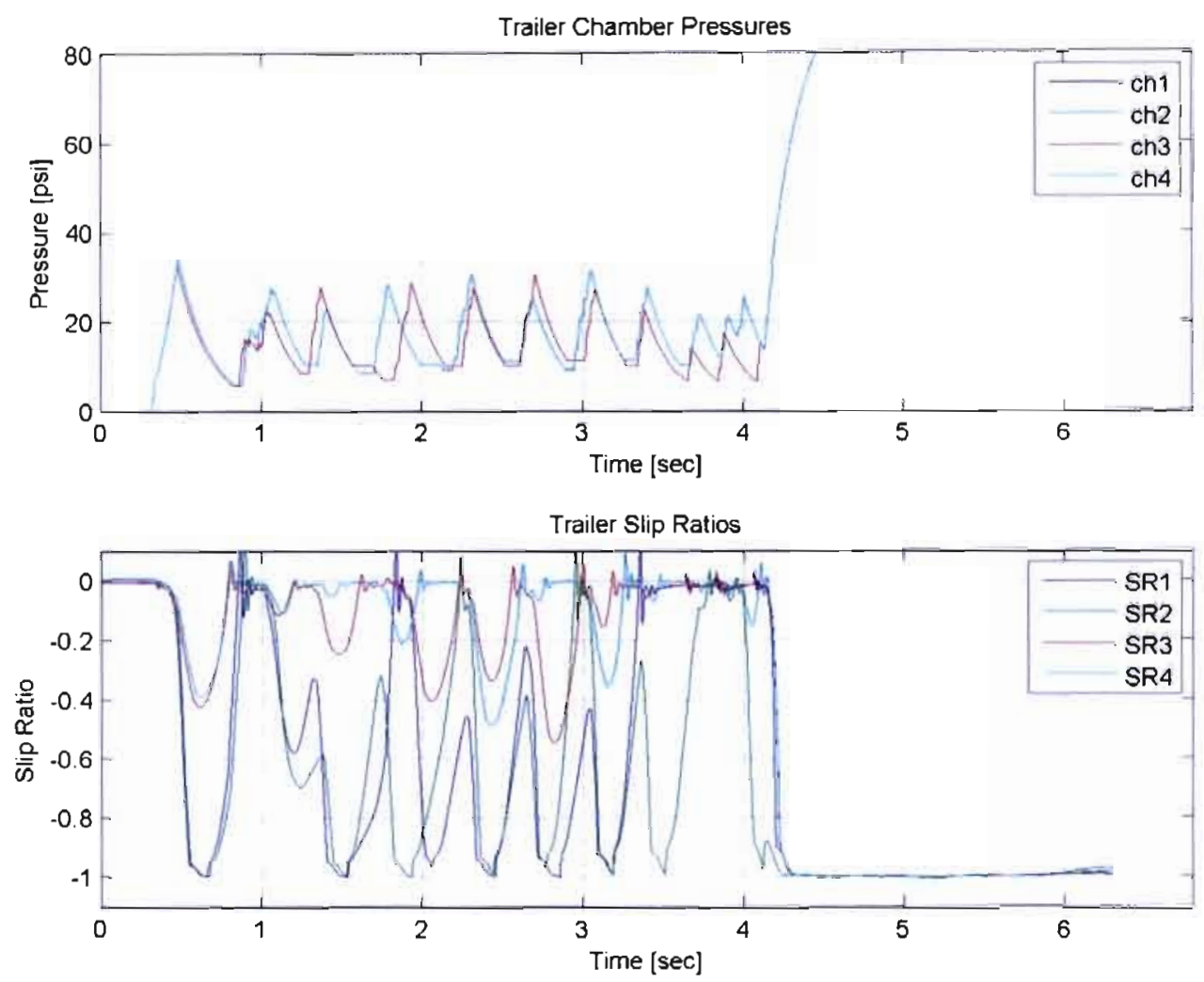

Figure 4.32 - Response to BIC Maneuver, 4s2m System at 75\% GAWR

Table 4.10 shows that the $2 \mathrm{~s} 1 \mathrm{mC}$ and $4 \mathrm{~s} 4 \mathrm{~m}$ systems were the poorest performers for the BIC maneuvers at 75\% GAWR. The rear axle of the trailer was the first to leave the lane for these tests, as seen in the table, because these systems allowed significant trailer wheel lock-up for these simulations, in the same manner as the 25\% GAWR simulations. These two systems were also without the benefits of select-low logic, as select-high is used at all times for $2 \mathrm{~s} 1 \mathrm{mC}$ and because each wheel is modulated independently for $4 \mathrm{~s} 4 \mathrm{~m}$. Figure 4.33 shows how each brake chamber was modulated independently and that large values of slip were experienced at each wheel. 


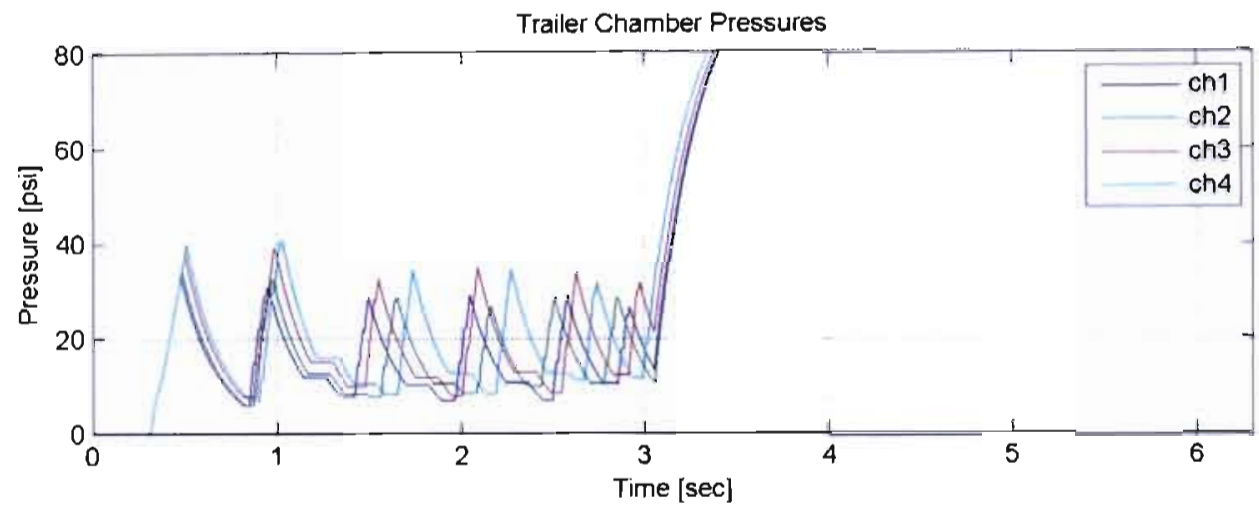

Trailer Slip Ratios

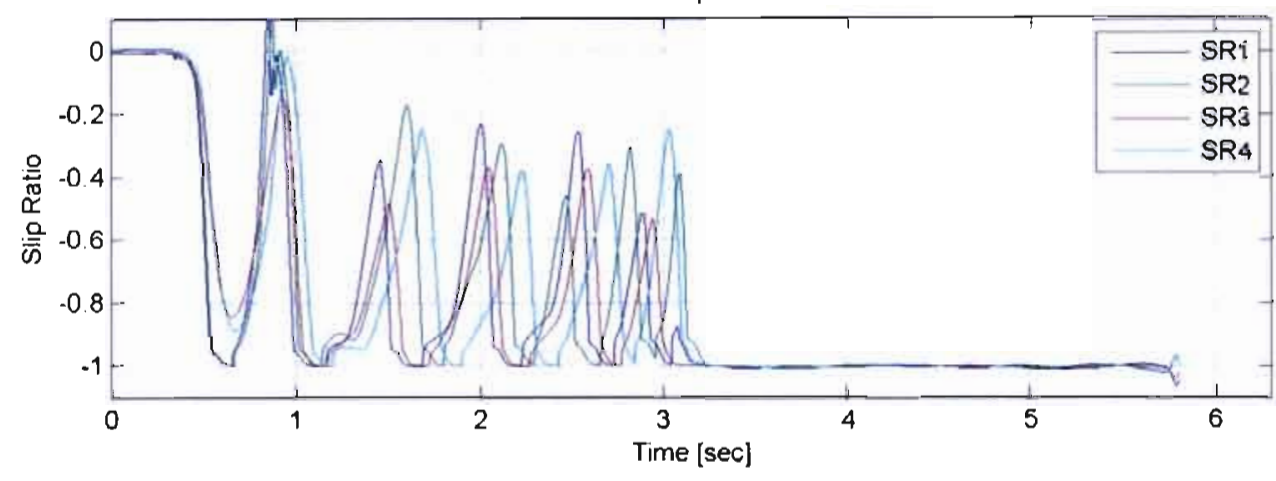

Figure 4.33 - Response to BIC Maneuver, $4 \mathrm{~s} 4 \mathrm{~m}$ System at $75 \%$ GAWR 


\section{CHAPTER 5}

\section{CONCLUSIONS AND RECOMMENDATIONS}

\subsection{Conclusions}

\subsubsection{Peterbilt Straight Truck Model}

For three out of the four cases, the model was able to accurately predict the braking behavior of the $6 \times 4$ Peterbilt truck under all three tested ABS configurations:

$6 \mathrm{~s} 6 \mathrm{~m}, 4 \mathrm{~s} 4 \mathrm{~m}$ with leading axle control, and $4 \mathrm{~s} 4 \mathrm{~m}$ with trailing axle control. However, the results for the high friction stop from $60 \mathrm{mph}$ at the GVWR condition resulted in stopping distances that were up to $33 \%$ less than the experimentally measured mean. It can be seen from the brake chamber pressure plots that the wheel dynamics were simulated to a high degree of accuracy, yet the stopping distances fell well short of the experimentally gathered results. In order to obtain a more accurate simulation of this scenario, further research would have to be conducted with the torque output model of the S-cam brakes, as they do not accurately simulate the output of these brakes under high speed, high load, and high pressure conditions. Fortunately, stops at the high load 
and high friction condition are of the least concern to those designing these ABS systems. This is because it is very unlikely that the wheels would approach lock-up under that condition; this can be seen from the slip ratio traces in the wheel dynamics plots contained in Chapter 2 .

Also, the exact friction levels of the surfaces are not known. These coefficients of friction could vary from test to test. This and other environmental factors could have resulted in simulations whose stopping distances lie just outside of the experimental confidence intervals, like those seen for the $4 \mathrm{~s} 4 \mathrm{~m}$ trailing axle control system.

The resulting Peterbilt model can accurately predict the wheel dynamics of the truck as well as its longitudinal (with an updated torque model) and lateral performance. With the entry of a few commands to the Matlab environment, the simulation of the Peterbilt straight truck utilizing a $6 \mathrm{~s} 6 \mathrm{~m}, 4 \mathrm{~s} 4 \mathrm{~m}$, or $4 \mathrm{~s} 3 \mathrm{~m}$ ABS system can be run, which will lead to predictable and reliable results.

\subsubsection{Semi-Trailer Model}

Upon the creation of an experimentally verified model consisting of the Sterling tractor and the Fruehaf 48 foot trailer, a series of simulations were completed in order to study the longitudinal and lateral effectiveness of the vehicle equipped with the five different ABS systems, described in Section 3.5.1. Longitudinal performance was studied by simulating straight ahead stops from 30 and from $60 \mathrm{mph}$. These tests were conducted over two different trailer loading conditions, on two different friction levels, and for two different vehicle braking schemes (full vehicle and trailer-only). Lateral 
performance was studied by using a brake-in-curve test, in which the final speed at which the tractor-trailer remains in lane can be compared.

The results of the longitudinal performance tests are summarized in Table 5.1. This table gives the average surface utilization factor over all tests for each ABS configuration; such a comparison allows one to compare the performance of these systems over the whole gamut of possible testing situations. This information, along with the details of Chapter 4 , shows that for the full vehicle braking case, the 2 s $1 \mathrm{mB}$ system fails to perform as well as the other configurations. Also shown in this table is that the $2 \mathrm{~s} 1 \mathrm{mB}$ system, designed to exhibit poor longitudinal performance, had the best performance for the trailer-only tests. Also, it can be noted that the $2 \mathrm{~s} 1 \mathrm{~mA}, 2 \mathrm{~s} 1 \mathrm{mC}$, $4 \mathrm{~s} 2 \mathrm{~m}$, and $4 \mathrm{~s} 4 \mathrm{~m}$ systems performed similarly for each set of tests.

\begin{tabular}{|c|c|c|}
\hline ABS System & Full Vehicle & Trailer-Only \\
\hline $2 \mathrm{~s} 1 \mathrm{~m}-\mathrm{A}$ & $101.79 \%$ & $101.05 \%$ \\
\hline $2 \mathrm{~s} 1 \mathrm{~m}-\mathrm{B}$ & $83.09 \%$ & $102.56 \%$ \\
\hline $2 \mathrm{~s} 1 \mathrm{~m}-\mathrm{C}$ & $101.14 \%$ & $100.38 \%$ \\
\hline $4 \mathrm{~s} 2 \mathrm{~m}$ & $101.61 \%$ & $101.10 \%$ \\
\hline $4 \mathrm{~s} 4 \mathrm{~m}$ & $101.35 \%$ & $101.31 \%$ \\
\hline
\end{tabular}

Table 5.1 - Average Surface Utilization Factors for Longitudinal Tests

The $2 \mathrm{~s} 1 \mathrm{~mA}, 4 \mathrm{~s} 2 \mathrm{~m}$, and $4 \mathrm{~s} 4 \mathrm{~m}$ simulated systems had similar behaviors for the straight-ahead braking tests; this trend was expected, however, because the controller parameters (thresholds, build and dump durations, etc) of the $2 \mathrm{~s} 1 \mathrm{~mA}$ system were used to create the $4 \mathrm{~s} 2 \mathrm{~m}$ and $4 \mathrm{~s} 4 \mathrm{~m}$ systems, along with the assistance of the trailer ABS Control Selector. Also, it was expected that the dynamics of the two wheels on a particular axle 
of the trailer would be very similar, considering that the longitudinal tests consisted of straight-ahead braking only. Because the leading axle and trailing axle were very close to each other (only separated by 4.25 feet), it was also expected that the dynamics of the two axles would be very similar, as well. These facts make the similarities between the longitudinal performances of the $2 \mathrm{~s} 1 \mathrm{~mA}, 4 \mathrm{~s} 2 \mathrm{~m}$, and $4 \mathrm{~s} 4 \mathrm{~m}$ systems logical.

The $2 \mathrm{~s} 1 \mathrm{mC}$ system, designed to allow significant wheel lock-up (to result in poor lateral performance) performed as well as the $2 \mathrm{~s} 1 \mathrm{~mA}$ system. An interesting discovery was found after further investigation. Because the $2 \mathrm{~s} 1 \mathrm{mC}$ system allowed the trailer wheels to stay near lock-up, higher brake chamber pressures were exhibited in the $2 \mathrm{~s} 1 \mathrm{mC}$ stops than the $2 \mathrm{~s} 1 \mathrm{~mA}$ stops. The $2 \mathrm{~s} 1 \mathrm{~mA}$ system, however, resulted in lower chamber pressures and slip ratio traces which fluctuated between $15 \%$ or $20 \%$ to near $100 \%$ in deep, low frequency cycles. These two systems performed to an equal degree because even though the $2 \mathrm{~s} 1 \mathrm{mC}$ system had high brake chamber pressures, the $2 \mathrm{~s} 1 \mathrm{~mA}$ system allowed the tires of the trailer to spend more time in their optimum range for longitudinal braking force. This behavior was displayed in all tests and more details are given in Section 4.1.1.

Designed to keep wheel slip ratios near $0 \%$ slip, the $2 \mathrm{~s} 1 \mathrm{mB}$ system was expected to have the poorest longitudinal performance. This was the case for full vehicle braking, as the $2 \mathrm{~s} 1 \mathrm{mB}$ system had the poorest longitudinal effectiveness, especially in the $75 \%$ GAWR case in which very low slip ratios were obtainable. The longitudinal tractive force of the tires has a value near 0 at $0 \%$ slip, reaches a peak around $20 \%$ and asymptotically approaches a value $70 \%$ to $80 \%$ of its peak as the wheel approaches lock- 
up. Therefore, it follows that a system which aims to keep slip ratios as close to $0 \%$ as possible would have the poorest performance longitudinally. This system had the best longitudinal performance for trailer-only tests, however. This is due to the complex problem of vehicle speed estimation in the controller, and how the trailer-only braking situation "tricks" the controller into thinking that the vehicle is decelerating at a higher rate that it actually is. The details of this behavior are discussed in detail in Section 4.2.

When comparing the three $2 \mathrm{~s} 1 \mathrm{~m}$ systems for the brake-in-curve simulations, it was clear that the $2 \mathrm{~s} 1 \mathrm{mB}$ system was capable of the highest lateral performance. This was especially evident in the $25 \%$ GAWR case. Because it was designed to allow significant lock-up in the trailer wheels under extreme braking maneuvers, the $2 \mathrm{~s} 1 \mathrm{mC}$ system had the poorest lateral performance for each loading condition. It was discovered that the $2 \mathrm{~s} 1 \mathrm{~mA}$ and $4 \mathrm{~s} 2 \mathrm{~m}$ systems outperformed the $4 \mathrm{~s} 4 \mathrm{~m}$ system laterally, even though the three ABS systems consisted of the exact same controller parameters. Upon further investigation, the superior performance of the $2 \mathrm{~s} 1 \mathrm{~mA}$ and $4 \mathrm{~s} 2 \mathrm{~m}$ systems was due to the select-low logic that they employed. Because the brake chamber of each wheel position was modulated independently, the same benefits were not seen in the $4 \mathrm{~s} 4 \mathrm{~m}$ case.

\subsection{Recommendations}

More accurate modeling of the Peterbilt straight truck could be obtained through the adjustment of the Simulink brake torque model coefficients. During conditions where the brake chamber pressure is held at very high pressures, the brake models calculate 
torques which are probably not possible with the actual S-cam brakes in which the Peterbilt is equipped. Although they were adequate for the simulated tests of the Peterbilt for this study, further research into the vehicle speed estimation system and surface friction level estimation system could be conducted. Refinement of these systems would make the model more robust in that it could handle changes in the simulated environment, such as surface friction level and elevation.

The previously described tractor-trailer model could be improved through the collection of experimental data of the Sterling tractor and van trailer, together. ABS models of the tractor and trailer were created by examining the behavior of each system independently of the other, because such a data set did not exist. The tractor-trailer is believed to adequately simulate the behavior of these systems, but refinement of the model would be possible with this data.

In order to further study the performance of trailer ABS systems, experimental data should be collected for the trailer-only braking condition. It is believed that trailer ABS controllers behave differently under this condition than they do for full vehicle braking, and this behavior was certainly seen in the results of this study. For the traileronly braking case, the controller was not able to accurately estimate the speed of the trailer, which is paramount to the performance of the ABS system. Experimental data needs to be collected and trailer ABS manufacturers need to be solicited in order to find out if this problem happens in actual controllers as well. If actual controllers do not have this problem, then further refinement into the trailer speed estimation module of the semitrailer model needs to be conducted. 
In conclusion, I'd like to acknowledge the vast amount of development necessary just to simulate an ABS system in one mode of operation. Further research should be conducted to verify that the ABS controller models of the Peterbilt and tractor-trailer vehicles are adaptable to real-life situations. For example, the ABS model of the Peterbilt was proven to adequately simulate the braking performance of the truck for 4 different conditions: a high friction stop from $60 \mathrm{mph}$ at LLVW and GVWR and a low friction, BIC maneuver at LLVW and GVWR. The ABS model should be validated against experimental data of other situations, such as a low friction straight-ahead stop at a high speed, to see if the model is robust enough to handle any situation presented to it. 


\section{REFERENCES}

1. United States Department of Transportation, Federal Motor Carrier Safety Administration (FMCSA). Large Truck Crash Facts 2002. April 2004.

2. U.S. D.O.T. National Highway Traffic Safety Administration, FMVSS 121, Air Brake Systems, 49 CFR, Ch. V (10-01-03 edition), §571.121, S. 5.3.6

3. Dunn, Ashley, L. Jackknife Stability of Articulated Tractor Semitrailer Vehicles with High-Output Brakes and Jackknife Detection on Low Coefficient Surfaces. PhD. Dissertation. The Ohio State University, 2003.

4. Dunn, A. L., Heydinger, G. J., Guenther, D. A., "In-Depth Analysis of the Influence of High Torque Brakes on the Jackknife Stability of Heavy Trucks," SAE Paper 2003-01-3398, 2003.

5. Zagorski, Scott, B. Compatibility of ABS Disc/Drum Brakes on Class VIII Vehicles with Multiple Trailers and their Effect on Jackknife Stability. MS Thesis. The Ohio State University, 2003

6. Zagorski, S. B., Guenther, D. A., Heydinger, G. J., "A Study of Jackknife Stability of Class VIII Vehicles with Multiple Trailers with ABS Disc/Drum Brakes," SAE Paper 2004-01-1741, 2004.

7. Zaugg, Brian, C. Development of Heavy Truck ABS and Limit Maneuvers Model. MS Thesis. The Ohio State University, 2004.

8. Zaugg, B. C., Heydinger, G. J., Guenther, D. A., Dunn, A. L., Zagorski, S.B., Grygier, P.A., "The Development of a Heavy Truck ABS Model," SAE Paper 200501-0413, 2005.

9. Doebelin, Ernest. Measurement Systems: Application and Design $4^{\text {th }}$ Ed. Boston, Mass.: McGraw-Hill, 1990.

10. Meritor WABCO. Anti-Lock Braking System (ABS) for Trucks, Tractors, and Buses. Maintenance Manual MM-0112. pp. 8 Arvin Meritor Tech Library, 2001. 
11. U.S. D.O.T. National Highway Traffic Safety Administration, Laboratory Test Procedure for FMVSS 121V (vehicles), Air Brake Systems, TP121V-04, June 4, 1999

12. Gillespie, Thomas D., Fundamentals of Vehicle Dynamics. pp. 335-374, SAE, Warrendale, PA, 1992. 